\title{
ANÁLISE DA APLICABILIDADE DE UM SISTEMA ERP NO PROCESSO DE DESENVOLVIMENTO DE PRODUTOS
}

Eduardo de Senzi Zancul

Dissertação apresentada à Escola de Engenharia de São Carlos, da Universidade de São Paulo, como parte dos requisitos para obtenção do título de Mestre em Engenharia de Produção

ORIENTADOR: Prof. Titular Henrique Rozenfeld

São Carlos

2000 
Dedico este trabalho aos meus avós, José, Josefina (in memorian), Waldemar e Lucy 


\section{AGRADECIMENTOS}

Ao Professor Titular Henrique Rozenfeld pela orientação e pelas oportunidades de desenvolvimento profissional e aprendizado.

À FAPESP pela bolsa de estudos.

A todas as empresas e profissionais que gentilmente participaram deste trabalho, contribuindo para o fortalecimento da relação Universidade-empresa em nosso país.

Aos colegas do NUMA que colaboraram com a realização da pesquisa, especialmente à Ana Paula pelas contribuições e revisão do texto, ao Lucas pela implantação do fluxo de trabalho no Cenário e críticas, ao Rodrigo pelo apoio na implantação do Cenário, ao Vander pelas discussões sobre integração ERP-PDM e ao Sergio e Daniel pelas conversas sobre o trabalho como um todo.

Aos amigos Rogério Omokawa e Cristiano Oliveira, pelo interesse e participação.

Ao pessoal de administração do NUMA - Francis, Cristiane, Fernando, André - que apoiou gerencialmente e tecnicamente a realização do trabalho.

Às Professoras Maria Lúcia Moura de Senzi e Maria Helena de Moura Neves, pela cuidadosa revisão do texto.

Aos meus pais pelo incentivo.

À Ana Paula pelo apoio e compreensão. 


\section{SUMÁRIO}

LISTA DE FIGURAS

LISTA DE TABELAS VIII

LISTA DE ABREVIATURAS E SIGLAS IX

RESUMO XI

ABSTRACT XII

1 INTRODUÇÃO 1

1.1 Contexto e Justificativa do Trabalho 1

1.2 Objetivo do Trabalho 3

1.3 Limitações do Trabalho 3

1.4 Método de Pesquisa 4

1.4.1 Perguntas de Pesquisa 5

1.4.2 Escolha do Método de Pesquisa e das Técnicas de Coleta de Dados ________ 5

1.4.3 Fases da Pesquisa 6

1.4.4 Etapas do Trabalho 8

1.5 Seleção do Sistema ERP 16

1.6 Organização deste Texto 17

\section{O PROCESSO DE DESENVOLVIMENTO DE PRODUTOS:}

\section{CARACTERÍSTICAS, MODELOS DE REFERÊNCIA E INTEGRAÇÃO} 19

2.1 O Processo de Desenvolvimento de Produtos e a Engenharia Simultânea 19

2.1.1 O Desenvolvimento de Produtos Seqüencial 19

2.1.2 O Desenvolvimento de Produtos como um Processo de Negócio 21

2.1.3 A Filosofia de Engenharia Simultânea 23

2.2 Características do Processo de Desenvolvimento de Produtos 25

2.2.1 Etapas do Processo de Desenvolvimento de Produtos 26

2.2.2 Formas de Organização do Desenvolvimento de Produtos 27

2.2.3 Recursos Utilizados no Desenvolvimento de Produtos 30

2.2.4 Tipos de Processo de Desenvolvimento de Produtos 38

2.3 Modelos de Referência do Processo de Desenvolvimento de Produtos 41

2.3.1 Definição e Tipos de Modelos de Referência 41

2.3.2 Visões dos Modelos 42

2.3.3 Métodos de Modelagem 43

2.3.4 Método de Comparação de Modelos 46

2.4 Ambientes Integrados de Desenvolvimento de Produtos 46

2.4.1 Importância da Integração e Níveis de Integração 47

2.4.2 Conceitos de Integração 48

2.4.3 Situação Atual dos Ambientes Integrados de Desenvolvimento de Produtos _ 53 
3.1 Evolução dos Sistemas ERP__ 56

3.2 Características dos Sistemas ERP _ 60

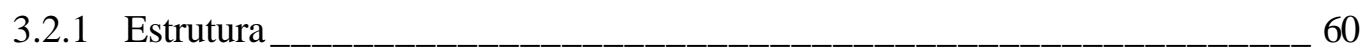

3.2.2 Módulos e Funcionalidades ______________________________________________ 61

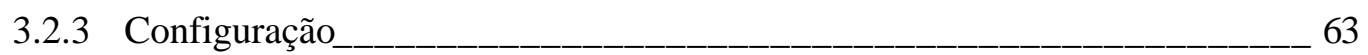

3.3 Modelos de Referência dos Sistemas ERP___ 64

3.4 Integração entre os Sistemas de Engenharia e os Sistemas ERP __ 65

3.5 O Sistema SAP R/3 69

4 ESTUDO EXPLORATÓRIO DA APLICABILIDADE DO SISTEMA ERP EM UM PROCESSO DE DESENVOLVIMENTO DE PRODUTOS __ 72

4.1 Seleção do Processo de Desenvolvimento de Produtos ___ 73

4.2 Obtenção do Modelo de Referência do Processo de Desenvolvimento de Produtos__ 75

4.3 Obtenção do Modelo de Referência do Sistema ERP ___ 79

4.4 Comparação dos Modelos de Referência____ 82

4.5 Busca de Funcionalidades Adicionais do Sistema ERP___ 84

4.6 Análise das Funcionalidades do Sistema ERP ___ 87

4.7 Seleção dos Sistemas Complementares de Desenvolvimento de Produtos _ 89

4.8 Estudo dos Sistemas Complementares de Desenvolvimento de Produtos__ 91

4.9 Validação das Sobreposições ___ 92

4.10 Definição dos Pontos de Integração ___ 96

4.11 Modelo de Referência do Processo de Desenvolvimento de Produtos

Considerando a Aplicação de um Sistema ERP __ 97

5 ESTUDO DESCRITIVO DA APLICAÇÃO DO SISTEMA ERP EM UM CENÁRIO DE DESENVOLVIMENTO DE PRODUTOS

5.1 Implantação do Cenário de Desenvolvimento de Produtos Utilizando o Sistema ERP 98

5.2 Análise da Aplicação do Sistema ERP no Cenário de Desenvolvimento de Produtos 101

\section{ESTUDOS DE CASO DA APLICAÇÃO DO SISTEMA ERP NO PROCESSO DE DESENVOLVIMENTO DE PRODUTOS}

6.1 Seleção das Empresas e Coleta dos Dados

6.2 Análise da Aplicação do Sistema ERP no Processo de Desenvolvimento de Produtos das Empresas Estudadas 
Anexo A - Roteiro de Entrevista - Funcionalidades de DP do Sistema ERP 131

Anexo B - Roteiro de Entrevista - Sobreposição ERP / PDM 132

Anexo C - Roteiro de Entrevista - Sobreposição ERP / CAPP 134

Anexo D - Roteiro de Entrevista - Integração 136

Anexo E - Roteiro de Entrevista - Estudos de Caso 137

Anexo F - Modelo de Referência do Processo de Desenvolvimento de Produtos Considerando a Utilização de um Sistema ERP

Anexo G - Modelo de Referência do Cenário de Desenvolvimento de Produtos 175 Anexo H - Grupos de Funcionalidades de Desenvolvimento de Produtos do Sistema ERP 181 


\section{LISTA DE FIGURAS}

FIGURA 1 - Fases da pesquisa e etapas do trabalho 9

FIGURA 2 - Exemplo de desenvolvimento de produtos seqüencial 20

FIGURA 3 - Fragmentação dos dados de produto no desenvolvimento seqüencial 20

FIGURA 4 - Processo de desenvolvimento de produtos 22

FIGURA 5 - Integração dos dados do produto para apoiar a Engenharia Simultânea 25

FIGURA 6 - Formas de organização do desenvolvimento de produtos 29

FIGURA 7 - Visões de um modelo de processo de negócio 43

FIGURA 8 - SADT - Princípio de decomposição funcional e elementos de representação 44

FIGURA 9 - Elementos do EPC e estrutura construtiva básica 45

FIGURA 10 - Elementos gráficos do modelo de Entidade-Relacionamento 45

FIGURA 11 - Método de comparação de modelos 46

FIGURA 12 - Níveis de integração 47

FIGURA 13 - Tipos de arquitetura cliente/servidor 49

FIGURA 14 - Princípio de troca de dados STEP 53

FIGURA 15 - Dimensões de análise de aplicativos empresariais 59

FIGURA 16 - Estrutura típica de um sistema ERP 60

FIGURA 17 - Exemplo de tabela de configuração de um sistema ERP 63

FIGURA 18 - Exemplo de um modelo de referência de um sistema ERP 64

FIGURA 19 - SAP R/3 - Tela Engineering com menus expandidos 70

FIGURA 20 - Representação gráfica do modelo de referência do processo de desenvolvimento de produtos do NUMA em três níveis de detalhamento 76 FIGURA 21 - Representação tabular do modelo de referência do processo de desenvolvimento de produtos do NUMA em três níveis de detalhamento 77

FIGURA 22 - Visão de processos do modelo de referência do sistema SAP R/3 4.0B 79

FIGURA 23 - Níveis de detalhamento do modelo de referência do sistema SAP R/3 4.0B 80

FIGURA 24 - Exemplo de EPC do modelo de referência do sistema SAP R/3 4.0B 80

FIGURA 25 - Relacionamento entre EPC, características e transações do sistema SAP R/3 $4.0 \mathrm{~B}$

FIGURA 26 - Matriz de comparação de modelos e modelo de referência do processo de desenvolvimento de produtos considerando a aplicação do sistema ERP 82 FIGURA 27 - Grupos de Funcionalidades de Desenvolvimento de Produtos do Sistema ERP 
FIGURA 28 - Principais sobreposições de funcionalidades entre o sistema ERP e os sistemas complementares de desenvolvimento de produtos 92

FIGURA 29 - Programação das atividades do Cenário e gráfico de Gantt no sistema ERP102 FIGURA 30 - Planejamento macro no sistema ERP e detalhamento das atividades no sistema complementar de gerenciamento de projetos 103

FIGURA 31 - Função de importação de componentes do ERP para o sistema CAPP 104 FIGURA 32 - Parâmetros utilizados no gerenciamento e controle de estruturas de produto do Cenário 105

FIGURA 33 - Visualização gráfica dos relacionamentos de uma estrutura de produto no Cenário 106

FIGURA 34 - Localização de um componente do Cenário a partir de suas características 107

FIGURA 35 - "Ficha" de um documento do Cenário 108

FIGURA 36 - Liberação de documento no Cenário 109

FIGURA 37 - Plano de processo elaborado no sistema CAPP e exportado para o sistema ERP 110

FIGURA 38 - Definição do fluxo de trabalho do Cenário no sistema ERP 112

FIGURA 39 - Recebimento de uma tarefa do fluxo de trabalho do Cenário na "caixa de entrada" do sistema ERP e do sistema de correio eletrônico 113 FIGURA 40 - Execução de uma tarefa do fluxo de trabalho do sistema ERP a partir do sistema complementar de correio eletrônico 114 


\section{LISTA DE TABELAS}

TABELA 1 - Sistemas ERP e percentual de empresas usuárias 17

TABELA 2 - Tipologia de processos de desenvolvimento de produtos 39

TABELA 3 - Classificação dos módulos e funções dos sistemas ERP 61

TABELA 4 - Classificação do processo de desenvolvimento de produtos do NUMA de acordo com a tipologia proposta por ROZENFELD \& AMARAL ( 1999) 75

TABELA 5 - Documentos do sistema ERP considerados na análise das funcionalidades de desenvolvimento de produtos 88

TABELA 6 - Sistemas complementares de desenvolvimento de produtos 90

TABELA 7 - Características do processo de desenvolvimento de produtos da Empresa A de acordo com a tipologia proposta por ROZENFELD \& AMARAL (1999) 116

TABELA 8 - Características do processo de desenvolvimento de produtos da Empresa $B$ de acordo com a tipologia proposta por ROZENFELD \& AMARAL (1999) 117

TABELA 9 - Características do processo de desenvolvimento de produtos da Empresa $C$ de acordo com a tipologia proposta por ROZENFELD \& AMARAL (1999) 118

TABELA 10 - Tipologia de processos de desenvolvimento de produtos 138

TABELA 11 - Grupos de Funcionalidades de Desenvolvimento de Produtos do Sistema ERP 181 


\section{LISTA DE ABREVIATURAS E SIGLAS}

AMR

APQP

API

APO

APS

$\mathrm{BD}$

BOM

BW

CAD

CAE

CAM

CAPP

$\mathrm{CN}$

$\mathrm{CNC}$

CORBA

CRM

DBMS

DFMA

DP

ECM

EDM

EIP

EPC

EQFD

ERP

FIM

FMEA

FTP

GF

GP

GUI

ISO

MER
Advanced Manufacturing Research

Advanced Product and Quality Planning

Application Program Interface

Advanced Planner Optimizer

Advanced Planning and Scheduling

Base de Dados

Bill of Materials

Business Information Warehouse

Computer Aided Design

Computer Aided Engineering

Computer Aided Manufacturing

Computer Aided Process Planning

Comando Numérico

Comando Numérico Computadorizado

Common Object Request Broker Architecture

Customer Relationship Management

Data Base Management Systems

Design for Manufacturing and Assembly

Desenvolvimento de Produtos

Engineering Change Management

Electronic Document Management

Enterprise Information Portals

Event-driven Process Chain

Enhanced Quality Function Deployment

Enterprise Resource Planning

Fábrica Integrada Modelo

Failure Mode and Effect Analysis

File Transfer Protocol

Gerente Funcional

Gerente de Produto

Graphical User Interface

International Organization for Standardization

Modelo Entidade-Relacionamento 
MRP

MRP II

NUMA

ODBC

OLE

ORDBMS

PCP

PDM

PLM

PP

PPAP

PS

QFD

QS

SADT

SAP

SQL

STEP

WBS
Materials Requirement Planning

Manufacturing Resource Planning

Núcleo de Manufatura Avançada

Open Database Connectivity

Object Linking Embedding

Object/Relationsl Data Base Management Systems

Planejamento e Controle da Produção

Product Data Management

Product Lifecycle Management

Produção

Production Parts Approval Process

Projetos

Quality Function Deployment

Quality Systems

Structured Analysis and Design Technique

Systems, Applications and Products in Data Processing

Structured Query Language

Standard for the Exchange of Product Model Data

Work Breakdown Structure 


\section{RESUMO}

ZANCUL, E.S. (2000) Análise da Aplicabilidade de um Sistema ERP no Processo de Desenvolvimento de Produtos. São Carlos, 2000. 192p. Dissertação (Mestrado) - Escola de Engenharia de São Carlos, Universidade de São Paulo.

O processo de desenvolvimento de produtos geralmente não tem sido considerado na implantação de sistemas ERP. No entanto, devido ao aumento da abrangência dos ERPs com a inclusão de novas funcionalidades, e devido à importância desses sistemas para a integração dos processos de negócio, muitas empresas passam a considerar a sua utilização para apoiar as atividades e gerenciar as informações de desenvolvimento de produtos. Este trabalho apresenta uma análise abrangente e detalhada da aplicabilidade de um sistema ERP no processo de desenvolvimento de produtos. Tal análise é subdividida em três fases. Inicialmente, é realizado um estudo exploratório da aplicabilidade do sistema ERP em um processo específico de desenvolvimento de produtos representado por um modelo de referência. Em seguida, é executado um estudo descritivo de uma aplicação piloto do ERP em um ambiente de desenvolvimento de produtos. Por fim, são realizado estudos de caso para caracterizar a utilização do ERP no desenvolvimento de produtos de três empresas.

Palavras-chave: Desenvolvimento de produtos; Sistemas ERP; Reengenharia de processos 


\section{ABSTRACT}

ZANCUL, E.S. (2000) Analysis of the Applicability of one ERP System in Product Development Process. São Carlos, 2000. 192p. Dissertação (Mestrado) - Escola de Engenharia de São Carlos, Universidade de São Paulo.

Product development process has not been considered within ERP systems' implementation projects. However, due to the widening of ERP systems scope, with the inclusion of new functionalities, and due to the actual importance of these systems to business process integration, many industries are considering applying ERP systems to support product development activities and to manage product development information. This research presents an extended and detailed analysis of the applicability of one ERP system in product development process. The analysis is divided in three phases: first, an exploratory study is conducted in order to verify the applicability of the ERP system in a specific product development process represented by a reference model. Second, a descriptive study of a pilot application of the ERP system in a product development environment is presented; and finally, three case studies about the use of the ERP system in product development process are discussed.

Key Words: Product development; ERP systems; Process reengineering 


\section{INTRODUÇÃO}

Neste capítulo são apresentados o contexto no qual se insere este trabalho e as justificativas que motivaram a sua realização, o objetivo proposto, as limitações consideradas, o método de pesquisa adotado, a seleção do sistema ERP analisado e, por fim, a forma de organização deste texto.

\subsection{Contexto e Justificativa do Trabalho}

As empresas são tradicionalmente organizadas em departamentos responsáveis por atividades específicas, com predominância de estruturas hierárquicas rígidas e com vários níveis de autoridade.

Essa forma de organização, baseada na especialização funcional, enfatiza a realização e o gerenciamento de atividades individuais. O trabalho é fragmentado e transferido entre pessoas e departamentos sem que exista um responsável pelo resultado final. O isolamento dos departamentos e a falta de comunicação dificultam o gerenciamento de atividades interdependentes. Conseqüentemente, o fluxo de informações é excessivamente lento e sujeito a erros.

Para melhorar a coordenação entre atividades interdependentes e agilizar o fluxo de informações, muitas empresas adotam a abordagem de processos de negócio. Um processo de negócio é definido, simplificadamente, como um conjunto de atividades estruturadas, destinadas a resultar em um produto especificado para um determinado cliente ou mercado (DAVENPORT, 1994). A visão por processos de negócio pode coexistir com a organização departamental, mas a ênfase gerencial é transferida dos departamentos para o processo, com maior foco no cliente (HAMMER \& STANTON, 1999).

Processos de negócio, conforme a definição apresentada, sempre existiram nas empresas. Os processos, no entanto, não eram formalizados e gerenciados, devido ao modo de organização funcional e hierárquica. A tendência atual em se gerenciar os processos de negócio surgiu somente a partir da aplicação dos conceitos da Qualidade Total e da Reengenharia (GARVIN, 1995), no início dos anos 90.

A Reengenharia propõe a obtenção de enormes ganhos de produtividade pelo rompimento com a situação vigente das empresas e o projeto de novos processos de negócio 
mais eficientes (HAMMER, 1990), viabilizados pelo uso intensivo de recursos da tecnologia da informação (HAMMER, 1990; DAVENPORT, 1994; HAMMER \& CHAMPY, 1994; MOREIRA, 1994; GARVIN, 1995; TAPSCOTT \& CASTON, 1995).

Nesse contexto, os sistemas ERP (Enterprise Resource Planning) são considerados como uma das mais importantes evoluções na aplicação da tecnologia da informação realizada pelas empresas nos últimos anos (DAVENPORT, 1998).

Os sistemas ERP são sistemas de gestão empresarial caracterizados principalmente por abranger um amplo escopo de funcionalidades ${ }^{1}$, pela integração de seus dados e pela capacidade de adaptação a vários tipos de organização.

Tais sistemas melhoram o fluxo de dados nas empresas e facilitam o acesso a informações gerenciais, resultando, na maioria das vezes, em enormes ganhos de produtividade e em maior velocidade de resposta (DAVENPORT, 1998).

Paralelamente à adoção da abordagem de processos de negócio e à implantação de sistemas ERP, as empresas têm procurado constantemente melhorar o seu desempenho no processo de desenvolvimento de produtos.

Isso se deve à importância atual do desenvolvimento de novos produtos para a competitividade das empresas (CLARK \& FUJIMOTO, 1991; CLAUSING, 1994; EVERSHEIM et al., 1997; SCHEER, 1998), principalmente nos setores mais dinâmicos, caracterizados por concorrência extremamente acirrada e por mudanças muito rápidas (BROWN \& EISENHARDT, 1995; EISENHARDT \& BROWN, 1998).

Deve-se ressaltar, entretanto, que as iniciativas de implantação de sistemas ERP e de melhoria do processo de desenvolvimento de produtos têm sido freqüentemente tratadas de forma isolada pelas organizações. Conforme se pôde constatar por relatos obtidos em empresas usuárias e em fornecedores de sistemas, o processo de desenvolvimento de produtos geralmente não é considerado na implantação de sistemas ERP (ROZENFELD \& ZANCUL, 2000). Isso se deve principalmente a dois motivos: primeiro, um sistema ERP não possui todas as funcionalidades necessárias para apoiar as atividades do processo de desenvolvimento de produtos (MARTIN, 1998; ROZENFELD \& ZANCUL, 2000), ou seja,

\footnotetext{
${ }^{1}$ As funcionalidades dos sistemas ERP são geralmente organizadas em módulos referentes às áreas funcionais das empresas. O agrupamento das funcionalidades em módulos e a denominação dada a cada um dos módulos é arbitrária e definida pelos fornecedores desses sistemas. De uma forma geral, os módulos dos sistemas ERP abrangem o seguinte escopo: Finanças e Contabilidade, Vendas e Gerenciamento do Relacionamento com Clientes, Planejamento da Produção, Compras e Gestão de Suprimentos, Gerenciamento de Projetos, Recursos Humanos, Gestão da Qualidade, entre outros (ORACLE, 1998; DATASUL, 1999; SAP, 2000a).
} 
na maioria das vezes, o desenvolvimento de produtos requer sistemas mais específicos, complementares aos sistemas ERP; segundo, a integração dos sistemas complementares de desenvolvimento de produtos com os sistemas ERP é bastante complexa, tanto no que se refere ao projeto conceitual da integração quanto à sua implantação (BOURKE, 1996; FERMAN, 1998; HOUGH, 1998; MILLER, 1999).

Observa-se, no entanto, que os sistemas ERP estão tornando-se a "espinha dorsal" dos sistemas de informação das empresas (CARUSO, 1998; MARTIN, 1998; GIURLIANI, 2000) e, conseqüentemente, vem-se estabelecendo uma plataforma comum para as várias tecnologias atualmente empregadas pelas organizações (VENKATRAMAN \& HENDERSON, 1998).

Além disso, os fornecedores de ERPs estão aumentando a abrangência dos sistemas com a inclusão de novas funcionalidades (CHAUDHRY, 1998; CARUSO \& JOHNSON, 1999; STODDER, 1999a).

Uma tendência é a incorporação de funcionalidades características de sistemas de gerenciamento de dados de produto (PDM - Product Data Management), entre as quais o cadastramento de materiais, o gerenciamento de estruturas de produto, o gerenciamento de documentos, a automação de fluxos de trabalho, a classificação de itens e o gerenciamento de projetos (MILLER \& MENDEL, 1997; SAP, 1997; WESSNER, 1999).

Uma outra tendência, mais atual, é a inclusão de funções de gerenciamento de todo o ciclo de vida de produtos (PLM - Product Lifecycle Management), tais como a análise do portfolio de produtos, o gerenciamento de programas completos e a infra-estrutura necessária para permitir o compartilhamento de informações entre parceiros (AMR, 2000; SAP, 2000b).

Dessa forma, muitas empresas passam a considerar a utilização dos sistemas ERP para apoiar as atividades e gerenciar as informações de desenvolvimento de produtos. Para isso, as empresas precisam verificar a adequação dos sistemas ERP, que utilizam ou que pretendem implantar, aos seus processos de desenvolvimento.

\subsection{Objetivo do Trabalho}

O objetivo deste trabalho é analisar a aplicabilidade de um sistema ERP no processo de desenvolvimento de produtos.

\subsection{Limitações do Trabalho}

Este trabalho apresenta uma análise abrangente e detalhada sobre os mais importantes aspectos relacionados com a aplicação de um sistema ERP para apoiar o processo de desenvolvimento de produtos. 
A limitação da análise realizada nesta pesquisa a apenas um sistema ERP deve-se à alta complexidade e ao amplo escopo de aplicação desse tipo de sistema, o que inviabilizaria uma análise detalhada se fossem considerados todos os sistemas disponíveis no mercado.

A definição dos aspectos do sistema ERP que são enfatizados na análise realizada neste trabalho é baseada nos critérios tradicionais de avaliação de sistemas ERP, apresentados por JETLY (1999), e nas observações sobre os critérios de avaliação, feitas por CARUSO \& JOHNSON (1999).

De acordo com JETLY (1999), a estrutura clássica para a avaliação de sistemas ERP baseia-se em critérios funcionais, técnicos, corporativos e de custos ${ }^{2}$. Dentre esses critérios, CARUSO \& JOHNSON (1999) consideram a adequação funcional dos sistemas aos requisitos dos processos de negócio das empresas como o critério mais importante para a avaliação de ERPs.

Assim, a análise realizada nesta pesquisa enfatiza os aspectos funcionais do sistema ERP para o processo de desenvolvimento de produtos. Além disso, devido à importância da integração entre os sistemas ERP e os sistemas complementares, no desenvolvimento de produtos, são estudados também alguns aspectos de integração do sistema ERP. Os aspectos corporativos e de custo do sistema ERP para o desenvolvimento de produtos, por sua vez, não são considerados no escopo deste trabalho.

\subsection{Método de Pesquisa}

A seguir são discutidos os aspectos metodológicos considerados na realização desta pesquisa. Partindo-se do objetivo estabelecido são elaboradas as perguntas de pesquisa, são escolhidos o método de pesquisa empregado e as técnicas de coleta de dados utilizadas e são definidas as fases da pesquisa e as etapas do trabalho.

\footnotetext{
${ }^{2}$ Os critérios funcionais referem-se às funcionalidades disponíveis no sistema. Os critérios técnicos dizem respeito à arquitetura (plataforma, sistema operacional e base de dados), à escalabilidade, à robustez, à tolerância a falhas e à integração com outros sistemas. Os critérios corporativos referem-se à situação financeira do fornecedor e à estratégia de canais de venda e de apoio aos clientes. Por fim, os critérios de custo referem-se aos custos totais envolvidos em um projeto de ERP, englobando o custo do próprio sistema e das licenças de utilização, somados aos custos do hardware necessário, dos serviços de configuração e de customização e do treinamento aos usuários (JETLY, 1999).
} 


\subsubsection{Perguntas de Pesquisa}

A partir do objetivo do trabalho, foram definidas as seguintes perguntas de pesquisa:

a Quais atividades do processo de desenvolvimento de produtos podem ser apoiadas por funcionalidades do sistema ERP?

a Em quais atividades do processo de desenvolvimento de produtos ocorrem sobreposições de funcionalidades entre o sistema ERP e os sistemas complementares de desenvolvimento de produtos?

- Quais são os principais pontos de integração entre o sistema ERP e os sistemas complementares de desenvolvimento de produtos?

a Como as empresas estão aplicando o sistema ERP em seus processos de desenvolvimento de produtos?

\subsubsection{Escolha do Método de Pesquisa e das Técnicas de Coleta de Dados}

A fim de se atingir o objetivo proposto e de se responder às perguntas de pesquisa estabelecidas para este trabalho, é empregada uma abordagem de pesquisa descritiva.

A pesquisa descritiva envolve o exame de um fenômeno para defini-lo de maneira ampla (DANE, 1990). Nesse tipo de pesquisa, as informações são observadas, registradas, analisadas e correlacionadas, sem serem manipuladas (CERVO \& BERVIAN, 1983).

Considera-se a abordagem de pesquisa descritiva adequada a este trabalho, pois o que se pretende é analisar um sistema ERP e o processo de desenvolvimento de produtos, determinando-se o relacionamento existente entre eles, sem contudo modificá-los.

Para a coleta de dados neste trabalho são utilizadas as técnicas de análise documental, de observação direta e de entrevista focalizada.

A técnica de análise documental refere-se ao estudo de documentos. Considera-se aqui a definição de documento, no seu sentido mais amplo, como sendo toda e qualquer base de conhecimento fixada materialmente e acessível para consulta (PÁDUA, 1997). Ou seja, são considerados como documentos os materiais que descrevam o funcionamento do sistema ERP e que representem as características do processo de desenvolvimento de produtos.

A observação direta possibilita um contato pessoal e estreito do pesquisador com o objeto de estudo. Essa técnica permite que o pesquisador recorra aos seus conhecimentos e experiências pessoais como auxiliares no processo de compreensão e interpretação do fenômeno estudado (LÜDKE \& ANDRÉ, 1986).

A entrevista focalizada baseia-se em um roteiro pré-definido, contendo os tópicos sobre o problema que vai ser estudado, mas o pesquisador tem liberdade para não abordar 
algumas das questões e incluir novas perguntas à medida que a entrevista evolui. (MARCONI \& LAKATOS, 1990).

$\mathrm{Na}$ elaboração de todos os roteiros de entrevista, neste trabalho, são observadas as considerações feitas por PÁDUA (1997): formular perguntas que estimulem respostas descritivas e analíticas; possibilitar uma flexibilidade quanto à ordem de apresentação das questões; verificar a distribuição do tempo para cada assunto; manter o controle dos objetivos a serem atingidos.

\subsubsection{Fases da Pesquisa}

De acordo com CERVO \& BERVIAN (1983), a pesquisa descritiva pode assumir diversas formas. Este trabalho é subdividido em três fases principais, empregando-se três das formas de pesquisa descritiva citadas por esses autores: o estudo exploratório, o estudo descritivo e o estudo de caso.

O emprego de três formas de pesquisa descritiva, complementarmente, visa à obtenção de uma análise sobre o tema do trabalho, que seja ao mesmo tempo abrangente e detalhada.

Além das fases da pesquisa descritiva, citadas anteriormente, são realizadas outras três fases complementares: a definição do trabalho, a pesquisa bibliográfica e a avaliação dos resultados. Todas essas fases da pesquisa são descritas detalhadamente a seguir.

\section{Definição do Trabalho}

A definição do trabalho compreende o estabelecimento do objetivo a ser cumprido, a determinação das perguntas de pesquisa, a escolha do método de pesquisa e das técnicas de coleta de dados, a definição das fases da pesquisa e das etapas do trabalho e, por fim, a seleção do sistema ERP analisado.

\section{Pesquisa Bibliográfica}

A pesquisa bibliográfica neste trabalho é realizada conforme os objetivos estabelecidos por DANE (1990) e CERVO \& BERVIAN (1983): evitar duplicidade de pesquisa; evitar problemas ocorridos em trabalhos anteriores; determinar a contribuição da pesquisa para a base de conhecimentos; obter fundamentação teórica para o desenvolvimento do projeto. 


\section{Estudo Exploratório}

O estudo exploratório é recomendável nos casos em que há poucos conhecimentos sobre o problema a ser estudado. Além disso, os estudos exploratórios são importantes para a obtenção de uma nova percepção ou mesmo para a descoberta de novas idéias sobre o tema da pesquisa (CERVO \& BERVIAN, 1983).

Assim, inicialmente, considerando-se que o tema deste trabalho ainda é pouco estudado na literatura científica, é pertinente realizar um estudo exploratório dos aspectos funcionais e de integração do sistema ERP em um processo específico de desenvolvimento de produtos.

A restrição a somente um processo de desenvolvimento de produtos deve-se à grande variabilidade que esse processo pode ter em decorrência de fatores como o setor da indústria, a tecnologia do produto, o grau de inovação, entre outros. Dessa forma, para que seja possível realizar uma análise considerando os requisitos detalhados do processo de desenvolvimento de produtos, é necessário restringir o estudo exploratório a um processo específico

Esta fase da pesquisa compreende a identificação das atividades do processo de desenvolvimento de produtos que podem ser apoiadas por funcionalidades do sistema ERP, e, conseqüentemente, a identificação das lacunas não atendidas pelo sistema ERP, a determinação das sobreposições de funcionalidades entre o sistema ERP e os sistemas complementares de desenvolvimento de produtos e a especificação dos pontos de integração entre tais sistemas.

\section{Estudo Descritivo}

Em seguida, a partir dos fundamentos obtidos no estudo exploratório, é realizado um estudo descritivo de uma aplicação piloto do sistema ERP em um ambiente de desenvolvimento de produtos.

O estudo descritivo compreende o estudo e a descrição das características, propriedades ou relações existentes em uma realidade estudada (CERVO \& BERVIAN, 1983), contribuindo de forma ilustrativa para o desenvolvimento do tema de pesquisa.

A aplicação piloto do sistema ERP, denominada de Cenário de Desenvolvimento de Produtos Utilizando o Sistema ERP, ou simplesmente Cenário, reflete um possível modo de utilização do ERP no processo de desenvolvimento.

O estudo do Cenário permite a observação de soluções e de limitações da aplicação do ERP no processo de desenvolvimento de produtos que não são verificadas no estudo exploratório inicial. 


\section{Estudos de Caso}

Por fim, são realizados estudos de caso para se caracterizar e avaliar a aplicação do sistema ERP no processo de desenvolvimento de produtos de três empresas.

O estudo de caso é uma pesquisa sobre um indivíduo específico (CERVO \& BERVIAN, 1983), com foco em suas características mais relevantes para o tema que se está pesquisando (PÁDUA, 1997).

Dessa forma, em cada uma das três empresas estudadas, são identificadas as funcionalidades do sistema ERP que são utilizadas no desenvolvimento de produtos; são verificadas as funcionalidades do ERP que não são empregadas por serem substituídas por sistemas complementares; são analisados os motivos que levaram à opção pelo sistema ERP ou pelos sistemas complementares; e são observadas as soluções adotadas para integrar tais sistemas.

\section{Avaliação dos Resultados}

Finalmente, são discutidos os resultados observados em todas as fases anteriores, são apresentadas as conclusões obtidas e são realizadas sugestões para trabalhos futuros nesta área de pesquisa.

\subsubsection{Etapas do Trabalho}

A partir do método adotado e da determinação das fases que configuram a pesquisa, são definidas as etapas do trabalho nas quais são empregadas as técnicas de coleta de dados.

As etapas definidas para este trabalho em cada uma das fases da pesquisa são apresentadas na FIGURA 1. Os retângulos maiores, no fundo da FIGURA 1, representam as seis fases da pesquisa, discutidas anteriormente. O nome de cada uma das fases é apresentado no canto superior esquerdo de cada um desses retângulos. Já os retângulos menores representam as etapas do trabalho, que são especificadas, como tarefas, por um verbo no infinitivo e um complemento. A sequiência lógica entre as etapas é representada por flechas que interligam os retângulos. $\mathrm{O}$ documento obtido como resultado de uma etapa é representado por um retângulo com a parte inferior curvilínea. As etapas do trabalho são discutidas detalhadamente após a apresentação da FIGURA 1. 


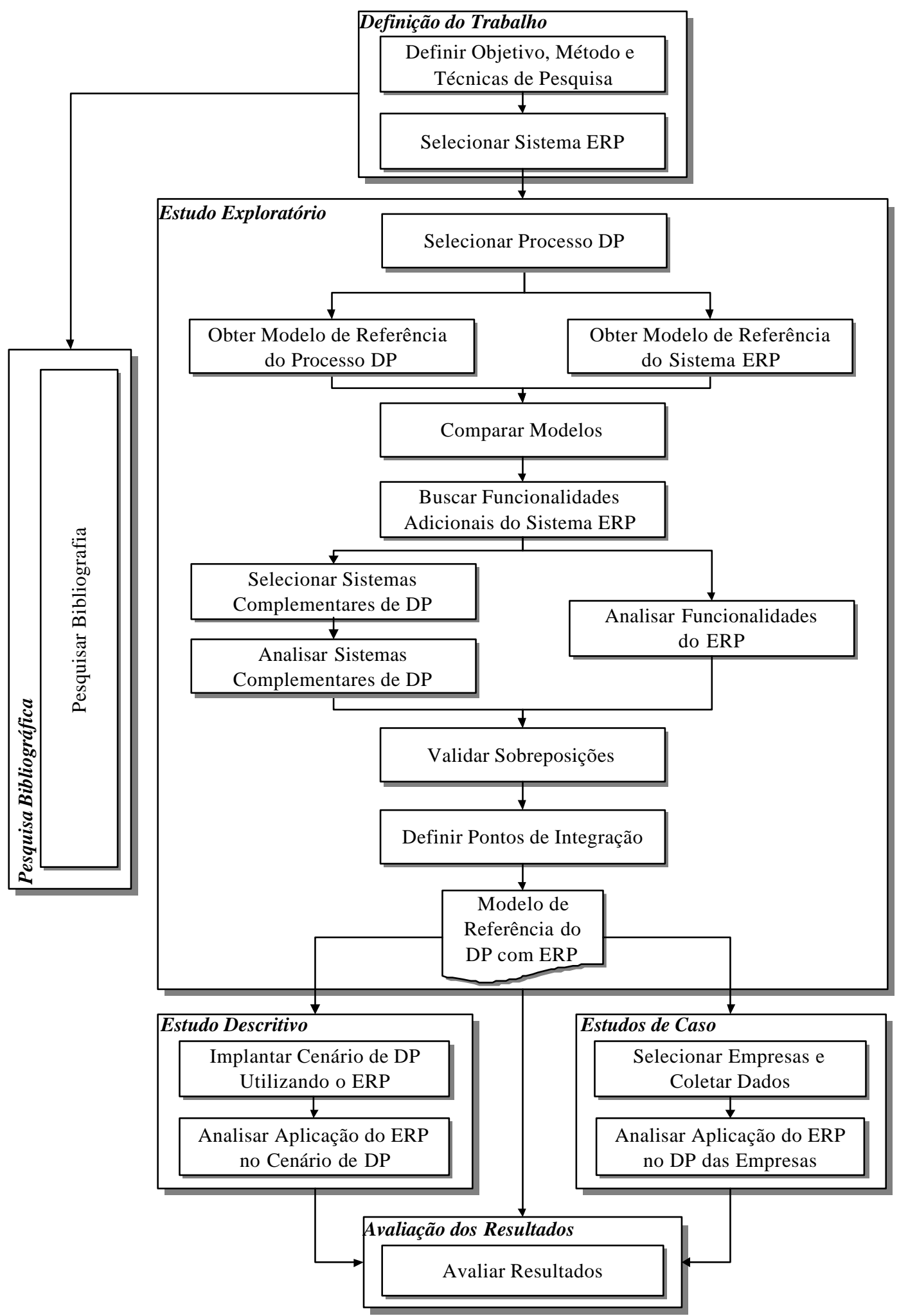

FIGURA 1 - Fases da pesquisa e etapas do trabalho 


\section{Definição do Trabalho}

\section{Definir Objetivo, Método e Técnicas de Pesquisa}

Esta etapa inicial compreende o estabelecimento do objetivo a ser cumprido, a determinação das perguntas de pesquisa, a escolha do método de pesquisa e das técnicas de coleta de dados e a definição das fases da pesquisa e das etapas do trabalho.

\section{Selecionar Sistema ERP}

Em seguida, é selecionado o sistema ERP analisado. Parte-se do pressuposto de que o sistema ERP escolhido deve refletir a realidade encontrada na maior quantidade possível de empresas localizadas no Brasil, ou seja, o sistema ERP selecionado deve ser o sistema com maior número de empresas usuárias no Brasil.

\section{Pesquisa Bibliográfica \\ Pesquisar Bibliografia}

A pesquisa bibliográfica é realizada praticamente ao longo de todo o trabalho. São definidos dois temas principais para direcionar a revisão da bibliografia: processo de desenvolvimento de produtos e sistemas ERP.

O primeiro tema é muito amplo, abrangendo diversas áreas do conhecimento. Dessa forma, procurou-se limitar a pesquisa bibliográfica sobre o processo de desenvolvimento de produtos aos assuntos de interesse para este trabalho.

Sobre o segundo tema ainda não existem muitos trabalhos científicos publicados. Devido a essa limitação, a pesquisa bibliográfica é complementada com publicações sobre soluções específicas, tais como manuais e livros de referência de sistemas ERP. Além disso, são consultados também periódicos não científicos, voltados para as áreas de tecnologia da informação e de negócios.

\section{Estudo Exploratório}

\section{Selecionar Processo de Desenvolvimento de Produtos}

O estudo exploratório é iniciado com a seleção de um processo de desenvolvimento de produtos para a análise da aplicabilidade do sistema ERP.

Pressupõe-se que o processo de desenvolvimento de produtos escolhido deve ser bastante amplo, englobando as etapas características do desenvolvimento de produtos, desde o surgimento da idéia até o lançamento no mercado. Além disso, o processo deve ser atual, incluindo as melhores práticas utilizadas pelas empresas no desenvolvimento de produtos. 


\section{Obter Modelo de Referência do Processo de Desenvolvimento de Produtos}

Nesta etapa, o modelo de referência do processo de desenvolvimento de produtos selecionado para o estudo exploratório é obtido, estudado e preparado para as etapas seguintes do trabalho.

Considera-se que o processo já esteja modelado, ou seja, que o modelo de referência do processo exista e esteja disponível. Mais ainda, o grau de abstração utilizado na representação deve ser tal que o modelo descreva, pelo menos, as atividades, as informações, os recursos e a forma organizacional do processo.

O estudo do modelo de referência do processo de desenvolvimento de produtos é realizado empregando-se a técnica de análise documental. Tal estudo envolve uma análise detalhada de cada uma das atividades do processo, considerando as informações de entrada, as informações de saída, os elementos organizacionais responsáveis e os recursos utilizados. Procura-se, assim, compreender a essência de cada atividade do modelo de referência e os seus requisitos específicos.

Em seguida, o modelo é preparado para as etapas seguintes do trabalho. Os recursos especificados para as atividades são excluídos da representação do modelo, tornando as atividades independentes de recursos computacionais específicos e possibilitando a análise da aplicação do ERP ao processo.

\section{Obter Modelo de Referência do Sistema ERP}

Paralelamente à etapa anterior, o modelo de referência do sistema ERP também é obtido e estudado de forma detalhada.

Para isso, o sistema ERP considerado deve ser representado por um modelo de referência que descreva as suas soluções e funcionalidades, e esse modelo deve estar disponível para ser acessado.

Tal como no estudo do modelo do processo, procura-se compreender a essência das soluções representadas no modelo de referência do sistema ERP por meio de uma análise documental.

\section{Comparar Modelos}

Os modelos de referência do processo de desenvolvimento de produtos e do sistema ERP, obtidos nas duas etapas anteriores, são comparados por meio de um método específico de comparação de modelos, proposto por KIRCHMER (1998) ${ }^{3}$.

${ }^{3}$ O método de comparação de modelos de KIRCHMER (1998) é apresentado no subitem 2.3.4 Método de Comparação de Modelos da revisão bibliográfica. 
Nessa comparação procura-se identificar as funcionalidades do ERP que podem ser utilizadas para apoiar as atividades do processo, relacionando as funcionalidades representadas no modelo do ERP às atividades do modelo do processo.

A comparação de modelos tem algumas limitações para a identificação das funcionalidades de desenvolvimento de produtos do sistema ERP. Dependendo do grau de detalhamento e de abstração do modelo do ERP, nem todas as suas funcionalidades estão representadas. Além disso, a comparação baseia-se muito no conhecimento e na experiência do pesquisador.

Dessa forma, é necessário pesquisar outras funcionalidades que podem ser empregadas no desenvolvimento de produtos e que não são identificadas na comparação. Além disso, é preciso validar os resultados obtidos na comparação de modelos.

\section{Buscar Funcionalidades Adicionais do Sistema ERP}

Nesta etapa procura-se identificar funcionalidades adicionais do ERP que podem ser utilizadas no desenvolvimento de produtos e que não são localizadas na comparação de modelos. Para isso são realizadas duas atividades, baseadas em técnicas de pesquisa distintas: a observação direta e a entrevista focalizada.

Na observação direta, o pesquisador parte do modelo de referência do processo de desenvolvimento de produtos e procura sistematicamente por funcionalidades do ERP que possam ser utilizadas para apoiar as atividades do processo. Essa atividade é realizada em um ambiente de testes do sistema ERP manipulado pelo pesquisador.

A entrevista focalizada, com um especialista no sistema ERP, é realizada para a identificação de outras funcionalidades do ERP que possam ser utilizadas no desenvolvimento de produtos e que, eventualmente, ainda não tenham sido localizadas. Além disso, a entrevista tem como objetivo validar os resultados obtidos até esta etapa.

\section{Analisar Funcionalidades do Sistema ERP}

As funcionalidades do sistema ERP que podem ser utilizadas para apoiar as atividades do processo de desenvolvimento de produtos, identificadas nas etapas anteriores, são analisadas de forma detalhada.

O objetivo desta etapa é verificar se as características das funcionalidades atendem aos requisitos específicos do processo de desenvolvimento de produtos.

Procura-se, primeiramente, verificar as características das funcionalidades de desenvolvimento de produtos do ERP com uma análise de toda a documentação disponível 
sobre o sistema (livros de referência, artigos, apostilas de cursos, material de divulgação, apresentações, ajuda do sistema, entre outras fontes de informação do ERP).

Posteriormente, as especificidades das funcionalidades que não são descritas na documentação consultada são observadas diretamente no sistema ERP. Para isso é utilizado um ambiente de testes do sistema ERP que pode ser manipulado pelo pesquisador.

Verifica-se, então, se as características detalhadas de cada uma das funcionalidades do sistema ERP atendem aos requisitos específicos do processo de desenvolvimento, definidos pelo modelo de referência.

\section{Selecionar Sistemas Complementares de Desenvolvimento de Produtos}

Paralelamente à análise das funcionalidades do sistema ERP são selecionados sistemas complementares que podem ser utilizados para apoiar as atividades do processo de desenvolvimento de produtos.

São definidas, inicialmente, as classes genéricas de sistemas complementares considerados na seleção, a partir do conjunto de recursos especificados na versão original do modelo de referência do processo de desenvolvimento de produtos. São tratados como classes genéricas de sistemas complementares, por exemplo, os gerenciadores de dados de produtos, os editores de textos e as planilhas eletrônicas.

Em seguida, para cada classe genérica de sistema complementar é selecionado um sistema específico, disponível comercialmente, com base em critérios pré-definidos como, por exemplo, maior participação de mercado.

\section{Analisar Sistemas Complementares de Desenvolvimento de Produtos}

Nesta etapa é realizada uma análise dos sistemas complementares selecionados na etapa anterior. Nessa análise procura-se determinar todos os sistemas que podem ser utilizados para apoiar cada uma das atividades do processo de desenvolvimento de produtos.

Com esse objetivo, nos casos em que os sistemas complementares representam as suas soluções por meio de modelos de referência, é realizada uma comparação entre o modelo de referência do processo de desenvolvimento de produtos e os modelos dos sistemas complementares.

Caso os sistemas complementares não sejam representados por modelos de referência, a identificação das funcionalidades dos sistemas complementares que apóiam as atividades do processo de desenvolvimento é realizada por uma análise da documentação do sistema (catálogos, manuais, entre outros) e da observação direta de suas funcionalidades. 
Dessa forma, são especificados os recursos computacionais para as atividades que não são apoiadas pelo sistema ERP, e definidas as sobreposições de funcionalidades entre os sistemas complementares e o sistema ERP.

\section{Validar Sobreposições}

As principais sobreposições de funcionalidades entre o sistema ERP e os sistemas complementares, definidas na etapa anterior, são validadas em entrevistas focalizadas feitas com especialistas dos diversos sistemas complementares, que tenham bons conhecimentos do sistema ERP.

\section{Definir Pontos de Integração}

Nesta etapa são determinados os principais pontos de integração entre o sistema ERP e os sistemas complementares de desenvolvimento de produtos.

Para isso, com base nos resultados das etapas anteriores, é realizada uma entrevista focalizada com um especialista que tenha bons conhecimentos de integração entre sistemas de informação, principalmente com relação aos sistemas ERP e aos sistemas de desenvolvimento de produtos.

\section{Modelo de Referência do Processo de Desenvolvimento de Produtos Considerando a Aplicação do Sistema ERP}

Como resultado das etapas anteriores é obtido um modelo de referência do processo de desenvolvimento de produtos considerando a aplicação do sistema ERP.

Nesse modelo estão especificadas as atividades do processo de desenvolvimento de produtos que podem ser apoiadas pelo sistema ERP, as atividades não apoiadas pelo ERP (lacunas do ERP), as atividades nas quais ocorre sobreposição de funcionalidades entre o sistema ERP e os sistemas complementares, e os principais pontos de integração entre tais sistemas.

\section{Estudo Descritivo}

\section{Implantar o Cenário de Desenvolvimento de Produtos Utilizando o ERP}

A implantação do Cenário de Desenvolvimento de Produtos Utilizando o Sistema ERP é realizada com base em uma adaptação do método de montagem de Cenários proposto por AGUIAR et al. (1997) e aperfeiçoado por ROZENFELD et al. (1998), ZANCUL et al. (1998) e AMARAL et al. (1999).

Inicialmente, é selecionado um ambiente de desenvolvimento de produtos para a montagem do Cenário. Esse ambiente deve possuir toda a infra-estrutura necessária para a 
instalação do Cenário (microcomputadores, servidores, rede, sistema ERP, sistemas complementares, etc.). Mais ainda, tal ambiente deve ser flexível para permitir a realização de testes e simulações.

Em seguida, é criada uma instância do modelo de referência do processo de desenvolvimento de produtos, obtido como resultado do estudo exploratório anterior, para ser utilizada como modelo de referência do Cenário.

A partir da escolha do ambiente de desenvolvimento de produtos e da definição do modelo de referência do Cenário, é especificado um "contexto" para direcionar a realização dos testes e das simulações da aplicação do sistema ERP.

De acordo com a representação do modelo de referência do Cenário e considerandose o "contexto" especificado, o sistema ERP é configurado e integrado aos sistemas complementares de desenvolvimento de produtos.

Finalmente, as informações representadas no modelo de referência do Cenário são geradas conforme o "contexto" estabelecido (cronogramas, desenhos, estruturas de produto, planos de processo, relatórios, entre outras).

\section{Analisar a Aplicação do Sistema ERP no Cenário de Desenvolvimento de Produtos}

Após a implantação do Cenário, são realizados testes e simulações da utilização do sistema ERP no processo de desenvolvimento de produtos definido pelo modelo de referência e pelo "contexto".

Para a coleta de dados nesta etapa é empregada a técnica de observação direta, procurando-se registrar as soluções e as limitações da aplicação prática do sistema ERP no processo de desenvolvimento de produtos. As principais soluções e limitações observadas são descritas e discutidas.

\section{Estudos de Caso}

\section{Selecionar Empresas e Coletar Dados}

Nesta etapa são selecionadas as empresas analisadas nos estudos de caso e são coletados os dados que caracterizam a aplicação do sistema ERP no processo de desenvolvimento de produtos dessas empresas.

A escolha das empresas analisadas é realizada com base em critérios previamente estabelecidos. Pressupõe-se que tais empresas desenvolvam produtos e utilizem o sistema ERP considerado neste trabalho. Observando-se tais critérios, são escolhidas as três empresas analisadas nesta fase da pesquisa. 
A coleta de dados nos estudos de caso é efetuada por meio de entrevistas focalizadas com membros das empresas, os quais possuam bons conhecimentos da forma de aplicação do sistema ERP no processo de desenvolvimento de produtos. A preparação para essas entrevistas compreende a elaboração prévia de um roteiro, a especificação de critérios para a escolha dos membros das empresas a serem entrevistados e a definição dos entrevistados.

\section{Analisar a Aplicação do Sistema ERP no Desenvolvimento de Produto das Empresas Estudadas}

Os dados obtidos nas entrevistas realizadas na etapa anterior, referentes à aplicação do sistema ERP no processo de desenvolvimento de produtos das três empresas estudadas, são apresentados e discutidos.

\section{Avaliação dos Resultados}

\section{Avaliar os Resultados}

Os resultados observados no estudo exploratório, no estudo descritivo e nos estudos de caso são avaliados e discutidos. São também apresentadas as conclusões obtidas, relacionadas tanto com o tema da pesquisa quanto com o método empregado.

\subsection{Seleção do Sistema ERP}

A seleção do sistema ERP considerado neste trabalho é baseada na premissa de que o sistema analisado deve refletir a realidade encontrada na maior quantidade possível de empresas instaladas no Brasil.

A partir dessa premissa, determinou-se um único critério para a seleção do sistema ERP. Tal critério estabelece que o sistema selecionado deve ser o ERP com o maior número de empresas usuárias no Brasil.

Uma pesquisa sobre a utilização de sistemas ERP por empresas localizadas no Brasil é apresentada por MAYER (1998). Esta pesquisa demonstra a segmentação do mercado brasileiro de ERPs de acordo com o percentual de empresas que utiliza cada um dos sistemas ERP existentes. Os resultados obtidos por MAYER (1998) na amostra pesquisada são listados na TABELA 1. 
TABELA 1 - Sistemas ERP e percentual de empresas usuárias (MAYER, 1998)

\begin{tabular}{c|c}
\hline SISTEMA & $\begin{array}{c}\text { QUANTIDADE } \\
\text { DE EMPRESAS } \\
\text { USUÁRIAS (\%) }\end{array}$ \\
\hline SAP & $27,3 \%$ \\
\hline Magnus & $26,3 \%$ \\
\hline Baan & $18,4 \%$ \\
\hline Oracle & $7,9 \%$ \\
\hline BPCS & $7,9 \%$ \\
\hline JDEdwards & $5,3 \%$ \\
\hline Outros & $7,9 \%$ \\
\hline
\end{tabular}

Assim, considerando-se o critério de seleção pré-estabelecido e os dados apresentados por MAYER (1998), o sistema ERP SAP (SAP R/3) foi escolhido para ser analisado neste trabalho.

O SAP R/3 é fornecido pela software house SAP (Systems, Applications and Products in Data Processing), fundada em 1972 em Walldorf, na Alemanha. A SAP é atualmente a quinta maior fornecedora mundial de softwares e a maior fornecedora mundial de aplicativos empresariais (CURRAN \& KELLER, 1998).

Nesta pesquisa foi considerada a versão $4.0 \mathrm{~B}$ do sistema SAP R/3 em inglês. A opção por tal versão deve-se a dois fatores: essa versão é a mais atual existente durante a realização da maior parte das etapas deste trabalho; essa versão está disponível para ser utilizada pelo pesquisador no Laboratório de Sistematização e Integração da Manufatura, do NUMA (Núcleo de Manufatura Avançada), localizado na Escola de Engenharia de São Carlos da Universidade de São Paulo.

\subsection{Organização deste Texto}

Este texto está organizado em sete capítulos, divididos de acordo com as fases do método de pesquisa.

Capítulo 1 - apresenta a definição do trabalho. São discutidos, inicialmente, o contexto no qual se insere o trabalho $\mathrm{e}$ as justificativas que motivaram o seu desenvolvimento. Em seguida, são definidos o objetivo e as limitações do trabalho, as perguntas de pesquisa, o método de pesquisa e as técnicas de coleta de dados, e são determinadas as fases da pesquisa e as etapas do trabalho. Finalmente, é selecionado o sistema ERP para a análise.

Capítulos 2 e 3 - apresentam, respectivamente, a pesquisa bibliográfica sobre o processo de desenvolvimento de produtos e a pesquisa bibliográfica sobre os sistemas ERP. 
Capítulo 4 - trata do estudo exploratório da aplicabilidade do sistema ERP em um processo de desenvolvimento de produtos. A partir do modelo de referência do processo de desenvolvimento de produtos e do sistema ERP: são definidas as atividades do processo de desenvolvimento que podem ser apoiadas por funcionalidades do sistema ERP; são determinadas as atividades do processo nas quais ocorrem sobreposições de funcionalidades entre o ERP e os sistema complementares; são especificados os principais pontos de integração entre tais sistemas.

Capítulo 5 - apresenta o estudo descritivo do Cenário de Desenvolvimento de Produtos Utilizando o Sistema ERP. A partir dos resultados obtidos no capítulo anterior é realizada a implantação do Cenário. A aplicação do ERP no desenvolvimento de produtos é simulada e as principais soluções e limitações observadas são descritas e discutidas.

Capítulo 6 - refere-se aos estudos de caso sobre a aplicação do sistema ERP no processo de desenvolvimento de produtos de três empresas. Inicialmente, são selecionadas as empresas que participam desta fase da pesquisa e são coletados os dados pertinentes. Em seguida, são discutidas as particularidades observadas na aplicação do sistema ERP no processo de desenvolvimento de cada empresa analisada.

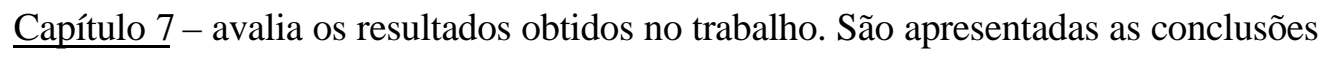
obtidas e são feitas algumas considerações finais e sugestões para trabalhos futuros nesta área de pesquisa. 


\section{O PROCESSO DE DESENVOLVIMENTO DE PRODUTOS: CARACTERÍSTICAS, MODELOS DE REFERÊNCIA E INTEGRAÇÃO}

Este capítulo é subdividido em quatro itens. Inicialmente são apresentas as definições de processo de desenvolvimento de produtos e de Engenharia Simultânea. Em seguida, são apresentadas algumas características do processo de desenvolvimento de produtos relevantes para o escopo deste trabalho e são analisados os fatores de influência que determinam os tipos de processo de desenvolvimento. É discutida, então, a representação do processo de desenvolvimento utilizando-se modelos de referência. Por fim, são apresentados conceitos de integração utilizados em ambientes integrados de desenvolvimento de produtos.

\subsection{O Processo de Desenvolvimento de Produtos e a Engenharia Simultânea}

Neste item discutem-se as características da abordagem seqüencial de desenvolvimento de produtos. Em seguida, são apresentadas a definição de processo de negócio, aplicada ao desenvolvimento de produtos, e a definição de Engenharia Simultânea adotada neste trabalho.

\subsubsection{O Desenvolvimento de Produtos Seqüencial}

Tradicionalmente, o desenvolvimento de produtos é constituído por uma seqüência ordenada de atividades realizadas por vários departamentos de uma empresa. Uma atividade só é iniciada quando a atividade anterior é concluída.

De acordo com CLAUSING (1994), essa abordagem seqüencial de desenvolvimento de produtos prevaleceu durante os anos 50 e 60, mas continua sendo amplamente empregada pelas empresas.

As etapas gerais típicas de um desenvolvimento de produtos seqüencial em uma empresa de manufatura são exemplificadas na FIGURA 2. 


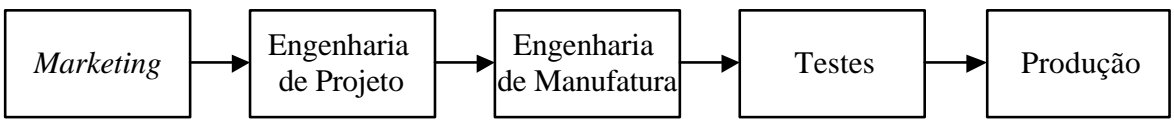

Erros, mudanças e correções

FIGURA 2 - Exemplo de desenvolvimento de produtos seqüencial (SYAN, 1994, p. 4)

Nesse exemplo, o Marketing especifica a necessidade de novos produtos, o preço alvo e o desempenho requerido por potenciais consumidores. A Engenharia de Projeto recebe especificações pouco detalhadas e trabalha isoladamente na definição dos requisitos técnicos e no detalhamento da documentação do produto. O primeiro contato da Engenharia de Manufatura com o novo produto ocorre somente após o final da etapa de Engenharia de Projeto (FIGURA 2) (SYAN, 1994).

Pode-se notar, na FIGURA 2, que o desenvolvimento seqüencial, baseado na organização departamental, não favorece a integração entre as unidades funcionais envolvidas. Os departamentos tendem a preocupar-se somente com as suas atividades específicas, e não existe um responsável pelo desenvolvimento como um todo. A falta de uma visão ampla sobre todo o desenvolvimento dificulta a medição dos resultados obtidos e a realização de projetos de melhoria.

SCHEER (1998) discute as implicações do desenvolvimento seqüencial e do isolamento dos departamentos na fragmentação dos dados de produtos. As diferentes visões descritivas utilizadas pelas várias unidades organizacionais envolvidas no desenvolvimento resultam em bases de dados independentes, separadas em vários sistemas e plataformas de hardware (FIGURA 3).

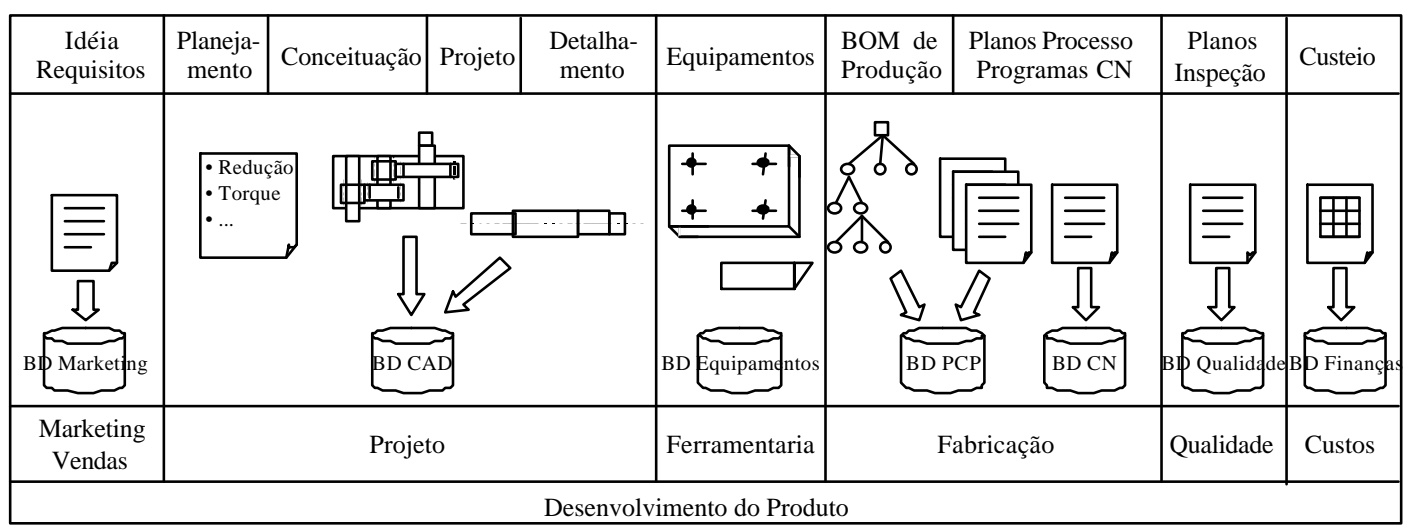

FIGURA 3 - Fragmentação dos dados de produto no desenvolvimento seqüencial (SCHEER, 1998, p. 508) 
A descrição geométrica do produto, por exemplo, é armazenada na base de dados do sistema $\mathrm{CAD}$, enquanto que a estrutura de produto e os planos de processo macro, gerados em uma fase posterior, são armazenados na base de dados do sistema de planejamento da produção (FIGURA 3) (SCHEER, 1998).

A literatura descreve inúmeros problemas e desvantagens decorrentes da abordagem seqüencial de desenvolvimento de produtos.

Segundo PRASAD (1996), a premissa de que uma etapa só possa ser iniciada quando a etapa anterior for finalizada e aprovada resulta em ciclos de desenvolvimento de produtos excessivamente longos.

De acordo com ROZENFELD (1997), a falta de integração funcional nas etapas iniciais do desenvolvimento dificulta a tomada de decisões adequadas e pode comprometer o custo final dos produtos, uma vez que parte significativa (85\%) do custo dos produtos é determinada pelas alternativas adotadas nessa fase.

Segundo SYAN (1994), o desenvolvimento seqüencial faz que uma grande quantidade de alterações ocorra muito tardiamente, quando o custo de modificações é mais alto, pois um maior número de decisões já tomadas precisam ser invalidadas.

Além desses problemas pode-se citar o projeto de produtos inadequados para a produção, a falta de preocupação com a qualidade final do produto durante o projeto e o baixo índice de satisfação dos clientes.

As inúmeras desvantagens do desenvolvimento seqüencial de produtos são consideradas como um dos fatores responsáveis pela perda de competitividade da indústria norte-americana e européia nos anos 80, frente à concorrência japonesa (CLARK \& FUJIMOTO, 1991).

\subsubsection{O Desenvolvimento de Produtos como um Processo de Negócio}

A fim de melhorar o desempenho do desenvolvimento de produtos e aumentar a sua competitividade, muitas empresas passam a considerar o desenvolvimento de produtos como um processo de negócio.

Atualmente, diversas definições e aplicações da abordagem de processos de negócio podem ser encontradas na literatura. GARVIN (1998) sistematizou essas diferentes visões em uma taxonomia para a classificação e definição de processos.

De acordo com GARVIN (1998), os processos de negócio podem ser Organizacionais ou Gerenciais. Os processos Organizacionais são classificados em Processos de Trabalho, Processos Comportamentais e Processos de Mudança. Já os 
processos Gerenciais são classificados em Processos de Direcionamento, Processos de Negociação e Processos de Monitoramento e Controle.

Nessa taxonomia, o processo de desenvolvimento de produtos é classificado como um Processo de Trabalho. O conceito de Processos de Trabalho de GARVIN (1998) originase das definições de processos de negócio propostas pelos movimentos da Reengenharia e da Qualidade Total.

As definições de processos de negócio dos autores dessas duas áreas (HARRINGTON, 1991; DAVENPORT, 1994; HAMMER \& CHAMPY, 1994; ROZENFELD, 1996) são bastante semelhantes (GONÇALVES, 1994).

Neste trabalho é adotada, para o desenvolvimento de produtos, a definição de processos de negócio de ROZENFELD (1996). De acordo com esse autor, um processo de negócio é um fenômeno que ocorre dentro das empresas. Os processos contêm um conjunto de atividades, associadas às informações que manipulam, utilizando os recursos e a organização da empresa. Formam uma unidade coesa que geralmente é focalizada em um determinado tipo de negócio.

A FIGURA 4 representa o processo de desenvolvimento de produtos como um conjunto de atividades realizadas por diversas unidades funcionais de uma organização, desde o surgimento de novas idéias e a identificação de requisitos de mercado, até o lançamento do produto.

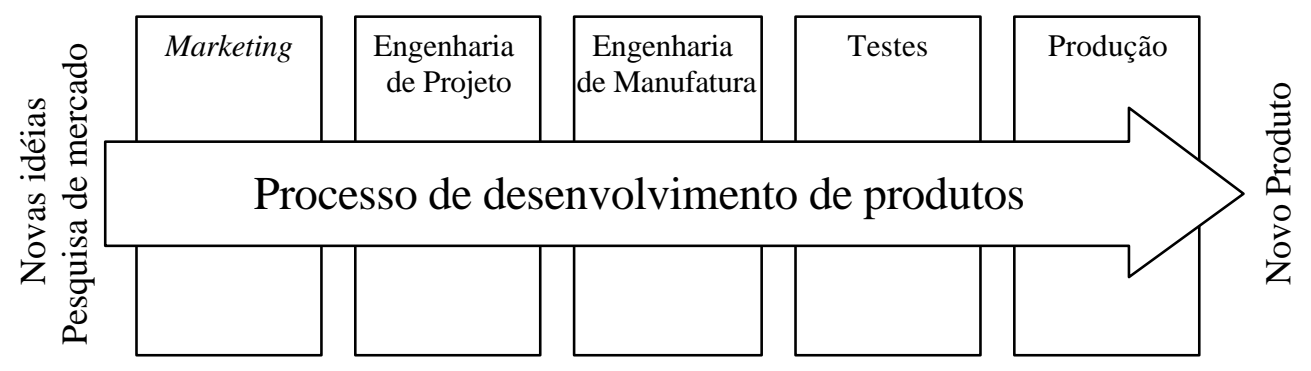

FIGURA 4 - Processo de desenvolvimento de produtos

A visão por processo, representada FIGURA 4, implica várias mudanças em comparação com a abordagem seqüencial de desenvolvimento de produtos, discutida no subitem anterior.

A estrutura departamental é uma visão fragmentária e estanque das responsabilidades e das relações de subordinação, enquanto que a estrutura de processo é uma visão dinâmica da forma como a organização produz valor (DAVENPORT, 1994). 
Essa visão facilita a medição dos resultados e a realização de projetos de melhoria. Os processos bem definidos podem ter várias de suas dimensões medidas, como, por exemplo, o tempo e o custo de execução. As entradas e saídas do processo também podem ser avaliadas quanto à utilidade ou à qualidade (DAVENPORT, 1994).

Além disso, a atribuição do processo a um "dono" claramente definido, responsável pela sua execução, também contribui para melhorar a compreensão do ponto de vista dos clientes do processo (DAVENPORT, 1994).

Os benefícios da adoção da abordagem de processos de negócio no desenvolvimento de produtos são comprovados por pesquisas amplas e atuais. Benchmarkings e surveys realizados recentemente indicam que a existência de um processo bem definido é um dos principais fatores de sucesso no desenvolvimento de produtos (COOPER \& KLEINSHMIDT, 1995; GRIFFIN, 1997).

HAMMER \& STANTON (1999) citam os benefícios obtidos por uma empresa que adotou a abordagem de processos de negócio no desenvolvimento de produtos. Nessa empresa, a duração do ciclo de desenvolvimento de produtos foi reduzida em 50\%, enquanto que o tempo necessário para o equilíbrio financeiro dos projetos de novos produtos diminuiu $80 \%$.

A adoção da abordagem de processos de negócio no desenvolvimento de produtos é freqüentemente associada à introdução parcial ou completa da filosofia de Engenharia Simultânea, discutida no próximo subitem.

\subsubsection{A Filosofia de Engenharia Simultânea}

A Engenharia Simultânea foi proposta inicialmente como uma forma de se reduzir o ciclo de desenvolvimento de produtos por meio do paralelismo de atividades.

Conceitos básicos da Engenharia Simultânea já eram aplicados por empresas ocidentais no início dos anos 80, apesar de a primeira definição formal de Engenharia Simultânea ter sido publicada somente no final da década de 80 (WINNER et al., $1988^{4}$ apud CARTER \& BAKER, 1992).

Por essa definição, a Engenharia Simultânea é considerada "uma abordagem sistemática para o projeto simultâneo e integrado de produtos e de seus processos relacionados, incluindo manufatura e suporte. Tal abordagem procura fazer com que os

${ }^{4}$ WINNER, R.I., PENNELL, J.P., BERTREND, H.E. \& SLUSARCZUK, M.M.G. (1988). The Role of Concurrent Engineering in Weapons System Acquisition. IDA Report R-338. Alexandria, Institute for Defense Analysis. 
envolvidos considerem, desde o início, todos os elementos do ciclo de vida do produto, do conceito ao descarte, incluindo a qualidade, o custo, os prazos e os requisitos dos clientes." (WINNER et al., 1988 apud CARTER \& BAKER, 1992, p. 2).

Desde então surgiram várias definições mais abrangentes de Engenharia Simultânea focalizando outros aspectos além da simultaneidade de atividades, como a cooperação e o consenso entre os envolvidos e a utilização de metodologias de apoio.

CLAUSING (1994) considera que a maioria dessas definições refere-se à Engenharia Simultânea Básica (Basic Concurrent Engineering) e propõe o Total Quality Development, também chamado de Engenharia Simultânea de Classe Mundial (World-class Concurrent Engineering).

A Engenharia Simultânea Básica consiste de dois elementos: melhores processos e maior cooperação. A melhoria dos processos baseia-se na simultaneidade de atividades, no foco tanto na qualidade como no custo e na entrega, na ênfase dada à satisfação dos clientes e na aplicação de benchmarkings competitivos. O aumento da cooperação baseia-se na integração da organização em times multi-funcionais, no envolvimento dos empregados e no relacionamento estratégico com os fornecedores (CLAUSING, 1994).

Além da aplicação desses elementos, a Engenharia Simultânea de Classe Mundial coloca maior ênfase no atendimento dos requisitos dos clientes e na consistência de desempenho do produto pela aplicação do EQFD (Enhanced Quality Function Deployment) e do projeto robusto (CLAUSING, 1994).

Segundo CLAUSING (1994), o EQFD e o projeto robusto preenchem a lacuna existente entre a Engenharia Simultânea Básica e a abordagem necessária para que as empresas concorram globalmente com sucesso.

Neste trabalho, Engenharia Simultânea é definida como a filosofia de atuação no processo de desenvolvimento de produtos, visando ao aumento de qualidade do produto, à diminuição do ciclo de desenvolvimento e, conseqüentemente, à diminuição dos custos. Essa filosofia toma como base a sinergia entre os agentes do processo que devem trabalhar em uma equipe multifuncional formada por pessoas de diversas áreas da empresa. O trabalho dessa equipe é apoiado em métodos e técnicas integrados, tais como: QFD (Quality Function Deployment), FMEA (Failure Mode and Effect Analysis), Taguchi, entre outros (ROZENFELD, 1998).

Essa definição é apropriada para este trabalho pois considera a abordagem por processos de negócio, definida no subitem anterior, como base para a aplicação da Engenharia Simultânea. 
A aplicação da Engenharia Simultânea resulta na necessidade de maior integração entre os dados de produto. Tais informações devem estar localizadas em uma base de dados uniforme em vez de estar divididas em diferentes sistemas, que, além da separação física, referem-se a diferentes fases do desenvolvimento (FIGURA 5) (SCHEER, 1998).

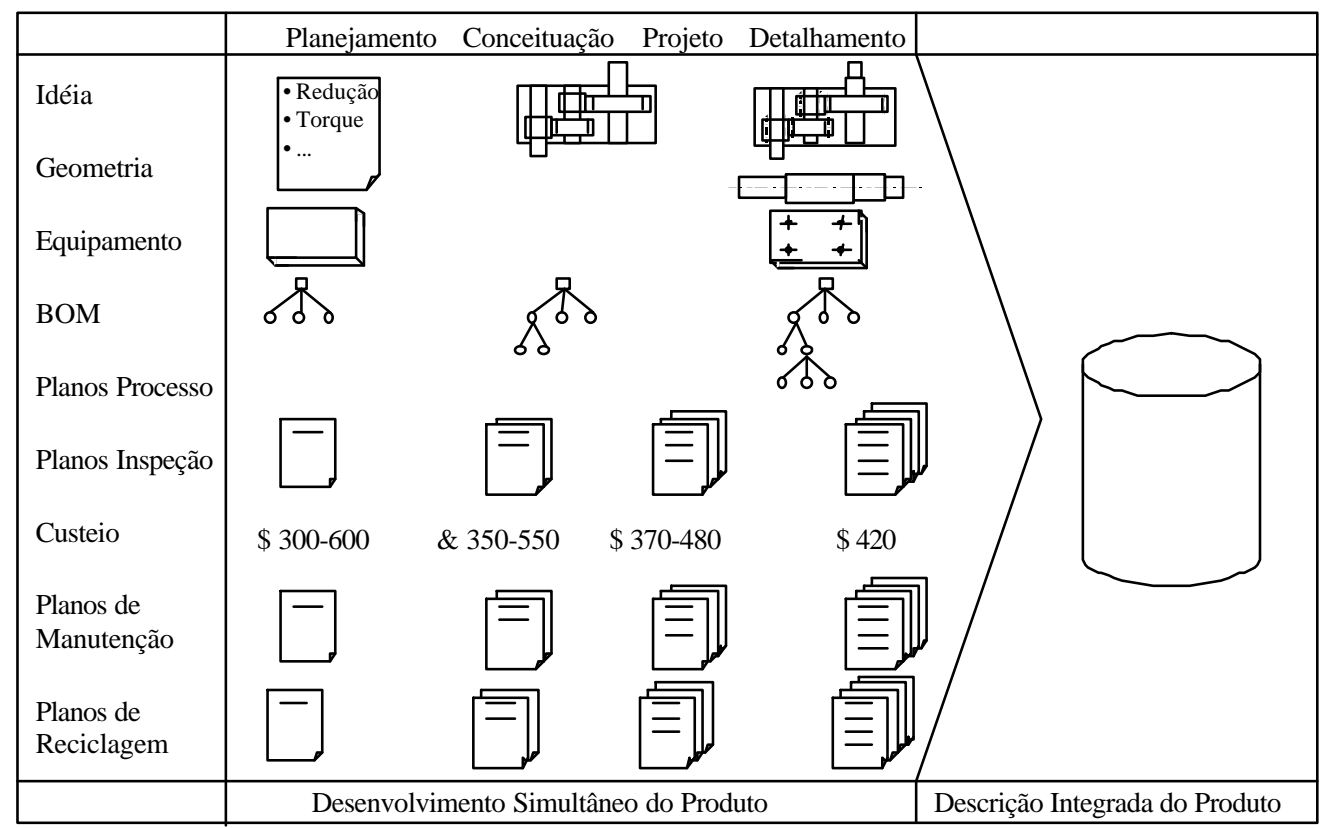

FIGURA 5 - Integração dos dados do produto para apoiar a Engenharia Simultânea (SCHEER, 1998, p. 509)

Entre os benefícios atribuídos à adoção da Engenharia Simultânea destacam-se a redução do ciclo de desenvolvimento com o paralelismo de atividades, o aumento da qualidade por meio do foco nos requisitos dos clientes e da utilização de metodologias de apoio (QFD, FMEA, entre outras) e a diminuição do custo final do produto obtida pela tomada de decisões adequadas nas fases iniciais do desenvolvimento e pela conseqüente redução do número de modificações.

\subsection{Características do Processo de Desenvolvimento de Produtos}

Estudos recentes indicam que as características do processo de desenvolvimento de produtos $^{5}$ (entre as quais as etapas, a organização e os recursos) são dependentes do contexto do desenvolvimento, ou seja, do tipo de processo considerado.

5 A partir deste item, o emprego do termo processo de desenvolvimento de produtos incorpora no seu significado a aplicação da filosofia de Engenharia Simultânea. 
Neste item, são apresentadas as características do processo de desenvolvimento de produtos relevantes para o escopo deste trabalho. A descrição realizada inicialmente é genérica, isto é, independente de um tipo específico de processo.

Em seguida, são discutidos os fatores que definem um tipo de processo de desenvolvimento de produtos e a forma de influência desses fatores nas características do desenvolvimento de produtos.

\subsubsection{Etapas do Processo de Desenvolvimento de Produtos}

O processo de desenvolvimento de produtos é composto por uma grande quantidade de atividades que envolvem desde a identificação de novas idéias e de necessidades de mercado até o lançamento do novo produto. Para facilitar a compreensão do processo, tais atividades são agrupadas em etapas coesas, delimitadas por marcos de projeto ou stage gates ${ }^{6}$.

A divisão do processo em etapas é uma simplificação didática já que, na prática, etapas podem ocorrer em paralelo, e existem interações entre diferentes etapas. O paralelismo de atividades é um dos fundamentos da Engenharia Simultânea.

Por se tratar de uma simplificação, a definição das etapas do processo de desenvolvimento de produtos é puramente arbitrária e depende da adequação ao tipo de processo ou do autor considerado.

WHEELWRIGHT \& CLARK (1992), por exemplo, definem quatro etapas do processo de desenvolvimento de produtos: Desenvolvimento do Conceito; Planejamento do Produto; Engenharia do Produto/Processo; e Produção Piloto/Aumento da Produção. Já a APQP (Advanced Product and Quality Planning) da QS- $9000^{7}$ propõe o agrupamento das atividades de desenvolvimento de produtos na indústria automobilística em cinco etapas: Planejamento; Projeto e Desenvolvimento do Produto; Projeto e Desenvolvimento do Processo; Validação do Produto e do Processo; Análise da Retroalimentação e Ação Corretiva (AIAG, 1994).

${ }^{6}$ Stage gates são definidos como pontos do desenvolvimento de produtos nos quais são realizadas revisões de qualidade do produto e do processo de desenvolvimento. Em cada gate, o produto e o processo são avaliados em relação a parâmetros pré-estabelecidos (COOPER, 1994).

${ }^{7}$ A QS-9000 é uma norma de qualidade estabelecida pela indústria automobilística de origem norte-americana. Essa norma é baseada na ISO-9000, acrescida de requisitos adicionais específicos do setor automotivo (HOYLE, 1997). 
Para identificar as etapas mais empregadas pelas empresas no desenvolvimento de produtos com alto grau de inovação, GRIFFIN (1997) realizou uma pesquisa com base em uma sistematização desse processo em nove etapas.

Considera-se que as etapas utilizadas por GRIFFIN (1997) são bastante abrangentes e gerais pois procuram permitir analogias com as etapas realizadas em vários tipos de processo. As nove etapas são detalhadas a seguir:

a Planejamento da Linha de Produtos - análise do portfolio atual de produtos em relação ao ambiente competitivo;

a Desenvolvimento da Estratégia de Projeto - definição do mercado alvo e determinação das necessidades do mercado;

- Geração da Idéia/Conceito - identificação das oportunidades e início da geração de possíveis soluções;

- Avaliação das Idéias - avaliação e priorização das soluções, e eliminação das opções não atrativas;

- Análise do Negócio - avaliação financeira do conceito;

口 Desenvolvimento - conversão do conceito em um produto funcional;

- $\quad$ Teste e Validação - utilização do produto e realização de testes de campo, de mercado e de conformidade com as normas;

口 Desenvolvimento da Manufatura - desenvolvimento dos processos de manufatura e realização de testes piloto;

- Comercialização - lançamento do novo produto em escala de produção e vendas.

As empresas pesquisadas foram classificadas em empresas de alto desempenho e empresas de baixo desempenho no desenvolvimento de produtos. Verificou-se que as empresas de alto desempenho realizam, no desenvolvimento de produtos com alto grau de inovação, na média 6,2 das 9 etapas, enquanto que as empresas de baixo desempenho realizam 4,7 das 9 etapas. Isso sugere que processos de desenvolvimento de produtos mais bem estruturados e completos são um dos fatores do melhor desempenho de algumas empresas (GRIFFIN, 1997).

\subsubsection{Formas de Organização do Desenvolvimento de Produtos}

Existem várias formas de organização do desenvolvimento de produtos. A escolha da forma mais adequada para cada caso também é decorrente do tipo do processo de 
desenvolvimento de produtos e tem influência direta no desempenho e no resultado do desenvolvimento.

O tipo de processo de desenvolvimento exerce influência em três dimensões da organização do desenvolvimento de produtos identificadas por CLARK \& FUJIMOTO (1991): o grau de especialização, a integração interna e a integração externa. O grau de especialização refere-se aos conhecimentos específicos necessários para se projetar funcionalmente os elementos de um produto. A integração interna diz respeito à coordenação da equipe de desenvolvimento, e a integração externa relaciona-se com o atendimento das necessidades dos consumidores.

O desenvolvimento de um produto baseado em componentes tecnológicos que evoluem muito rapidamente, por exemplo, requer um alto nível de conhecimentos específicos. O alto grau de especialização necessário determina a segmentação da organização em departamentos e unidades e pode dificultar a coordenação e comunicação entre os grupos funcionais, ou seja, diminuir a integração interna (CLARK \& FUJIMOTO, 1991).

Em um estudo realizado na indústria automobilística, CLARK \& FUJIMOTO (1991) compilaram os diferentes tipos de organização do desenvolvimento de produtos observados em quatro formas principais (FIGURA 6). Fora da indústria automobilística CLAUSING (1994) identificou mais uma possível forma de organização do desenvolvimento de produtos. Essas cinco formas básicas e suas combinações em formas híbridas ou variações refletem a organização do desenvolvimento de produtos da maioria das empresas.

Na Estrutura Funcional tradicional o desenvolvimento é organizado por departamentos (representados pelos retângulos D1, D2, e assim por diante). Não existe uma pessoa responsável pelo desenvolvimento como um todo. Os gerentes funcionais (GF) são responsáveis somente pela alocação de recursos e pela realização das atividades atribuídas aos seus departamentos (CLARK \& FUJIMOTO, 1991).

Na organização por Gerente de Produtos Peso Leve existe um gerente de produto (GP) que coordena as atividades de desenvolvimento por meio de representantes nos departamentos (R). Tais representantes formam o elo de ligação entre o GP e os especialistas nos departamentos, uma vez que o GP não tem autoridade sobre as pessoas envolvidas no trabalho (representadas pelos círculos hachurados), nem acesso direto a elas. A área de influência do GP (delimitada pela linha tracejada) não incluí contato direto com o mercado ou responsabilidade pelo conceito do produto (CLARK \& FUJIMOTO, 1991). 

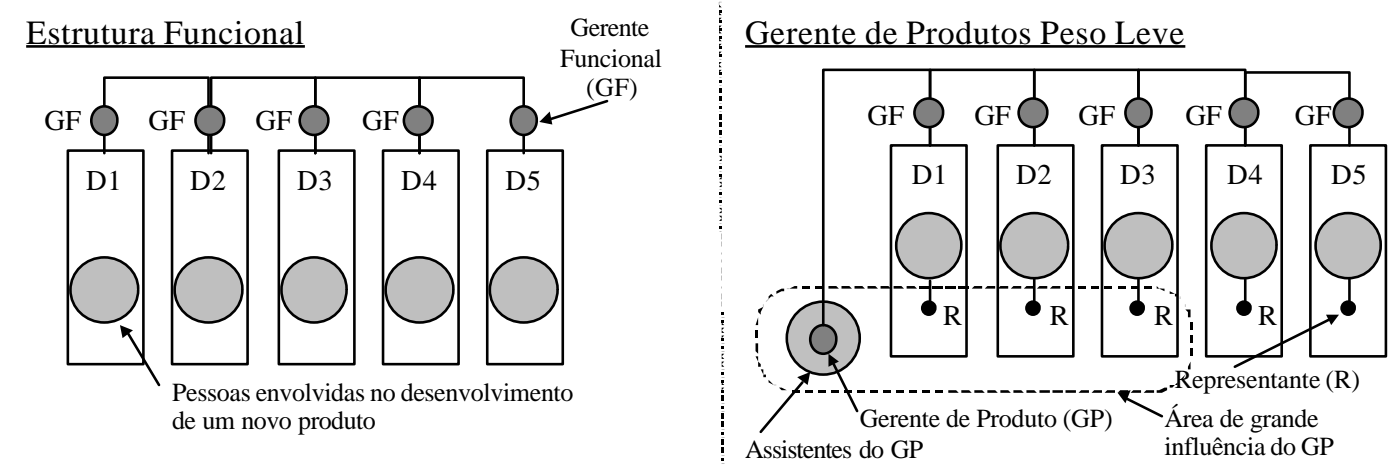

Gerente de Produtos Peso Pesado

Times de Execução de Projetos
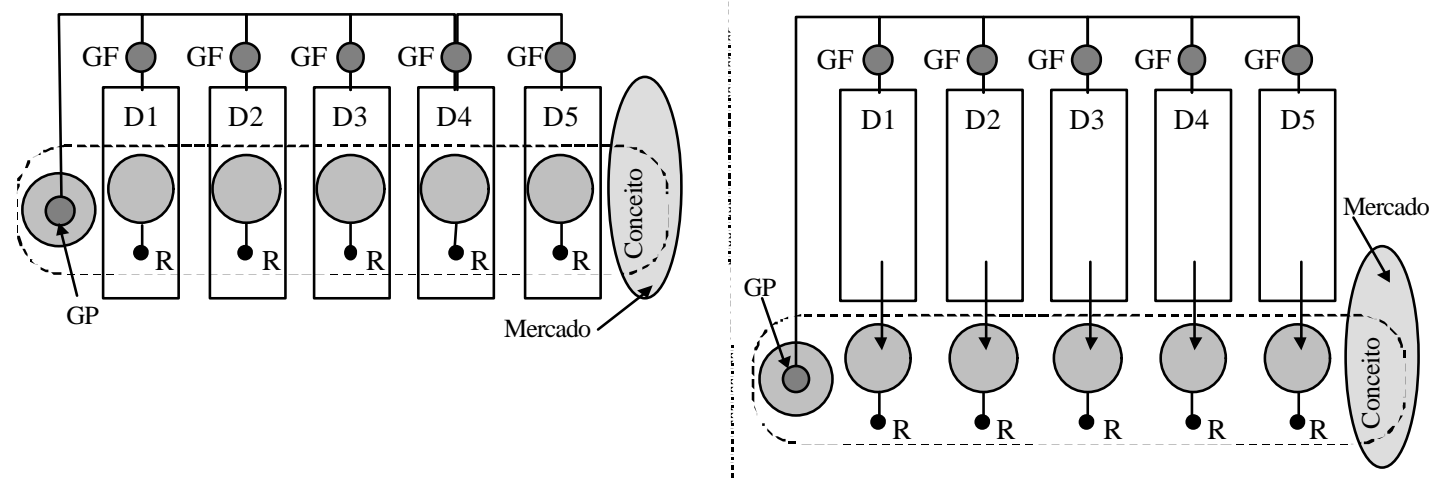

FIGURA 6 - Formas de organização do desenvolvimento de produtos (CLARK \& FUJIMOTO, 1991, p. 254)

Na estrutura de Gerente de Produtos Peso Pesado, o gerente de produto (GP) possui mais responsabilidade e poder de influência. O trabalho é feito pelos representantes nos departamentos, mas, quando necessário, o GP tem acesso direto às pessoas envolvidas e grande poder de influência sobre as atividades do projeto. O GP também é responsável pelo planejamento do produto e desenvolvimento do conceito (CLARK \& FUJIMOTO, 1991).

No desenvolvimento de produtos estruturado por Times de Execução de Projetos, o GP coordena uma equipe de pessoas dedicadas integralmente ao desenvolvimento. As pessoas envolvidas no desenvolvimento deixam as suas áreas funcionais e passam a se reportar diretamente ao GP (CLARK \& FUJIMOTO, 1991). Ao final do desenvolvimento as pessoas retornam para as suas áreas funcionais.

CLAUSING (1994) identificou uma quinta forma de organização do desenvolvimento de produtos, chamada de Time de Desenvolvimento de Produtos Independente. Nessa estrutura não existe relação das pessoas com departamentos funcionais. As pessoas dedicam-se exclusivamente à equipe de desenvolvimento e reportam-se somente ao gerente de produto. 
O grau de especialização e de integração varia de acordo com as formas de organização do desenvolvimento de produtos citadas, desde baixo nível de integração interna e externa e alto grau de especialização na Estrutura Funcional, até altos níveis de integração com menor especialização no Time de Desenvolvimento de Produtos Independente .

\subsubsection{Recursos Utilizados no Desenvolvimento de Produtos}

Para desenvolver produtos as empresas utilizam grande quantidade e variedade de recursos, tais como recursos financeiros, equipamentos, sistemas computacionais, entre outros.

Dado o escopo deste trabalho, este subitem é limitado à apresentação das diversas classes de sistemas computacionais que apóiam o processo de desenvolvimento de produtos, com ênfase nas principais características e funcionalidades desses sistemas.

A apresentação das classes de sistemas computacionais de desenvolvimento de produtos é genérica e independente de qualquer sistema disponível comercialmente. Para a descrição de algumas classes de sistemas, no entanto, é citada bibliografia referente a sistemas específicos, existentes no mercado. Essa opção é justificada pela ênfase dada por essa bibliografia (manuais, folders, páginas de Internet, entre outros) às funcionalidades dos sistemas. Contudo, deve-se destacar que tal bibliografia é empregada de forma neutra, para representar as características e as funcionalidades típicas da maioria dos sistemas pertencentes a uma mesma classe.

Neste subitem, são apresentados, inicialmente, os sistemas de gerenciamento de dados de produto e de gerenciamento do processo de desenvolvimento, e os sistemas de apoio ao trabalho em grupo. Em seguida, são descritos os aplicativos CAx (Computer Aided) e os sistemas relacionados com métodos e técnicas específicas de desenvolvimento de produtos. São apresentados, então, os sistemas mais gerais utilizados no desenvolvimento de produtos, tais como os editores de texto e as planilhas eletrônicas. Por fim são analisados os sistemas ERP e os sistemas de modelagem de processos.

\section{Sistemas PDM (Product Data Management)}

Os sistemas PDM são ferramentas que possuem funcionalidades para organizar e controlar todos os dados relativos a produtos e para gerenciar o ciclo de vida de produtos (DICKERSON, 1996).

Os sistemas PDM são tipicamente compostos por um "cofre eletrônico" (vault), uma base de dados e um conjunto de funcionalidades. O vault é utilizado como um repositório para o armazenamento de todos os tipos de informação de produtos. Os dados sobre as 
informações armazenadas no vault são mantidos na base de dados. Tais dados são manipulados pelas funcionalidades do PDM (MILLER \& MENDEL, 1997).

O CIMDATA (1996) classifica as funcionalidades dos sistemas PDM em um conjunto de funcionalidades principais e um grupo de funcionalidades de apoio. Essas funcionalidades são descritas a seguir:

Funcionalidades principais:

a Gerenciamento de documentos - armazenamento de qualquer tipo de documento eletrônico que descreva o produto em um "cofre" (vault) com controle de acesso e gerenciamento de metadados (dados sobre os dados) como, por exemplo, versões, status, histórico de modificações, aprovações;

- Fluxo de trabalho e gerenciamento de processos - definição, controle e automação de processos das organizações;

- Gerenciamento de estruturas de produto - criação de estruturas de produto e gerenciamento de configurações;

- Classificação e recuperação - agrupamento de objetos semelhantes em famílias, e recuperações de objetos por seus atributos;

- Gerenciamento de projetos - planejamento detalhado e controle da execução de projetos (essa funcionalidade ainda é pouco desenvolvida na maioria dos sistemas PDM disponíveis comercialmente).

Funcionalidades de apoio:

- Comunicação e notificação - notificação automática de eventos críticos e comunicação entre pessoas por meio de serviços de correio eletrônico;

- Transporte de dados - transporte automático de dados entre servidores e computadores sem necessidade de interferência do usuário;

- Conversão de dados - conversão de dados entre diferentes aplicativos;

- Serviços de visualização e comentários (mark-up) - visualização de vários tipos de documentos sem necessidade de acesso ao aplicativo de origem, e realização de comentários e anotações nos documentos sem alteração do documento original;

- Administração - administração de usuários, de autorizações, de procedimentos de aprovação, entre outros. 
O termo sistemas PDM é muitas vezes empregado de maneira muito ampla para designar os diversos tipos de sistemas de gerenciamento de dados de produto existentes atualmente (OMOKAWA, 1999).

Neste trabalho, assim como em OMOKAWA (1999), adota-se a diferenciação realizada por SWANTON (1997), que classifica os sistemas de gerenciamento de dados de produto em dois grupos: os sistemas PDM, apresentados nesta seção, e os sistemas EDM (Electronic Document Management), descritos na seção seguinte.

\section{Sistemas EDM (Electronic Document Management)}

Os sistemas EDM são aplicativos que controlam o ciclo de vida de documentos eletrônicos e de imagens de documentos (BIELAWSKI \& BOYLE, 1997).

Tais sistemas são voltados para a área de manufatura, gerenciando a documentação técnica dos produtos em produção, ou ainda são direcionados para aplicações gerais que abrangem toda a empresa, como, por exemplo, gerenciando normas e procedimentos internos e controlando publicações técnicas (SWANTON, 1997).

As principais funcionalidades dos sistemas EDM são descritas a seguir (BIELAWSKI \& BOYLE, 1997):

a $\underline{\text { Armazenamento }}$ - armazenamento de documentos em um repositório com controle de acesso;

- Conversão - alteração do formato de documentos eletrônicos e digitalização de documentos em papel;

口 Localização - procura sistemática de documentos apoiada por mecanismos de busca como, por exemplo, busca Booleana e a localização por sinônimos;

- Criação - criação de novos documentos a partir da utilização de modelos (templates) e padronização de formatos;

- $\quad$ Fluxo de trabalho - programação e execução de fluxos de trabalho;

口 Distribuição - realização de anotações (mark-up), aumento/diminuição da imagem (zoom) e a impressão em papel, entre outras funcionalidades utilizadas pelos usuários finais de documentos.

\section{Sistemas de Gerenciamento de Projetos}

Os sistemas de gerenciamento de projetos possuem funcionalidades que possibilitam o planejamento detalhado (definição das atividades, determinação dos prazos de realização, 
alocação de recursos e avaliação dos custos envolvidos) e o controle da execução de projetos.

São funcionalidades típicas dos sistemas de gerenciamento de projetos: a definição de WBSs (Work Breakdown Structures), o estabelecimento de redes de atividades, a determinação de marcos de projeto (milestones), a visualização das atividades em gráficos de Gantt e PERT, o cálculo do caminho crítico, a alocação de recursos às atividades, o nivelamento da utilização de recursos, a estimativa de custos, o acompanhamento da execução e a geração de relatórios de projetos (MICROSOFT, 1997; DRÄGER, 1998; PRIMAVERA, 2000).

Além dessas funcionalidades típicas, os sistemas gerenciadores de projetos mais recentes apóiam a publicação de informações de projetos em páginas da Internet (MICROSOFT, 1997; PRIMAVERA, 2000) e possuem integração com os sistemas ERP (SAP, 1998; PRIMAVERA, 2000). Os gerenciadores de projetos também podem ser módulos constituintes de sistemas ERP (DRÄGER, 1998; SAP, 1998a).

\section{Sistemas de Trabalho em Grupo (Groupware)}

Os sistemas de trabalho em grupo são sistemas que apóiam o trabalho cooperativo e a troca de informações entre as pessoas (TIBERTI, 1996).

Tais sistemas englobam um conjunto de funcionalidades e aplicativos, entre as quais: o correio eletrônico, a agenda eletrônica em grupo, a vídeo conferência, a manipulação de documentos em grupo e o gerenciamento de fluxo de trabalho (TIBERTI, 1996).

\section{Sistemas CAD (Computer Aided Design)}

Os sistemas CAD são ferramentas para a criação, a análise e a modificação de modelos geométricos de produtos (NOLEN, 1989).

Tais modelos podem ser bidimensionais ou tridimensionais (NOLEN, 1989). Atualmente, tem-se enfatizado a utilização de sistemas CAD que possibilitam a criação de modelos tridimensionais sólidos, devido à ampla aplicação desses modelos nas demais atividades do processo de desenvolvimento como, por exemplo, na geração de protótipos eletrônicos (digital mock-up) (SCHÜTZER \& SOUZA, 1998), na construção rápida de protótipos físicos (rapid prototyping), no cálculo por elementos finitos, na construção do ferramental, entre outras ${ }^{8}$ (EVERSHEIM et al., 1997).

${ }^{8}$ Apesar das vantagens da utilização de modelos geométricos tridimensionais, tais modelos são empregados por apenas 15 a 20\% dos usuários de CAD, considerando todos os possíveis setores de aplicação (EVERSHEIM et al., 1997). Uma pesquisa realizada no Brasil, englobando somente o 
Os sistemas $\mathrm{CAD}$ podem ser genéricos ou especializados em uma determinada área de aplicação. Por exemplo, existem sistemas CAD voltados para o projeto mecânico, sistemas CAD direcionados para o projeto de instalações eletro-hidráulicas (EVERSHEIM et al., 1997) e sistemas CAD especializados no projeto de circuitos impressos (NOLEN, 1989).

Os sistemas CAD atuais oferecem uma ampla gama de funcionalidades e de módulos de apoio ao projeto, entre os quais o projeto paramétrico e por características geométricas (features), a geração de seções e de perspectivas, a análise de montagens e a explosão de montagens para a elaboração de documentação técnica (EVERSHEIM et al., 1997).

Além dessas funções, alguns sistemas CAD também têm funcionalidades que apóiam a criação e o gerenciamento de dados e especificações de produto, como, por exemplo, a definição de estruturas de produto e a especificação de dados tecnológicos dos itens projetados.

\section{Sistemas CAE (Computer Aided Engineering)}

O termo sistemas CAE engloba uma série de tecnologias e sistemas utilizados para apoiar as atividades de projeto detalhado durante o desenvolvimento de produtos, como a análise baseada no método de elementos finitos e a determinação das propriedades de modelos sólidos (LIRANI, 1999) ${ }^{9}$.

O método de elementos finitos tem várias aplicações nas atividades de projeto detalhado, como, por exemplo, na análise de tensões e de deformações, na determinação de freqüências naturais e de modos de vibrar, e nos estudos de transmissão de calor, de escoamentos de fluídos e de campos elétricos e magnéticos (LIRANI, 1999).

As funcionalidades dos sistemas CAE para a determinação das propriedades de sólidos, por sua vez, compreendem os cálculos de massa, de área e de volume e a determinação do centro de gravidade e do momento de inércia de itens projetados (LIRANI, 1999).

Deve-se observar que existe uma tendência crescente de integração entre as ferramentas de CAE e os sistemas CAD (EVERSHEIM et al.,1997). Atualmente, as funções típicas de CAE podem ser módulos de sistemas CAD.

setor de autopeças, indicou que $79 \%$ das empresas já utilizam sistemas CAD tridimensionais. No entanto, o maior volume de trabalho (cerca de 80\%) continua baseado em modelos geométricos bidimensionais (SCHÜTZER \& SOUZA, 1999).

${ }^{9}$ LIRANI, J. (1999). SEM 391 - CAE /notas de aula/ 


\section{Sistemas CAPP (Computer Aided Process Planning)}

Os sistemas CAPP são sistemas que apóiam as atividades de criação e de gerenciamento de planos de processo macro e dos detalhamentos dos planos de processo ${ }^{10}$.

De acordo com o método de planejamento, os sistemas CAPP são classificados em Interativo, Variante e Automático. O CAPP Interativo possui funcionalidades para a elaboração de planos de processo utilizando padrões de planejamento. O sistema Variante apóia a criação de planos de processo com base em planos semelhantes recuperados. A utilização de sistemas CAPP Automáticos possibilita a geração automática de planos de processo a partir da descrição da peça (ROZENFELD, 1992).

Os sistemas CAPP também podem ter funcionalidades adicionais, tais como: a classificação e a recuperação de itens, o gerenciamento de estruturas de produto e a estimativa de custo de produtos (KSR, 1998a; KSR, 1998b).

\section{Sistemas CAM (Computer Aided Manufacturing)}

A sigla CAM pode ser utilizada para representar um conjunto amplo de tecnologias utilizadas na produção, incluindo as máquinas $\mathrm{CN}$ (comando numérico), o gerenciamento de ferramentas, o controle de depósitos e de materiais, o controle de qualidade e a manutenção (SCHEER, 1998). O termo sistemas CAM, no entanto, é geralmente empregado de forma menos abrangente para denominar os sistemas que apóiam as atividades de programação $\mathrm{CN}$.

Tais sistemas têm funcionalidades que calculam o caminho da ferramenta a partir da representação da peça, simulam o programa $\mathrm{CN}$ obtido e estimam os tempos de fabricação. Além disso, os sistemas CAM mais completos possuem funções para o cálculo das condições de usinagem (ROZENFELD, 1992).

\section{Sistemas de Simulação}

Os softwares de simulação apóiam a modelagem de sistemas reais e possibilitam a realização de simulações computacionais, reduzindo a necessidade de construção de modelos físicos (protótipos, maquetes, entre outros) para a realização de testes durante o processo de desenvolvimento de produtos.

${ }^{10} \mathrm{O}$ plano de processo macro contém a seqüência de operações de fabricação, a especificação das máquinas e os tempos padrão. São detalhamentos do plano de processo: a seqüência de suboperações, os croquis de fabricação, a lista de ferramental e de dispositivos, a especificação das condições de usinagem, entre outras informações necessárias para a fabricação da peça (ROZENFELD, 1992). 
EVERSHEIM et al., (1997) diferenciam os softwares de simulação, aplicáveis no desenvolvimento de produtos, em softwares de simulação de sistemas de manufatura, softwares de simulação de sistemas dinâmicos e softwares de análise por elementos finitos.

A simulação de sistemas de manufatura descreve o comportamento de um sistema de produção com relação ao tempo e à sua capacidade produtiva. A simulação dinâmica apresenta as relações e interações cinemáticas entre componentes individuais de uma montagem de um produto (EVERSHEIM et al., 1997). A simulação por métodos de elementos finitos, por sua vez, é considerada neste trabalho como um dos componentes dos sistemas CAE, apresentados anteriormente.

De acordo com EVERSHEIM et al. (1997), a simulação pode ser utilizada mesmo nas fases iniciais do desenvolvimento de produtos para apoiar, por exemplo, a análise de seqüências de movimentação, a detecção de colisões, a determinação da melhor forma de fixação de ferramentas e a realização de estudos de ciclos de produção.

\section{Sistemas de Apoio à Aplicação de Métodos e Técnicas de Desenvolvimento de Produtos}

Esta classe engloba um conjunto de sistemas utilizados para apoiar a aplicação de métodos e técnicas específicos de desenvolvimento de produtos. Cada um dos sistemas é descrito resumidamente a seguir:

- Sistemas de QFD (Quality Function Deployment) - são sistemas utilizados para apoiar a construção gráfica de diagramas matriciais de QFD (QUALISOFT, 1991).

- Sistemas de DFMA (Design for Manufacturing and Assembly) - são aplicativos que calculam o potencial de melhoria na fabricação de itens e na montagem de produtos e apresentam relatórios com sugestões para a modificação dos itens e dos produtos analisados, a partir dos dados fornecidos pelos usuários (BOOTHROYD DEWHURST, 1996).

- Sistemas de FMEA (Failure Mode and Effects Analysis) - são sistemas que apóiam a elaboração de formulários de FMEA, por meio de maior padronização e da automação do cálculo dos índices de risco, e possibilitam o gerenciamento centralizado das ações corretivas de diversos FMEAs (KSR, 1999).

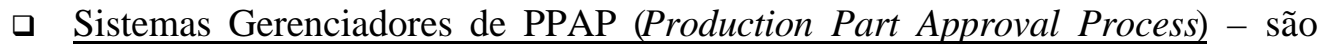
softwares que apóiam a criação e o gerenciamento de toda a documentação de PPAP, bem como a geração de relatórios de PPAP (IQS, 2000; KSR, 2000). 


\section{Sistemas de Visualização}

Os visualizadores possibilitam a visualização de dezenas de tipos de documentos eletrônicos (textos, planilhas eletrônicas, desenhos em CAD, imagens digitalizadas, entre outros) sem necessidade de acesso aos aplicativos que originaram tais documentos. Além disso, os visualizadores também provêem uma série de serviços adicionais, tais como a realização de anotações e comentários nos documentos sem alteração do documento original (mark-up), a comparação entre documentos e a impressão de documentos (EAI, 2000).

Os sistemas de visualização podem ser utilizados isoladamente ou podem ser funcionalidades integradas a outros sistemas, como aos sistemas PDM e aos sistemas ERP.

\section{Sistemas de Automação de Escritório}

Os sistemas de automação de escritório apóiam várias atividades gerais realizadas no desenvolvimento de produtos. Entre esses sistemas estão os editores de texto, as planilhas eletrônicas e os sistemas de apresentação.

Os editores de texto possuem funções para a criação, a edição, a formatação, o armazenamento e a impressão de textos eletrônicos. Além disso, os editores de texto mais completos oferecem funcionalidades avançadas, como, por exemplo, a verificação e a correção automática de erros de ortografia, e o dicionário de sinônimos (LAUDON \& LAUDON, 1998).

As planilhas eletrônicas são aplicativos que apóiam a realização de cálculos numéricos de maneira flexível. Nesses aplicativos, os dados são apresentados no formato de uma matriz. Cada elemento da matriz (célula) pode ser relacionado matematicamente com outros elementos da mesma matriz e de outras matrizes. Após o estabelecimento das relações matemáticas, a alteração de qualquer um dos valores envolvidos no relacionamento provoca o recálculo instantâneo dos demais elementos da matriz. As planilhas eletrônicas típicas também possuem funções para a elaboração de vários tipos de gráficos (LAUDON \& LAUDON, 1998).

De acordo com ULLMAN (1992), as planilhas eletrônicas atendem as necessidades mais simples de cálculo e de análise matemática durante o desenvolvimento de produtos. Além disso, ULLMAN (1992) destaca outras aplicações das planilhas eletrônicas no desenvolvimento de produtos, como a utilização da estrutura matricial para a elaboração de tabelas de apoio à tomada de decisões e para o planejamento das atividades de desenvolvimento.

Os sistemas de apresentação, por sua vez, apóiam a preparação e a realização de apresentações gráficas. Tais sistemas possuem várias funcionalidades de desenho e de 
formatação que facilitam a preparação de slides para apresentações. Os slides podem ser impressos ou apresentados pelo próprio sistema, de acordo com uma seqüência pré-definida pelo usuário.

LAUDON \& LAUDON (1998) também consideram os sistemas que apóiam a comunicação no escritório (Sistemas de Trabalho em Grupo - correio eletrônico, agenda eletrônica e videoconferência) e o gerenciamento de documentos (Sistemas EDM gerenciadores de documentos) como sistemas de automação de escritório. Neste trabalho, entretanto, tais sistemas são tratados separadamente devido à sua importância para o desenvolvimento de produtos.

\section{Sistemas ERP (Enterprise Resource Planning)}

Os sistemas ERP são sistemas integrados de gestão empresarial que abrangem um amplo escopo de funcionalidades. Algumas dessas funcionalidades podem ser utilizadas para apoiar o processo de desenvolvimento de produtos, tais como as funcionalidades de geração dos dados mestres de produto (cadastro de itens, estruturas de produto, planos de processo, entre outros) (SAP, 1996), as funcionalidades de gerenciamento de projetos (DRÄGER, 1998; SAP, 1998b) e as funcionalidades de PDM do ERP (MILLER \& MENDEL, 1997; SAP, 1997; WESSNER, 1999).

No entanto, conforme se pôde verificar pelos relatos de membros de empresas usuárias e de fornecedores de sistemas, as funcionalidades dos sistemas ERP ainda são pouco utilizadas no processo de desenvolvimento de produtos (ROZENFELD \& ZANCUL, 2000).

Devido à sua importância para a realização deste trabalho, os sistemas ERP são apresentados detalhadamente no Capítulo 3.

\subsubsection{Tipos de Processo de Desenvolvimento de Produtos}

A aplicação de filosofias, técnicas e métodos, formas organizacionais e sistemas computacionais de desenvolvimento de produtos, tais como as soluções relacionadas à Engenharia Simultânea (equipes multifuncionais, QFD, Taguchi, entre outras), é muitas vezes apontada pela literatura como as melhores práticas de aplicação geral.

No entanto, estudos recentes sugerem que as melhores práticas são dependentes do contexto do desenvolvimento de produtos (GRIFFIN, 1997). Essa hipótese é ressaltada por ROZENFELD \& AMARAL (1999), que apontam a existência de fatores que condicionam a eficácia e a eficiência das melhores práticas em um determinado contexto. 
Partindo desse pressuposto, ROZENFELD \& AMARAL (1999) elaboraram uma tipologia para a identificação das características fundamentais que afetam a forma de gerenciar o processo de desenvolvimento de produtos. Essa tipologia, apresentada na TABELA 2, engloba vários fatores divididos em três níveis: mercado, corporação e empresa. Os fatores relacionados com cada um dos níveis são listados na segunda coluna da TABELA 2. A terceira coluna especifica os possíveis tipos dos fatores.

TABELA 2 - Tipologia de processos de desenvolvimento de produtos (ROZENFELD \& AMARAL, 1999)

\begin{tabular}{|c|c|c|c|}
\hline NÍVEL & \multicolumn{2}{|c|}{ FATOR } & TIPOS \\
\hline \multirow[t]{4}{*}{ Mercado } & \multicolumn{2}{|l|}{ Setor } & $\begin{array}{l}\text { Automobilístico, aeronáutico, petroquímico, } \\
\text { máquinas-ferramenta, eletrodomésticos, linha } \\
\text { branca, indústria de base }\end{array}$ \\
\hline & \multicolumn{2}{|l|}{ Concorrência } & $\begin{array}{l}\text { Monopólio, oligopólio competitivo, oligopólio } \\
\text { diferenciado, concorrência perfeita }\end{array}$ \\
\hline & \multirow[t]{2}{*}{ Alvo } & Geográfico & Local, regional, mundial \\
\hline & & $\begin{array}{l}\text { Posição na cadeia } \\
\text { de produção }\end{array}$ & $\begin{array}{l}\text { Contato com cliente final, intermediário na } \\
\text { cadeia de suprimentos }\end{array}$ \\
\hline \multirow[t]{3}{*}{ Corporação } & \multicolumn{2}{|l|}{ Inserção } & Unidade independente, matriz, filial \\
\hline & \multirow[t]{2}{*}{$\begin{array}{l}\text { Interação com } \\
\text { unidades }\end{array}$} & Responsabilidade & $\begin{array}{l}\text { Coordenador de desenvolvimento, participante } \\
\text { de co-desenvolvimento }\end{array}$ \\
\hline & & Equipe & Local, regional, mundial \\
\hline \multirow[t]{8}{*}{ Empresa } & \multicolumn{2}{|c|}{ Responsabilidade técnica } & $\begin{array}{l}\text { Centro de adaptação tecnológico, aquisição e } \\
\text { adaptação de tecnologia, centro de } \\
\text { desenvolvimento de produto, centro de } \\
\text { desenvolvimento tecnológico de manufatura, } \\
\text { centro de manufatura }\end{array}$ \\
\hline & \multirow[t]{2}{*}{ Estratégia } & Competitiva & Custo, qualidade, tempo, misto \\
\hline & & Interprojetos & Novo, simultâneo, seqüencial, posterior \\
\hline & \multicolumn{2}{|c|}{ Informações iniciais } & $\begin{array}{l}\text { Idéia, requisitos de desempenho, parte do } \\
\text { projeto do produto, parte do projeto do produto } \\
\text { e protótipos, produto em produção }\end{array}$ \\
\hline & \multirow[t]{3}{*}{$\begin{array}{l}\text { Complexidade } \\
\text { do produto }\end{array}$} & $\begin{array}{l}\text { Tecnologia } \\
\text { principal }\end{array}$ & $\begin{array}{l}\text { Mecânica, elétrica, eletrônica, mecatrônica, } \\
\text { opto-eletrônica, química }\end{array}$ \\
\hline & & Interna & $\begin{array}{l}\text { Número de componentes, números de linhas de } \\
\text { softwares, número de insumos e etapas }\end{array}$ \\
\hline & & $\begin{array}{l}\text { Interface com o } \\
\text { usuário }\end{array}$ & Alta complexidade, baixa complexidade \\
\hline & \multicolumn{2}{|l|}{ Grau de inovação } & $\begin{array}{l}\text { Pesquisa e desenvolvimento avançados, } \\
\text { breakthrough ou radical, plataformas ou nova } \\
\text { geração e derivados }\end{array}$ \\
\hline
\end{tabular}

De acordo com ROZENFELD \& AMARAL (1999), as diferentes atividades, as formas de organização e os recursos do processo de desenvolvimento de produtos podem ganhar ou perder importância conforme os fatores de contingência do processo listados na 
O setor da indústria, por exemplo, determina a realização de algumas atividades específicas no desenvolvimento de produtos. $\mathrm{O}$ setor aeroespacial é submetido às exigências de uma série de normas e regulamentos internacionais que impõem a realização de determinadas atividades e a geração de informações relacionadas com a segurança dos produtos. A APQP especifica de forma macro as atividades de desenvolvimento que devem ser realizadas pelas empresas do setor automobilístico certificadas pela QS-9000.

O grau de inovação do produto, por sua vez, tem forte influência em várias dimensões do desenvolvimento de produtos (ROZENFELD \& AMARAL, 1999). Quanto maior o grau de inovação, mais deve-se aumentar a sobreposição entre o desenvolvimento da tecnologia e as etapas de detalhamento do projeto (FUNK, $1997^{11}$ apud ROZENFELD \& AMARAL, 1999), aplicar medidas de viabilidade econômica que considerem adequadamente os riscos maiores envolvidos nesses projetos (SWINK et al., $1996^{12}$ apud ROZENFELD \& AMARAL, 1999) e direcionar os esforços de desenvolvimento para a qualidade.

Nos casos em que a inovação é muito grande deve-se ainda antecipar a construção de modelos e protótipos (VERYZER, 1998 ${ }^{13}$ apud ROZENFELD \& AMARAL, 1999) e aumentar a interação entre as pessoas de marketing e de testes (VERYZER, 1998b ${ }^{14}$ apud ROZENFELD \& AMARAL, 1999).

Nos projetos incrementais e de baixo grau de inovação, por sua vez, deve-se seguir um processo menos estruturado (VERYZER, 1998a apud ROZENFELD \& AMARAL, 1999), dar maior ênfase à redução do tempo necessário até o lançamento do produto no mercado (SWINK et al., 1996 apud ROZENFELD \& AMARAL, 1999) e diminuir a influência da manufatura nas decisões do início do processo de desenvolvimento (SWINK et al., 1996 apud ROZENFELD \& AMARAL, 1999).

A tipologia proposta por ROZENFELD \& AMARAL (1999) visa à caracterização do processo de desenvolvimento de produtos para a construção de modelos de referência que

11 FUNK, J.L. (1997), Concurrent Engineering and the Underlying Structure of Design Problem. IEEE Transaction on Engineering Management, v.44, n.3, p.305-315, August.

12 SWINK, M.L.; SANDVIG, J.C. \& MABERT, V.A. (1996). Customizing Concurrent Engineering Processes: Five Case Studies. Journal of Product Innovation Management, v.13, n.13, p. 230-244, May.

${ }^{13}$ VERYZER, R.W. (1998a). Discontinuous Innovation and the New Product Development Process. Journal of Product Innovation Management, v.15, n.4, p.304-321, July.

${ }^{14}$ VERYZER, R.W. (1998b). Key Factors Affecting Customer Evaluation of Discontinuous New Products. Journal of Product Innovation Management, v.15, n.2, p.136-150, March. 
representem esse processo. A utilização de modelos de referência para representar o processo de desenvolvimento de produtos é discutida no próximo item.

\subsection{Modelos de Referência do Processo de Desenvolvimento de Produtos}

Neste item discute-se a representação da empresa por modelos de referência. São apresentadas as visões do modelo necessárias para se descrever o processo de desenvolvimento de produtos, e detalhados três diferentes métodos de modelagem. Além disso, é apresentada uma técnica específica que permite a comparação de modelos de referência.

\subsubsection{Definição e Tipos de Modelos de Referência}

Um modelo é uma representação de algo. É uma abstração da realidade expressa em termos de um formalismo especificado por um método de modelagem em função dos objetivos de um usuário (VERNADAT, 1996).

Um modelo de empresa é uma representação da empresa. Esse modelo pode ser constituído de um conjunto consistente de modelos complementares que descrevem vários aspectos da empresa para atender às necessidades de determinados usuários (VERNADAT, 1996).

A representação da empresa em um modelo facilita a compreensão dos elementos descritos e melhora a comunicação entre as pessoas, que passam a discutir e tomar decisões com base em uma "linguagem" comum expressa no modelo. Isso evidencia a importância da utilização de modelos na implantação de abordagens de melhoria nas empresas.

Modelos de empresa são utilizados, por exemplo, na documentação de procedimentos para certificação de qualidade (ISO-9000), na especificação de novos processos de negócio em projetos de Reengenharia, no apoio à implantação de sistemas de fluxo de trabalho, de gerenciamento de dados e de processamento de ordens, e na especificação de requisitos para o desenvolvimento de sistemas de informação (SCHUH et al., 1997).

Uma classe especial de modelos de empresa é formada por modelos mais amplos e genéricos, denominados modelos de referência.

Um modelo de referência é um modelo que pode ser usado como base para o desenvolvimento ou avaliação de modelos específicos. Ou seja, modelos específicos podem ser derivados de modelos de referência pré-definidos, e modelos de referência podem ser utilizados como referência de comparação de um modelo específico (VERNADAT, 1996). 
De acordo com o seu conteúdo, os modelos de referência são classificados em modelos de referência do setor, modelos de referência dos sistemas de informação e modelos de referência da empresa (KELLER \& TEUFEL, 1998).

Os modelos de referência para um setor representam as soluções mais gerais aplicáveis a um setor da indústria. Esses modelos procuram considerar as melhores práticas para o setor, podendo ser utilizados como ponto de partida em diversas abordagens de melhoria nas empresas.

Os modelos de referência dos sistemas de informação são uma descrição das soluções disponíveis nos sistemas (CURRAN \& KELLER, 1998). Esses modelos podem ser aplicados na implantação e integração de sistemas de informação.

Pode-se também denominar os modelos que descrevem uma empresa específica como modelos de referência já que esses modelos são uma "referência" de representação da empresa. Os modelos de referência das empresas diferenciam-se em modelos que descrevem a situação vigente (denominados modelos as-is) e modelos que expressam a situação futura desejada (denominados modelos to-be).

Um modelo é composto basicamente de visões e métodos. As visões podem ser modeladas separadamente, mas em conjunto criam um modelo único. Os métodos são formalismos utilizados para descrever cada uma das visões (BREMER, 1995).

Neste trabalho serão discutidas somente as visões e os métodos do modelo de empresa necessários para se representar um processo de negócio.

\subsubsection{Visões dos Modelos}

Para representar processos de negócio, um modelo deve descrever todos os elementos do processo, ou seja, as atividades realizadas, os eventos e as condições existentes, as informações acessadas ou geradas, os responsáveis pela execução e os recursos utilizados. Todas as inter-relações entre esses elementos também precisam ser especificadas no modelo. Desse modo, a complexidade resultante da modelagem de todos esses elementos em conjunto pode ser muito alta.

Para se reduzir a complexidade de modelagem, o modelo é dividido em visões que podem ser tratadas com certa independência (SCHEER, 1998).

O modelo de um processo pode ser representado em quatro visões: dados, atividades, organização e recursos (SCHEER, 1998). A visão de dados contém os eventos e as condições representados como objetos de informação. O encadeamento de atividades é representada na visão de atividades. As unidades organizacionais e os elementos 
organizacionais são descritos na visão de organização. A visão de recursos trata dos componentes de tecnologia da informação (FIGURA 7) (SCHEER, 1992; SCHEER, 1998).

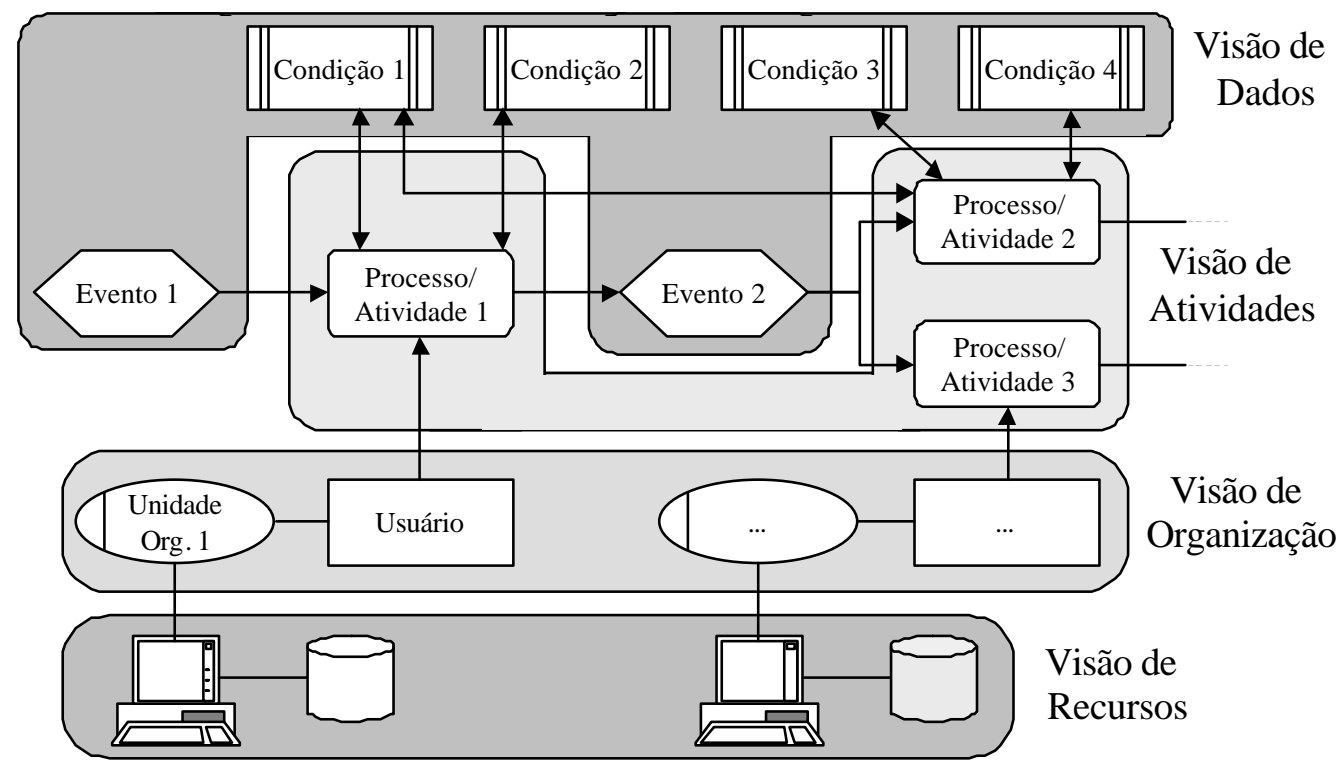

FIGURA 7 - Visões de um modelo de processo de negócio (SCHEER, 1998, p. 12)

Cada uma das visões pode ser descrita independentemente, utilizando-se métodos especializados. Alguns dos métodos representam mais de uma das visões em conjunto.

\subsubsection{Métodos de Modelagem}

Segundo VERNADAT (1996), não existe atualmente nenhum método de modelagem que seja completo. Os vários métodos existentes descrevem diferentes aspectos das organizações.

Neste trabalho são selecionados para análise o método SADT (Structured Analysis and Design Technique) utilizado para o modelamento de atividades e informações, o método EPC (Event-Driven Process Chain) próprio para o modelamento de atividades, dados, eventos e organização, e o método MER (Modelo de Entidade-Relacionamento) que possibilita o modelamento de estruturas de dados.

\section{SADT}

O método SADT foi desenvolvido para ser utilizado na análise e projeto de sistemas computacionais. Com o tempo, seu campo de utilização foi ampliado, de forma que hoje o SADT é utilizado na análise de problemas, na definição de requisitos e na especificação de funções em diversas aplicações (VERNADAT, 1996). 
O método SADT é baseado no princípio de decomposição funcional. Sistemas complexos são decompostos em funções, subfunções, e assim por diante (FIGURA 8). Os elementos básicos utilizados no modelo SADT são retângulos e setas. Os retângulos representam as atividades; a seta posicionada à esquerda do retângulo representa os objetos ou dados de entrada; a seta na parte superior representa os objetos ou dados de controle; a seta inferior representa os mecanismos ou recursos. O resultado da atividade, ou seja, os objetos ou dados de saída, são representados pela seta à direita do retângulo (FIGURA 8) (VERNADAT, 1996).

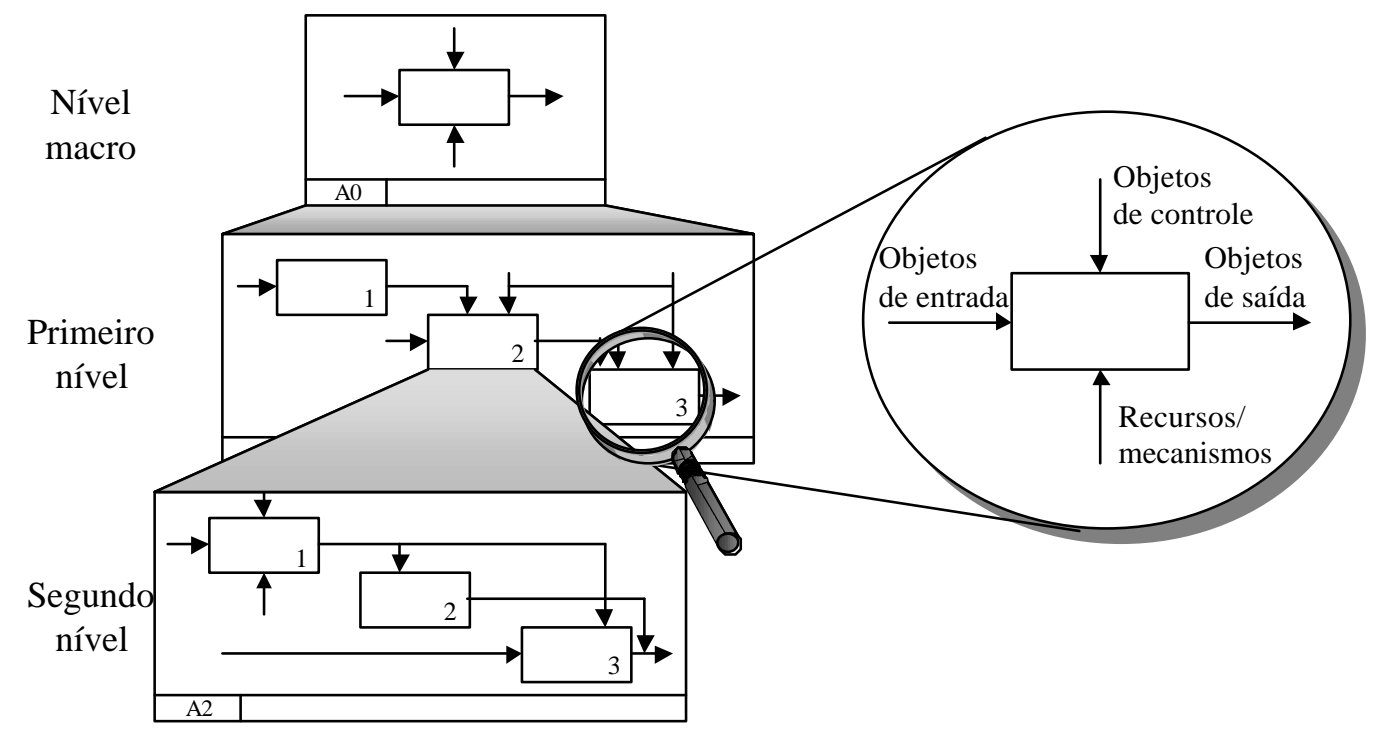

FIGURA 8 - SADT - Princípio de decomposição funcional e elementos de representação (VERNADAT, 1996, p. 94-95)

\section{EPC}

O método EPC permite a descrição de processos de negócio por meio do fluxo seqüencial de eventos e atividades (KELLER \& TEUFEL, 1998).

O EPC sempre começa e termina com um evento que descreve um estado que causa uma consequiência. Os eventos são ligados às funções que representam a transformação realizada desde o estado inicial até o estado final. Se necessário, operadores lógicos podem ser utilizados nas ligações entre os eventos e as funções. A cada função podem ser associados elementos organizacionais responsáveis e informações de entrada e saída (KELLER \& TEUFEL, 1998). A FIGURA 9 representa os elementos gráficos do EPC e sua estrutura construtiva básica. 


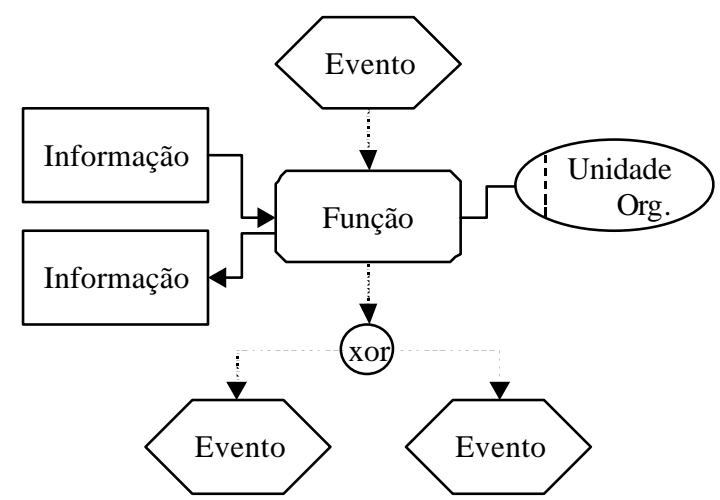

FIGURA 9 - Elementos do EPC e estrutura construtiva básica (KELLER \& TEUFEL, 1998, p. 151)

MER

O Modelo de Entidade-Relacionamento foi desenvolvido para auxiliar na especificação de bancos de dados. Esse modelo baseia-se na percepção do universo constituído por entidades, por relacionamentos e por atributos (DATE, 1986).

As entidades representam objetos reais, concretos ou abstratos, descritos por um conjunto de atributos. Os atributos são características ou propriedades de uma entidade ou relacionamento. Os relacionamentos determinam as ligações entre entidades. A funcionalidade de um relacionamento entre um par de entidades pode ser definido como 1:1 (ou seja, cada ocorrência de uma entidade é ligada a somente uma ocorrência da outra entidade), 1:n (cada ocorrência de uma entidade pode ser ligada a mais de uma ocorrência da outra entidade), n:1 (simétrico a 1:n) e m:n (produto cartesiano entre as ocorrências de ambas as entidades). Para se identificar unicamente uma ocorrência de uma entidade ou de um relacionamento são definidos atributos chave (identificadores) (VERNADAT, 1996).

Graficamente as entidades são representadas por retângulos, os relacionamentos são representados por losangos e os atributos são representados por elipses. No caso em que os atributos são chaves de identificação, o nome do atributo é sublinhado (FIGURA 10).

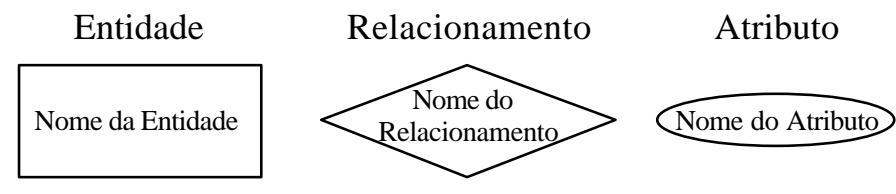

Atributo Chave Funcionalidades

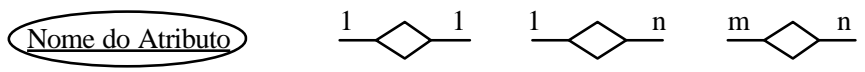




\subsubsection{Método de Comparação de Modelos}

Comparações entre modelos de referência são utilizadas na implantação de sistemas de informação, para se verificar as atividades de uma empresa que podem ser apoiados por um sistema, ou seja, para se verificar o grau de aderência de um sistema a um processo de uma empresa (KIRCHMER, 1998).

Um método de comparação de modelos é apresentado por KIRCHMER (1998). Originariamente, esse método é empregado no contexto da metodologia de implantação de sistemas ERP proposta por KIRCHMER (1998), mas a sua aplicação pode ser extrapolada para outras situações. O método de KIRCHMER (1998) é apresentado na FIGURA 11.

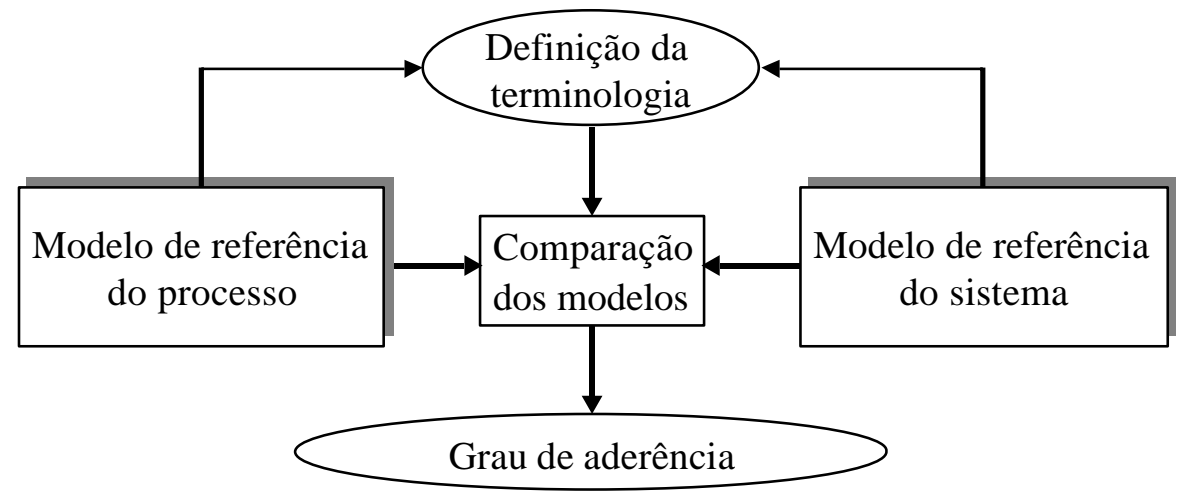

FIGURA 11 - Método de comparação de modelos (KIRCHMER, 1998, p. 114)

Segundo KIRCHMER (1998), a comparação entre modelos é dificultada pelo emprego de diferentes terminologias e pelos diferentes graus de abstração dos modelos. Para superar essas dificuldades, KIRCHMER (1998) sugere que a comparação de modelos seja realizada com base em definições existentes para terminologia empregada (FIGURA 9). Além disso, o autor recomenda que um ou mais elementos do modelo da empresa possam ser comparados com um ou múltiplos elementos do modelo do sistema.

Observa-se, assim, que a comparação envolve, além dos aspectos técnicos, aspectos semânticos dos modelos (KELLER \& TEUFEL, 1998). Dessa forma, a comparação de modelos pode requerer conhecimentos detalhados da entidade modelada que não estão expressos no modelo.

\subsection{Ambientes Integrados de Desenvolvimento de Produtos}

Neste item é discutida, inicialmente e de forma geral, a importância da integração. Em seguida são apresentados conceitos de integração relevantes para o processo de 
desenvolvimento de produtos. Finalmente, é analisada a situação atual dos ambientes integrados de desenvolvimento de produtos.

\subsubsection{Importância da Integração e Níveis de Integração}

A Integração é definida como o agrupamento de componentes heterogêneos em um conjunto sinérgico (VERNADAT, 1996). Partes distintas integradas passam a comportar-se como um sistema único.

De acordo com VERNADAT (1996), as três mais importantes justificativas para a busca de integração nas empresas são as necessidade atuais de compartilhamento das informações, de interoperabilidade ${ }^{15}$ e de coordenação das atividades. O objetivo da integração é melhorar a comunicação, a cooperação e a coordenação na empresa, possibilitando maior produtividade, flexibilidade e capacidade de mudança.

Com a evolução da Tecnologia da Informação e a busca das empresas por maior integração, o conceito de integração evoluiu da integração física para a integração dos aplicativos e, mais recentemente, para a integração do negócio como um todo (FIGURA 12).

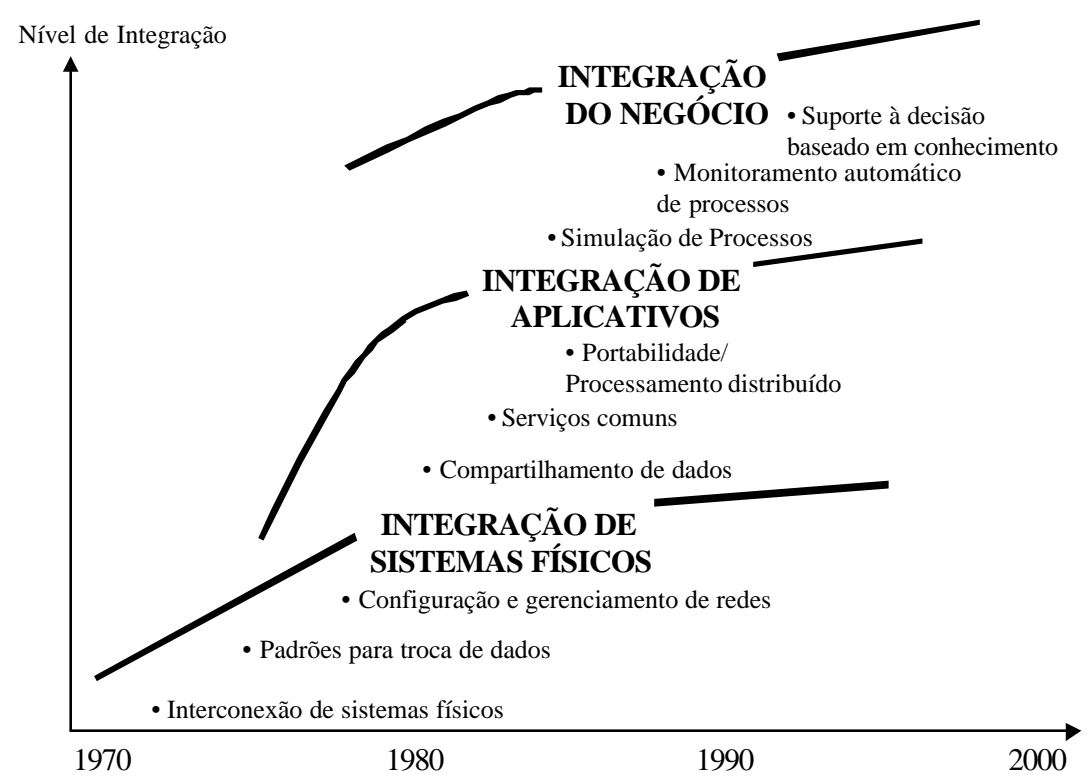

FIGURA 12 - Níveis de integração (VERNADAT, 1996, p. 15 e 327)

A integração física está relacionada com a interface e com os protocolos de comunicação entre os diferentes equipamentos, aplicativos computacionais, instrumentos, entre outros (ALLIPRANDINI, 1996); a integração dos aplicativos trata da interoperabilidade dos aplicativos em plataformas heterogêneas e do acesso de vários

${ }^{15}$ Interoperabilidade é definida como a habilidade de duas entidades para trocar informações e utilizar funcionalidades uma da outra (VERNADAT, 1996). 
aplicativos a dados comuns, e a integração de negócios procura obter coordenação entre os processos de negócio (VERNADAT, 1996).

Pode-se observar na FIGURA 12 que o nível de integração possível de se obter com a integração física é limitado. Para se aumentar o nível de integração é necessário integrar os aplicativos e o negócio.

\subsubsection{Conceitos de Integração}

A evolução de um nível de integração para outro mais elevado é baseada na integração do nível inferior. Assim, a integração dos aplicativos baseia-se na integração física, e, consequientemente, só será possível integrar o negócio se os aplicativos forem integrados.

Partindo-se dessa premissa, são analisados neste subitem conceitos de integração de aplicativos e de negócio relevantes para a integração do processo de desenvolvimento de produtos. Considera-se aqui que a infra-estrutura física necessária para a integração dos aplicativos já esteja estabelecida.

A arquitetura cliente/servidor é o modelo computacional necessário para a integração dos aplicativos. A integração dos aplicativos pode ser, basicamente, de dois tipos: homogênea e heterogênea. Nesses dois tipos de integração, as bases de dados desempenham um papel extremamente importante. No caso de ambientes heterogêneos, como a maioria dos ambientes de desenvolvimento de produtos, é necessário viabilizar a comunicação entre os aplicativos por meio de uma plataforma de integração, baseada em serviços de middleware e no emprego de APIs (Application Program Interfaces). Além disso, é preciso estabelecer padrões, como, por exemplo, o STEP (Standard for the Exchange of Product Model Data). Já a integração do negócio depende do conhecimento sobre a empresa, que pode ser expresso em seus modelos. Esses conceitos de integração são detalhados a seguir.

\section{Arquitetura Cliente/Servidor}

Em uma arquitetura computacional cliente/servidor o armazenamento, o processamento e a apresentação dos dados são distribuídos entre clientes e servidores conectados a uma rede, em vez de serem controlados centralmente (VERNADAT, 1996).

A FIGURA 13 apresenta cinco diferentes formas de divisão dos componentes de um aplicativo em clientes e servidores. O componente de apresentação é a interface ${ }^{16} \mathrm{com} \mathrm{o}$ usuário; o componente aplicativo contém a lógica de processamento e o componente de

${ }^{16}$ Os componentes de apresentação atuais são geralmente baseados em elementos gráficos e são usualmente conhecidos por GUI (Graphical User Interface). 
gerenciamento de dados armazena e gerencia os dados utilizados pelo aplicativo (LAUDON \& LAUDON, 1998).

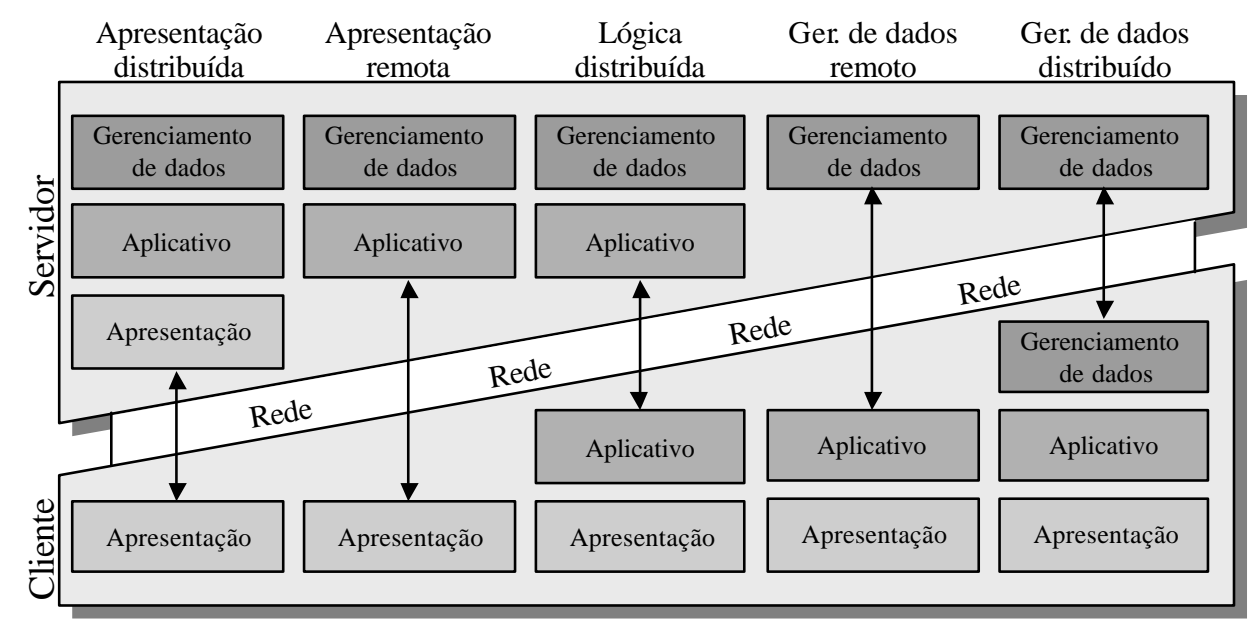

FIGURA 13 - Tipos de arquitetura cliente/servidor (LAUDON \& LAUDON, 1998, p.339)

De acordo com CURRAN \& KELLER (1998), os aplicativos cliente/servidor são freqüentemente estruturados em uma arquitetura de três níveis (three-tier), baseada em clientes que contêm o componente de apresentação, em servidores de aplicativos e em servidores de gerenciamento de dados.

\section{Bases de Dados}

Uma base de dados é uma coleção organizada de dados. Para se criar e manter uma base de dados são utilizados sistemas gerenciadores de bases de dados (DBMS - Data Base Management Systems) (DATE, 1986).

Um sistema gerenciador de base de dados é composto por três componentes: uma linguagem de definição de dados, uma linguagem de manipulação de dados e um dicionário de dados. A linguagem de definição de dados é utilizada na especificação da estrutura da base de dados, enquanto que a linguagem de manipulação é empregada diretamente no acesso e na manipulação dos dados ${ }^{17}$. O dicionário de dados é uma ferramenta que contém informações sobre os dados da base (LAUDON \& LAUDON, 1998).

Os dados armazenados em uma base de dados podem ser organizados de diversas formas. Três modelos de organização de dados são mais freqüentemente utilizadas pelos sistemas convencionais de gerenciamento de bases de dados: o modelo hierárquico, o

${ }^{17}$ A linguagem SQL (Structured Query Language) é a linguagem de manipulação de dados mais difundida atualmente (LAUDON \& LAUDON, 1998). 
modelo em rede e o modelo relacional (LAUDON \& LAUDON, 1998), sendo que esse último é o mais empregado atualmente.

No modelo relacional os dados são armazenados em tabelas bidimensionais formadas por linhas e por colunas. Em cada tabela, as linhas são registros únicos e as colunas são campos do registro. Uma das vantagens desse método é a possibilidade de relacionamento dos dados de uma base ou tabela com dados de outras bases ou tabelas (LAUDON \& LAUDON, 1998).

Deve-se ressaltar que os sistemas gerenciadores de bases de dados relacionais não são adequados para o armazenamento de informações complexas, como é o caso de alguns tipos de dados gerados no processo de desenvolvimento de produtos (desenhos em CAD, imagens, entre outros). Para se superar essa limitação, foi desenvolvida recentemente uma nova geração de sistemas gerenciadores de base de dados chamados de Object/Relational Data Base Management Systems (ORDBMS). Segundo GRIMES (1998), essa tecnologia é uma evolução das bases de dados relacionais que possibilita o armazenamento de objetos complexos.

A utilização de bases de dados reduz a necessidade de armazenamento redundante de informações. Os sistemas gerenciadores de base de dados permitem que diversos aplicativos extraiam e manipulem os dados de uma mesma base, sem que seja necessário criar arquivos separados ou definições de dados próprias para cada sistema (LAUDON \& LAUDON, 1998). Assim, as bases de dados desempenham um papel fundamental na integração de aplicativos isolados (VERNADAT, 1996).

\section{Integração Homogênea e Integração Heterogênea}

A integração entre aplicativos pode ser basicamente de dois tipos: homogênea e heterogênea (ROZENFELD, 1996).

$\mathrm{Na}$ integração homogênea, uma base de dados única é compartilhada por todos os aplicativos (PETRIE, $1992^{18}$ apud ROZENFELD, 1996). Para que as informações da base de dados possam ser compartilhadas, os aplicativos devem utilizar a mesma lógica de armazenamento de dados. Isso geralmente só ocorre entre aplicativos de um mesmo fornecedor ou entre aplicativos desenvolvidos em parcerias firmadas entre os fornecedores.

Um exemplo desse tipo de integração são os sistemas ERP. Tais sistemas são constituídos por diversos módulos e por uma base de dados central (DAVENPORT, 1998).

${ }^{18}$ PETRIE, C.J. (1992). The Model / Application Link. Workgroup 1 Report - ICEIMT Workshop II. In: Proceeding of the First International Conference on Enterprise Integration Modeling, p. 42-46, Cambridge, The MIT Press. 
Todos os módulos aplicativos dos sistemas ERP manipulam a mesma base de dados. Assim, não há necessidade de armazenamento redundante das informações que são utilizadas por mais de um módulo.

A integração homogênea é mais complexa no caso em que são utilizados aplicativos de diferentes fornecedores. Segundo CARUSO (1998), a estrutura do modelo de dados de um fornecedor pode ser diferente da adotada por outros fornecedores, dificultando a integração sobre uma mesma base de dados.

Já a integração heterogênea refere-se à integração de sistemas distintos, desenvolvidos por diferentes fornecedores (PETRIE, 1992 apud ROZENFELD, 1996), e que utilizam repositórios de dados próprios.

A integração de sistemas heterogêneos fundamenta-se em um repositório de dados, chamado de meta base de dados, que contém informações sobre todos os dados armazenados nas bases de dados individuais de cada um dos aplicativos a serem integrados (ROZENFELD, 1996).

Esse tipo de integração pressupõe ainda a existência de uma plataforma de integração, baseada em serviços de middleware, a utilização de interfaces para a comunicação entre os aplicativos (APIs) e o emprego de padrões de integração (como, por exemplo, a norma STEP).

As principais desvantagens da integração heterogênea são o armazenamento redundante de dados utilizados por mais de um sistema e a sobreposição de funcionalidades semelhantes oferecidas por dois ou mais aplicativos (ROZENFELD, 1996).

\section{Middleware}

Segundo VERNADAT (1996), o termo middleware compreende os softwares dispostos em uma camada intermediária entre os sistemas aplicativos e o sistema operacional dos computadores. Tais softwares constituem a base necessária para a interoperabilidade entre diferentes tipos de aplicativos distribuídos.

O middleware é responsável por oferecer uma série de serviços para os aplicativos, tais como a comunicação e o intercâmbio de informações entre diferentes aplicativos em uma arquitetura cliente/servidor. Ou seja, o middleware é o agente que transmite mensagens (requisições e resultados) entre aplicativos distribuídos que precisam comunicar-se (VERNADAT, 1996).

Como exemplos de middleware pode-se citar os padrões ODBC (Open Database Connectivity), OLE (Object Linking Embedding) e CORBA (Common Object Request Broker Architecture). 
O ODBC é um padrão para a troca de informações entre bases de dados (VERNADAT, 1996).

O OLE é um protocolo para a interoperabilidade de aplicativos baseados no sistema operacional Windows (VERNADAT, 1996). Tal protocolo possibilita que informações como gráficos e textos sejam compartilhados por diferentes documentos e aplicativos. O "relacionamento" (linking) permite que a informação compartilhada, contida em um documento, seja atualizada caso ela seja alterada no documento de origem. O "encaixamento" (embedding) possibilita a edição da informação contida em um documento, utilizando o aplicativo que gerou a informação (MICROSOFT, 1997)

O último exemplo considerado, o padrão CORBA, possibilita o gerenciamento de objetos distribuídos e provê serviços essenciais para a transmissão de requisições e respostas entre objetos, ou seja, para a comunicação entre objetos distribuídos (VERNADAT, 1996). Deve-se frisar que o CORBA é uma estrutura aberta, não proprietária, e independente da linguagem de programação e até mesmo da plataforma dos objetos (PIRES, 1997).

\section{API (Application Program Interface)}

A utilização de APIs disponíveis nos sistemas computacionais facilita a integração de aplicativos.

APIs são bibliotecas pré-definidas de funções dedicadas de um sistema computacional que podem ser acessadas tanto diretamente quanto por outros sistemas. As APIs simplificam o acesso às funcionalidades de um sistema, encobrindo toda a complexidade interna de implantação. Dessa forma, as APIs podem ser utilizadas como um padrão de interface de sistemas computacionais (VERNADAT, 1996).

\section{STEP (Standard for the Exchange of Product Model Data)}

O padrão STEP compreende uma série de normas para a representação e o intercâmbio de dados de produto entre diferentes sistemas.

Esse conjunto de normas está sendo desenvolvido pela ISO (International Organization for Standardization) com o objetivo de estabelecer um formato neutro e completo para a representação e o intercâmbio das características do produto ao longo de todo o seu ciclo de vida. As características do produto englobam, além da descrição geométrica, informações como as tolerâncias dimensionais, os tipos de materiais, o acabamento superficial, entre outras (BRADHAM, 1998).

O princípio de intercâmbio de dados STEP é descrito na FIGURA 14. A troca de dados entre sistemas de diferentes fornecedores é feita por um arquivo neutro especificado 
de acordo com o padrão STEP. A conversão dos dados de produto do formato proprietário de um sistema para o arquivo neutro, e vice-versa, é feita por tradutores (pré e pósprocessadores) (VERNADAT, 1996).

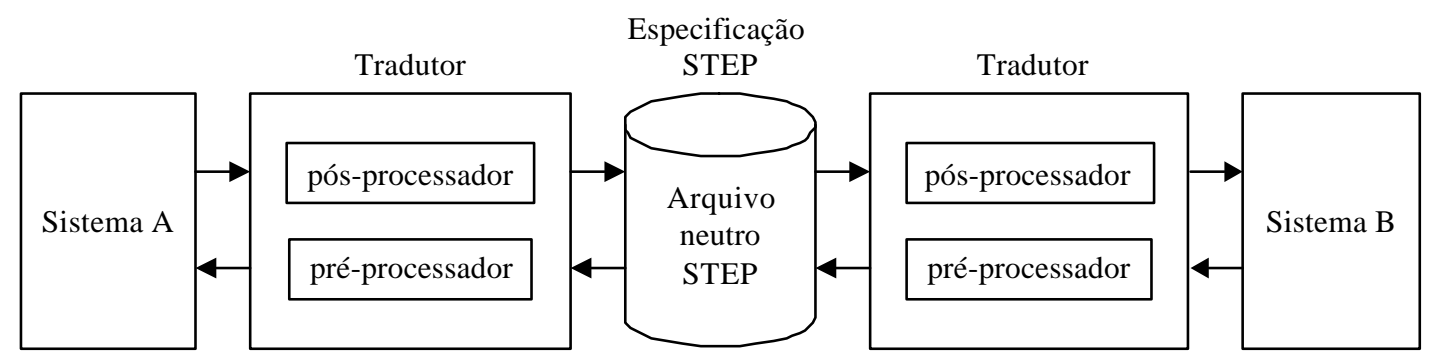

FIGURA 14 - Princípio de troca de dados STEP (VERNADAT, 1996, p. 360)

A possibilidade de intercâmbio de dados entre diferentes aplicativos contribui para a redução da duplicação de dados com formatos diferentes.

\subsubsection{Situação Atual dos Ambientes Integrados de Desenvolvimento de Produtos}

Até o momento, os ambientes de desenvolvimento de produtos foram baseados na implantação e utilização de sistemas CAD/CAE/CAPP/CAM. Nem sempre esses sistemas são integrados.

A literatura descreve inúmeros problemas e limitações dos atuais ambientes integrados de desenvolvimento de produtos, entre os quais pode-se citar:

\ A utilização de sistemas CAD/CAE/CAPP/CAM/MRP não integrados possibilita a automação de algumas atividades do desenvolvimento de produtos, mas os dados do produto continuam sendo armazenados em bases de dados segmentadas, e, na maioria das vezes, as atividades são realizadas individualmente pelos departamentos (PRASAD, 1996). A falta de integração resulta em "ilhas de informação".

- A integração de "ilhas de informação" ocorre, geralmente, por meio de uma abordagem "um-a-um", ou seja, pelo desenvolvimento de interfaces específicas para cada par de sistemas que precisam ser integrados (JARDIM-GONÇALVES et al., 1997). Essa abordagem de integração apresenta inúmeras desvantagens como o alto custo de desenvolvimento e de manutenção.

- A troca de informações entre os sistemas CAD/CAE/CAPP/CAM também é dificultada pela incompatibilidade entre os múltiplos formatos de dados 
existentes e pelos problemas decorrentes dos processos de conversão de dados (HAMERI \& NIHTILÄ, 1998).

- A conversão de dados baseada nas normas e padrões disponíveis atualmente (IGES, VDA-FS, DXF, entre outras) resulta freqüentemente em perda de informações e em necessidade de retrabalho (SCHÜTZER \& SOUZA, 1999).

- O padrão STEP, desenvolvido pela ISO para o intercâmbio de dados de produto entre diferentes sistemas, ainda é pouco conhecido e utilizado (SCHÜTZER \& SOUZA, 1999).

a A incompatibilidade entre os formatos de dados existentes e a falta de padronização também dificultam a troca de dados entre clientes e fornecedores no desenvolvimento de produtos (HAMERI \& NIHTILÄ, 1998; SCHÜTZER \& SOUZA, 1999).

- A intensa utilização de sistemas de engenharia não integrados leva à proliferação descontrolada dos dados de produto (GASCOIGNE, 1995), dificultando a localização dos dados gerados, o controle de acesso e o gerenciamento de versões.

口 Os sistemas PDM, considerados como viabilizadores da Engenharia Simultânea e da integração no desenvolvimento de produtos (GASCOIGNE, 1995), ainda são pouco conhecidos (OMOKAWA, 1999). De acordo com um estudo realizado pela AMR (Advanced Manufacturing Research), menos de 10\% das empresas pesquisadas utilizam ou estão implantando um sistema PDM atualmente (SWANTON, 1997).

- As atuais implantações de soluções PDM não apóiam o gerenciamento de dados ao longo de todo o ciclo de vida dos produtos. Tais sistemas não gerenciam os dados da fase de produção e possuem lacunas com relação ao gerenciamento de projetos (HAMERI \& NIHTILÄ, 1998).

- A aplicação de sistemas ERP no desenvolvimento de produtos, por sua vez, é geralmente limitada ao apoio das necessidades administrativas desse processo (MARTIN, 1998).

口 Os sistemas PDM não estão integrados com os sistemas ERP, dificultando a transferência dos dados do produto necessários à produção (estrutura de produto, planos de processo, entre outros) (BOURKE, 1996; KEMPFER, 1998). 
Atualmente, a busca de soluções para os problemas citados acima deve considerar que os sistemas ERP estão incorporando uma série de funcionalidades de desenvolvimento de produtos e que tais sistemas estão se tornando a "espinha dorsal" dos sistemas de informação das empresas. A revisão bibliográfica sobre os sistemas ERP é apresentada no capítulo seguinte. 


\section{OS SISTEMAS ERP}

Neste capítulo é apresentado o histórico de evolução dos sistemas ERP ${ }^{19}$, desde a sua origem até as tendências mais atuais para o seu desenvolvimento. São apresentadas também algumas características gerais desses sistemas. Em seguida, são discutidos dois aspectos específicos dos sistemas ERP relevantes para o escopo deste trabalho: a utilização de modelos de referência para representar os processos de negócio apoiados por esses sistemas e a integração entre os sistemas ERP e os sistemas de desenvolvimento de produtos. Por fim, são apresentadas as principais características do sistema SAP R/3.

\subsection{Evolução dos Sistemas ERP}

Os sistemas ERP atuais surgiram a partir da evolução dos sistemas tradicionais de gestão das necessidades de materiais (MRP - Material Resource Planning), amplamente empregados pela indústria de manufatura desde os anos 70 .

Os sistemas MRP desempenham um papel fundamental no gerenciamento da produção (VOLLMANN et al., 1993). Tais sistemas calculam a quantidade de itens requisitados em um dado momento com base nas necessidades de produtos finais, nas informações das estruturas de produto e nos dados de estoque (SLACK et al., 1998).

O escopo de aplicação dos sistemas MRP tradicionais foi expandido, no início dos anos 80, com a inclusão de novas funcionalidades que estenderam a sua abrangência da gestão de materiais para a gestão dos recursos de manufatura.

Esses novos sistemas, mais amplos, passaram a ser chamados de MRP II (Manufacturing Resource Planning). O MRP II inclui, além do cálculo da necessidade de materiais, funções como o planejamento de vendas, o cálculo da necessidade de capacidade em vários níveis e o controle do chão-de-fábrica (CORRÊA et al., 1997).

${ }^{19}$ Os sistemas Enterprise Resource Planning também são conhecidos na literatura por outros termos, tais como: Enterprise Systems, empregado por DAVENPORT (1998), Standard Software, utilizado por KIRCHMER (1998), e Sistemas Integrados de Gestão Empresarial, empregado em periódicos da área de negócios. Neste trabalho adotou-se o termo Enterprise Resource Planning por ser o mais freqüentemente utilizado. 
A necessidade de maior integração entre os dados de gestão da manufatura e os dados de outras unidades funcionais das empresas, principalmente com relação às informações dos departamentos financeiro e contábil, impulsionou a expansão dos sistemas MRP II, no final da década de 80.

Os sistemas MRP II foram, então, acrescidos de novos módulos integrados aos módulos de gestão dos recursos de manufatura. Foram desenvolvidos, por exemplo, módulos de controladoria, de gerenciamento financeiro, de compras, de apoio às atividades de vendas e de gerenciamento dos recursos humanos (CORRÊA et al., 1997).

Esses novos sistemas integrados, capazes de atender às necessidades de informação de diversos departamentos e processos de negócio das empresas, passaram a ser chamados de sistemas ERP.

Os sistemas ERP evoluíram rapidamente nos últimos anos, de forma que os ERPs típicos adquiriram as seguintes características básicas: arquitetura cliente/servidor, independência de plataforma e apoio integrado a todas as principais áreas funcionais das organizações (CARUSO \& JOHNSON, 1999).

Atualmente, os fornecedores de sistemas ERP continuam expandindo seus sistemas com novos desenvolvimentos, aquisições de sistemas especializados em determinadas funcionalidades e parcerias com fornecedores de soluções complementares (CHAUDHRY, 1998).

Os principais grupos de funcionalidades recentemente incluídos nos sistemas ERP são listados a seguir:

- Advanced Planning and Scheduling (APS) - possibilita a utilização de métodos e algoritmos sofisticados na programação detalhada da produção ao longo da cadeia de suprimentos (CHAUDHRY, 1998; CARUSO \& JOHNSON, 1999; JETLY, 1999).

- Customer Relationship Management (CRM) - agrupa uma série de funcionalidades de apoio a vendas, marketing e serviços aos clientes (ECONOMIST, 1999; STOODER, 1999a; STOODER, 1999b).

- Product Data Management (PDM) - compreende um conjunto de funções para o gerenciamento de dados de produtos (MILLER \& MENDEL, 1997; SAP, 1997; CHAUDHRY, 1998; WESSNER, 1999).

- Product Lifecycle Management (PLM) - gerencia o ciclo de vida de produtos ao longo da cadeia de suprimentos, desde o projeto até o descarte, englobando as funções de PDM e de gerenciamento de projetos (AMR, 2000; SAP, 2000b). 
Além da inclusão de novas funcionalidades, outras tendências de evolução dos sistemas ERP apontam mudanças na arquitetura e no conteúdo dos aplicativos. Algumas dessas mudanças encontram-se em estágio adiantado de desenvolvimento e já estão sendo incorporadas por fornecedores mais avançados, enquanto que outras ainda são incipientes.

As tendências mais significativas de evolução dos sistemas ERP são apresentadas a seguir:

- Aplicativos para segmentos verticais - os fornecedores de sistemas ERP estão desenvolvendo soluções específicas para os diversos segmentos verticais da indústria (aeroespacial, automobilístico, entre outros) a fim de facilitar a implantação e aumentar o grau de aderência dos sistemas ao negócio (CARUSO \& JOHNSON, 1999; CARUSO, 1999a; JETLY, 1999; STOODER, 1999a).

- Active Business Modeling - os sistemas ERP estão tornando-se mais flexíveis com a inclusão de ferramentas de modelamento dinâmico que possibilitam o desenho de processos de negócio apoiados pelo sistema e permitem a alteração de parâmetros do sistema por meio de modificações nos modelos de processos (CARUSO, 1999b).

- Data Warehousing - os sistemas ERP estão incorporando ferramentas analíticas, baseadas em soluções de data warehousing, para apoiar a tomada de decisões gerenciais (CARUSO \& JOHNSON, 1999; JETLY, 1999; GEIGER, 1999).

口 Componentização - a estrutura dos sistemas ERP está evoluindo para uma arquitetura de componentes, o que teoricamente reduz a complexidade de implantação e facilita a integração e a interoperabilidade com outros sistemas de informação (CARUSO \& JOHNSON, 1999; JETLY, 1999).

- Enterprise Information Portals (EIP) - os fornecedores de ERP estão criando portais na Internet para oferecer uma série de serviços on-line às comunidades virtuais, entre os quais o acesso a funcionalidades do ERP a partir dos portais, e a infra-estrutura necessária para viabilizar o comercio eletrônico entre organizações (ECONOMIST, 1999; GREENBAUM, 1999; STOODER, 1999a).

O impacto da inclusão de novas funcionalidades e das tendências de evolução dos sistemas ERP pode ser examinado segundo as três dimensões utilizadas pelo Gartner Group para a análise de aplicativos empresariais: o foco de negócios, o tipo operacional e o segmento vertical (GARTNER GROUP, 1998). 
O foco de negócios varia do back office (funcionalidades que apóiam as atividades tipicamente internas de uma empresa) para o front office (funcionalidades voltadas para o meio exterior). O tipo operacional varia do apoio à transação (operacional) para o apoio à decisão (analítico). Finalmente, cada segmento vertical tem as suas particularidades (FIGURA 15).

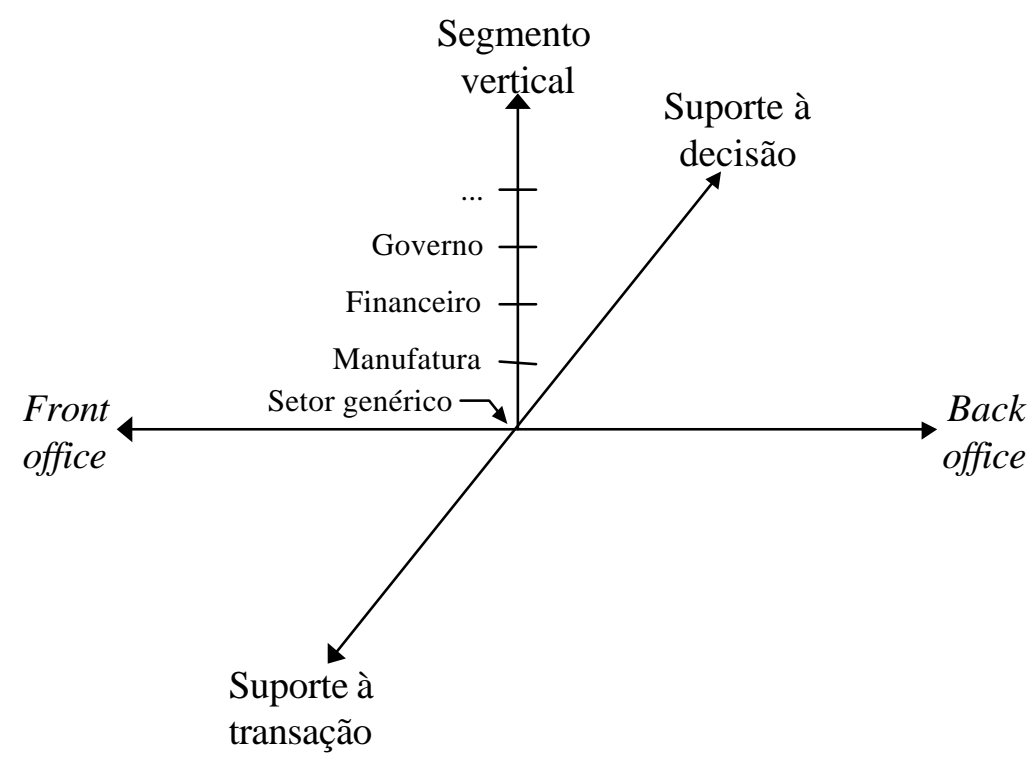

FIGURA 15 - Dimensões de análise de aplicativos empresariais (GARTNER GROUP, 1998)

As novas funcionalidades de CRM, recentemente incorporadas nos ERPs, e o desenvolvimento de portais (EIPs) indica que o foco de negócios dos sistemas ERP está evoluindo em direção às funcionalidades de front office. A inclusão de ferramentas de data warehousing, por sua vez, indica a evolução do tipo operacional em direção ao apoio à decisão. Já o desenvolvimento de aplicativos para segmentos verticais sinaliza uma clara tendência em relação à especialização por setores.

Dessa forma, pode-se observar que os sistemas ERP, até então aplicativos genéricos voltados para o apoio operacional de atividades de back office, estão se tornando um conjunto de aplicativos especializados por segmentos verticais, englobando também funcionalidades de front office e recursos analíticos.

Com relação à aplicação dos sistemas ERP, CORRÊA et al. (1997) identificaram que as estruturas dos ERPs estão sendo utilizadas pelas organizações como a grande base de dados corporativa dos sistemas de informação das empresas. Tal tendência significa, de acordo com CARUSO (1998), MARTIN (1998) e GIURLIANI (2000), que os sistemas ERP estão se tornando a "espinha dorsal" dos sistemas de informação das empresas. Conseqüentemente, esses sistemas estão estabelecendo uma plataforma comum para as 
várias tecnologias atualmente empregadas pelas organizações (VENKATRAMAN \& HENDERSON, 1998).

\subsection{Características dos Sistemas ERP}

Este item trata das características gerais dos sistemas ERP. Inicialmente analisa-se a estrutura de funcionamento dos sistemas ERP. Em seguida, apresenta-se uma classificação genérica dos seus módulos e funcionalidades. Por fim, discutem-se alguns aspectos de configuração desses sistemas.

\subsubsection{Estrutura}

Pode-se dizer, simplificadamente, que os sistemas ERP são compostos por uma base de dados central e um conjunto de módulos aplicativos. A FIGURA 16 apresenta a estrutura típica de funcionamento de um sistema ERP, segundo DAVENPORT (1998).

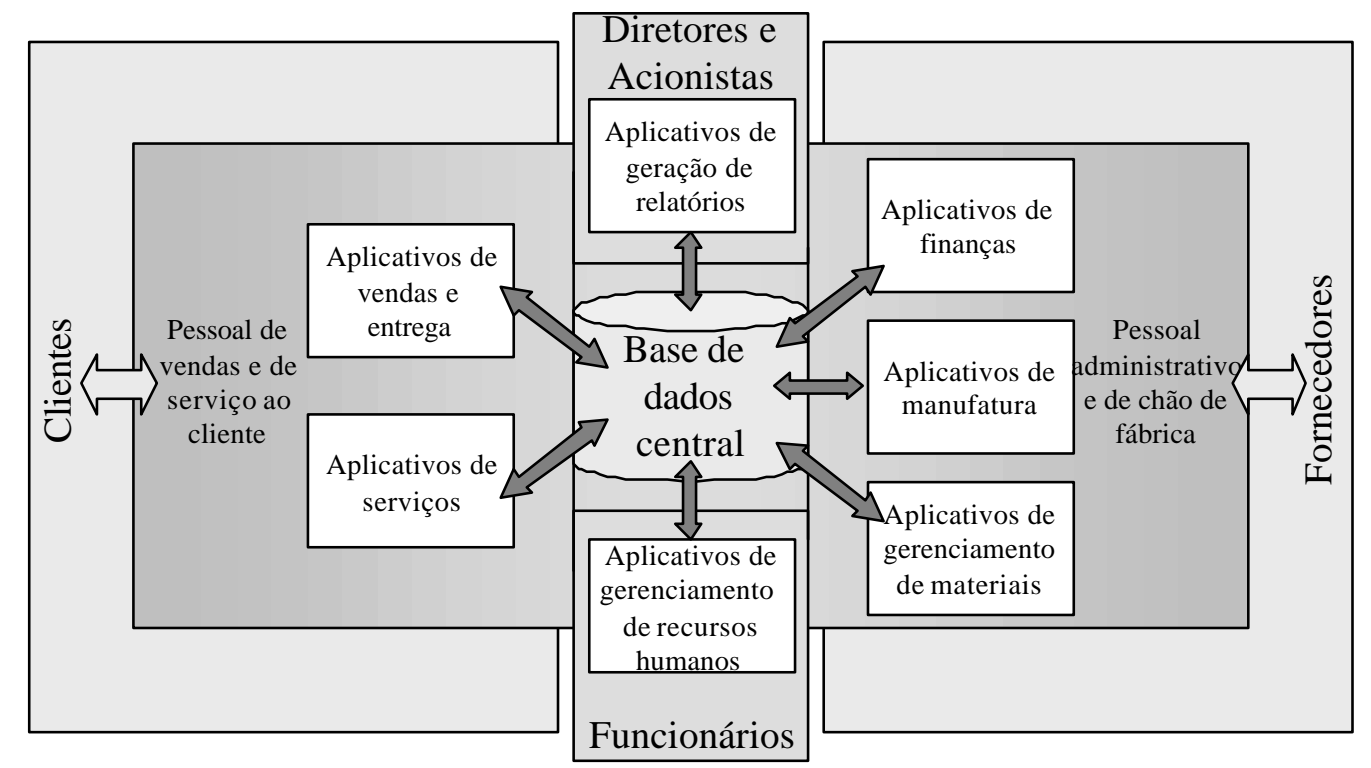

FIGURA 16 - Estrutura típica de um sistema ERP (DAVENPORT, 1998, p. 124)

A base de dados central recebe e fornece dados para os diversos módulos, apoiando as atividades dos processos de negócio das organizações. Quando uma nova informação é manipulada por um módulo e armazenada, as informações relacionadas são automaticamente atualizadas (DAVENPORT, 1998). Assim, a integração entre os módulos aplicativos é garantida.

Deve-se ressaltar que o termo base de dados central é empregado no sentido da definição centralizada da lógica de armazenamento e manipulação de dados, uma vez que, fisicamente, os dados podem estar distribuídos em mais de uma base de dados. 


\subsubsection{Módulos e Funcionalidades}

A maioria dos sistemas ERP disponíveis atualmente oferece um conjunto de funcionalidades básicas ${ }^{20}$ bastante semelhante. Alguns sistemas ERP mais avançados e completos possuem funcionalidades adicionais.

As funcionalidades dos ERPs são geralmente agrupadas em módulos que correspondem às áreas funcionais ou aos processos de negócio das empresas. $\mathrm{O}$ agrupamento das funcionalidades em módulos e a denominação dada a cada um dos módulos é arbitrária e definida pelos fornecedores desses sistemas.

De acordo com JETLY (1999), as variações na nomenclatura adotada por diferentes fornecedores para designar as mesmas funcionalidades e módulos dificultam a comparação entre dois ou mais sistemas ERP. JETLY (1999) sugere, então, que a comparação entre ERPs seja baseada em uma classificação neutra que reflita os principais módulos e funcionalidades desses sistemas.

Uma classificação genérica dos módulos e funcionalidades típicas de um sistema ERP é apresentada por CORRÊA et al. (1997). Essa classificação é independente de qualquer sistema específico disponível comercialmente.

CORRÊA et al. (1997) classificam os módulos dos sistemas ERP de acordo com o seu escopo de aplicação em módulos relacionados a operações e ao gerenciamento da cadeia de suprimentos, módulos relacionados à gestão financeira e contábil, e módulos relacionados à gestão dos recursos humanos.

Essa classificação dos módulos dos sistemas ERP e a relação das principais funcionalidades de cada um dos módulos é apresentada na TABELA 3.

TABELA 3 - Classificação dos módulos e funções dos sistemas ERP (CORRÊA et al., 1997)

\begin{tabular}{c|l}
\hline \multicolumn{1}{c|}{ MÓDULOS } & \multicolumn{1}{c}{ FUNCIONALIDADES } \\
\hline \multicolumn{1}{c}{ Operações e gerenciamento da cadeia de suprimento } \\
\hline \multicolumn{1}{c|}{ Previsões / análises de vendas } & $\begin{array}{l}\text { Estimativa de vendas por meio de modelos matemáticos; } \\
\text { levantamentos estatísticos do histórico de vendas. }\end{array}$ \\
\hline Lista de materiais & $\begin{array}{l}\text { Geração e manutenção de estruturas de produto; substituição } \\
\text { em massa de componentes; geração de estrutura baseada em } \\
\text { outra já existente. }\end{array}$ \\
\hline $\begin{array}{l}\text { Programação mestre da produção } \\
\text { / capacidade aproximada }\end{array}$ & $\begin{array}{l}\text { Definição de programas detalhados de produção de produtos } \\
\text { acabados (plano mestre); análise da capacidade de produção } \\
\text { do plano mestre. }\end{array}$ \\
\hline Planejamento de materiais (MRP) & $\begin{array}{l}\text { Cálculo das quantidades de itens necessários em um } \\
\text { determinado momento. }\end{array}$ \\
\hline
\end{tabular}

${ }^{20}$ Consideram-se como funcionalidades básicas aquelas necessárias para apoiar as principais atividades das áreas funcionais mais importantes das empresas. 


\begin{tabular}{|c|c|}
\hline MÓDULOS & FUNCIONALIDADES \\
\hline $\begin{array}{l}\begin{array}{l}\text { Planejamento detalhado de } \\
\text { capacidade }\end{array} \\
\end{array}$ & Análise da capacidade de produção dos itens. \\
\hline Compras & $\begin{array}{l}\text { Auxílio a cotações; emissão e gestão de pedido de compra; } \\
\text { acompanhamento de compras; cadastro de fornecedores; } \\
\text { acompanhamento do desempenho dos fornecedores. }\end{array}$ \\
\hline Controle de fabricação & $\begin{array}{l}\text { Gerência dos lotes de produção; gestão detalhada dos } \\
\text { recursos; alocação e coordenação de recursos humanos e } \\
\text { ferramental; instruções de trabalho; rastreabilidade. }\end{array}$ \\
\hline Controle de estoques & $\begin{array}{l}\text { Posição de níveis de estoque; transações de recebimento, } \\
\text { transferências, baixas e alocações de materiais. }\end{array}$ \\
\hline Engenharia & $\begin{array}{l}\text { Controle das mudanças de engenharia e de processos } \\
\text { produtivos; controle de números de desenhos; determinação } \\
\text { de tempos de fabricação. }\end{array}$ \\
\hline Distribuição física & $\begin{array}{l}\text { Planejamento das necessidades de distribuição; planejamento } \\
\text { dos recursos de distribuição. }\end{array}$ \\
\hline Gerenciamento de transporte & $\begin{array}{l}\text { Cadastramento e controle de transportadoras; alocação de } \\
\text { veículos a rotas; montagens de cargas em veículos. }\end{array}$ \\
\hline Gerenciamento de projetos & Gestão da rede de atividades (PERT/CPM). \\
\hline Apoio à produção repetitiva & $\begin{array}{l}\text { Gestão da manufatura por taxas para produções de alto } \\
\text { volumes. }\end{array}$ \\
\hline $\begin{array}{l}\text { Apoio à gestão da produção em } \\
\text { processos }\end{array}$ & $\begin{array}{l}\text { Gestão da produção em fluxo contínuo; tratamento de co- } \\
\text { products e by-products }\end{array}$ \\
\hline $\begin{array}{l}\text { Apoio à programação com } \\
\text { capacidade finita de produção } \\
\text { discreta }\end{array}$ & $\begin{array}{l}\text { Planejamento da produção com base no modelo do sistema } \\
\text { produtivo, na demanda e nas condições reais do sistema } \\
\text { produtivo em um dado momento. }\end{array}$ \\
\hline Configuração de produtos & $\begin{array}{l}\text { Gerenciamento de estruturas de produto modulares genéricas; } \\
\text { geração de estruturas específicas baseadas na estrutura } \\
\text { modular. }\end{array}$ \\
\hline
\end{tabular}

\begin{tabular}{l|l}
\hline \multicolumn{1}{l}{ Gestão financeira / contábil / fiscal } & \multicolumn{2}{l}{} \\
\hline Contabilidade geral & Funções tradicionais de contabilidade geral. \\
\hline Custos & $\begin{array}{l}\text { Apuração de custos de produção (custos padrão e custos } \\
\text { efetivos); custeio por atividades (ABC). }\end{array}$ \\
\hline Contas a pagar & Controle de pagamentos devidos; cadastro de fornecedores. \\
\hline Contas a receber & $\begin{array}{l}\text { Controle de contas a receber; cadastro de clientes; análise de } \\
\text { crédito de clientes. }\end{array}$ \\
\hline Faturamento & Emissão e controle de faturas e duplicatas; receitas fiscais. \\
\hline Recebimento fiscal & Transações fiscais referentes ao recebimento de materiais. \\
\hline Contabilidade fiscal & Manutenção de livros fiscais. \\
\hline Gestão de caixa & Planejamento e controle financeiro. \\
\hline Gestão de ativos & Aquisição, manutenção e baixas de ativos. \\
\hline Gestão de pedidos & $\begin{array}{l}\text { Administração dos pedidos de clientes; aprovação de crédito; } \\
\text { controle de datas. }\end{array}$ \\
\hline $\begin{array}{l}\text { Definição e gestão do processo de } \\
\text { negócio / fluxo de trabalho }\end{array}$ & Mapeamento e redefinição dos processos administrativos. \\
\hline Gestão de recursos humanos & $\begin{array}{l}\text { Controle de pessoal; alocação a centros de custo; } \\
\text { programação de férias; currículos; programação de } \\
\text { treinamentos; avaliações. }\end{array}$ \\
\hline Pessoal & \begin{tabular}{l} 
Controle da folha de salários. \\
\hline Folha de pagamentos
\end{tabular} \\
\hline
\end{tabular}


Deve-se observar que a classificação dos módulos e funcionalidades de sistemas ERP proposta por CORRÊA et al. (1997) não considera todas as funcionalidades recentemente adicionadas a esses sistemas.

\subsubsection{Configuração}

A configuração de um sistema ERP é a adaptação do sistema para atender aos requisitos específicos de uma organização, sem alteração dos códigos de programação (KIRCHMER, 1998).

De acordo com DAVENPORT (1998), existem dois mecanismos utilizados na configuração de sistemas ERP: a seleção dos módulos que serão utilizados e o ajuste dos módulos em tabelas de configuração.

A configuração de um sistema ERP em uma solução particular para uma empresa é iniciada com a escolha dos módulos que serão implantados. As empresas podem simplesmente não requerer certos módulos ou já dispor de uma solução satisfatória para determinadas funções (DAVENPORT, 1998).

Cada módulo selecionado pode então ser ajustado para atender aos requisitos específicos e das características da empresa. Para isso são alterados os parâmetros das tabelas de configuração (DAVENPORT, 1998). A alteração dos parâmetros influencia no comportamento do sistema (KIRCHMER, 1998).

Na FIGURA 17 pode-se observar um exemplo de uma tabela de configuração e de seus parâmetros. Essa tabela é utilizada na definição dos tipos de status que podem ser atribuídos aos documentos gerenciados por um sistema ERP.

\begin{tabular}{|c|c|c|c|c|c|c|c|c|}
\hline $\begin{array}{ll}\text { Typ } & \text { Doc.St } \\
\end{array}$ & Devciption & Atbiar. & Ty. & Obiect shosk & Relessedina. & Comoleve & Audi & fir \\
\hline DRO $x x$ & Worke request & AQ & P & $\pm \Gamma$ & $\Gamma$ & $\Gamma$ & $\Gamma$ & 요 \\
\hline DRUAL & Change Iequest & $\Omega x$ & & $\Gamma$ & $\Gamma$ & $\Gamma$ & $\Gamma$ & - \\
\hline DRO AP & Inspection req. & $X P$ & & ᄃ & $\Gamma$ & ᄃ & $\Gamma$ & \\
\hline DREAR & scchived & AR & $\lambda$ & $\Gamma$ & $\Gamma$ & $\Gamma$ & $\Gamma$ & \\
\hline DROFR & Released & $7 \pi$ & 9 & F & $\bar{v}$ & $\Gamma$ & $\Gamma$ & \\
\hline DRo Ix & In uark & Is & $a$ & Г & $\Gamma$ & $\Gamma$ & ᄃ & \\
\hline DROPR & cuecked & PR. & & $\Gamma$ & $\Gamma$ & $\Gamma$ & $\Gamma$ & \\
\hline DRO SP & Locketed & SP & 3 & $\Gamma$ & 다 & $\Gamma$ & ㅍ & \\
\hline \multirow{4}{*}{ DRO $2 G$} & Bejected & $8 G$ & & $\Gamma$ & $\Gamma$ & $\Gamma$ & $\Gamma$ & \\
\hline & \multirow{2}{*}{\begin{tabular}{|c|} 
Definição de \\
Status
\end{tabular}} & & & & & & & \multirow{3}{*}{7} \\
\hline & & & & & & & & \\
\hline & \begin{tabular}{|l|l|}
$4 \mid$ \\
\end{tabular} & & & & & & & \\
\hline
\end{tabular}

FIGURA 17 - Exemplo de tabela de configuração de um sistema ERP

Apesar de os mecanismos de configuração garantirem uma certa flexibilidade de adaptação aos sistemas ERP, as opções existentes são limitadas. Os sistemas ERP são soluções genéricas que refletem uma série de suposições sobre a forma que as empresas 
operam de maneira geral. Provavelmente, formas muito particulares de se realizar uma atividade não são apoiadas por um sistema ERP (DAVENPORT, 1998).

\subsection{Modelos de Referência dos Sistemas ERP}

Os modelos de referência dos sistemas ERP representam os processos de negócio apoiados por esses sistemas (KELLER \& TEUFEL, 1998). Tais modelos descrevem os processos como um conjunto de alternativas que correspondem às possíveis soluções disponíveis nos ERPs.

A FIGURA 18 apresenta um exemplo de um modelo de referência de um sistema ERP que representa três alternativas existentes no sistema para o cadastramento de estruturas de produto.

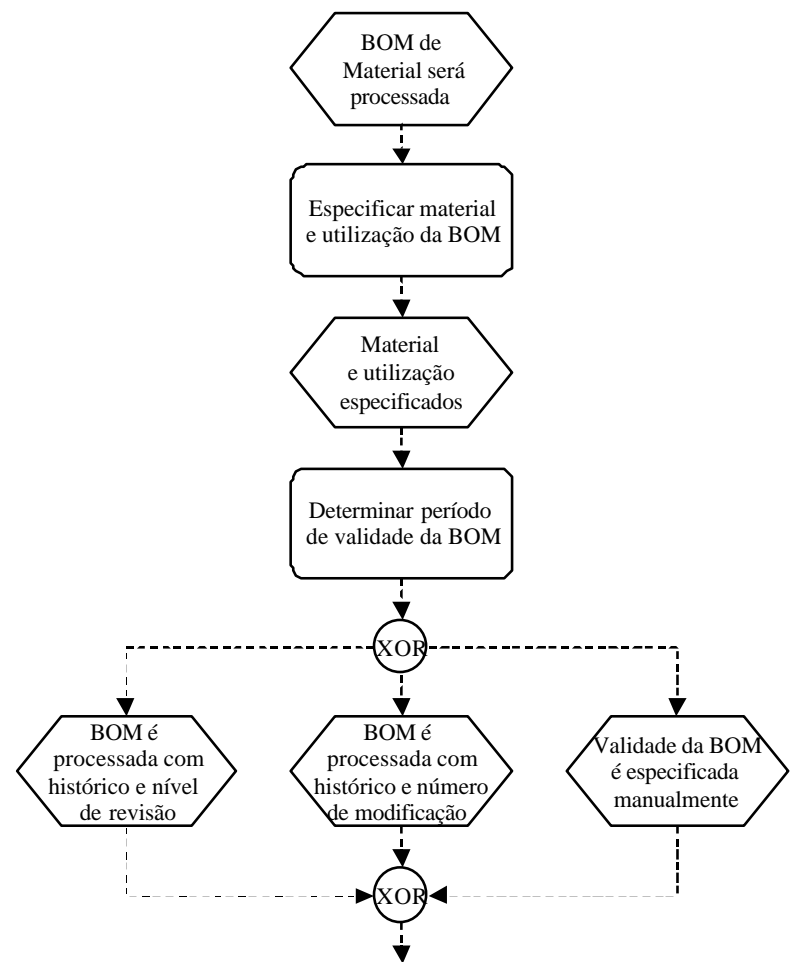

FIGURA 18 - Exemplo de um modelo de referência de um sistema ERP

(KELLER \& TEUFEL, 1998, p. 406)

Basicamente, os modelos de referência dos sistemas ERP podem ser utilizados de duas formas distintas em projetos de implantação desses sistemas: na configuração de modelos de empresa específicos ou na verificação da aderência do sistema a modelos de empresa específicos (KELLER \& TEUFEL, 1998).

Na primeira forma, o modelo de referência do sistema ERP é configurado em um modelo específico para uma empresa. Entre todas as soluções disponíveis no modelo de 
referência do sistema, selecionam-se as alternativas mais adequadas para atender aos requisitos da empresa.

A configuração do modelo de referência determina a configuração que deverá ser realizada no sistema, uma vez que cada alternativa do modelo corresponde a um conjunto de parâmetros das tabelas de configuração do ERP (DIRKS et al., 1997).

A principal vantagem dessa abordagem é a garantia de que os processos definidos no modelo configurado para a empresa serão apoiados pelas funcionalidades do sistema (KELLER \& TEUFEL, 1998).

Na segunda forma de utilização, o modelo de referência do ERP é empregado para se verificar o grau de aderência do sistema a uma empresa específica. Para isso deve-se comparar o modelo de referência da empresa com o modelo de referência do sistema ERP (KELLER \& TEUFEL, 1998). Nessa comparação são identificadas as funcionalidades do ERP que podem ser utilizadas para apoiar as atividades do modelo da empresa.

\subsection{Integração entre os Sistemas de Desenvolvimento de Produtos e os Sistemas ERP}

Neste item analisam-se as integrações entre os sistemas de desenvolvimento de produtos - PDM, CAPP e CAD - e os sistemas ERP. Enfatiza-se a integração entre os sistemas PDM e ERP devido ao maior destaque que lhe é dado na literatura estudada.

\section{Integração PDM/ERP}

Os sistemas PDM são sistemas de gerenciamento de dados de produto aplicados tradicionalmente ao processo de desenvolvimento de produtos. As informações geradas no desenvolvimento de produtos e gerenciadas pelo PDM (cadastro mestre de itens, estruturas de produto, documentos, etc.) são utilizadas pelos sistemas ERP nas etapas seguintes do ciclo de vida dos produtos (fabricação, vendas, serviço, manutenção, descarte). Nessas etapas o ERP também gera informações adicionais sobre os produtos, tais como dados de custo e informações de configuração.

Dessa forma, o fluxo contínuo e o completo gerenciamento das informações de produtos ao longo do ciclo de vida só é possível com a integração entre os sistemas PDM e ERP (BOURKE, 1998).

Segundo MILLER (1999), as empresas enfrentam uma grande dificuldade na especificação da melhor forma de integração entre esses sistemas. Não existe uma solução única e cada organização deve considerar os seus requisitos específicos e as suas particularidades. 
Em uma integração desse tipo as empresas precisam determinar o sistema utilizado para apoiar cada atividade, definir o sistema que controlará cada informação e determinar como os sistemas serão efetivamente integrados (MILLER, 1999).

Essas definições são dificultadas pela crescente sobreposição de funcionalidades dos sistemas PDM e ERP. O PDM está expandido-se para além das fronteiras da engenharia, apoiando as necessidades de gerenciamento de todas as informações do produto, incluindo informações de chão-de-fábrica e de manufatura. Ao mesmo tempo, os sistemas ERP começaram a apoiar algumas das atividades de engenharia pela incorporação de funções clássicas dos sistemas PDM (KEMPFER, 1998).

As principais sobreposições de funcionalidades decorrentes da expansão de ambos os sistemas são: gerenciamento de estruturas de produto, classificação de itens, gerenciamento de fluxo de trabalho, gerenciamento de projetos (MILLER, 1999), cadastro mestre de itens e gerenciamento de modificações de engenharia (BOURKE, 1999).

Conforme observado por BOURKE (1996) em duas conferências nas quais foi discutida a integração entre os sistemas PDM e ERP ${ }^{21}$, há um certo consenso quanto aos principais pontos de integração entre tais sistemas. Esses pontos de integração coincidem com as sobreposições de funcionalidades: cadastro mestre de itens, classificação de itens, estrutura de produtos e gerenciamento de modificações (BOURKE, 1996), sendo que a estrutura de produto é considerada por vários autores como o mais importante elemento de ligação entre os sistemas PDM e ERP (SWANTON, 1997; KEMPFER, 1998; BOURKE, 1999; MILLER, 1999).

Além disso, parece também haver concordância quanto ao controle da estrutura de produto ao longo do ciclo de vida. O PDM deve controlar a estrutura desde o início e durante todo o desenvolvimento, até a liberação para a produção. A estrutura passa então a ser gerenciada pelo ERP (BOURKE, 1997; SWANTON, 1997).

A determinação dos sistemas utilizados para apoiar cada atividade e a definição da forma de controle das informações também devem considerar as soluções técnicas disponíveis para se conectarem os sistemas. É necessário que haja um compromisso entre as definições conceituais da integração e a viabilidade técnica de implantação (ZANCUL et al., 1999).

ZANCUL et al. (1999) apresentam uma análise detalhada das soluções técnicas de integração entre sistemas PDM e ERP, entre as quais as mais empregadas atualmente são a transferência de informações por arquivos e a comunicação via APIs.

${ }^{21}$ Conferências do CIMdata e do Management Roundtable realizadas no ano de 1996. 
A transferência de arquivos contendo dados de um sistema para outro pode ser facilmente implantada. Nessa integração os dados são extraídos de um sistema, armazenados em um arquivo e carregados no sistema destino. O processo de transferência dos dados pode ser iniciado manualmente ou pode ocorrer em períodos de tempo pré-determinados. Como o processo não ocorre em tempo real, ambos os sistemas mantêm cópias dos dados (FERMAN, 1998).

Um exemplo dessa solução de integração para a transferência da estrutura de produto de um sistema PDM para o ERP é citado por MILLER (1999). Nesse exemplo, um programa extrai a estrutura de produto da base de dados do sistema PDM em um arquivo de planilha eletrônica que é carregado diretamente no ERP.

Outra solução de integração muito empregada atualmente é baseada na utilização de APIs. Para isso, é necessário que pelo menos um dos sistemas possua esse recurso, permitindo que suas funções internas sejam acessadas por outros sistemas por meio de programas específicos de integração.

A integração por API pode ser implantada de modo unidirecional ou bidirecional. Uma integração unidirecional pode ser desenvolvida, por exemplo, para transmitir estrutura de produto do sistema PDM diretamente para o ERP (BOURKE, 1999).

Em uma integração bidirecional, a transferência de dados ocorre tanto do PDM para o ERP quanto do ERP para o PDM. Dessa forma, além da transferência da estrutura de produto do sistema PDM para o ERP, o PDM pode, por exemplo, receber dados de custo de produtos (BOURKE, 1999) e requisições de modificações de engenharia (KEMPFER, 1998) do sistema ERP.

Alguns fornecedores de sistemas PDM oferecem kits de integração por APIs certificados pelos fornecedores de ERP (REIMANN \& RADEMEIER, 1999). A utilização de kits pré-definidos reduz a complexidade de integração.

Em alguns casos, a utilização de APIs elimina a necessidade de se manterem dados redundantes, permitindo o acesso em tempo real aos dados de ambos os sistemas. Os programas de integração também podem rodar continuamente, aguardando serem requisitados, em vez de serem iniciados manualmente ou em um períodos de tempo prédeterminados (FERMAN, 1998).

\section{Integração CAPP/ERP}

Os sistemas CAPP são utilizados em ambientes de engenharia para apoiar as atividades de geração das informações e da documentação necessária para a fabricação de 
um item. Entre essas informações, o plano de processo macro é essencial para o planejamento da produção nos sistemas ERP.

A necessidade de utilização de dados básicos semelhantes em ambos os sistemas resultou em sobreposições de funcionalidades. Para o planejamento do processo de um item, os sistemas CAPP incorporaram funcionalidades de gerenciamento e classificação de itens e de geração de estruturas de produto. Os sistemas ERP, por sua vez, têm algumas funções que apóiam a geração de planos de processo macro e de alguns detalhamentos (plano de suboperações e de operações de qualidade), além do gerenciamento de itens e estruturas, necessários para viabilizar o planejamento da produção.

No caso em que ambos os sistemas são utilizados, deve-se considerar um processo de integração que defina o sistema que gera cada uma das informações compartilhadas e determine o sistema que controle as informações ao longo do ciclo de vida. É preciso também estabelecer um procedimento para a atualização dessas informações.

Uma integração desse tipo entre sistemas CAPP e ERP ainda é pouco estudada. Um exemplo prático desse tipo de integração, voltado para a obtenção da documentação exigida pela QS-9000, é apresentado por ROZENFELD et al. (1999).

Nesse exemplo, foi definido que o sistema ERP, como "espinha dorsal" dos sistemas de informação da empresa, é o "dono" de todos os dados. O sistema CAPP é a base de conhecimentos da engenharia e apóia as atividades de geração das informações e da documentação exigida pela QS-9000 (ROZENFELD et al., 1999).

Os itens são criados no sistema ERP devido à grande quantidade de informações, de várias áreas, que são preenchidas no seu cadastramento. Dessa forma, o sistema CAPP é cliente do cadastro de itens do ERP. As estruturas de produto, por sua vez, podem ser criadas em ambos os sistemas, pois a sua integração é bidirecional. Os planos de processo macro são gerados no sistema CAPP e disponibilizados para o ERP após a aprovação, assim como os detalhamentos do plano de processo que são utilizados pelo ERP (ROZENFELD et al., 1999).

\section{Integração CAD/ERP}

Os sistemas CAD são utilizados para apoiar a geração de modelos geométricos e a especificação de alguns dados de produto, durante o processo de desenvolvimento. Essas atividades podem requerer informações disponíveis na base de dados do ERP (estruturas de produto, características de itens, entre outras). Os modelos geométricos e os dados de produtos criados no CAD precisam ser controlados pelo ERP para serem utilizados nas fases 
seguintes do ciclo de vida dos produtos. Assim, é necessário viabilizar a transferência de informações entre esses sistemas.

A integração entre os sistemas CAD e ERP também é pouco estudada na bibliografia. As soluções existentes para essa integração são apresentadas por um fornecedor de sistemas ERP (SAP, 1996) e por um fornecedor de sistemas CAD (PTC, 2000).

Nas soluções disponíveis, funções internas tanto do CAD quanto do ERP podem ser acessadas pelo outro sistema via APIs pré-definidas disponíveis em bibliotecas.

Entre as funcionalidades do ERP que podem ser acessadas pelo CAD por meio de APIs estão, por exemplo, a criação, a modificação e a recuperação de itens e de estruturas de produto, o gerenciamento de modificações de engenharia, a busca de informações por características de itens e o gerenciamento de documentos (SAP, 1996).

\subsection{O Sistema SAP R/3}

O sistema ERP SAP R/3 versão 4.0B é basicamente composto por módulos que podem ser utilizados tanto individualmente quanto de maneira integrada.

O SAP R/3 4.0B possui os seguintes módulos: Vendas e Distribuição (SD), Materiais (MM), Produção (PP), Contabilidade Financeira (FI), Controladoria (CO), Gerenciamento de Ativos (AM), Controle de Qualidade (QM), Manutenção (PM), Recursos Humanos (HR), Projetos (PS) e Cross Applications (CA)22 (KELLER \& TEUFEL, 1998; SAP, 1998a; SAP, 2000a).

Adicionalmente, o sistema SAP R/3 4.0B pode ser integrado a componentes externos recentemente desenvolvidos pela SAP, entre os quais o componente de APS, denominado Advanced Planner Optimizer (APO), e o componente de data warehousing, denominado Business Information Warehouse (BW).

O PDM do SAP R/3 4.0B não constitui um módulo nem um componente isolado do sistema, mas pode ser considerado como um agrupamento lógico de funcionalidades típicas de sistemas PDM, pertencentes aos módulos PP, PS e CA.

São funcionalidades de PDM do SAP R/3 4.0B: o cadastro mestre de itens, o sistema de classificação, o gerenciamento de estruturas de produto, o navegador de estruturas de produto, a configuração de produtos, o gerenciamento de documentos, o controle de modificações de engenharia (ECM - Engineering Change Management), o fluxo de trabalho,

${ }^{22}$ O CA agrupa funcionalidades comuns a vários módulos, tais como as funções de classificação e de gerenciamento de documentos. 
a integração com sistemas CAD e o gerenciamento de projetos (MILLER \& MENDEL, 1997; SAP, 1997; WESSNER, 1999).

A maioria dessas funcionalidades de PDM pode ser acessada, no SAP R/3 4.0B padrão ${ }^{23}$, a partir da tela de Engineering (caminho: Logistics $\rightarrow$ Central Functions $\rightarrow$ Engineering), com exceção das funcionalidades de configuração de produtos (caminho: Logistics $\rightarrow$ Central Functions $\rightarrow$ Variant Configuration) e de gerenciamento de projetos (caminho: Logistics $\rightarrow$ Project Management).

A tela Engineering do R/3 4.0B é apresentada na FIGURA 19. Para demonstrar as funcionalidades de PDM que podem ser acessadas a partir dessa tela, os seus menus estão expandidos e posicionados, de forma ilustrativa, no centro da FIGURA 19.

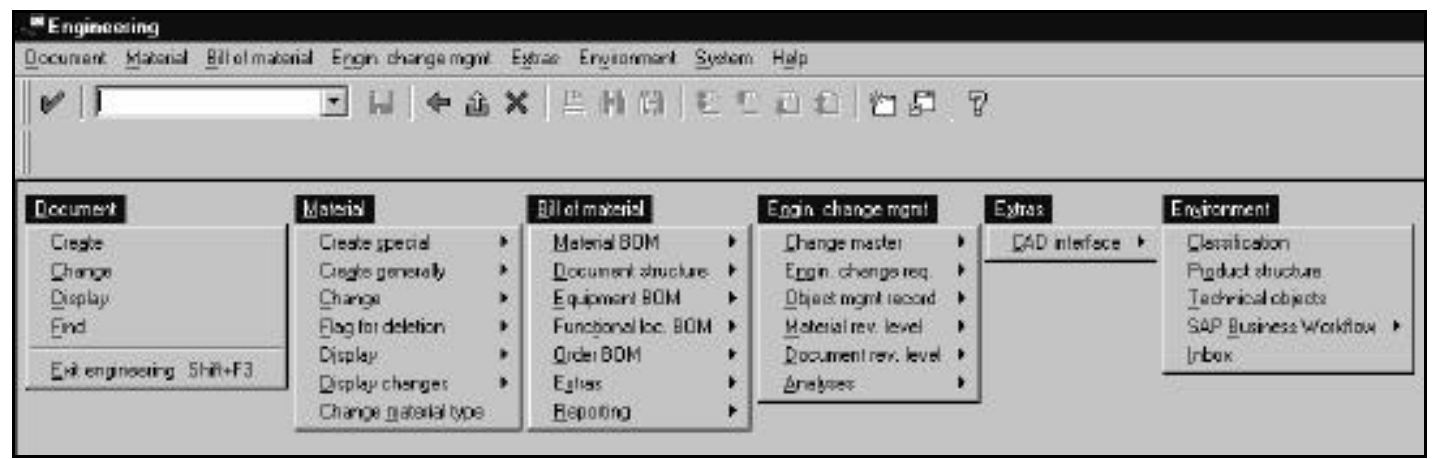

FIGURA 19 - SAP R/3 - Tela Engineering com menus expandidos

Deve-se ressaltar que o sistema SAP R/3 4.0B não possui as funcionalidades mais atuais de gerenciamento do ciclo de vida de produtos (PLM) recentemente anunciadas pela SAP. Segundo a AMR (2000), tais funcionalidades estão disponíveis somente a partir da versão $4.6 \mathrm{C}$ do $\mathrm{R} / 3$.

Uma das formas mais eficientes de integração do sistema SAP R/3 com os sistemas de desenvolvimento de produtos é baseada na utilização de APIs. A programação de uma interface para esse tipo de integração pode ser facilitada, no sistema R/3, com o emprego de funções pré-definidas de acesso às APIs. Tais funções estão disponíveis em bibliotecas localizadas no CD de instalação do aplicativo cliente do R/3.

O CD de instalação do aplicativo cliente do R/3 também contém outras ferramentas que apóiam a integração entre aplicativos complementares e o sistema R/3, tais como componentes OLE que possibilitam o acesso de aplicativos externos à funcionalidades do $\mathrm{R} / 3$. Adicionalmente, esse CD contém plug-ins de integração prontos para serem utilizados

${ }^{23}$ Considera-se como padrão o sistema em seu estado original, ou seja, sem nenhum tipo de configuração ou customização. 
como, por exemplo, a integração do R/3 com os sistemas de trabalho em grupo MS Outlook e Lotus Notes, as interfaces de exportação para os gerenciadores de projeto Graneda e MS Project e os geradores de relatórios para aplicativos de escritório MS Office e Lotus Smart Suite. 


\section{ESTUDO EXPLORATÓRIO DA APLICABILIDADE DO SISTEMA ERP EM UM PROCESSO DE DESENVOLVIMENTO DE PRODUTOS}

Neste capítulo, são apresentadas as etapas realizadas no estudo exploratório dos aspectos funcionais e de integração do sistema ERP em um processo específico de desenvolvimento de produtos.

Inicialmente é selecionado o processo de desenvolvimento de produtos considerado nesta fase da pesquisa. São obtidos, em seguida, os modelos de referência do processo de desenvolvimento de produtos e do sistema ERP. Ambos os modelos são, então, comparados de acordo com uma técnica específica de comparação de modelos. A comparação dos modelos visa à identificação de funcionalidades do ERP que podem ser utilizadas para apoiar o processo de desenvolvimento de produtos. A localização de funcionalidades do ERP para o desenvolvimento de produtos é complementada por uma busca adicional feita pela observação direta no sistema e da realização de uma entrevista com um especialista.

As funcionalidades de desenvolvimento de produtos do ERP, identificadas nas etapas anteriores, são individualmente verificadas de forma detalhada. Paralelamente, são selecionados e analisados sistemas complementares de desenvolvimento de produtos, determinando-se as sobreposições de funcionalidades existentes entre tais sistemas e o ERP. As sobreposições determinadas são validadas por entrevistas com especialistas, e, em seguida, servem de base para a definição dos pontos de integração do ERP com os sistemas complementares de desenvolvimento de produtos.

Como resultado das etapas realizadas nesta fase da pesquisa obtém-se um modelo de referência do processo de desenvolvimento de produtos considerando a aplicação e integração do sistema ERP.

Esse modelo de referência define as atividades de desenvolvimento de produtos que são apoiadas por funcionalidades do ERP, identifica as sobreposições de funcionalidades entre o sistema ERP e os sistemas complementares de desenvolvimento de produtos, e determina os principais pontos de integração entre tais sistemas.

A apresentação das etapas do estudo exploratório, realizada neste capítulo, é abrangente e detalhada. Além da descrição do conteúdo de cada uma das etapas, são 
relatados também as principais dificuldades e limitações observadas na aplicação dos instrumentos de coleta de dados. As informações adicionais relacionadas com a realização das etapas, tais como os roteiros de entrevistas, são anexadas a este texto. Os resultados parciais das etapas, por sua vez, são omitidos, devido ao fato de esses resultados serem apresentados, de forma compilada, no modelo de referência obtido no final desta fase da pesquisa.

\subsection{Seleção do Processo de Desenvolvimento de Produtos}

A seleção do processo de desenvolvimento de produtos considerado nesta fase da pesquisa foi baseada em dois critérios previamente estabelecidos. Definiu-se que o processo selecionado deve ser amplo, abrangendo as etapas características de um desenvolvimento de produtos completo. Mais ainda, determinou-se que o processo escolhido deve ser atual, incluindo as melhores práticas efetivamente utilizadas pelas empresas no desenvolvimento de produtos.

Com base nesses critérios foi selecionado o processo de desenvolvimento de produtos do NUMA, apresentado inicialmente por ROZENFELD (1997). O NUMA é um núcleo de pesquisa em manufatura e tecnologia da informação com grande ênfase na especificação de processos de negócio ${ }^{24}$.

O processo de desenvolvimento de produtos do NUMA é resultado de projetos de consultoria em empresas, dos requisitos da norma de qualidade QS-9000 e de pesquisas avançadas na área. Atualmente, tal processo está sendo aperfeiçoado por um projeto de doutorado em andamento (AMARAL, 1997) e por novas pesquisas, como, por exemplo, estudos sobre a introdução de stage gates e sobre gerenciamento de dados de produto em ambientes distribuídos. Assim, pode-se considerar que o processo de desenvolvimento de produtos do NUMA é bastante atual.

De acordo com ROZENFELD (1997) e com os trabalhos em andamento, o processo de desenvolvimento de produtos do NUMA abrange as seguintes etapas:

a Desenvolver Plano Estratégico e Portfolio de Produtos - desenvolvimento do plano estratégico e programação das plataformas e das ofertas de produtos;

- Conceber Produto - especificação inicial de diretrizes do produto (custo alvo, volume de produção, entre outras) e planejamento do desenvolvimento;

24 Informações relevantes sobre o NUMA estão disponíveis na Internet no endereço www.numa.org.br. 
- Conceituar Produto - detalhamento das diretrizes, definição macro das características técnicas do produto e dos processos de manufatura e avaliação financeira do projeto;

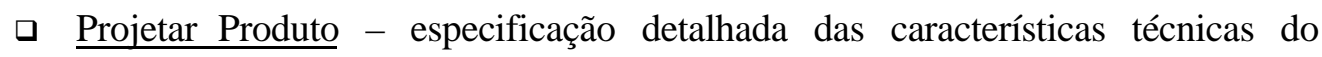
produto e dos processos de manufatura;

- Homologar Projeto - construção de protótipos e realização de testes funcionais do produto;

- $\quad$ Homologar Processo - realização de testes de produção do produto (lote piloto);

- Lançar Produto - preparação de manuais técnicos e treinamento do pessoal envolvido no lançamento do produto.

Essas etapas compreendem as atividades características de um processo de desenvolvimento completo, desde o planejamento estratégico até o lançamento do produto no mercado. Dessa forma, pode-se considerar também que o processo de desenvolvimento de produtos do NUMA é bastante amplo.

Verifica-se, então, que o processo de desenvolvimento do NUMA satisfaz ambos os critérios de seleção previamente estabelecidos e é adequado para ser analisado nesta fase da pesquisa.

As características do processo de desenvolvimento de produtos do NUMA, de acordo com a tipologia proposta por ROZENFELD \& AMARAL (1999), são apresentadas na TABELA 4. Essas características identificam um tipo de processo de desenvolvimento.

Segundo ROZENFELD \& AMARAL (1999), o tipo de processo de desenvolvimento de produtos determina as características fundamentais que afetam a forma de gerenciar o desenvolvimento de produtos.

Assim, considera-se que os resultados obtidos nesta fase da pesquisa para o processo de desenvolvimento do NUMA podem ser estendidos, com algumas ressalvas, para outros processos de desenvolvimento de mesmo tipo, ou seja, para outros processos que possuam as mesmas características.

Mais ainda, a partir das características listadas na TABELA 4, podem ser definidas analogias entre o tipo de processo analisado neste trabalho e outros tipos de processo de desenvolvimento, facilitando a adaptação dos resultados obtidos a outras situações. 
TABELA 4 - Classificação do processo de desenvolvimento de produtos do NUMA de acordo com a tipologia proposta por ROZENFELD \& AMARAL ( 1999)

\begin{tabular}{|c|c|c|c|}
\hline NÍVEL & \multicolumn{2}{|c|}{ FATOR } & TIPO \\
\hline \multirow[t]{4}{*}{ Mercado } & \multicolumn{2}{|l|}{ Setor } & Automobilístico \\
\hline & \multicolumn{2}{|l|}{ Concorrência } & Oligopólio competitivo \\
\hline & \multirow[t]{2}{*}{ Alvo } & Geográfico & Mundial \\
\hline & & $\begin{array}{l}\text { Posição na cadeia } \\
\text { de produção }\end{array}$ & Intermediário na cadeia de suprimentos \\
\hline \multirow[t]{3}{*}{ Corporação } & \multicolumn{2}{|l|}{ Inserção } & Unidade independente \\
\hline & \multirow{2}{*}{$\begin{array}{l}\text { Interação com } \\
\text { unidades }\end{array}$} & Responsabilidade & Coordenador de desenvolvimento \\
\hline & & Equipe & Local \\
\hline \multirow[t]{8}{*}{ Empresa } & \multicolumn{2}{|c|}{ Responsabilidade técnica } & Aquisição e adaptação de tecnologia \\
\hline & \multirow[t]{2}{*}{ Estratégia } & Competitiva & Misto \\
\hline & & Interprojetos & Simultâneo \\
\hline & \multicolumn{2}{|c|}{ Informações iniciais } & Idéia \\
\hline & \multirow[t]{3}{*}{$\begin{array}{l}\text { Complexidade } \\
\text { do produto }\end{array}$} & $\begin{array}{l}\text { Tecnologia } \\
\text { principal }\end{array}$ & Mecânica \\
\hline & & Interna & Número de componentes \\
\hline & & $\begin{array}{l}\text { Interface com o } \\
\text { usuário }\end{array}$ & Baixa complexidade \\
\hline & \multicolumn{2}{|c|}{ Grau de inovação } & Plataformas ou nova geração e derivados \\
\hline
\end{tabular}

\subsection{Obtenção do Modelo de Referência do Processo de Desenvolvimento de Produtos}

Esta etapa foi subdividida em três atividades principais. Inicialmente, obteve-se o modelo de referência que representa o processo de desenvolvimento de produtos do NUMA. Em seguida, esse modelo de referência foi estudado de maneira detalhada. Por fim, o conteúdo do modelo foi preparado para as etapas seguintes do trabalho.

ROZENFELD (1997) apresenta a versão 3.0 do modelo de referência do processo de desenvolvimento de produtos do NUMA. No entanto, desde a sua publicação por ROZENFELD (1997), tal modelo tem sido constantemente atualizado para incorporar as melhorias realizadas no processo representado.

Optou-se por analisar a versão mais recente do modelo de referência disponível no início desta etapa. Essa versão, identificada como 4.1, foi obtida no Laboratório de Sistematização e Integração da Manufatura do NUMA.

A versão 4.1 do modelo de referência do processo de desenvolvimento de produtos do NUMA é representada de duas maneiras distintas: de forma gráfica e de forma tabular. Ambas as formas de representação são descritas em três níveis de detalhamento.

A representação gráfica do modelo de referência do processo de desenvolvimento de produtos do NUMA é apresentada na FIGURA 20. 


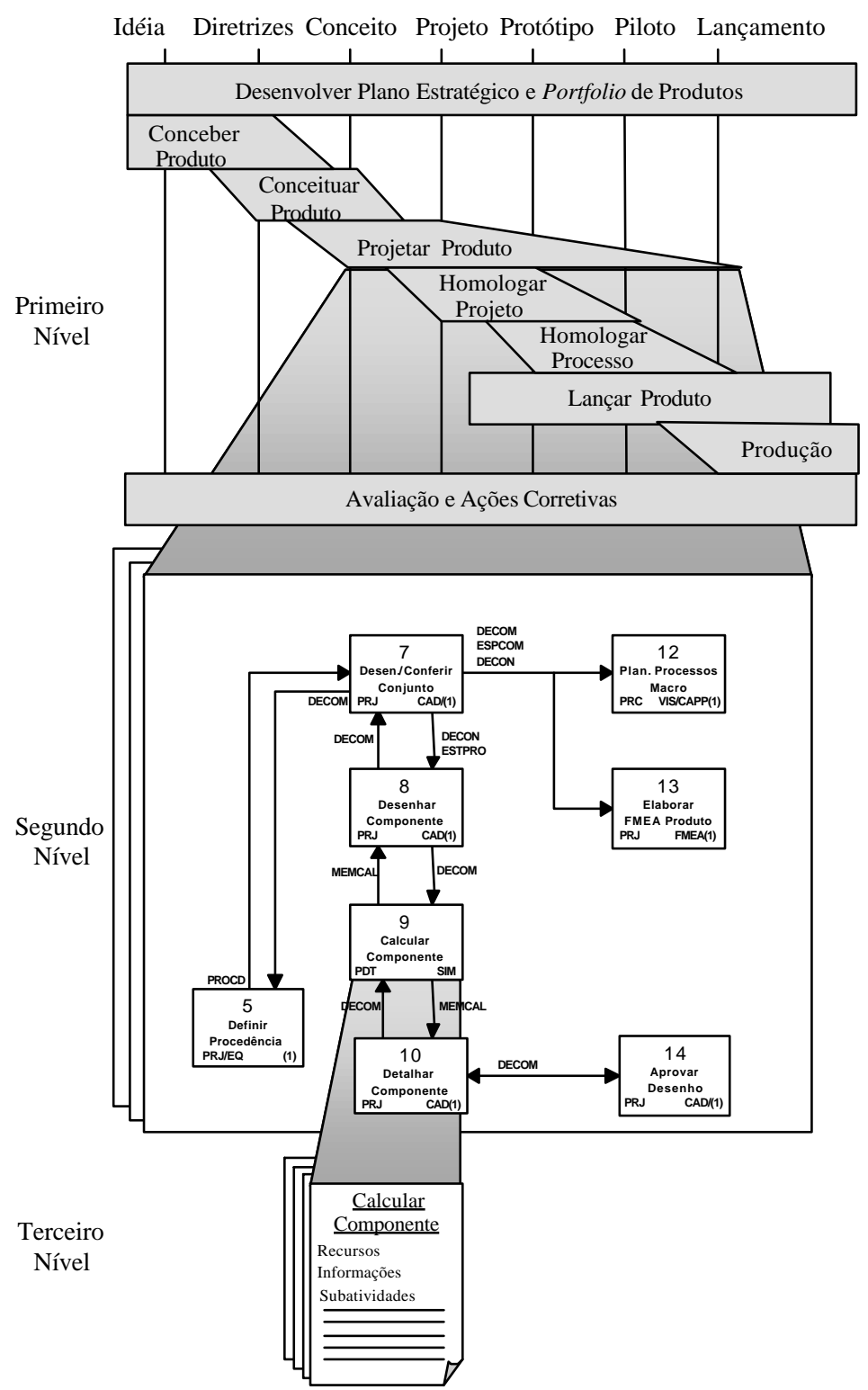

FIGURA 20 - Representação gráfica do modelo de referência do processo de desenvolvimento de produtos do NUMA em três níveis de detalhamento

Na representação gráfica, o primeiro nível do modelo é uma descrição analógica das etapas do processo de desenvolvimento, muito parecida visualmente com a forma de representação empregada pela APQP da QS-9000 (FIGURA 20).

No segundo nível do modelo, cada uma das etapas do processo é detalhada em atividades. Esse nível é descrito segundo um formalismo de representação adaptado do método de modelagem SADT. As atividades são representadas por retângulos e especificadas por um verbo no infinitivo e por um complemento. Os retângulos (atividades) são interligados por setas que indicam o fluxo de informações, determinando as informações de entrada e as informações de saída de cada uma das atividades. Dentro de cada retângulo 
são especificados, ainda, no canto inferior esquerdo, os elementos organizacionais responsáveis pela execução das atividades e, no canto inferior direito, os recursos empregados para apoiar as atividades (FIGURA 20).

No terceiro nível do modelo as atividades são detalhadas em subatividades utilizando-se texto estruturado. Esse nível de detalhamento define os procedimentos específicos que devem ser observados na realização de cada uma das atividades (FIGURA 20).

Uma forma alternativa de representação do modelo de referência do processo de desenvolvimento de produtos do NUMA é apresentada na FIGURA 21.

\begin{tabular}{|c|c|c|c|c|c|c|}
\hline Nível & Ação & Tipo & Recurso & \multicolumn{2}{|c|}{ Informação } & Organização \\
\hline 1 & etapa & & & & & \\
2 & $\begin{array}{c}\text { atividade } \\
3\end{array}$ & & & & & \\
& sub-atividade & & & & & \\
& & & & & & \\
& & & & & & \\
\hline
\end{tabular}

FIGURA 21 - Representação tabular do modelo de referência do processo de desenvolvimento de produtos do NUMA em três níveis de detalhamento

Nessa forma de representação, os mesmos elementos considerados na representação gráfica são dispostos em uma tabela. A primeira coluna da tabela define o nível de detalhamento. A segunda coluna especifica as ações do processo, de acordo com o nível de detalhamento (etapas, atividades e subatividades). A terceira coluna determina o tipo de ação (reunião, manual e computador). A quarta coluna indica o recurso utilizado. As duas colunas seguintes descrevem as informações de entrada e de saída para cada atividade. Por fim, a última coluna determina os elementos organizacionais responsáveis pelas atividades (FIGURA 21).

A representação gráfica do modelo de referência facilita a obtenção de uma visão geral do processo de desenvolvimento por meio da descrição de todos os seus elementos, bem como dos inter-relacionamentos existentes entre os seus vários componentes (atividades, informações, recursos e organização). No entanto, tal representação dificulta a manipulação dos elementos do modelo para a realização de análises, simulações e alterações.

A representação tabular, por sua vez, dificulta a compreensão do processo como um todo, mas facilita a manipulação e a realização de modificações no modelo de referência, tais como a inclusão de novos recursos. 
Observando-se as vantagens e desvantagens de cada forma de representação, optouse por realizar o estudo do modelo de referência do processo de desenvolvimento utilizandose a sua representação gráfica e por empregar a sua representação tabular nas etapas seguintes deste trabalho.

$\mathrm{O}$ estudo do modelo de referência do processo de desenvolvimento foi realizado aplicando-se a técnica de análise documental.

Tal estudo envolveu uma análise detalhada das atividades, procurando-se compreender a sua essência e os seus requisitos específicos. Observando-se as informações de entrada de cada atividade, foram analisadas as ações executadas, definidas pelas subatividades, para gerar as informações de saída. Avaliou-se também a atuação dos elementos organizacionais, bem como a extensão de aplicação de cada um dos recursos.

Após o estudo do modelo gráfico, o modelo tabular foi preparado para ser utilizado ao longo das etapas seguintes do estudo exploratório.

Inicialmente, os recursos definidos para as ações do processo, listados na coluna Recurso do modelo de referência, foram excluídos da tabela, tornando as ações independentes de qualquer recurso específico.

Em seguida, a representação de cada uma das ações do modelo foi analisada individualmente, para se verificar a existência de ações que pressupunham o emprego de um recurso determinado, como, por exemplo, ações cuja denominação define os recursos que devem ser utilizados na sua realização. Nesses casos, a representação das ações deveria ser "neutralizada" para possibilitar a análise da aplicabilidade do sistema ERP. Não foi encontrada, no entanto, nenhuma ação que precisasse ser modificada.

Foi então acrescentada uma nova etapa no modelo de referência, denominada Preparar Estruturas para Desenvolvimento. Tal etapa engloba as atividades relacionadas com a criação dos elementos básicos necessários ao desenvolvimento de produtos, como o estabelecimentos de procedimentos de controle de modificações e a definição de classes e características para classificação.

Finalmente, foram adicionadas três novas colunas na tabela do modelo de referência para a especificação do nome, do código e do caminho que definem as funcionalidades do sistema ERP.

O modelo tabular, após a preparação realizada, foi considerado adequado para ser complementado nas etapas seguintes do trabalho até transformar-se, ao final desta fase da pesquisa, no modelo de referência do processo de desenvolvimento de produtos considerando a aplicação e integração do sistema ERP. 


\subsection{Obtenção do Modelo de Referência do Sistema ERP}

Paralelamente à realização da etapa anterior, o modelo de referência que descreve as soluções disponíveis no sistema SAP R/3 versão 4.0B foi obtido e estudado.

$\mathrm{O}$ modelo de referência do sistema SAP R/3 4.0B foi obtido no próprio sistema a partir da tela Business Navigator (caminho: Tools $\rightarrow$ Business Engineer $\rightarrow$ Business Navigator). Tal modelo pode ser consultado em duas visões distintas: a visão por componentes do sistema (Component View) e a visão por processos de negócio (Process Flow View). A visão por componentes descreve as transações do sistema agrupadas por módulos funcionais, enquanto que a visão por processos descreve as transações do sistema agrupadas por processos de negócio.

Optou-se por adotar a visão do modelo por processos de negócio devido ao alinhamento com o embasamento teórico que fundamenta o trabalho. Os macro processos representados no modelo do ERP são listados na FIGURA 22.

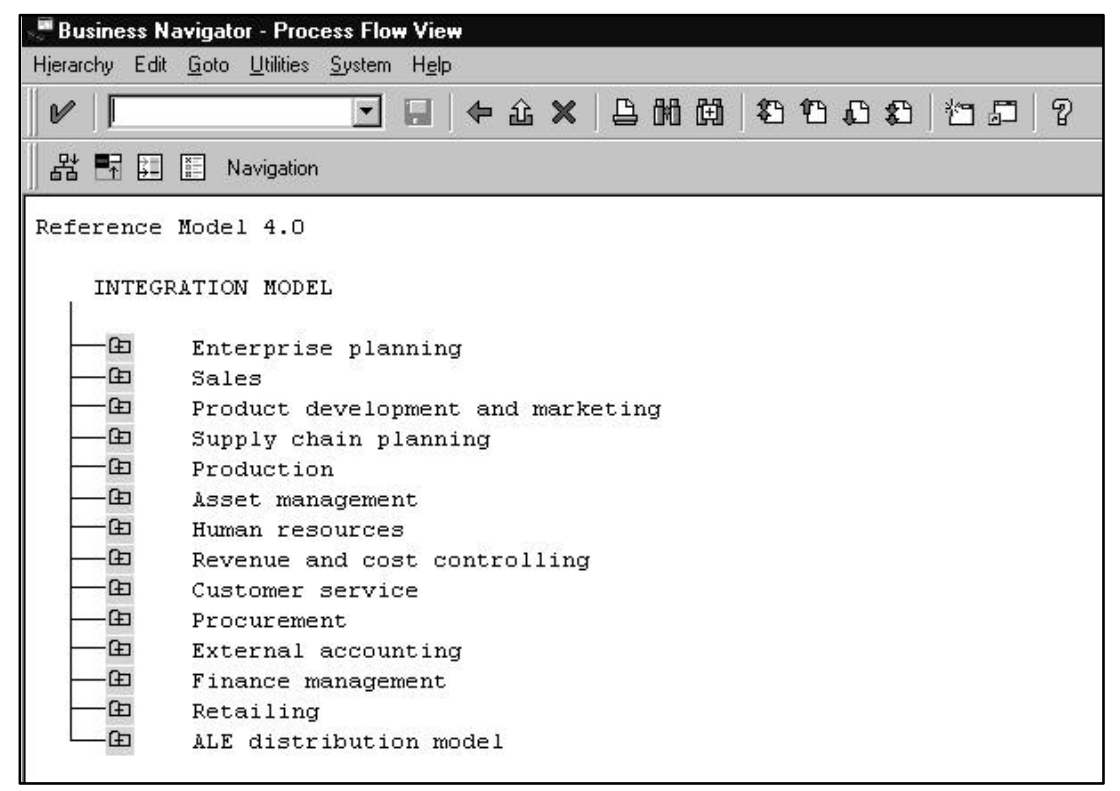

FIGURA 22 - Visão de processos do modelo de referência do sistema SAP R/3 4.0B

Cada um dos processos listados na FIGURA 22 é detalhado em subprocessos, chamados de cenários. Os subprocessos, por sua vez, são detalhados em sub-subprocessos e em atividades que são descritas por modelos segundo o formalismo EPC. Os EPCs são, então, detalhados em funções (FIGURA 23). 


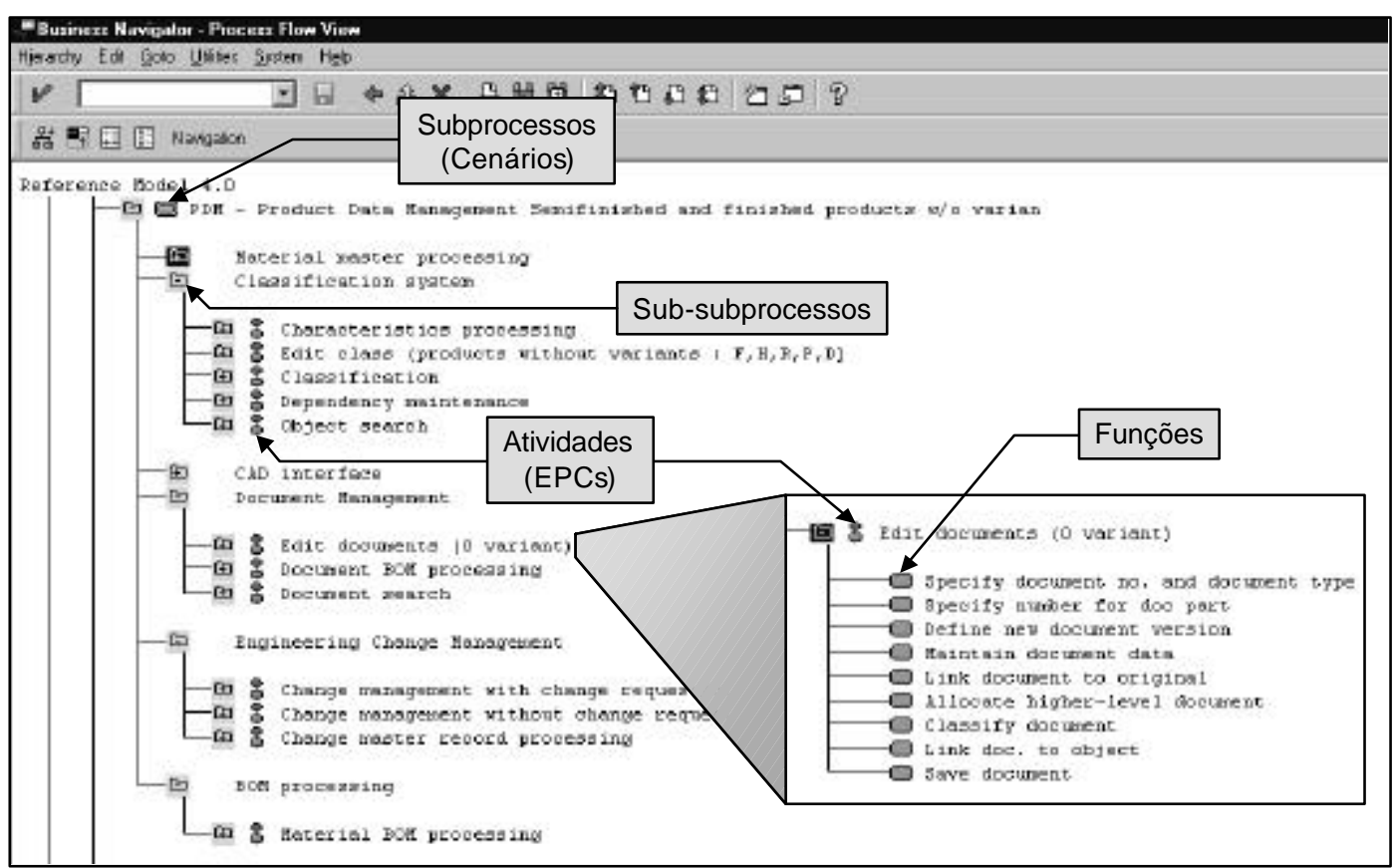

FIGURA 23 - Níveis de detalhamento do modelo de referência do sistema SAP R/3 4.0B

O encadeamento entre funções e eventos de cada um dos EPCs do modelo de referência do SAP R/3 4.0B pode ser visualizado em um "navegador" (IGURA 24).

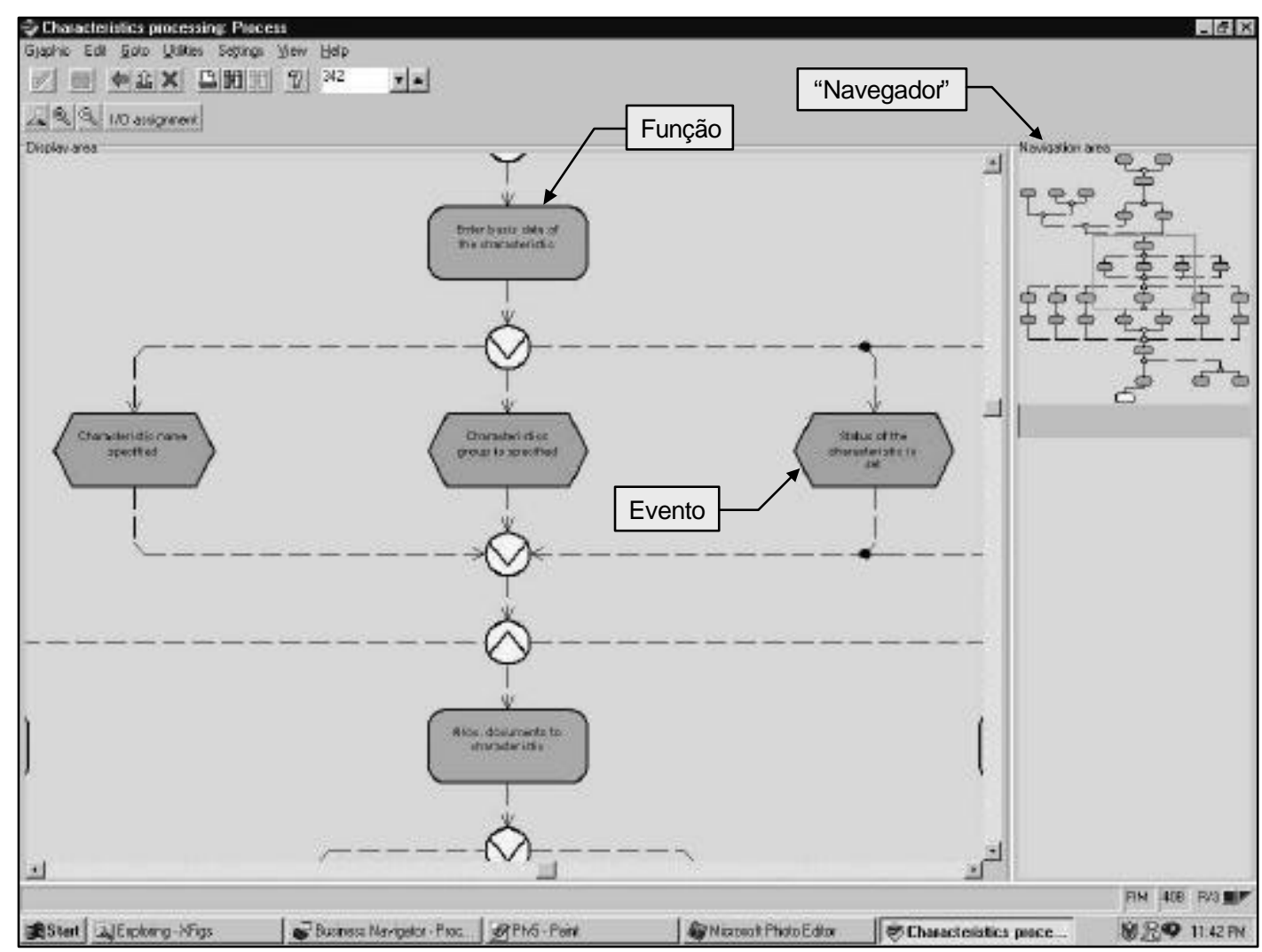

FIGURA 24 - Exemplo de EPC do modelo de referência do sistema SAP R/3 4.0B 
Os EPCs estão diretamente relacionados a uma série de características do sistema, tais como transações, documentação de ajuda (help) e atributos diversos. Pelo relacionamento entre os EPCs e as transações é possível verificar as funcionalidades do sistema que podem ser utilizadas para apoiar a execução das atividades definidas pelos EPCs. As funcionalidades do sistema SAP R/3 são geralmente definidas por um nome e por um código composto por quatro caracteres (FIGURA 25).

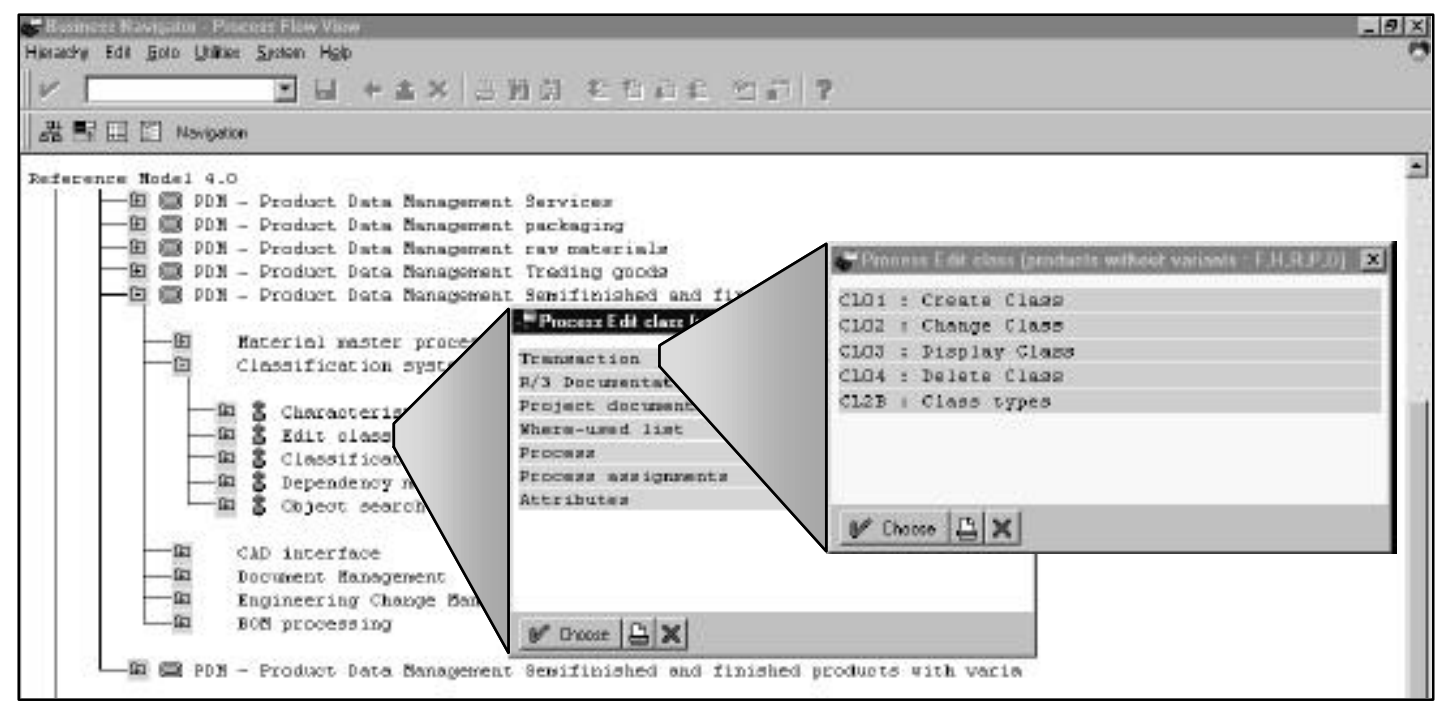

FIGURA 25 - Relacionamento entre EPC, características e transações do sistema SAP R/3 4.0B

Assim como na etapa anterior, o estudo do modelo de referência do sistema ERP também foi realizado empregando-se a técnica de análise documental.

Definiu-se que esse estudo seria baseado no nível de EPCs (atividades) do modelo de referência do ERP por dois motivos: primeiro, os EPCs representam as transações do sistema, enquanto que as funções dos EPCs representam um nível de detalhamento muito baixo, com pouco significado para o processo de negócio (as funções equivalem, por exemplo, aos campos das telas do sistema que devem ser preenchidos em uma determinada transação); segundo, constatou-se que o nível de detalhamento dos EPCs do modelo de referência do ERP é equivalente ao terceiro nível de detalhamento (subatividades) do modelo de referência do processo de desenvolvimento (essa equivalência é necessária para a comparação entre os modelos realizada na próxima etapa do trabalho).

Os EPCs do modelo de referência do ERP foram então estudados um a um. Tal como no estudo do modelo do processo, procurou-se compreender a essência de cada uma das soluções representadas no modelo do ERP. 


\subsection{Comparação dos Modelos de Referência}

Após serem obtidos e estudados, os modelos de referência do processo de desenvolvimento de produtos do NUMA e do sistema SAP R/3 4.0B foram comparados, a fim de que fossem identificadas as funcionalidades do sistema que podem ser utilizadas para apoiar o processo.

A comparação dos modelos de referência foi baseada no método de comparação de modelos proposto por KIRCHMER (1998). No entanto, esse método de comparação é definido de forma muito abstrata. A definição do método não especifica detalhadamente os procedimentos que devem ser executados durante a sua aplicação.

Determinou-se, então, que a aplicação do método de KIRCHMER (1998) seria realizada por meio de uma matriz de comparação. Nessa matriz, as linhas descrevem as ações (etapas, atividades e subatividades) do processo de desenvolvimento de produtos e as colunas representam os processos do sistema ERP, detalhados em subprocessos, subsubprocessos e EPCs (IGURA 26).

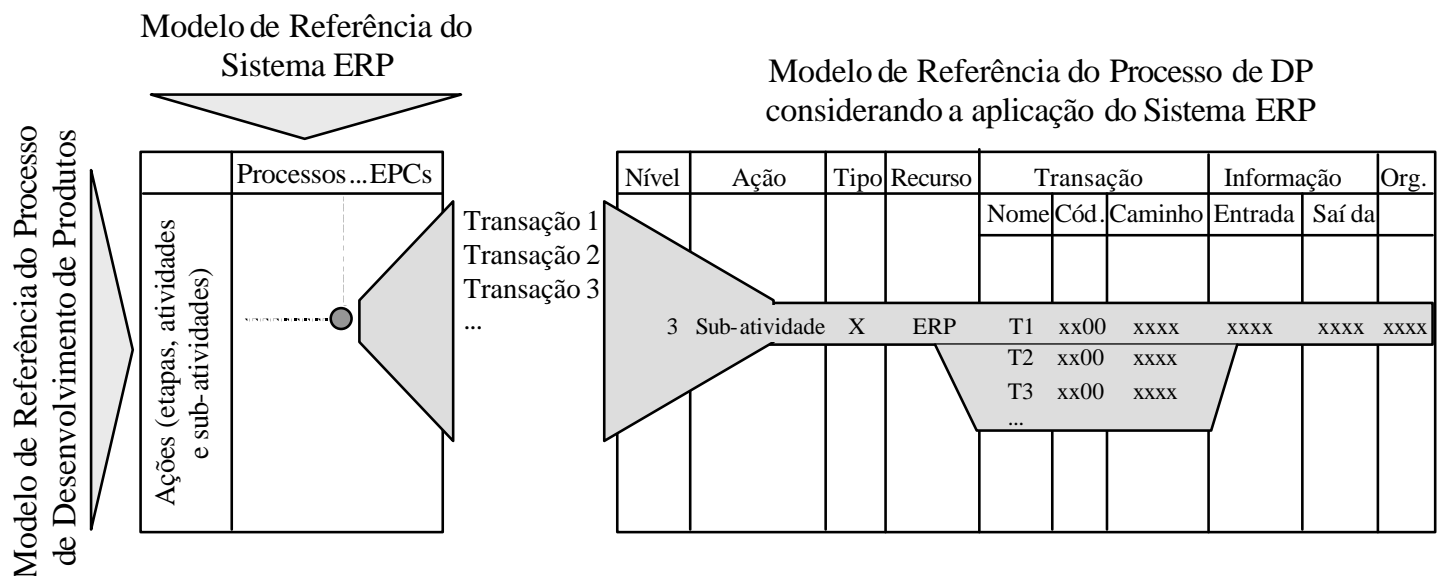

FIGURA 26 - Matriz de comparação de modelos e modelo de referência do processo de desenvolvimento de produtos considerando a aplicação do sistema ERP

A comparação dos modelos foi realizada relacionando-se as subatividades do modelo de referência do processo de desenvolvimento de produtos com os EPCs do modelo do sistema ERP.

Para cada relação existente entre uma subatividade do modelo de desenvolvimento de produtos e um EPC foi feita a seguinte pergunta: "A subatividade pode ser apoiada pelas soluções representadas no EPC?”. Em caso afirmativo, assinalou-se a intersecção entre a linha da subatividade e a coluna do EPC ( todas as relações da matriz. 
Em cada uma das relações assinaladas, foram identificadas as transações do sistema representadas pelo EPC, por meio da ligação existente entre os EPCs e as características do sistema (FIGURA 26).

Essas transações foram, em seguida, especificadas no modelo de referência do processo de desenvolvimento de produtos. Para cada subatividade apoiada por funcionalidades do ERP foram completados o recurso (sistema ERP), os nomes das transações identificadas e os códigos correspondentes a essas transações. Nos casos em que apenas o código não é suficiente para determinar a funcionalidade, foi especificado também o caminho para se localizar a transação no menu do sistema (IGURA 26).

$\mathrm{Na}$ comparação de modelos foram identificadas funcionalidades do sistema ERP para apoiar $43 \%$ das subatividades do processo de desenvolvimento de produtos.

Todas essas funcionalidades são listadas no modelo de referência do processo de desenvolvimento de produtos resultante do estudo exploratório. Nesse modelo, apresentado

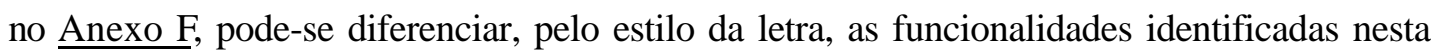
etapa do trabalho das funcionalidades localizadas nas etapas seguintes. As funcionalidades identificadas na comparação de modelos são listadas na coluna Transação - Nome com letra em estilo normal.

As principais dificuldades enfrentadas na comparação foram decorrentes das diferenças existentes entre o idioma, a terminologia e o nível de detalhamento adotados em cada um dos modelos.

A adoção de diferentes terminologias e idiomas como, por exemplo, o emprego do termo plano de processo, no modelo de desenvolvimento de produtos, com o mesmo significado de routing (roteiro), utilizado no modelo do sistema, dificultou o estabelecimento de relações entre os modelos.

Para superar esse obstáculo, KIRCHMER (1998) sugere que o relacionamento entre os modelos seja realizado com base em definições existentes, utilizadas como um padrão dos termos empregados nos modelos.

Observou-se, entretanto, que nenhum dos modelos define o significado dos termos utilizados em sua representação. Optou-se, então, por solucionar as dúvidas resultantes das diferenças existentes entre o idioma e a terminologia empregados nos modelos com o apoio de dicionários técnicos (SELL, 1953; FÜRSTENAU, 1978) à medida que ocorressem discrepâncias durante a comparação.

$\mathrm{O}$ estabelecimento de relações entre o modelo do processo e o modelo do sistema também foi dificultado pela definição de diferentes níveis de detalhamento em cada um dos modelos. 
Verificou-se que, na maioria das vezes, não seria possível estabelecer uma relação única entre as subatividades do modelo do processo e os EPCs do modelo do sistema. Em alguns casos, para apoiar uma subatividade do processo são necessárias transações representadas por mais de um EPC do sistema. Em outros casos, um único EPC pode representar as transações que apóiam totalmente mais de uma subatividade do processo.

Para superar esse problema permitiu-se, seguindo as recomendações de KIRCHMER (1998), que um ou mais elementos do modelo do processo fossem relacionados com um ou mais elementos do modelo do sistema.

Apesar dos bons resultados obtidos nesta etapa, deve-se ressaltar que a comparação de modelos tem algumas limitações na identificação das funcionalidades do ERP que podem ser utilizadas para apoiar o processo de desenvolvimento de produtos.

O modelo de referência do sistema ERP não representa todas as funcionalidades disponíveis no sistema. Além disso, o resultado da comparação é influenciado pelo conhecimento e pela experiência do pesquisador.

Assim, é necessário localizar as funcionalidades de desenvolvimento de produtos do ERP que não estão representadas em seu modelo de referência e validar os resultados obtidos na comparação.

\subsection{Busca de Funcionalidades Adicionais do Sistema ERP}

Devido às limitações observadas na etapa anterior, a pesquisa de funcionalidades do ERP que podem ser utilizadas no desenvolvimento de produtos foi complementada com a observação direta no sistema e com uma entrevista com um especialista.

A observação direta no sistema foi realizada no Laboratório de Sistematização e Integração da Manufatura do NUMA, em um ambiente de testes do ERP disponível para ser utilizado pelo pesquisador.

A partir do modelo de referência do processo de desenvolvimento de produtos, buscou-se, manipulando o ambiente de testes do ERP, identificar funcionalidades do sistema que podem ser utilizadas para apoiar cada uma das subatividades do processo.

Essa busca, realizada individualmente para cada subatividade do processo de desenvolvimento, foi concentrada nos módulos do sistema com maior probabilidade de conter as funcionalidades procuradas.

Assim, por exemplo, a busca de funcionalidades que apóiam a subatividade Cotar Fornecedores concentrou-se no módulo de gerenciamento de materiais, enquanto que a procura por funcionalidades que apóiam a subatividade Definir Planos de Inspeção centrouse no módulo de controle de qualidade do sistema ERP. 
Na observação direta foram localizadas 13 funcionalidades de desenvolvimento de produtos do sistema ERP que não haviam sido identificadas na etapa anterior de comparação dos modelos de referência.

Essas funcionalidades também são listadas no modelo de referência do processo de desenvolvimento de produtos considerando a aplicação do sistema ERP, apresentado no Anexo F. Tais funcionalidades são diferenciadas, pela grafia em estilo itálico, na coluna Transação - Nome do modelo.

Deve-se ressaltar, entretanto, que, apesar da observação direta no sistema ter sido realizada de forma sistemática e estruturada, os resultados obtidos também dependem dos conhecimentos do pesquisador sobre o processo de desenvolvimento de produtos bem como de sua experiência no sistema ERP.

Devido a essa restrição, intrínseca à técnica de coleta de dados utilizada, realizou-se uma entrevista focalizada com um especialista no sistema ERP a fim de serem identificadas funcionalidades do ERP que eventualmente ainda não tinham sido localizadas, e, adicionalmente, para validar os resultados obtidos até essa etapa do trabalho.

A realização da entrevista focalizada envolveu a elaboração prévia de um roteiro de entrevistas, a definição de critérios para a seleção do especialista a ser entrevistado, a escolha do especialista, a realização da entrevista e a sistematização dos resultados obtidos no modelo de referência do processo de desenvolvimento.

O roteiro de entrevistas foi elaborado a partir do modelo de referência do processo de desenvolvimento de produtos, considerando-se os fundamentos metodológicos sobre preparação de roteiros de entrevistas discutidos no item 1.4.2 Escolha do Método de Pesquisa e das Técnicas de Coleta de Dados deste texto.

Tal roteiro consiste basicamente de duas questões, formuladas repetidamente para cada uma das subatividades do modelo de referência do processo de desenvolvimento de produtos. A primeira questão verifica a adequação das funcionalidades do ERP atribuídas às subatividades do processo de desenvolvimento, e a segunda questão indaga sobre a existência de funcionalidades adicionais que ainda não foram identificadas. $\mathrm{O}$ roteiro também contém dois itens introdutórios para a explicação do trabalho e dos objetivos da entrevista e para a apresentação do entrevistado. Esse roteiro de entrevista é apresentado no Anexo A.

Paralelamente à elaboração do roteiro, foram definidos critérios para a seleção do especialista a ser entrevistado. Definiu-se previamente que o especialista deveria ser um consultor no sistema ERP com bons conhecimentos sobre desenvolvimento de produtos. 
Segundo OLIVEIRA (1999), a opção por entrevistar consultores é indicada, pois essas pessoas acumulam a experiência de trabalho em diversas empresas, e se propõem fornecer aos seus clientes as melhores práticas de negócios. O conhecimento sobre o desenvolvimento de produtos, por sua vez, é essencial por se tratar do tema desta pesquisa.

Com base nos critérios previamente estabelecidos, o Especialista $A$ foi escolhido para ser entrevistado nesta etapa do trabalho. O Especialista $A$ é formado e pós-graduado em engenharia mecânica. Foi pesquisador na área de desenvolvimento de produtos, com diversos artigos publicados. Atualmente é consultor no sistema ERP, especializado no módulo de gerenciamento de projetos.

A entrevista foi realizada formulando-se as duas questões do roteiro para cada uma das subatividades do modelo de referência do processo de desenvolvimento de produtos, resultando a identificação de 7 novas funcionalidades de desenvolvimento de produtos do sistema ERP e a validação das funcionalidades que já haviam localizadas, com exceção de 3 funcionalidades, que foram reposicionadas no modelo, e de 6 funcionalidades, que foram descartadas por terem sido empregadas de forma inadequada.

Além disso, durante a entrevista o Especialista A observou que, apesar de certas funcionalidades do ERP terem sido corretamente atribuídas a algumas das subatividades do processo de desenvolvimento, a sua utilização, na prática, pode não ser efetiva.

Trata-se, por exemplo, da utilização do fluxo de trabalho do sistema ERP para apoiar as atividades de distribuição de documentos. No caso de atividades estruturadas que se repetem, como os ciclos de aprovação de documentos, pode ser vantajoso estabelecer fluxos de trabalho padronizados e utilizar essa funcionalidade no sistema ERP. Por outro lado, no caso de atividades ad hoc, como simples envios de documentos, é geralmente mais prático utilizar sistemas complementares de trabalho em grupo, preferencialmente integrados ao sistema ERP.

As funcionalidades de desenvolvimento de produtos do ERP identificadas na entrevista focalizadas foram, em seguida, incluídas no modelo de referência do processo de

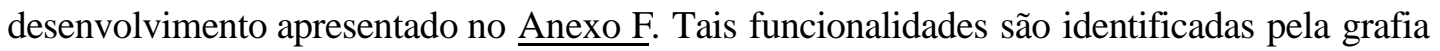
em estilo sublinhado, na coluna Transação-Nome do modelo.

Por fim, todas as funcionalidades de desenvolvimento de produtos do sistema ERP,

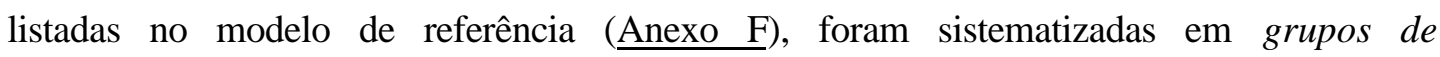
funcionalidades. Essa sistematização foi realizada para possibilitar a análise conjunta de funcionalidades relacionadas com atividades afins, nas fases e etapas seguintes do trabalho.

Os grupos de funcionalidades foram definidos a partir do modelo de referência, agrupando-se as funcionalidades que apóiam atividades correlatas. Assim, foram definidos 
21 grupos de funcionalidades, como, por exemplo, um grupo de funcionalidades de Gerenciamento de Documentos e um grupo de funcionalidades de Estimativa do Custo de Produtos (FIGURA 27).

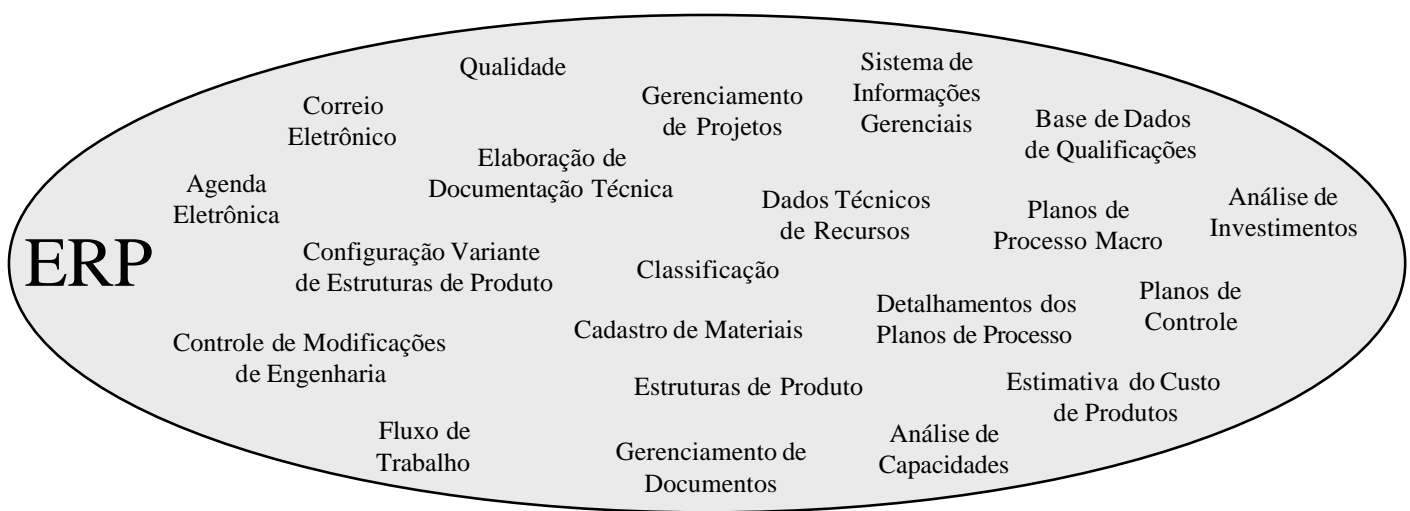

FIGURA 27 - Grupos de Funcionalidades de Desenvolvimento de Produtos do Sistema ERP

A lista completa das funcionalidades do sistema ERP alocadas a cada grupo de funcionalidades é apresentada no $\underline{\text { Anexo } \mathrm{H}}$ deste texto.

\subsection{Análise das Funcionalidades do Sistema ERP}

Após serem identificadas nas etapas anteriores, as funcionalidades de desenvolvimento de produtos do sistema ERP foram individualmente analisadas. Nessa análise procurou-se verificar se as funcionalidades identificadas satisfazem os requisitos específicos do processo de desenvolvimento de produtos.

O primeiro passo realizado nesta etapa foi a definição das características fundamentais de cada uma das funcionalidades do ERP atribuídas ao processo de desenvolvimento de produtos.

Procurou-se, inicialmente, definir essas características por meio de uma análise da documentação dos módulos do sistema ERP que contêm a maioria das funcionalidades de desenvolvimento de produtos (módulos PP e PS e funções de PDM). A relação dos documentos analisados, de acordo com o módulo do sistema e com o tipo de documento (livros de referência, relatórios, apostilas de cursos, material de divulgação, apresentações, ajuda do sistema), é apresentada TABELA 5. 
TABELA 5 - Documentos do sistema ERP considerados na análise das funcionalidades de desenvolvimento de produtos

\begin{tabular}{|c|c|c|c|}
\hline $\begin{array}{l}\text { MÓDULOS } \\
\text { / FUNÇÕES }\end{array}$ & $\begin{array}{c}\text { TIPO DE } \\
\text { DOCUMENTO }\end{array}$ & DESCRIÇÃO & $\begin{array}{c}\text { REFERÊNCIA } \\
\text { BIBLIOGRÁFICA }\end{array}$ \\
\hline \multirow[t]{3}{*}{$\mathrm{PP}$} & Apostila de curso & $\begin{array}{l}\text { Material do curso SAP PP } \\
\text { Partner Academy. }\end{array}$ & SAP (1998c) \\
\hline & Material de divulgação & $\begin{array}{l}\text { Apostila sobre manufatura } \\
\text { integrada. }\end{array}$ & SAP (1996) \\
\hline & Ajuda do sistema (help) & $\begin{array}{l}\text { CD de documentação do } \\
\text { sistema. }\end{array}$ & SAP (1998a) \\
\hline \multirow[t]{3}{*}{ PS } & Livro de referência & $\begin{array}{l}\text { Livro sobre gerenciamento de } \\
\text { projetos com o SAP R/3. }\end{array}$ & DRÄGER (1998) \\
\hline & Apostila de curso & $\begin{array}{l}\text { Material do curso Síntese de } \\
\text { Administração de Projetos. }\end{array}$ & SAP (1998b) \\
\hline & Ajuda do sistema (help) & $\begin{array}{l}\text { CD de documentação do } \\
\text { sistema. }\end{array}$ & SAP (1998a) \\
\hline \multirow[t]{7}{*}{ PDM } & Relatórios & $\begin{array}{l}\text { Relatório sobre o programa de } \\
\text { PDM da SAP, preparado pelo } \\
\text { CIMdata }^{25} \text {. }\end{array}$ & $\begin{array}{l}\text { MILLER \& } \\
\text { MENDEL (1997) }\end{array}$ \\
\hline & Apostilas de cursos & Material do curso Classificação. & $\operatorname{SAP}(1998 d)$ \\
\hline & \multirow[t]{2}{*}{ Material de divulgação } & $\begin{array}{l}\text { Apostila sobre o conjunto de } \\
\text { funcionalidades de PDM. }\end{array}$ & SAP (1997) \\
\hline & & $\begin{array}{l}\text { Folder sobre o sistema de } \\
\text { gerenciamento de documentos. }\end{array}$ & SAP (2000c) \\
\hline & \multirow[t]{2}{*}{ Apresentações } & $\begin{array}{l}\text { Apresentação sobre as } \\
\text { funcionalidades de PDM em } \\
\text { ambientes distribuídos. }\end{array}$ & DOLESCHEL (1999) \\
\hline & & $\begin{array}{l}\text { Apresentação detalhando as } \\
\text { tendências de evolução do } \\
\text { conjunto de funções de PDM. }\end{array}$ & SCHMIDT (1999) \\
\hline & Ajuda do sistema (help) & $\begin{array}{l}\text { CD de documentação do } \\
\text { sistema. }\end{array}$ & SAP (1998a) \\
\hline
\end{tabular}

Nos casos em que não foi possível determinar as características das funcionalidades do ERP pela documentação consultada, realizou-se uma observação direta das funcionalidades utilizando-se o ambiente de testes do ERP disponível no Laboratório de Sistematização e Integração da Manufatura do NUMA.

$\mathrm{Na}$ observação direta também foram examinadas as tabelas de configuração do sistema ERP para que fossem consideradas todas as possibilidades de parametrização das funcionalidades analisadas. As tabelas de configuração são acessadas no próprio ambiente do ERP (caminho: Tools $\rightarrow$ Business Engineer $\rightarrow$ Customizing).

Assim, verificou-se, por exemplo, que o "cofre de dados" (vault) do gerenciador de documentos do sistema ERP pode ser configurado de três formas distintas, de acordo com os

${ }^{25}$ O CIMdata é uma empresa de consultoria em sistemas PDM (www.cimdata.com). 
requisitos do desenvolvimento de produtos. O vault pode ser um diretório qualquer da rede, uma área protegida para a qual os arquivos gerenciados são transferidos via FTP (File Transfer Protocol) ou ainda um arquivo em mídia com grande capacidade de armazenamento.

As características fundamentais de cada uma das funcionalidades do ERP foram, em seguida, confrontadas com os requisitos do processo de desenvolvimento de produtos, definidos no modelos de referência.

Deve-se observar, entretanto, que o nível de detalhamento utilizado na representação do modelo de referência do processo de desenvolvimento de produtos não estabelece requisitos muito específicos do processo. No modelo não estão representados, por exemplo, os campos utilizados para descrever um material, os parâmetros empregados na localização de documentos e os tipos de status utilizados para controlar os objetos do processo (estruturas de produto, desenhos, entre outros).

Assim, nesta etapa foi analisada somente a adequação das funcionalidades de desenvolvimento de produtos do sistema ERP às subatividades do processo de desenvolvimento, nível mais detalhado do modelo de referência. Não foi possível, contudo, realizar a análise considerando requisitos mais específicos do processo.

Devido ao nível de detalhamento empregado (subatividades), semelhante ao utilizado nas etapas anteriores, todas as funcionalidades analisadas atenderam aos requisitos do processo de desenvolvimento.

O resultado desta etapa demonstra as limitações do emprego de modelos de referência pouco detalhados na determinação de lacunas específicas não atendidas pelo sistema ERP. O estabelecimento de requisitos bem detalhados é essencial para a definição de lacunas muito específicas do sistema ERP.

\subsection{Seleção dos Sistemas Complementares de Desenvolvimento de Produtos}

Paralelamente à análise das funcionalidades do ERP foram selecionados outros sistemas que podem ser utilizados de forma complementar ao ERP para apoiar o processo de desenvolvimento de produtos.

Esta etapa foi iniciada com a determinação das classes genéricas de sistemas complementares consideradas neste trabalho. Optou-se por empregar a mesma definição de classes de sistemas complementares utilizada na versão original do modelo de referência do processo de desenvolvimento de produtos. Essas classes são listadas na primeira coluna da TABELA 6. 
TABELA 6 - Sistemas complementares de desenvolvimento de produtos

\begin{tabular}{|c|c|c|}
\hline $\begin{array}{l}\text { CLASSE DE } \\
\text { SISTEMA }\end{array}$ & $\begin{array}{c}\text { SISTEMA } \\
\text { ESCOLHIDO / } \\
\text { FORNECEDOR }\end{array}$ & JUSTIFIATIVA/FONTE \\
\hline PDM & Metaphase 2.2 / SDRC & $\begin{array}{l}\text { Líder do segmento high end do mercado de } \\
\text { sistemas PDM com } 17 \% \text { de participação } \\
\text { (CIMDATA, 2000). }\end{array}$ \\
\hline CAD & $\begin{array}{l}\text { Mechanical Desktop } 3 \text { / } \\
\text { Autodesk }\end{array}$ & $\begin{array}{l}\text { A Autodesk é a principal fornecedora de sistemas } \\
\text { CAD para as empresas do setor automotivo no Brasil } \\
\text { (SCHÜTZER \& SOUZA, 1999). O Mechanical } \\
\text { Desktop é o mais novo produto da Autodesk voltado } \\
\text { para o projeto de conjuntos mecânicos. } \\
\text { Disponível para ser avaliado pelo pesquisador. }\end{array}$ \\
\hline CAE & $\begin{array}{l}\text { Ansys LS-DYNA / } \\
\text { LSTC }\end{array}$ & Disponível para ser avaliado pelo pesquisador. \\
\hline CAPP & CAPPE 5.4.06 / KSR & $\begin{array}{l}\text { Líder do mercado de sistemas CAPP no Brasil } \\
\text { (RIBEIRO, 2000). } \\
\text { Disponível para ser avaliado pelo pesquisador. }\end{array}$ \\
\hline CAM & SmartCAM 11 / SDRC & Disponível para ser avaliado pelo pesquisador. \\
\hline $\begin{array}{l}\text { Gerenciador de } \\
\text { Projetos }\end{array}$ & $\begin{array}{l}\text { MS Project 98 / } \\
\text { Microsoft }\end{array}$ & $\begin{array}{l}\text { O gerenciador de projetos da Microsoft está se } \\
\text { tornando um padrão para a indústria. } \\
\text { Disponível para ser avaliado pelo pesquisador. }\end{array}$ \\
\hline $\begin{array}{l}\text { Planilha } \\
\text { Eletrônica }\end{array}$ & $\begin{array}{l}\text { MS Excel } 97 \text { / } \\
\text { Microsoft }\end{array}$ & \multirow{3}{*}{$\begin{array}{l}\text { Os aplicativos de escritório da Microsoft estão se } \\
\text { tornando um padrão para a indústria. } \\
\text { Disponíveis para serem avaliados pelo } \\
\text { pesquisador. }\end{array}$} \\
\hline Editor de Textos & $\begin{array}{l}\text { MS Word 97 / } \\
\text { Microsoft }\end{array}$ & \\
\hline $\begin{array}{l}\text { Sistema de } \\
\text { Apresentação }\end{array}$ & $\begin{array}{l}\text { MS PowerPoint } 97 \text { / } \\
\text { Microsoft }\end{array}$ & \\
\hline $\begin{array}{l}\text { Agenda } \\
\text { Eletrônica }\end{array}$ & $\begin{array}{l}\text { MS Outlook } 97 \text { / } \\
\text { Microsoft }\end{array}$ & \multirow{2}{*}{$\begin{array}{l}\text { Os aplicativos de trabalho em grupo da Microsoft } \\
\text { são muito utilizados em toda a indústria. } \\
\text { Disponíveis para serem avaliados pelo } \\
\text { pesquisador. }\end{array}$} \\
\hline $\begin{array}{l}\text { Correio } \\
\text { Eletrônico } \\
\end{array}$ & $\begin{array}{l}\text { MS Outlook } 97 \text { / } \\
\text { Microsoft }\end{array}$ & \\
\hline Visualizador & AMView 3 / Cyco & \multirow{5}{*}{$\begin{array}{l}\text { Os sistemas de visualização, QFD, DFMA, } \\
\text { FMEA e PAPP são extremamente especializados. } \\
\text { Nesses mercados existem poucos concorrentes e a } \\
\text { participação de cada um deles raramente é } \\
\text { pesquisada e divulgada. } \\
\text { Disponíveis para serem avaliados pelo } \\
\text { pesquisador, com exceção do sistema APQP. }\end{array}$} \\
\hline QFD & $\begin{array}{l}\text { QFD Designer / } \\
\text { Qualisoft }\end{array}$ & \\
\hline DFMA & $\begin{array}{l}\text { DFA 8.0 e DFM 2.2.1/ } \\
\text { Boothroyd Dewhurst } \\
\text { Inc. }\end{array}$ & \\
\hline FMEA & KFMEA $1.1 .1 /$ KSR & \\
\hline PAPP & APQP / KSR & \\
\hline
\end{tabular}

Para cada uma das classes de sistemas complementares foi selecionado um sistema específico, disponível comercialmente. Procurou-se selecionar, preferencialmente, sistemas que estivessem disponíveis para serem avaliados pelo pesquisador no Laboratório de Sistematização e Integração da Manufatura do NUMA. Ao mesmo tempo, procurou-se

${ }^{26}$ RIBEIRO, C. (2000). Sistema APQP. /Palestra realizada no evento de lançamento do sistema APQP - São Paulo (31 Mar.)/ 
escolher sistemas líderes de mercado ou sistemas com participação significativa em seus respectivos segmentos.

Deve-se notar, entretanto, que, devido às características particulares de cada segmento do mercado de softwares, nem sempre foi possível fundamentar a escolha com análises mercadológicas. Em alguns segmentos, extremamente especializados, existem poucos concorrentes, e não são divulgados dados detalhados sobre a participação de cada um deles. Trata-se, por exemplo, dos sistemas que apóiam a aplicação dos métodos de QFD e de DFMA. Outros segmentos, como o de aplicativos de escritório, são extremamente concentrados e dominados por apenas um produto, que passa a ser considerado como um padrão de fato para toda a indústria.

Os sistemas selecionados e as justificativas utilizadas para fundamentar cada escolha são apresentadas, respectivamente, na segunda e na terceira coluna da TABELA 6.

\subsection{Estudo dos Sistemas Complementares de Desenvolvimento de Produtos}

Uma vez selecionados os sistemas complementares considerados neste trabalho, realizou-se um estudo para identificar quais desses sistemas podem ser utilizados para apoiar cada uma das subatividades do processo de desenvolvimento de produtos.

A especificação dos sistemas complementares para as subatividades do processo de desenvolvimento poderia ter sido iniciada com a comparação entre o modelo de referência do processo de desenvolvimento de produtos e os modelos de referência que descrevem as soluções disponíveis nos diversos sistemas complementares. Para isso seria empregado o método de comparação de modelos de KIRCHMER (1998), da mesma forma que na comparação realizada em uma etapa anterior, entre o modelo do processo de desenvolvimento e o modelo do sistema ERP. Entretanto, nenhum dos sistemas complementares selecionados representa as suas soluções em modelos de referência.

Realizou-se, então, uma ampla análise da documentação dos sistemas complementares (manuais, apostilas de cursos, material de divulgação, sites da Internet, entre outros). Nessa análise procurou-se identificar, na documentação dos sistemas complementares, as soluções que podem ser utilizadas para apoiar cada uma das subatividades do processo de desenvolvimento.

As soluções identificadas para cada subatividade do processo foram, em seguida, checadas por meio da observação direta nos diversos sistemas complementares. Para isso foram realizados testes e simulações, empregando-se os sistemas complementares de 
desenvolvimento de produtos disponíveis no Laboratório de Sistematização e Integração da Manufatura do NUMA.

Após serem verificados na observação direta, os sistemas complementares identificados para cada uma das subatividades do processo de desenvolvimento de produtos foram especificados no modelos de referência do processo de desenvolvimento considerando a aplicação do sistema ERP, apresentado no Anexo F.

Dessa forma, foram definidos recursos computacionais para as subatividades não apoiadas pelo sistema ERP e determinadas as sobreposições de funcionalidades entre o ERP e os sistemas complementares. As principais sobreposições de funcionalidade identificadas nesta etapa do trabalho são apresentadas na FIGURA 28.

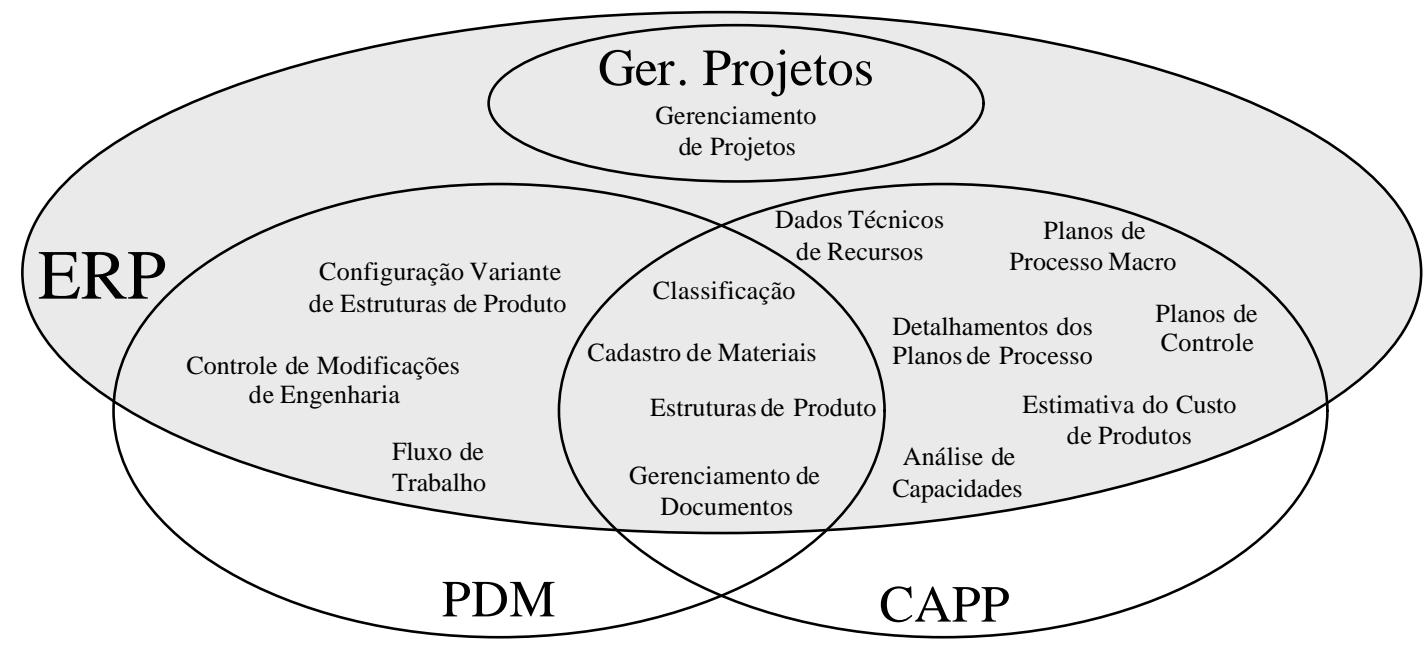

FIGURA 28 - Principais sobreposições de funcionalidades entre o sistema ERP e os sistemas complementares de desenvolvimento de produtos

No modelo de referência apresentado no Anexo F, as sobreposições de funcionalidades entre o sistema ERP e os sistemas complementares são indicadas na coluna Recurso por retângulos de fundo cinza envolvendo os sistemas que se sobrepõem em cada subatividade.

\subsection{Validação das Sobreposições}

As principais sobreposições de funcionalidades entre o sistema ERP e os sistemas complementares de desenvolvimento de produtos, definidas na etapa anterior, foram validadas por entrevistas focalizadas com especialistas.

Optou-se por restringir a validação realizada nesta etapa às sobreposições existentes entre o sistema ERP e os sistemas PDM e CAPP. A delimitação de tais sobreposições é 
extremamente complexa devido à abrangência desses sistemas e às diferenças existentes entre os conceitos e a nomenclatura empregados.

A sobreposição de funcionalidades entre o sistema ERP e o sistema gerenciador de projetos, por sua vez, é bem definida. O sistema ERP possui um módulo específico para o gerenciamento de projetos, e tanto as funcionalidades quanto os conceitos, termos e definições utilizados por ambos os sistemas são bastante semelhantes.

Realizou-se duas entrevistas de validação: a primeira abordou a sobreposição entre o ERP e o sistema PDM; a segunda tratou da sobreposição entre o ERP e o sistema CAPP.

Assim como em uma etapa anterior, a realização das entrevistas também envolveu a elaboração prévia de roteiros, a especificação de critérios para a escolha dos especialistas a serem entrevistados, a escolha dos especialistas, a realização das entrevistas e, por fim, a sistematização dos resultados obtidos.

Os roteiros de entrevista foram preparados observando-se os fundamentos metodológicos sobre a elaboração de roteiros de entrevistas, discutidos no item 1.4.2 Escolha do Método de Pesquisa e das Técnicas de Coleta de Dados deste texto. Na preparação de ambos os roteiros foi seguido um padrão único, ou seja, os dois roteiros de entrevistas contêm o mesmo conjunto de questões.

A primeira pergunta do roteiro, aplicada a todas as principais sobreposições de funcionalidades definidas no modelo de referência, busca validar as sobreposições observadas e, além disso, discutir alguns aspectos qualitativos relacionados com as funcionalidades de cada um dos sistemas sobrepostos (semelhanças/diferenças). A segunda pergunta indaga sobre a existência de alguma sobreposição de funcionalidade adicional que ainda não havia sido observada. Finalmente, a terceira pergunta questiona as principais funcionalidades exclusivas dos sistemas complementares, de forma a delimitar a sobreposição. Os roteiros também contêm dois itens introdutórios para a explicação do trabalho e dos objetivos das entrevistas e para a apresentação dos entrevistados.

$\mathrm{O}$ roteiro de entrevistas sobre a sobreposição entre os sistemas ERP e PDM é

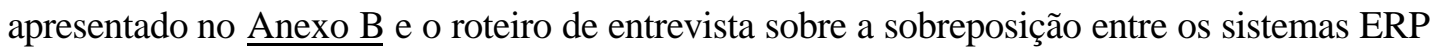
e CAPP é apresentado no Anexo C deste texto.

Simultaneamente à preparação dos roteiros, foram estabelecidos os critérios para a seleção dos especialistas a serem entrevistados. Definiu-se que os especialistas deveriam ser consultores nos sistemas complementares (PDM e CAPP) e possuir bons conhecimentos das funcionalidades semelhantes no sistema ERP.

A partir desses critérios, para a entrevista de validação das sobreposições entre o ERP e o PDM foi selecionado o Especialista B. O Especialista $B$ é engenheiro mecânico, 
com mestrado na área de sistemas PDM. Atualmente é consultor e participa de um projeto de implantação de um sistema PDM em uma empresa do setor automobilístico.

Considerando os mesmos critérios, para a entrevista de validação das sobreposições entre o ERP e o CAPP foi selecionado o Especialista $C$. O Especialista $C$ também é engenheiro mecânico, com mestrado na área de sistemas CAPP. É diretor comercial de uma empresa fornecedora de sistemas CAPP, tendo participado de inúmeros projetos de implantação de sistemas CAPP nos últimos anos.

$\mathrm{Na}$ entrevista sobre as sobreposições de funcionalidades entre o sistema ERP e o sistema PDM todas as sobreposições definidas no modelo de referência foram validadas e não foram identificadas sobreposições adicionais.

As funcionalidades do ERP e do PDM que se sobrepõem, apesar de serem utilizadas para apoiar as mesmas subatividades e de possuírem inúmeras características comuns, possuem algumas diferenças e particularidades específicas, destacadas pelo Especialista $B$.

De acordo com o Especialista $B$, ambos os sistemas permitem a manutenção de múltiplas visões da estrutura de produto, mas o sistema PDM é mais flexível para a definição de visões que atendem às necessidades da engenharia, como, por exemplo, visões da estrutura de produto por grupos funcionais ou visões por localização física no produto.

Da mesma forma, o controle de efetividade das estruturas de produto é apoiado tanto pelo ERP quanto pelo PDM, mas o PDM permite a utilização de parâmetros de controle mais flexíveis, muito úteis durante o processo de desenvolvimento.

O gerenciamento de documentos é bem desenvolvido em ambos os sistemas. Foi destacada, no entanto, a maior facilidade de integração dos sistemas CAD tridimensionais com o sistema PDM. A partir da definição de um subconjunto na estrutura de produto do PDM é possível, por exemplo, acessar o CAD para visualizar a montagem de todos os componentes desse subconjunto.

Com relação à configuração variante de estruturas de produto, o Especialista $B$ observou que a definição das regras e dos objetos de configuração muda de um sistema para outro, resultando grande dificuldade de integração caso um sistema seja utilizado para apoiar o processo de desenvolvimento e outro seja empregado para apoiar a produção.

Além disso, o Especialista $B$ ainda destacou as vantagens da interface gráfica do sistema PDM, principalmente com relação à navegação na estrutura de produto, que facilita a manutenção de documentos e o acesso a objetos do produto.

De forma geral, pode-se concluir da entrevista que o sistema ERP e o sistema PDM efetivamente apresentam grande sobreposição de funcionalidades. O ERP possui a maior 
parte das funcionalidades do sistema PDM. Entretanto, o PDM ainda tem características exclusivas que atendem a requisitos específicos do processo de desenvolvimento.

$\mathrm{Na}$ entrevista seguinte, que tratou das sobreposições de funcionalidades entre o sistema ERP e o sistema CAPP, também foram validadas todas as sobreposições definidas no modelo de referência. Além disso, foi identificada uma sobreposição adicional que não havia sido observada, referente às funcionalidades de gerenciamento dos documentos de detalhamento dos planos de processo.

Da mesma forma que na entrevista anterior, o Especialista $C$ também destacou algumas diferenças específicas existentes entre as funcionalidades comuns ao ERP e ao sistema CAPP.

Segundo o Especialista $C$, os dois sistemas apóiam o planejamento de processo de fabricação, mas o sistema CAPP tem recursos adicionais que facilitam a criação de novos planos de processo. No caso de famílias de componentes, por exemplo, o sistema CAPP pode criar planos de processo para todos os componentes da família a partir de um plano básico, de um conjunto de regras e de uma tabela com os dados de todos os componentes da família.

O detalhamento dos planos de processo também é apoiado por ambos os sistemas, mas o sistema CAPP tem funcionalidades e recursos adicionais que facilitam a transferência dos dados das operações de setup e das suboperações para os sistemas CAD, automatizando a geração de folhas de instrução. A partir dos parâmetros dos componentes e das operações é possível também automatizar o cálculo e o projeto do ferramental.

A classificação de componentes e a manutenção de dados técnicos de recursos (máquinas, ferramentas, dispositivos, entre outros) são apoiadas tanto pelo ERP quanto pelo CAPP. O Especialista $C$ destacou que a manutenção desses dados no ambiente do CAPP é necessária para a geração automática de planos de processo. Os dados técnicos dos equipamentos, tais como a potência das máquinas, são utilizados, por exemplo, na determinação dos tempos de fabricação com base em fórmulas pré definidas.

O Especialista $C$ destacou ainda inúmeras vantagens da interface gráfica do sistema CAPP que resultam em maior produtividade e eficiência no planejamento de processo, em comparação com o sistema ERP.

Assim como na entrevista anterior, pode-se concluir que os sistemas ERP e CAPP têm grande sobreposição de funcionalidades. Pode-se observar também que devido às suas características (interface, recursos, funcionalidades) o sistema CAPP é mais voltado para atender às necessidades específicas do desenvolvimento de produtos. O CAPP possui, por 
exemplo, recursos muito mais sofisticados de automatismo, que podem aumentar a produtividade e a eficiência da criação de planos de processo de fabricação.

\subsection{Definição dos Pontos de Integração}

A partir das lacunas do ERP e das sobreposições de funcionalidades, definidas nas etapas anteriores e especificadas no modelo de referência, foram identificados os principais pontos de integração entre o sistema ERP e os sistemas complementares de desenvolvimento de produtos.

As lacunas do ERP definem as subatividades nas quais informações precisam ser enviadas de um sistema para outro, para serem manipuladas. As sobreposições de funcionalidades, por sua vez, determinam as informações que podem ser utilizadas por mais de um sistema durante o desenvolvimento de produtos. Ou seja, tanto as lacunas do ERP quanto as sobreposições de funcionalidades especificam potenciais pontos de integração.

Para a identificação dos principais pontos de integração à partir das lacunas do ERP e das sobreposições de funcionalidades, realizou-se uma entrevista focalizada com um especialista em integração. Assim como em etapas anteriores, a realização dessa entrevista envolveu a elaboração prévia de um roteiro, a determinação de critérios para a escolha do especialista a ser entrevistado, a escolha do especialista, a realização da entrevista e, finalmente, a sistematização dos resultados obtidos.

$\mathrm{Na}$ elaboração do roteiro de entrevista utilizado nesta etapa também foram considerados os fundamentos metodológicos sobre a elaboração de roteiros de entrevistas, apresentados no item 1.4.2 Escolha do Método de Pesquisa e das Técnicas de Coleta de Dados deste texto.

O roteiro de entrevistas contém uma pergunta baseada no modelo de referência do processo de desenvolvimento de produtos utilizando o sistema ERP. A única questão do roteiro procura identificar, no modelo de referência, os principais pontos de integração entre o sistema ERP e os sistemas complementares de desenvolvimento de produtos, observandose as lacunas do ERP e as sobreposições de funcionalidades. O roteiro também contém dois itens introdutórios para a explicação do trabalho e dos objetivos da entrevista e para a apresentação do entrevistado. Esse roteiro de entrevistas é apresentado no Anexo D.

Simultaneamente à preparação do roteiro, definiu-se que o especialista a ser entrevistado deveria ter competência comprovada em integração de sistemas computacionais no processo de desenvolvimento de produtos e conhecimento do sistema ERP.

O Especialista D, selecionado com base nos critérios estabelecidos previamente, é professor universitário e pesquisador na área de desenvolvimento de produtos, com ênfase na 
aplicação da tecnologia da informação. O Especialista $D$ tem vários artigos publicados sobre integração de sistemas computacionais no processo de desenvolvimento de produtos e experiência prática em empresas na implantação e integração de sistemas ERP.

A entrevista com o Especialista $D$ resultou na identificação de 26 pontos de integração entre o ERP e os sistemas complementares. Cada um desses pontos de integração foi representado no modelo de referência pela introdução de um novo tipo de subatividade, denominada subatividade de integração. Além do tipo - integração - essas subatividades são identificadas pela grafia em estilo itálico, na coluna Ação do modelo de referência do processo de desenvolvimento de produtos apresentado no $\underline{\text { Anexo F}}$.

Os pontos de integração definidos nesta etapa do trabalho podem servir de base para a determinação das informações que devem ser enviadas do ERP para os sistemas complementares, e vice-versa, a fim de que esses sistemas sejam efetivamente integrados. Deve-se observar, entretanto, que tal definição depende da especificação do sistema que é o "dono" de cada uma das informações do modelo e dos sistemas que são utilizados para atualizar essas informações. Isso é necessário para definir o sentido do fluxo de informações de integração (sistema de origem e sistema destino).

\subsection{Modelo de Referência do Processo de Desenvolvimento de Produtos Considerando a Aplicação de um Sistema ERP}

Como resultado das etapas executadas no estudo exploratório da aplicabilidade do sistema ERP no processo de desenvolvimento de produtos obteve-se um modelo de referência desse processo considerando a utilização e integração do ERP.

Tal modelo de referência, apresentado no Anexo F, define as subatividades do processo de desenvolvimento que podem ser apoiadas por funcionalidade do sistema ERP e, conseqüentemente, determina as lacunas não apoiadas pelo ERP. Além disso, esse modelo identifica as sobreposições de funcionalidade entre o sistema ERP e os sistemas complementares de desenvolvimento de produtos. Mais ainda, no modelo são determinados os principais pontos de integração entre tais sistemas. 


\section{ESTUDO DESCRITIVO DA APLICAÇÃO DO SISTEMA ERP EM UM CENÁRIO DE DESENVOLVIMENTO DE PRODUTOS}

Este capítulo trata do estudo descritivo de uma aplicação piloto do sistema ERP em um ambiente de desenvolvimento de produtos denominado de Cenário de Desenvolvimento de Produtos Utilizando o Sistema ERP, ou simplesmente de Cenário .

$\mathrm{O}$ primeiro item do capítulo apresenta de forma breve as atividades realizadas na implantação do Cenário. O objetivo desse item é fundamentar a obtenção do Cenário como um instrumento de pesquisa, uma vez que a discussão da implantação do Cenário não constitui o foco principal do estudo descritivo.

O segundo item do Capítulo descreve e discute os resultados obtidos na observação direta de testes e de simulações da utilização do sistema ERP no Cenário de Desenvolvimento de Produtos.

\subsection{Implantação do Cenário de Desenvolvimento de Produtos Utilizando o Sistema ERP}

A implantação do Cenário de Desenvolvimento de Produtos Utilizando o Sistema ERP foi realizada de acordo com uma adaptação do método de montagem de Cenários proposto inicialmente por AGUIAR et al. (1997) e aperfeiçoado posteriormente por ROZENFELD et al. (1998), ZANCUL et al. (1998) e AMARAL et al. (1999).

O primeiro passo realizado nesta etapa do trabalho foi a definição de um ambiente de desenvolvimento de produtos para a montagem do Cenário. Determinou-se previamente que esse ambiente deveria possuir toda a infra-estrutura necessária para a instalação do Cenário (microcomputadores, servidores, rede, sistema ERP, sistemas complementares, etc.) e deveria ser flexível para permitir a realização de testes e simulações.

Com base nesses requisitos, optou-se por realizar a implantação do Cenário na Fábrica Integrada Modelo (FIM). A FIM é um laboratório do NUMA que simula uma empresa real que produz redutores de velocidade.

A infra-estrutura da FIM é composta por um escritório equipado com servidores e com microcomputadores ligados em rede, e por um chão-de-fábrica equipado com um robô e com máquinas CNC. Nos servidores e computadores da FIM já se encontravam instalados o 
sistema ERP considerado neste trabalho ( $\mathrm{SAP} \mathrm{R} / 3$ 4.0B), além de diversos sistemas complementares de desenvolvimento de produtos (CAD, CAPP, gerenciador de projetos, entre outros).

A estrutura organizacional da FIM é formada por personagens fictícios com cargos bem definidos. Por exemplo, a personagem Marta Marquete é a Diretora de Marketing. Assim como os funcionários de uma fábrica real, os personagens da FIM possuem senhas de acesso aos sistemas computacionais e contas de correio eletrônico.

Por não ser uma empresa real, a FIM permite a realização de testes e de simulações que não poderiam ser realizadas em uma empresa verdadeira devido ao risco de se prejudicar as suas operações.

Observa-se dessa maneira que a FIM satisfaz os requisitos pré-estabelecidos de infraestrutura e de flexibilidade, necessários para a instalação do Cenário de Desenvolvimento de Produtos Utilizando o Sistema ERP.

O passo seguinte realizado nesta etapa do trabalho foi a elaboração do modelo de referência do Cenário a partir do modelo de referência obtido como resultado do estudo exploratório anterior. Nesse sentido, foi criada uma instância do modelo de referência do processo de desenvolvimento de produtos considerando a utilização do sistema ERP, observando-se certas "condições de contorno" discutidas a seguir.

Para viabilizar a implantação do Cenário, optou-se por restringir a abrangência de seu modelo de referência a determinadas atividades das etapas de Conceituar Produto e de Projetar Produto. Procurou-se incluir no modelo do Cenário as atividades que possibilitassem a realização das simulações mais interessantes para o estudo descritivo e que resultassem em discussões relevantes para a pesquisa. Assim, foram incluídas no modelo de referência do Cenário as atividades nas quais existe grande sobreposição de funcionalidades entre o sistema ERP e os sistemas complementares de desenvolvimento de produtos, bem como as atividades nas quais ocorre integração entre tais sistemas.

Nas atividades em que ocorre sobreposição de funcionalidades, um sistema foi escolhido para ser especificado no modelo de referência e, conseqüentemente, para ser utilizado no Cenário. Buscou-se realizar escolhas que permitissem explorar ao máximo a aplicação do sistema ERP no desenvolvimento de produtos, e, ao mesmo tempo, avaliar a integração do ERP com os sistemas complementares. As escolhas realizadas também consideraram que o sistema ERP deveria ser a "espinha dorsal" dos sistemas de informação do Cenário. Dessa forma, definiu-se que as atividades de cadastramento de materiais, de geração de estruturas de produtos e de classificação são apoiadas pelo sistema ERP, assim como o gerenciamento de documentos e o gerenciamento de fluxos de trabalho. Por sua vez, 
o planejamento do processo de fabricação e de montagem é realizado no sistema CAPP, o recebimento e o envio de mensagens é realizado no sistema de correio eletrônico e o gerenciamento de projetos é apoiado tanto pelo ERP quanto por um gerenciador de projetos, dependendo do nível de detalhamento considerado.

Nas atividades nas quais ocorre integração entre sistemas, foram então especificadas as informações que devem ser enviadas do ERP para os sistemas complementares, e viceversa, para que esses sistemas fossem efetivamente integrados no Cenário.

O modelo de referência do Cenário, obtido a partir do modelo de referência do processo de desenvolvimento de produtos considerando a aplicação do sistema ERP, é apresentado no $\underline{\text { Anexo G. }}$

Após a obtenção do modelo de referência, foi definido um "contexto" de desenvolvimento de produtos para direcionar a realização dos testes e das simulações da aplicação do sistema ERP no Cenário. Segundo tal "contexto", o sistema ERP é utilizado para apoiar o desenvolvimento de uma nova família de redutores de velocidade na FIM.

Em seguida, o sistema ERP instalado na FIM foi configurado para ser utilizado conforme especificado no modelo de referência do Cenário. Entre as opções de configuração existentes definiu-se, por exemplo, que o "cofre de dados" (vault) do gerenciador de documentos seria utilizado como uma área protegida da rede para a qual os arquivos gerenciados são transferidos via FTP. A configuração do vault também envolveu a determinação dos tipos de arquivo (extensão, origem, etc.) que podem ser gerenciados.

O sistema ERP também foi integrado com os sistemas complementares de correio eletrônico, de gerenciamento de projetos, e com o sistema CAPP. Para integrar o ERP aos dois primeiros sistemas foram instalados os plug-ins de integração disponíveis no $\mathrm{CD}$ do aplicativo cliente do sistema ERP. Para integrar o ERP ao CAPP foi instalado um kit de integração desenvolvido pelo fornecedor do sistema CAPP e homologado pelo fornecedor do sistema ERP. O funcionamento desse kit é baseado na utilização de APIs do sistema ERP.

Foram então definidos os padrões de trabalho, tais como os procedimentos de controle de modificações de engenharia, as redes de atividades padronizadas e a infraestrutura de classificação (classes e características). A criação desses padrões foi realizada de acordo com a etapa Preparar Estruturas para o Desenvolvimento de Produtos, do modelo de referência do processo de desenvolvimento de produtos considerando a aplicação do ERP.

Finalmente, utilizando-se os sistemas configurados e integrados, foram geradas as informações do Cenário representadas no modelo de referência, tais como cronogramas de desenvolvimento, estruturas de produto, desenhos, planos de processo, relatórios, entre 
outras. Todas essas informações foram geradas considerando-se o "contexto" especificado para o Cenário.

\subsection{Análise da Aplicação do Sistema ERP no Cenário de Desenvolvimento de Produtos}

Após a implantação do Cenário, foram realizados testes e simulações da utilização do sistema ERP no processo de desenvolvimento de produtos definido pelo modelo de referência e pelo "contexto".

Para a coleta de dados nesta etapa do trabalho foi empregada a técnica de observação direta. As soluções e as limitações da aplicação prática do sistema ERP no desenvolvimento de produtos, observadas no Cenário, são apresentadas a seguir. A descrição e a discussão dos resultados obtidos é organizada em seções que correspondem aos grupos de funcionalidades de desenvolvimento de produtos do ERP implantados no Cenário.

\section{Gerenciamento de Projetos}

No Cenário, o desenvolvimento de produtos é planejado e controlado com o apoio do sistema ERP e do sistema complementar de gerenciamento de projetos, dependendo do nível de detalhamento considerado.

Inicialmente, os projetos de desenvolvimento são planejados no sistema ERP. Cada projeto é estruturado em uma WBS que é detalhada em redes de atividades. A WBS e as redes de atividades são geradas a partir de estruturas padronizadas pré-existentes (templates). Nas redes de atividades são incluídas tanto as atividades executadas internamente quanto as atividades realizadas externamente por terceiros.

O planejamento dos projetos no ERP também envolve a alocação dos recursos necessários às atividades correspondentes. De acordo com as necessidades de recursos e com os dados de capacidade disponível é realizada a análise e o nivelamento da utilização dos recursos. As atividades de desenvolvimento são programadas considerando-se as datas especificadas na WBS, as regras de precedência definidas pelas redes de atividades e a duração estimada de cada atividade. A programação das atividades é visualizada por meio de um gráfico de Gantt (FIGURA 29). 


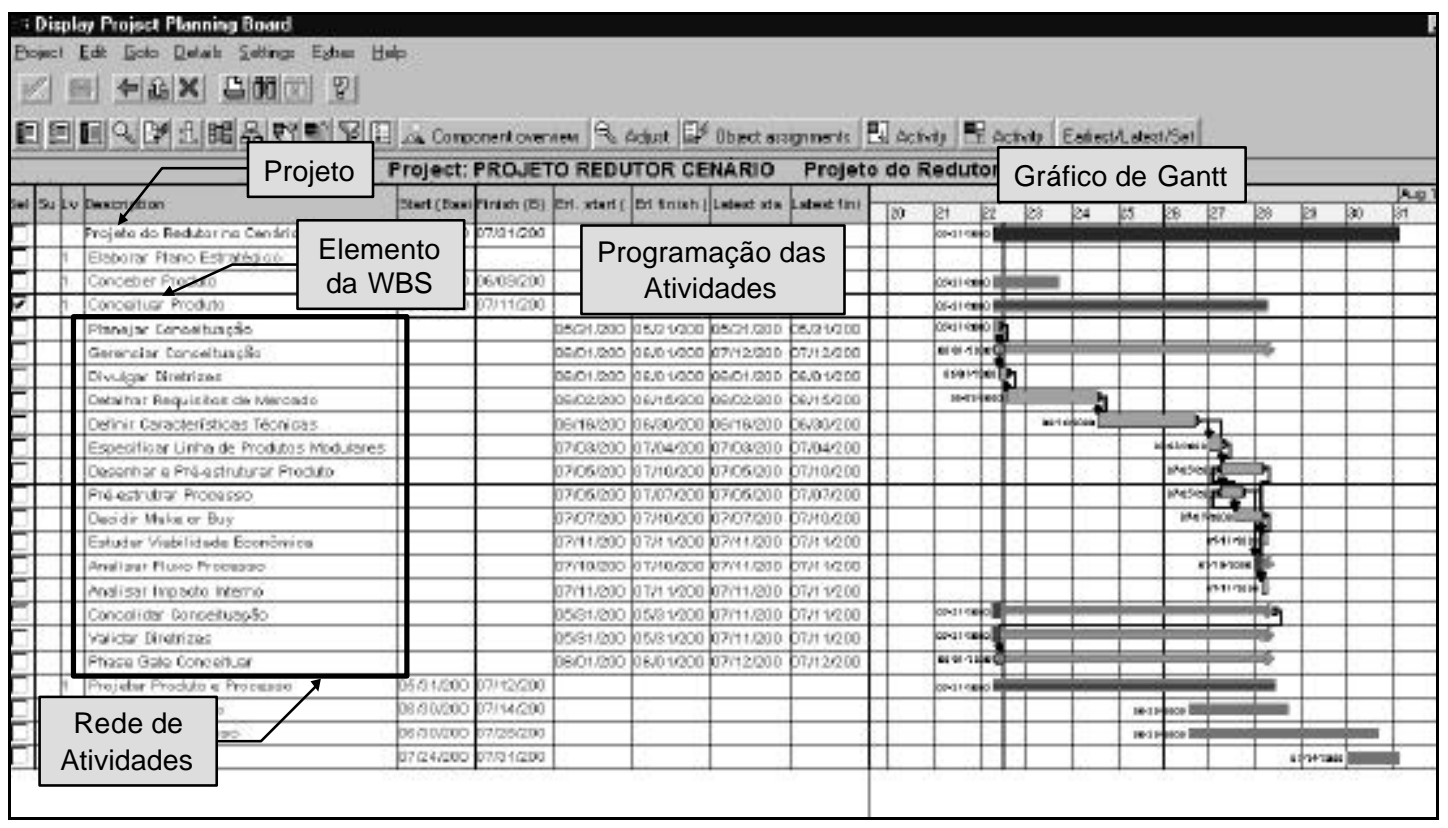

FIGURA 29 - Programação das atividades do Cenário e gráfico de Gantt no sistema ERP

Após a definição da WBS e das redes de atividades, foi verificada uma desvantagem da aplicação do sistema ERP no planejamento detalhado das atividades de desenvolvimento de produtos do Cenário. A especificação dos níveis mais detalhados de todas as atividades de desenvolvimento no sistema ERP resultaria em um planejamento muito extenso e complexo, dificultando o gerenciamento do projeto como um todo.

Assim, optou-se por utilizar o sistema ERP para estruturar os dois primeiros níveis de planejamento dos projetos do Cenário (WBS e redes de atividades), necessários para o gerenciamento macro do desenvolvimento de produtos, e por utilizar o sistema complementar de gerenciamento de projetos para planejar os níveis mais detalhados das atividade de desenvolvimento. Esse detalhamento é realizado de forma descentralizada, pelos responsáveis diretos pela execução das atividades, respeitando-se o planejamento dos níveis superiores estabelecidos no ERP.

A fim de manter a integridade das informações e evitar a necessidade de redigitação, o planejamento realizado no ERP (WBS e redes de atividades) é exportado para o sistema gerenciador de projetos. A exportação é realizada por meio de um arquivo gerado pelo ERP em um formato que pode ser interpretado pelo sistema gerenciador de projetos.

Nos testes do plug-in de integração instalado no Cenário, observou-se que as principais informações dos projetos são corretamente exportadas do ERP para o arquivo de transferência, mas alguns dados são perdidos durante a exportação como, por exemplo, as informações especificadas em certos campos configuráveis do sistema ERP. 
A FIGURA 30 apresenta, inicialmente, um projeto de desenvolvimento de produtos no Cenário estruturado no sistema ERP e, em seguida, o projeto importado no ambiente do sistema gerenciador de projetos.

No exemplo do Cenário apresentado na FIGURA 30, a atividade Desenhar Componentes planejada no sistema ERP é detalhada em subatividades (Desenhar Eixo de Entrada, Desenhar Eixo de Saída, Desenhar Engrenagem Intermediária, etc.) no gerenciador de projetos.

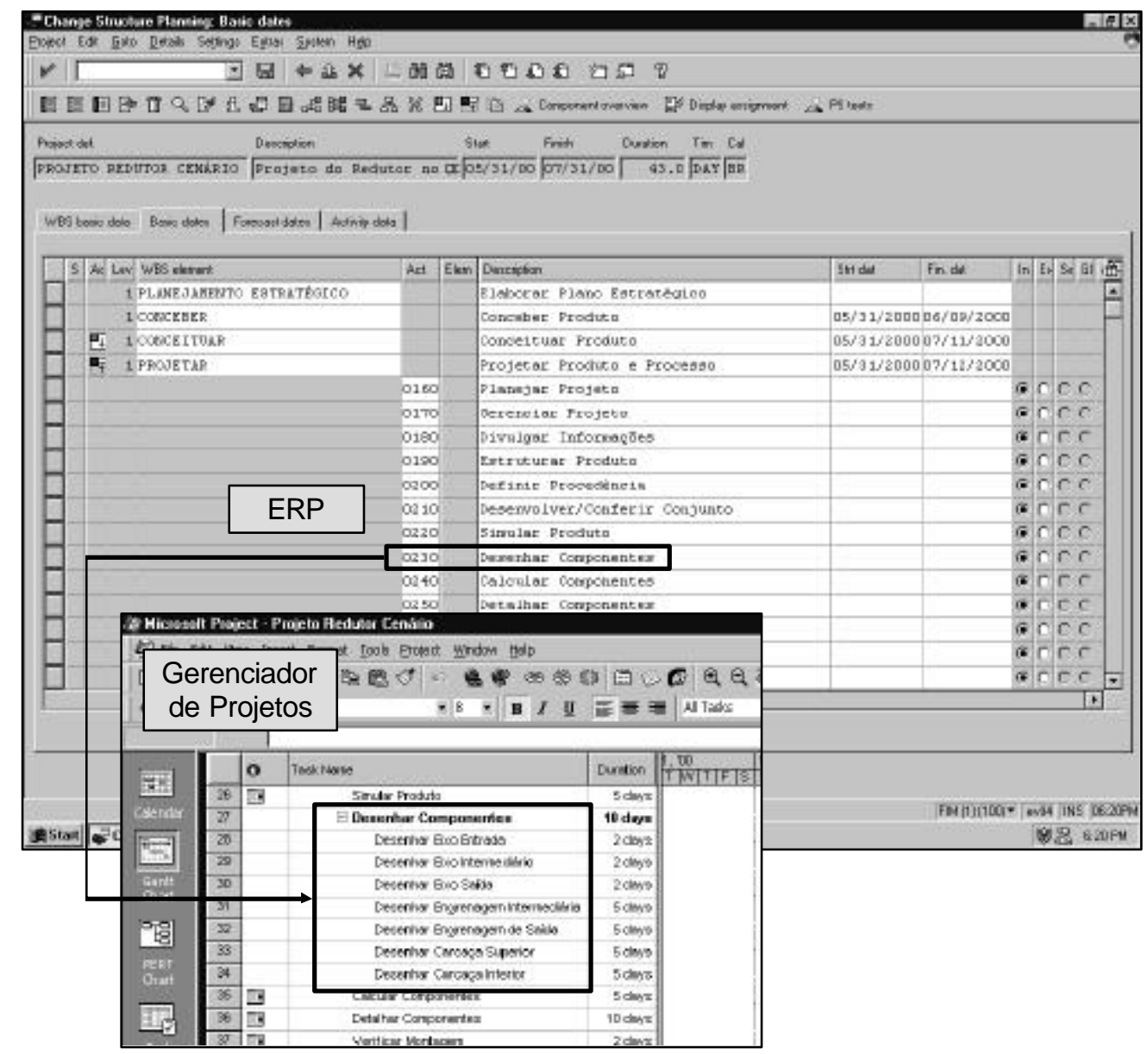

FIGURA 30 - Planejamento macro no sistema ERP e detalhamento das atividades no sistema complementar de gerenciamento de projetos

Durante a execução dos projetos do Cenário, as atividades de desenvolvimento só são iniciadas depois de terem sido liberadas no sistema ERP. Após a conclusão de cada atividade é realizada a confirmação do término, informando-se a quantidade de recursos que foram efetivamente consumidos (horas/homem, horas/máquina, materiais, etc.). O sistema ERP utiliza os dados de confirmação para contabilizar os custos dos projetos em desenvolvimento. 
A partir das observações realizadas no Cenário, considera-se que uma das principais vantagens da utilização do ERP para se gerenciar o desenvolvimento de produtos refere-se ao controle contábil dos projetos. No ERP, cada atividade de desenvolvimento está relacionada a centros de custo e a contas específicas (como, por exemplo, um pedido de cliente) de forma que é possível controlar a alocação de todas as despesas realizadas.

\section{Cadastro de Materiais}

No Cenário, definiu-se que o sistema ERP é a base de dados de todos os materiais utilizados no desenvolvimento. Essa definição foi fundamentada em dois fatores: o ERP é a “espinha dorsal" dos sistemas de informação do Cenário; o cadastro de materiais do ERP é o mais completo dentre todos os sistemas do Cenário.

Dessa forma, os materiais utilizados por qualquer sistema no Cenário, desde as etapas iniciais do processo de desenvolvimento, são primeiramente cadastrados no ERP. O cadastramento de materiais no ERP envolve a atribuição de uma identificação aos materiais (definida manualmente pelo usuário, ou determinada automaticamente pelo sistema) e a especificação de uma série de dados, dentre as quais os dados básicos (nome, unidade de medida, etc.) e as informações de produção (tipo de lote, tamanho do lote mínimo, tipo de fornecimento, etc.).

A identificação e os dados dos materiais cadastrados no ERP são compartilhados pelos demais sistemas utilizados no Cenário. Por exemplo, a identificação e alguns dos dados de materiais (nome, unidade de medida, entre outros) são enviados do sistema ERP para a base de dados do sistema CAPP. Essa transferência de informações, realizada pelo kit de integração instalado no Cenário, é iniciada por uma função incluída pela integração no ambiente do sistema CAPP (FIGURA 31).

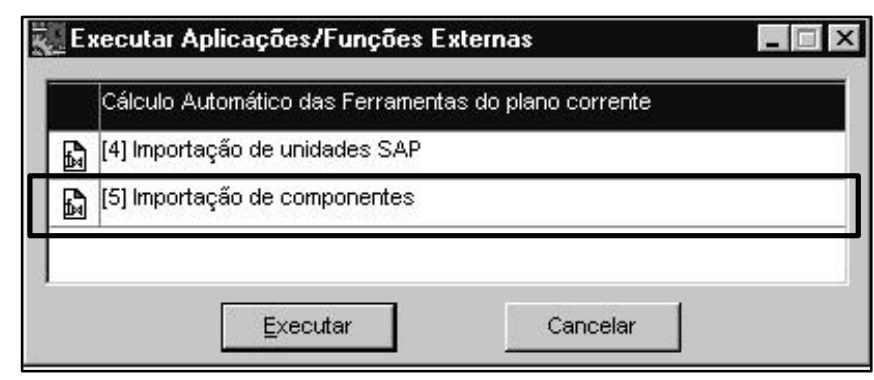

FIGURA 31 - Função de importação de componentes do ERP para o sistema CAPP

A opção de se utilizar o sistema ERP como a base de dados de materiais não é suficiente para garantir a integridade da identificação e dos dados de materiais. Conforme observou-se no Cenário, os dados de materiais podem ser livremente alterados no sistema 
CAPP depois de terem sido importados do ERP. Além disso, novos materiais podem ser facilmente criados, a qualquer momento, nas bases de dados dos demais sistemas do Cenário. Verificou-se, assim, que a garantia da integridade da identificação e dos dados de materiais também depende do estabelecimento de procedimentos rígidos de cadastramento e de alteração.

Além disso, observou-se no Cenário que o cadastramento no sistema ERP de materiais utilizados nos estudos realizados nas etapas iniciais do desenvolvimento de produtos pode resultar em um grande acúmulo de materiais descontinuados na base de dados corporativa. Devido ao alto grau de incerteza existente no começo do processo de desenvolvimento, são realizadas muitas modificações, e inúmeros materiais cadastrados são descartados. No entanto, verificou-se que a utilização de outras funcionalidades do ERP no início do desenvolvimento, tais como a criação de estruturas de produto e o cálculo de estimativas de custos de produtos, depende do cadastramento dos materiais na base de dados do ERP.

\section{Estruturas de Produto}

As estruturas de produto do Cenário também são criadas e gerenciadas no sistema ERP. Fez-se essa opção considerando-se que o ERP é a "espinha dorsal" dos sistemas de informação e a base de dados de materiais do Cenário.

As estruturas de produto em desenvolvimento no Cenário são diferenciadas das estruturas liberadas para produção pela especificação de um parâmetro do sistema ERP (BOM usage) que impede que estruturas não aprovadas sejam consideradas nos cálculos de necessidades de materiais (FIGURA 32).

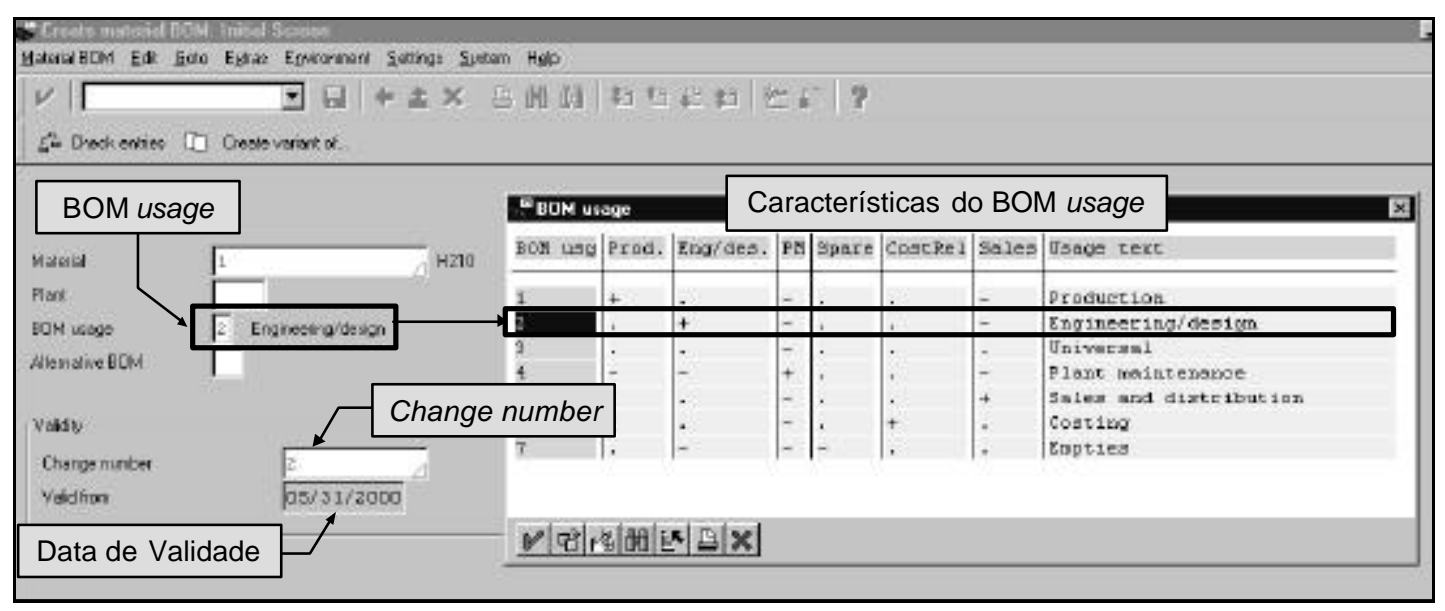

FIGURA 32 - Parâmetros utilizados no gerenciamento e controle de estruturas de produto do Cenário 
Do início do desenvolvimento até a liberação para produção, todas as modificações realizadas nas estruturas de produto são controladas pelo ECM do sistema ERP por meio da atribuição de um parâmetro de gerenciamento (Change number). Nesse período, o controle de efetividade das estruturas de produto do Cenário é realizado por datas de validade (FIGURA 32).

Durante o desenvolvimento de produtos no Cenário é utilizada a funcionalidade de "navegação" de estruturas de produto, que possibilita a visualização gráfica de todos os relacionamentos existentes entre os materiais das estruturas e outras informações do sistema, tais como documentos e dados de classificação (IGURA 33).

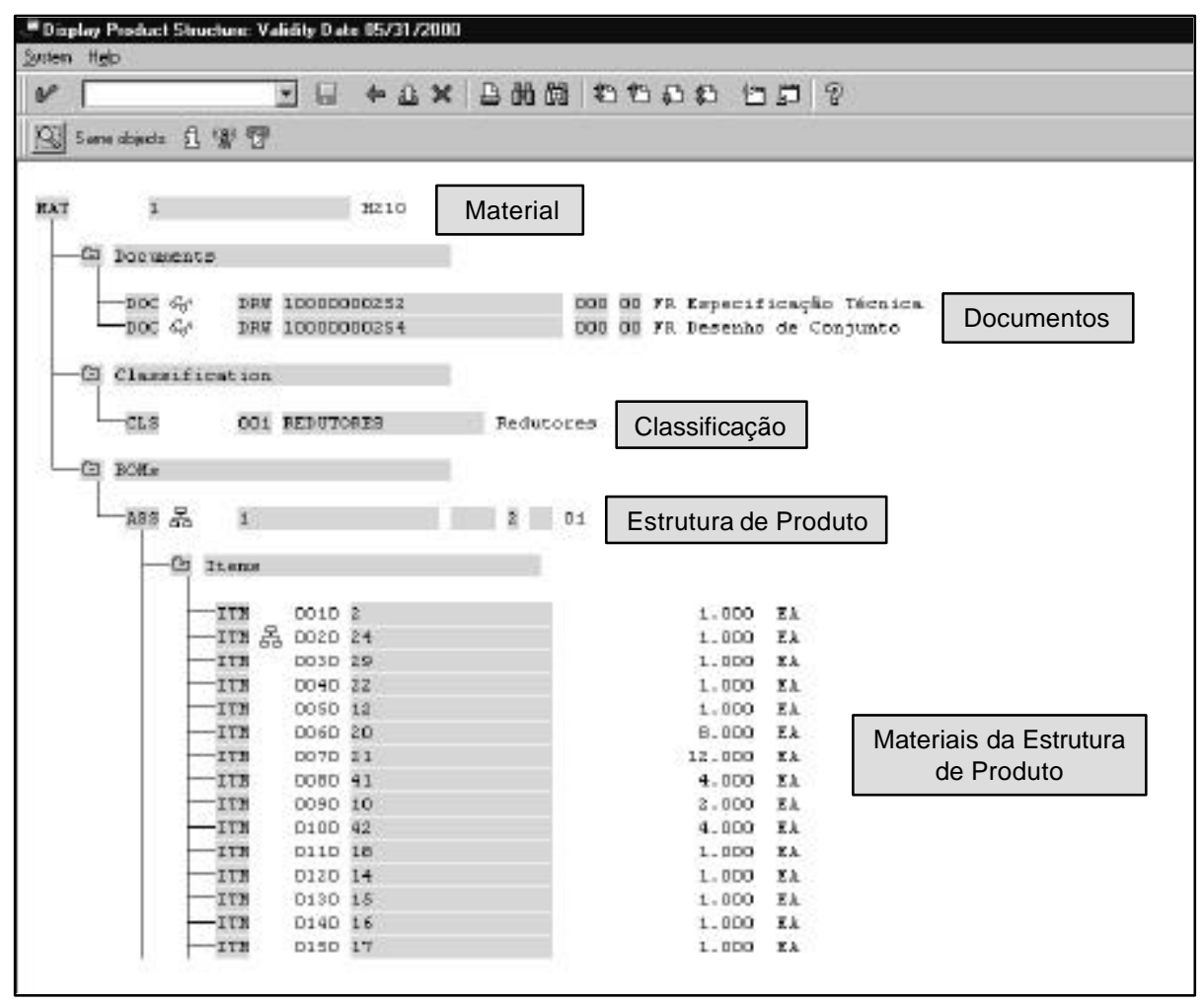

FIGURA 33 - Visualização gráfica dos relacionamentos de uma estrutura de produto no Cenário

Os plug-ins e kits de integração instalados no Cenário não apóiam nenhuma forma de exportação das estruturas de produto do sistema ERP para arquivos e para bases de dados de sistemas complementares de desenvolvimento de produtos.

Portanto, a única maneira de transferir as estruturas de produto do sistema ERP para outros sistemas utilizados no Cenário, é a redigitação de informações. É o caso, por exemplo, da redigitação das estruturas de produto do ERP no sistema de DFMA.

Observou-se que a falta de integração da estrutura de produto entre o sistema ERP e os sistemas complementares no Cenário, resulta em uma série de desvantagens e limitações. 
Durante a redigitação de informações podem ocorrer erros que seriam evitados com a transferência eletrônica das estruturas de produto. Além disso, existe grande dificuldade de se manter a integridade das informações, uma vez que as alterações realizadas nas estruturas de produto do sistema ERP não são automaticamente compartilhadas pelos sistemas complementares, e vice-versa.

Dessa forma, verificou-se que a atribuição do gerenciamento das estruturas de produto ao ERP não é suficiente para garantir a integridade das informações. Além disso, é preciso definir procedimentos que assegurem que as alterações realizadas no sistema ERP sejam incorporadas pelos demais sistemas e que as modificações realizadas no sistemas complementares sejam incluídas nas estruturas de produto gerenciadas pelo ERP.

\section{Classificação}

A organização dos materiais do Cenário em classes é realizada utilizando-se as funcionalidades de classificação do sistema ERP. Essa opção foi feita observando-se que o sistema ERP é a base de dados de materiais do Cenário.

Nesse sentido, montou-se a estrutura de classificação de materiais no sistema ERP. Definiram-se inicialmente todas as características e as classes necessárias. As características foram então atribuídas às classes correspondentes, e foram montadas hierarquias de classes.

A partir dessa estrutura, os materiais do Cenário são classificados e podem ser recuperados pela realização de buscas por características específicas. Um exemplo da procura por um material pertencente a uma classe do Cenário (Eixo com pinhão), que possui determinadas características (comprimento e diâmetro), é apresentado na FIGURA 34.

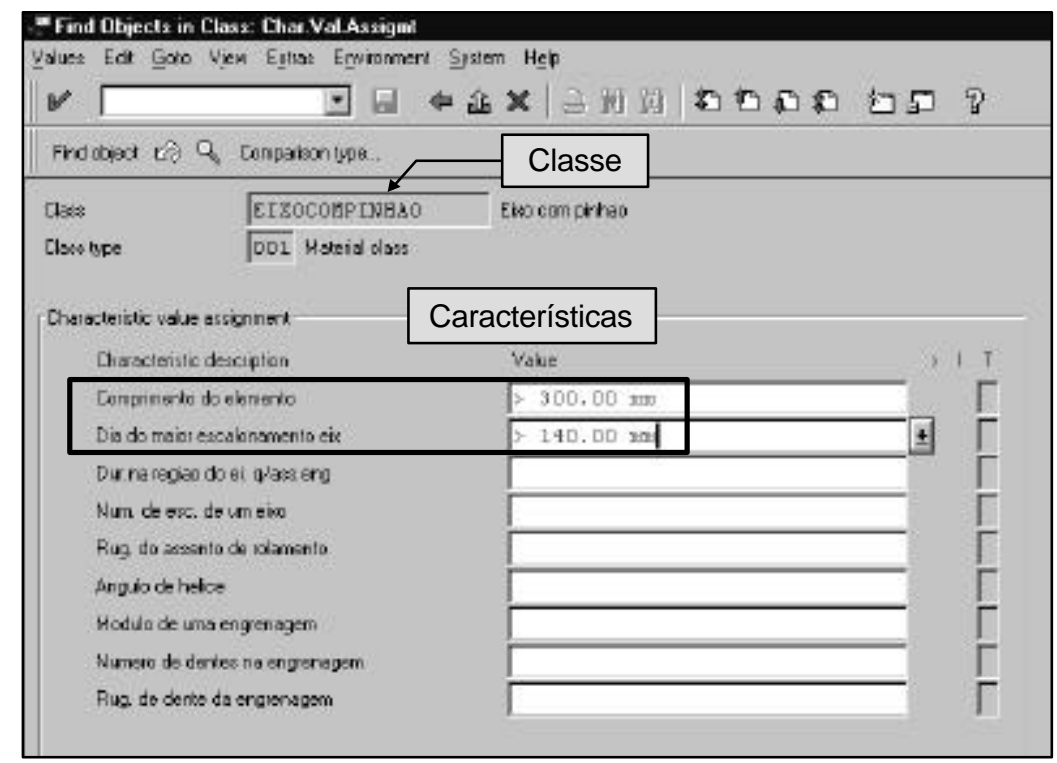

FIGURA 34 - Localização de um componente do Cenário a partir de suas características 
No Cenário pôde-se verificar que é possível estabelecer estruturas de classificação de materiais bastante complexas no sistema ERP, devido à flexibilidade de relacionamento entre as características e as classes, e entre diferentes classes (hierarquia de classes). Observou-se também que, além de materiais, diversos outros tipos de objetos podem ser classificados no ERP, tais como documentos, máquinas, ferramentas e operações de fabricação.

Nas simulações realizadas no Cenário verificou-se que o sistema CAPP também utiliza os dados de classificação de materiais. No entanto, o kit de integração do ERP com o CAPP instalado no Cenário não possibilita a transferência de informações de classificação entre esses sistemas. Dessa forma, as informações de classificação do ERP foram redigitadas no sistema CAPP.

A falta de integração na classificação de materiais resulta em uma série de problemas semelhantes aos discutidos na seção anterior para as estruturas de produtos. Na redigitação podem ocorrer erros, e a duplicação das informações dificulta a manutenção da integridade dos dados de classificação no Cenário.

\section{Gerenciamento de Documentos}

O controle dos documentos do Cenário é realizado utilizando-se as funcionalidades de gerenciamento de documentos do sistema ERP.

Cada documento do Cenário é cadastrado em uma "ficha" no ERP (IGURA 35).

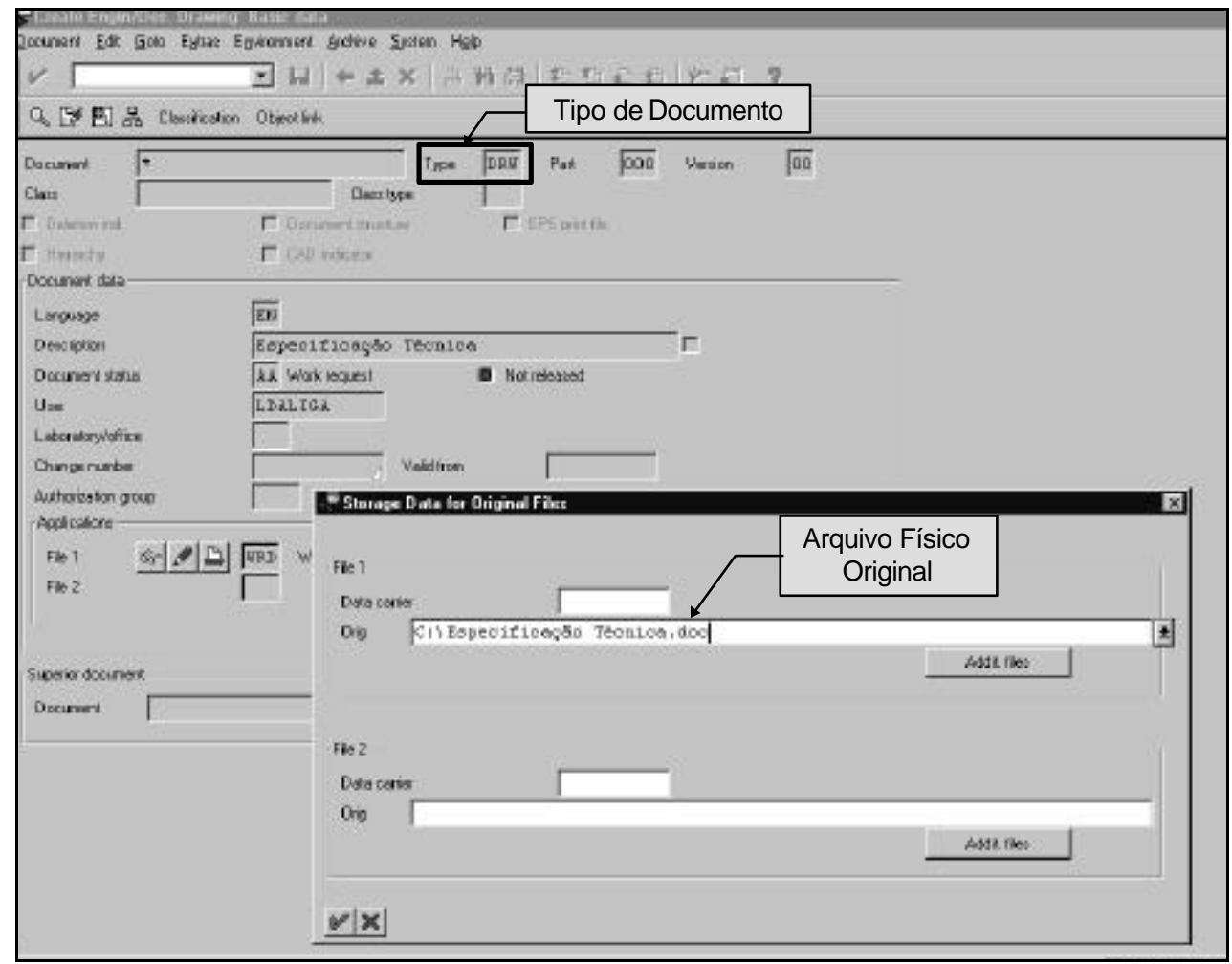

FIGURA 35 - "Ficha" de um documento do Cenário 
Nesse cadastramento é atribuída uma identificação ao documento e são especificadas dados, como, por exemplo, o nome e o tipo do documento. $\mathrm{O}$ tipo de documento determina uma série de características fundamentais relacionadas com seu gerenciamento, tal como a rede de status empregada no seu ciclo de vida. Para serem gerenciados, os arquivos físicos originais que definem os documentos são relacionados com as "fichas" correspondentes no sistema ERP (FIGURA 35).

Em seguida, é realizado o check in dos documentos. Os arquivos físicos originais são transferidos para o vault do Cenário e passam a ser gerenciados pelo sistema ERP.

De acordo com o tipo de documento utilizado no Cenário, um documento não pode mais ser alterado depois de sua liberação (IGURA 36).

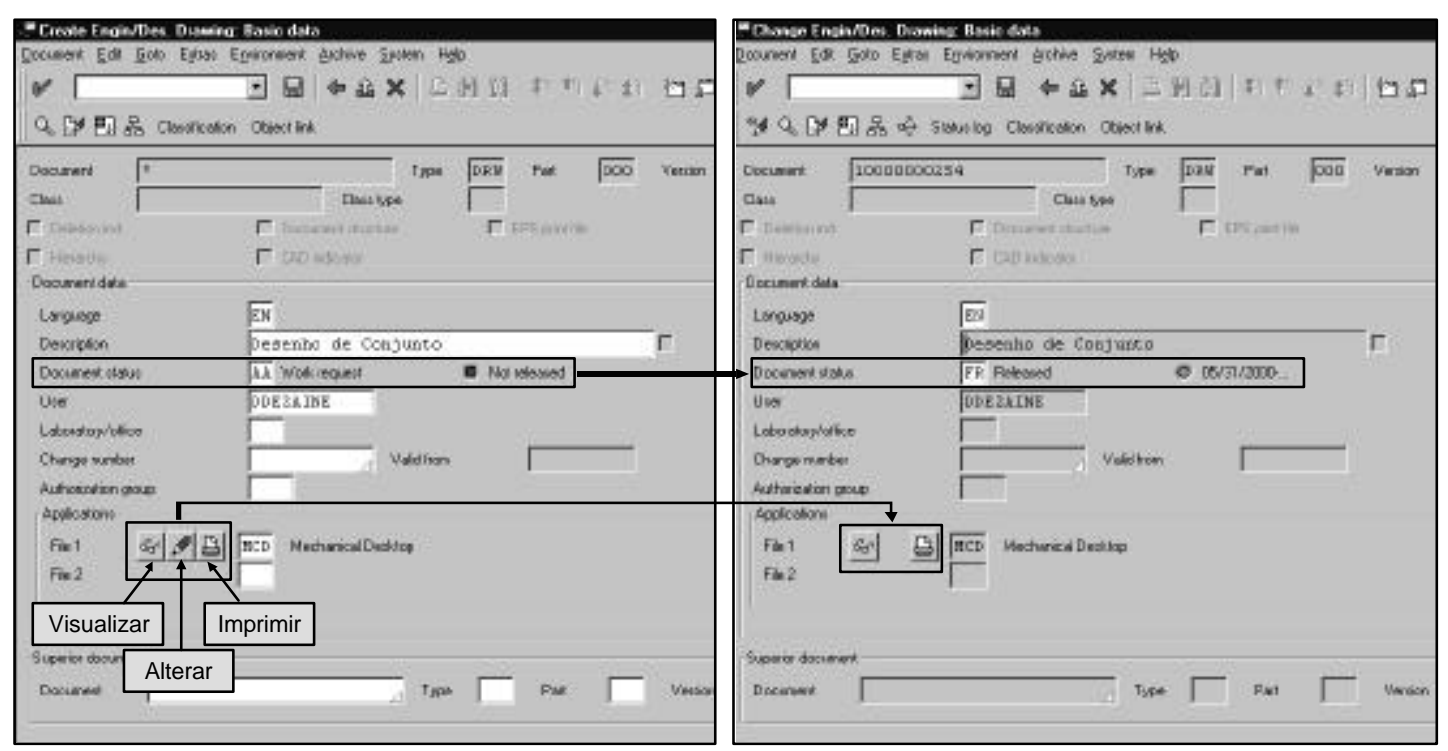

FIGURA 36 - Liberação de documento no Cenário

Após serem criados, os documentos representados pelas "fichas" podem ser livremente relacionados com vários tipos de objetos do sistema ERP utilizados no Cenário, tais como materiais, estruturas de produto, entre outros.

Nos testes realizados no Cenário verificou-se que devido à necessidade de especificação dos arquivos físicos que definem os documentos, não é possível utilizar o vault do sistema ERP para gerenciar documentos que são "visões" de base de dados. É o caso, por exemplo, dos FMEAs de produto e de processo do Cenário.

Além disso, observou-se que a segurança dos arquivos gerenciados pelo ERP e armazenados no vault pode ser violada por um usuário com permissão de acesso ao diretório do vault localizado em um servidor da rede de computadores. Verificou-se, assim, que a segurança dos arquivos de documentos depende diretamente do estabelecimento de restrições 
de acesso ao diretório do vault. No Cenário, essas restrições foram definidas no sistema operacional que gerencia a rede de computadores.

\section{Planos de Processo}

A fim de se avaliar a utilização de APIs do sistema ERP para a importação de informações de desenvolvimento de produtos, definiu-se que o planejamento de processo no Cenário é realizado no sistema CAPP e enviado para o ERP. Essa transferência de informações é realizada pelo kit de integração do sistema ERP com o CAPP.

Os planos de processo criados no CAPP especificam a sequiência de operações, os tempos de processamento (tempo de setup e tempo padrão) e as máquinas (centros de trabalho) utilizados na fabricação e montagem de materiais.

A aprovação dos planos no CAPP inicia uma função do kit de integração que envia as informações de planejamento de processo da base de dados do CAPP para o sistema ERP, por meio de APIs. A FIGURA 37 apresenta o plano de processo de um material do Cenário elaborado no sistema CAPP e exportado para o sistema ERP.

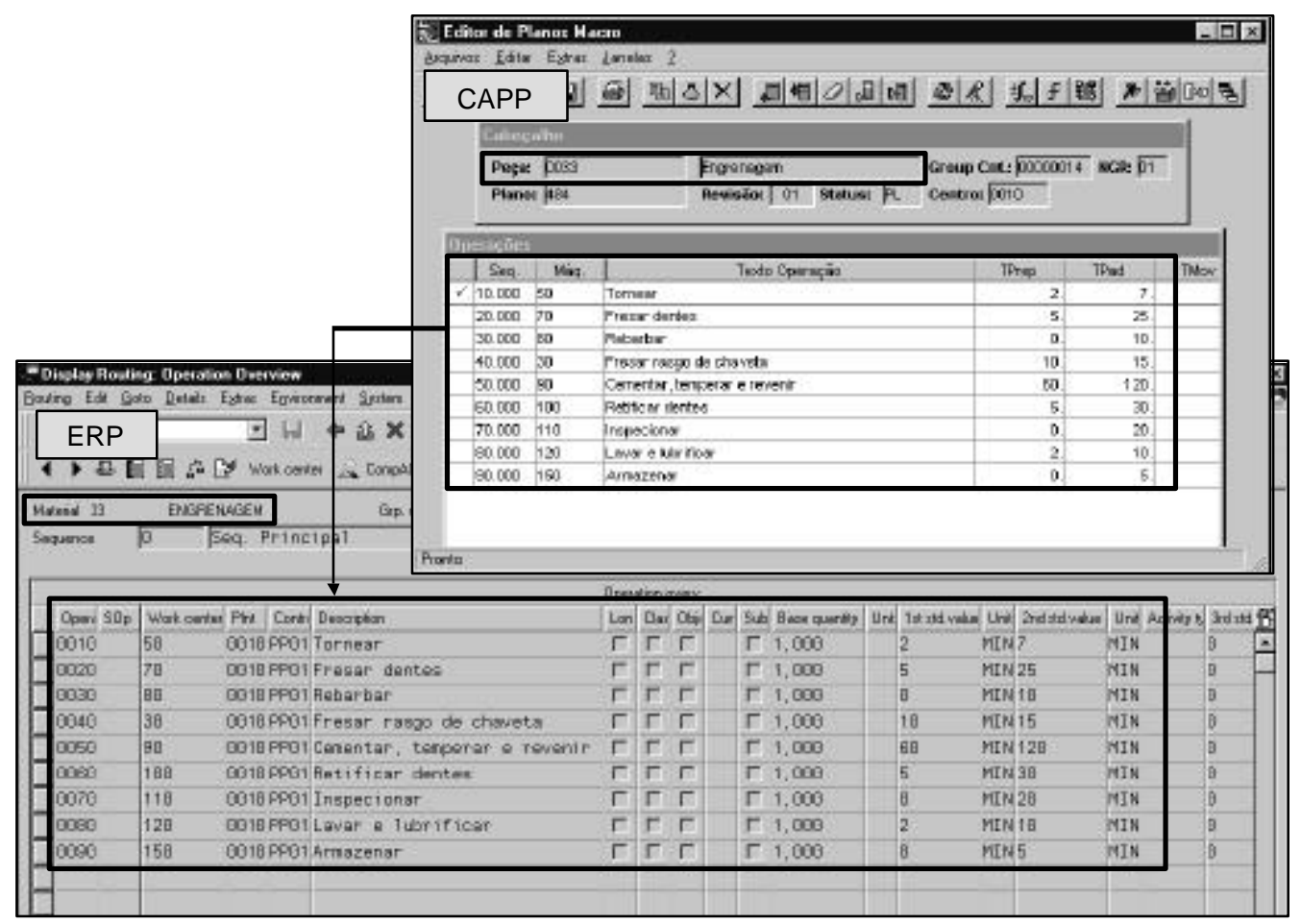

FIGURA 37 - Plano de processo elaborado no sistema CAPP e exportado para o sistema ERP

A exportação dos planos de processo do sistema CAPP para o ERP evita a necessidade de redigitação de informações e contribui para que haja maior consistência dos dados de planejamento. 
No entanto, observou-se no Cenário que a transferência dos planos de processo do CAPP para o ERP implica na duplicação de informações que passam a ser mantidas nas bases de dados de ambos os sistemas. Como o ERP e o CAPP não gerenciam um objeto comum, as modificações realizadas nos planos de processo em um desses sistemas não são automaticamente incorporadas nos planos armazenados na outra base de dados. Verificou-se assim, que a integridade dos planos de processo também depende do estabelecimento de procedimentos rígidos de manutenção e alteração.

Definiu-se então um procedimento que estabelece o sistema responsável pelo gerenciamento dos planos de processo do Cenário ao longo do ciclo de vida dos produtos. Tal procedimento determina que todos os planos de processo devem ser inicialmente criados e mantidos no sistema CAPP, até a sua aprovação. Na aprovação, uma cópia dos planos de processo é enviada do CAPP para o ERP. Após a aprovação, os planos são revisados e alterados sempre no sistema CAPP, até a aprovação de uma nova revisão que é enviada ao ERP. O procedimento especificado também determina que nenhuma modificação nos planos de processo pode ser realizada no sistema ERP. Dessa forma, o ERP atua como um repositório das versões aprovadas dos planos de processo que são criados e revisados no sistema CAPP.

\section{Fluxo de Trabalho}

No Cenário, o ciclo de elaboração e de aprovação de desenhos foi automatizado com a definição de um fluxo de trabalho no sistema ERP. Esse fluxo compreende as atividades de Desenhar Componentes, de Detalhar Componentes, de Calcular Componentes e de Aprovar Desenhos.

O desenvolvimento do fluxo de trabalho para o Cenário foi realizado em uma ferramenta de programação visual disponível no ambiente do sistema ERP. Tal ferramenta, baseada no paradigma de orientação a objetos, possibilita a inclusão de todos os objetos padronizados do sistema ERP (materiais, estruturas de produto, documentos, entre outros) na definição dos fluxos de trabalho.

Observou-se que o desenvolvimento de um fluxo de trabalho no ERP pode ser realizado adaptando-se uma série de fluxos padronizados pré-existentes (templates). No entanto, não foi encontrado nenhum fluxo pré-definido semelhante a um ciclo de elaboração e de aprovação de desenhos. Dessa forma, foi necessário programar um fluxo totalmente novo para automatizar o ciclo do Cenário. 
Na programação desse fluxo foram especificadas as tarefas realizadas e os eventos existentes. $\mathrm{O}$ encadeamento entre as tarefas e os eventos do fluxo pode ser visualizado por meio de um "navegador" (FIGURA 38).

Apesar do emprego de uma ferramenta de programação visual, verificou-se que é necessário especificar uma série de parâmetros em formulários que definem os elementos do fluxo de trabalho (FIGURA 38).

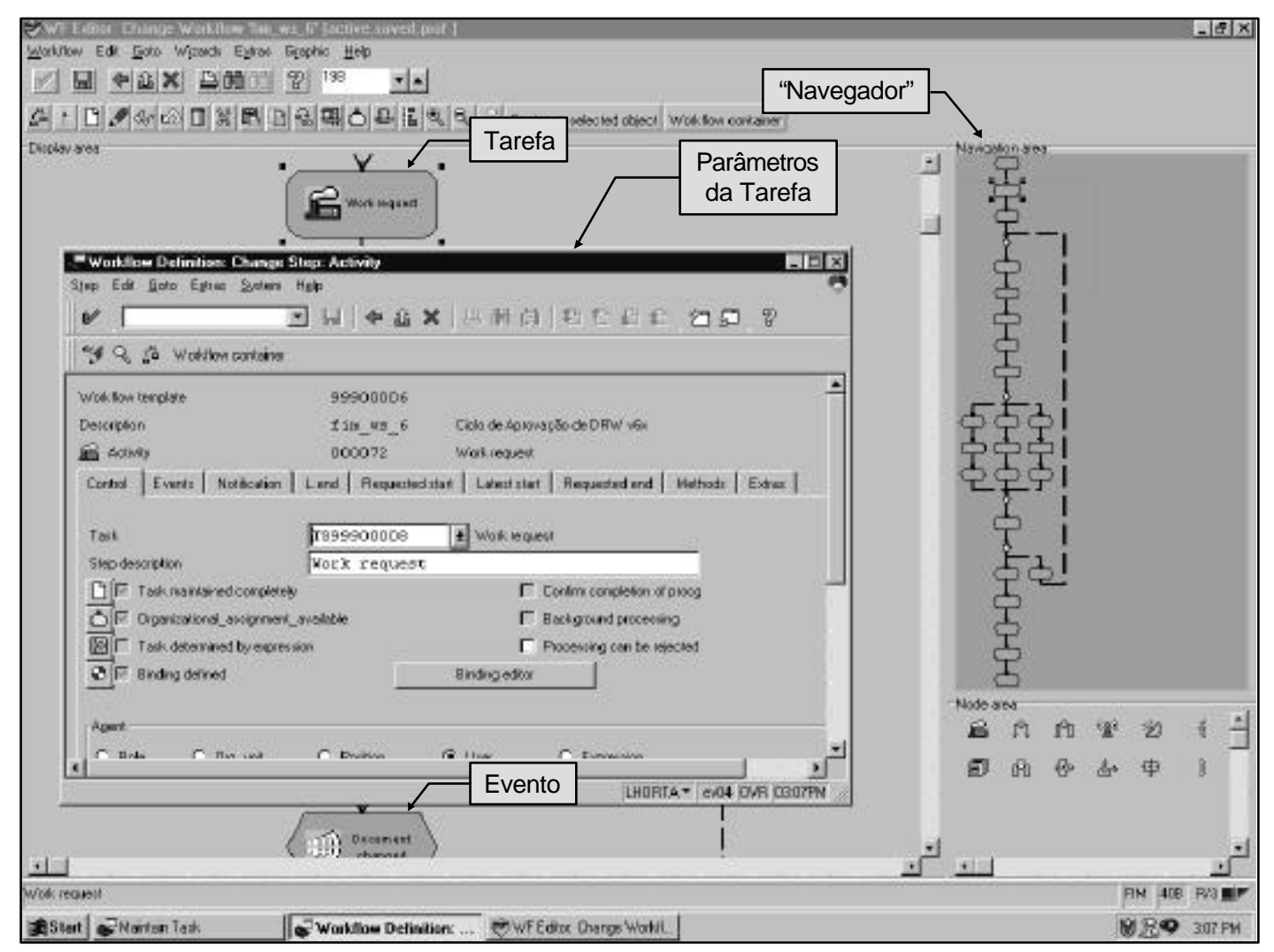

FIGURA 38 - Definição do fluxo de trabalho do Cenário no sistema ERP

O fluxo de trabalho do Cenário é iniciado com a atribuição, a um projetista, da tarefa de desenhar um determinado componente. Após a conclusão dessa tarefa, o desenho é automaticamente enviado para aprovação por um gerente de projetos. Caso seja reprovado, o desenho é reenviado ao projetista para ser modificado. Em caso de aprovação, o desenho é automaticamente encaminhado para o detalhamento e para a realização de cálculos. Depois de ser detalhado, o desenho é novamente conferido pelo gerente de projeto até a sua aprovação definitiva.

$\mathrm{Na}$ execução do fluxo, os responsáveis pelas atividades recebem uma notificação de tarefa na "caixa de entrada" do sistema ERP. No Cenário, essa "caixa de entrada" do ERP está integrada com o sistema complementar de correio eletrônico por meio de um plug-in. 
Dessa forma, os responsáveis pelas atividades recebem a notificação de tarefa no ERP e, simultaneamente, no sistema complementar de correio eletrônico (FIGURA 39).

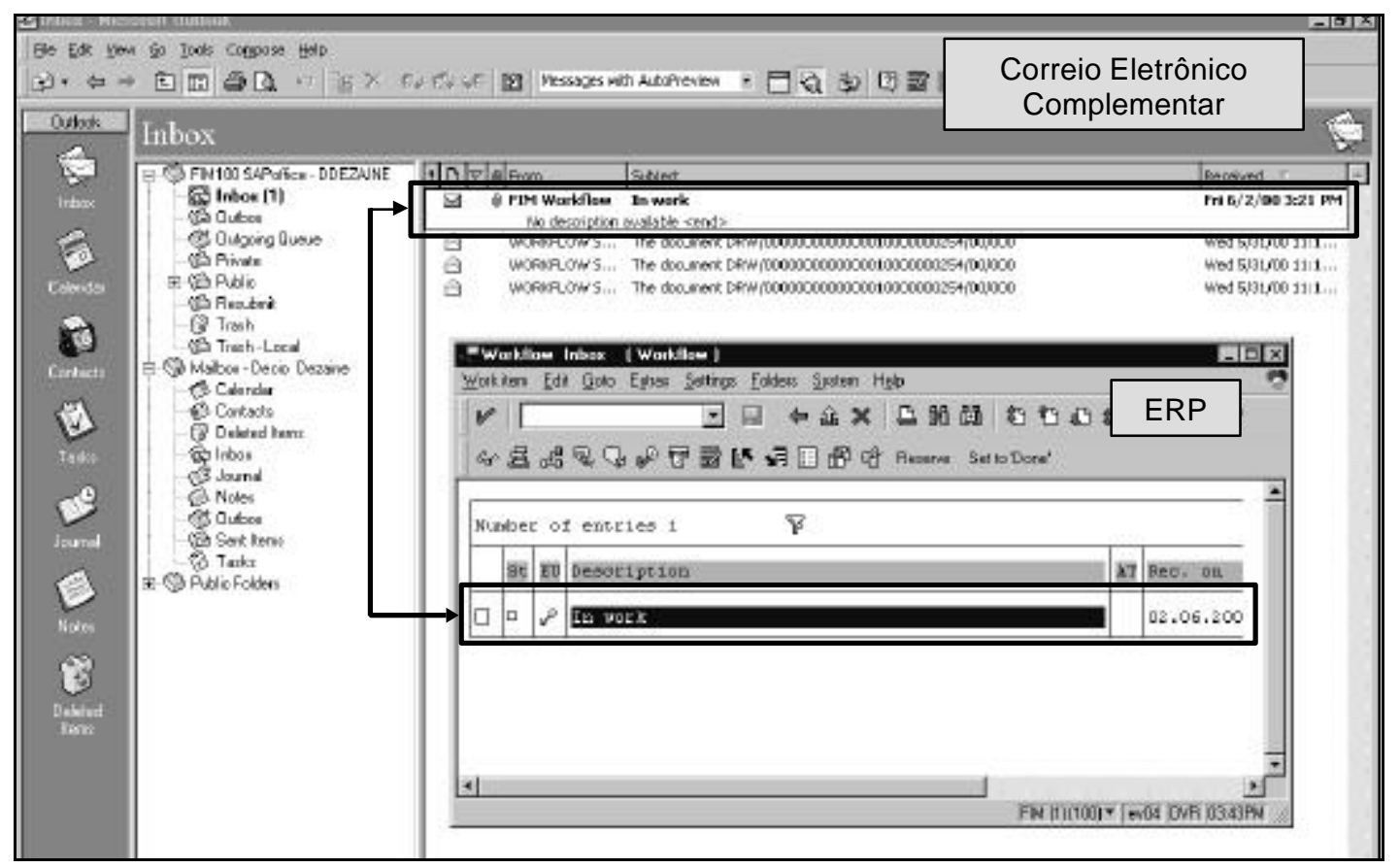

FIGURA 39 - Recebimento de uma tarefa do fluxo de trabalho do Cenário na "caixa de entrada" do sistema ERP e do sistema de correio eletrônico

Observando-se que o sistema de correio eletrônico é utilizado para enviar e receber todas as mensagens referentes ao desenvolvimento de produtos, optou-se também por utilizálo para enviar e receber as tarefas e os avisos do fluxo de trabalho do sistema ERP. Definiuse, assim, um único sistema para o envio e o recebimento de qualquer tipo de comunicação no desenvolvimento de produtos, evitando que os participantes do desenvolvimento tenham que verificar a existência de mensagens em duas "caixas de entrada".

O plug-in de integração instalado no Cenário possibilita que as tarefas do fluxo de trabalho do ERP sejam executadas a partir do sistema complementar de correio eletrônico. Pressionando-se o ícone Execute, recebido na notificação de uma tarefa, é automaticamente iniciada a funcionalidade do sistema ERP correspondente à tarefa e ao objeto do fluxo de trabalho (FIGURA 40). 


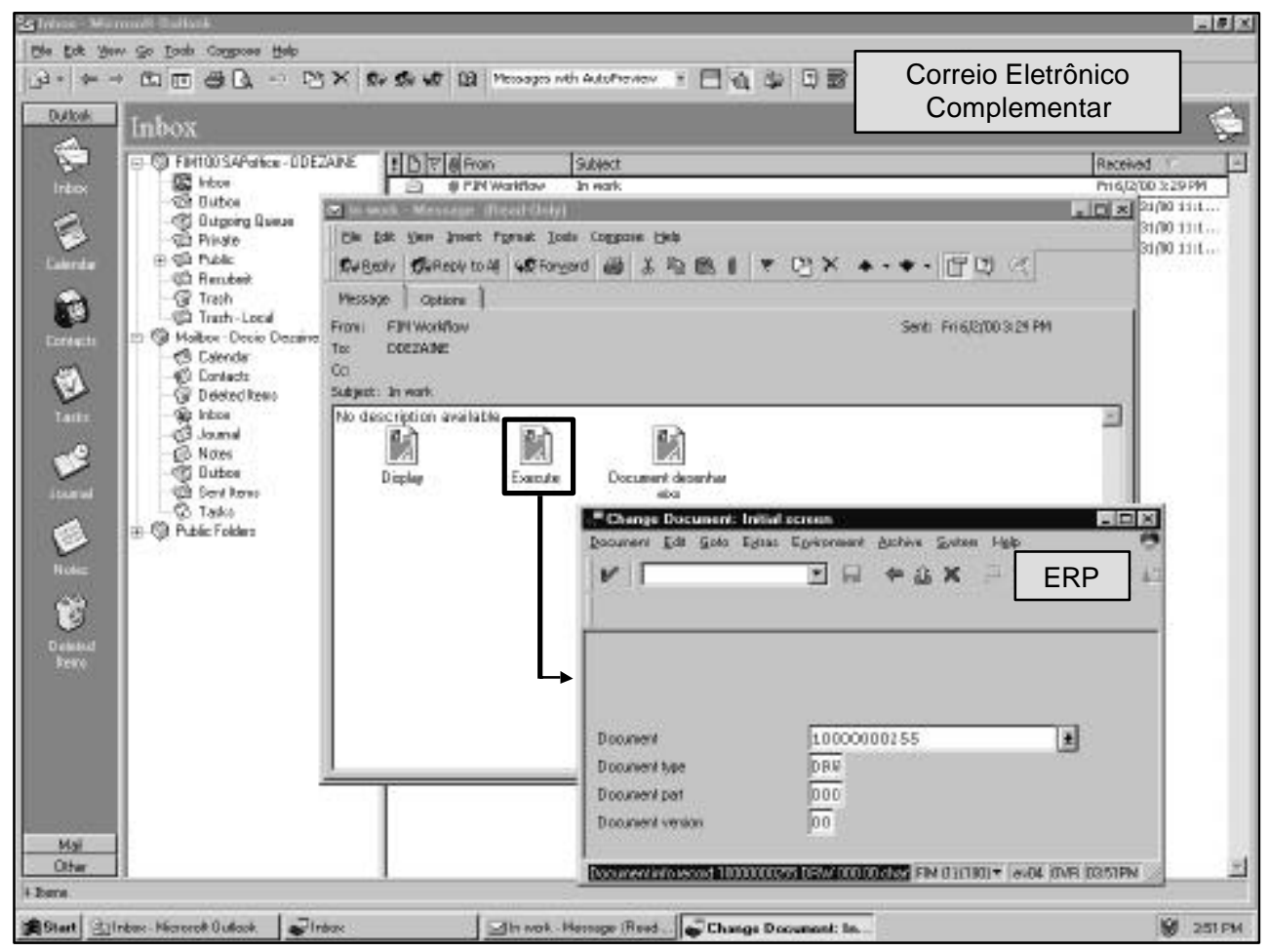

FIGURA 40 - Execução de uma tarefa do fluxo de trabalho do sistema ERP a partir do sistema complementar de correio eletrônico

Após a conclusão de uma tarefa realizada a partir do sistema complementar de correio eletrônico, a sua notificação também é automaticamente excluída da "caixa de entrada" do sistema ERP, evitando o acumulo de mensagens ultrapassadas e eliminando o risco de que uma mesma tarefa seja executada duas vezes.

A sincronização entre as "caixas de entrada" e a possibilidade de acessar as funcionalidades e os objetos do ERP a partir do sistema de correio eletrônico, evidenciam que ambos os sistemas estão efetivamente integrados por meio do plug-in instalado no Cenário de Desenvolvimento de Produtos. 


\section{ESTUDOS DE CASO DA APLICAÇÃO DO SISTEMA ERP NO PROCESSO DE DESENVOLVIMENTO DE PRODUTOS}

Este capítulo apresenta os estudos de caso da aplicação do sistema ERP no processo de desenvolvimento de produtos de três empresas.

No primeiro item do capítulo, são selecionadas as empresas estudadas nesta fase da pesquisa e são coletados os dados que caracterizam a aplicação do sistema ERP no processo de desenvolvimento de produtos dessas empresas.

No segundo item do capítulo, são apresentados e discutidos os resultados observados nos estudos de caso da aplicação do sistema ERP no processo de desenvolvimento de produtos das três empresas.

\subsection{Seleção das Empresas e Coleta dos Dados}

A seleção das empresas estudadas nesta fase da pesquisa foi realizada com base em dois critérios previamente estabelecidos. Definiu-se que as empresas analisadas deveriam desenvolver produtos e utilizar o sistema ERP considerado neste trabalho. Permitiu-se que as empresas estudadas utilizassem versões do sistema ERP anteriores à versão considerada nas outras fases da pesquisa (4.0B), pois verificou-se que no período de realização deste trabalho poucas empresas haviam concluído a implantação da versão mais atual do sistema ERP. A partir da definição desses critérios, foram escolhidas as três empresas analisadas nos estudos de caso.

A primeira empresa escolhida, denominada Empresa A é uma multinacional que projeta e produz equipamentos para a indústria petroquímica e para a indústria de papel e celulose. As características do processo de desenvolvimento de produtos da Empresa A, de acordo com a tipologia proposta por ROZENFELD \& AMARAL (1999), são apresentadas na TABELA 7. 
TABELA 7 - Características do processo de desenvolvimento de produtos da Empresa $A$ de acordo com a tipologia proposta por ROZENFELD \& AMARAL (1999)

\begin{tabular}{|c|c|c|c|}
\hline NÍVEL & \multicolumn{2}{|c|}{ FATOR } & TIPO \\
\hline \multirow[t]{4}{*}{ Mercado } & \multicolumn{2}{|l|}{ Setor } & Máquinas e equipamentos \\
\hline & \multicolumn{2}{|l|}{ Concorrência } & Oligopólio competitivo \\
\hline & \multirow[t]{2}{*}{ Alvo } & Geográfico & Regional \\
\hline & & $\begin{array}{l}\text { Posição na cadeia } \\
\text { de produção }\end{array}$ & Intermediário na cadeia de suprimentos \\
\hline \multirow[t]{3}{*}{ Corporação } & \multicolumn{2}{|l|}{ Inserção } & Filial \\
\hline & \multirow{2}{*}{\begin{tabular}{|l|} 
Interação com \\
unidades
\end{tabular}} & Responsabilidade & Coordenador de desenvolvimento \\
\hline & & Equipe & Mundial \\
\hline \multirow[t]{8}{*}{ Empresa } & \multicolumn{2}{|c|}{ Responsabilidade técnica } & Centro de desenvolvimento de produtos \\
\hline & \multirow[t]{2}{*}{ Estratégia } & Competitiva & Qualidade \\
\hline & & Interprojetos & Simultâneo \\
\hline & \multicolumn{2}{|c|}{ Informações iniciais } & Parte do projeto do produto \\
\hline & \multirow[t]{3}{*}{$\begin{array}{l}\text { Complexidade } \\
\text { do produto }\end{array}$} & \begin{tabular}{|l|} 
Tecnologia \\
principal
\end{tabular} & Mecânica \\
\hline & & Interna & Número de componentes \\
\hline & & \begin{tabular}{|lll}
$\begin{array}{l}\text { Interface com o } \\
\text { usuário }\end{array}$ & \\
\end{tabular} & Alta complexidade \\
\hline & \multicolumn{2}{|l|}{ Grau de inovação } & Plataformas ou nova geração e derivados \\
\hline
\end{tabular}

No processo de desenvolvimento de produtos da Empresa A são utilizados, além do sistema ERP (SAP R/3 3.0F), vários sistemas complementares, destacando-se: um sistema proprietário de gerenciamento de documentos; um sistema gerenciador de projetos; sistemas de trabalho em grupo; sistemas CAD bidimensionais e tridimensionais; um sistema CAD específico para o projeto de tubulações; sistemas CAE específicos para o projeto de componentes mecânicos e de vasos de pressão; um sistema CAPP; um sistema proprietário de controle de qualidade; aplicativos de escritório.

A segunda empresa selecionada, denominada Empresa B, é uma multinacional que desenvolve e fornece componentes mecânicos e eletrônicos para a indústria automobilística. As características do processo de desenvolvimento de produtos da Empresa B, de acordo com a tipologia proposta por ROZENFELD \& AMARAL (1999), são apresentadas na TABELA 8. 
TABELA 8 - Características do processo de desenvolvimento de produtos da Empresa $B$ de acordo com a tipologia proposta por ROZENFELD \& AMARAL (1999)

\begin{tabular}{|c|c|c|c|}
\hline NÍVEL & \multicolumn{2}{|c|}{ FATOR } & TIPO \\
\hline \multirow[t]{4}{*}{ Mercado } & \multicolumn{2}{|l|}{ Setor } & Automobilístico \\
\hline & \multicolumn{2}{|l|}{ Concorrência } & Oligopólio competitivo \\
\hline & \multirow[t]{2}{*}{ Alvo } & Geográfico & Mundial \\
\hline & & $\begin{array}{l}\text { Posição na cadeia } \\
\text { de produção }\end{array}$ & Intermediário na cadeia de suprimentos \\
\hline \multirow[t]{3}{*}{ Corporação } & \multicolumn{2}{|l|}{ Inserção } & Filial \\
\hline & \multirow{2}{*}{$\begin{array}{l}\text { Interação com } \\
\text { unidades }\end{array}$} & Responsabilidade & Participante de co-desenvolvimento \\
\hline & & Equipe & Mundial \\
\hline \multirow[t]{8}{*}{ Empresa } & \multicolumn{2}{|c|}{ Responsabilidade técnica } & $\begin{array}{l}\text { Centro de desenvolvimento tecnológico de } \\
\text { manufatura }\end{array}$ \\
\hline & \multirow[t]{2}{*}{ Estratégia } & Competitiva & Misto \\
\hline & & Interprojetos & Simultâneo \\
\hline & \multicolumn{2}{|c|}{ Informações iniciais } & Produto em produção \\
\hline & \multirow[t]{3}{*}{$\begin{array}{l}\text { Complexidade } \\
\text { do produto }\end{array}$} & $\begin{array}{l}\text { Tecnologia } \\
\text { principal }\end{array}$ & Mecânica / eletrônica \\
\hline & & Interna & Número de componentes \\
\hline & & \begin{tabular}{lll|}
$\begin{array}{l}\text { Interface } \\
\text { usuário }\end{array}$ & & \\
\end{tabular} & Alta complexidade \\
\hline & \multicolumn{2}{|c|}{ Grau de inovação } & Plataformas ou nova geração e derivados \\
\hline
\end{tabular}

Para apoiar o processo de desenvolvimento de produtos, a Empresa B utiliza o sistema ERP (SAP R/3 3.0F) e diversos sistemas complementares, dentre os quais destacamse: um sistema proprietário para a geração de imagens Raster; um sistema gerenciador de projetos; sistemas de trabalho em grupo; sistemas CAD bidimensionais e tridimensionais; um sistema proprietário de FMEA; um visualizador; aplicativos de escritório.

Por fim, foi escolhida uma empresa pertencente ao setor mecânico, denominada Empresa $C$. Essa empresa desenvolve e fabrica componentes para a indústria de bens de consumo duráveis. As características do processo de desenvolvimento de produtos da Empresa C, de acordo com a tipologia proposta por ROZENFELD \& AMARAL (1999), são apresentadas na TABELA 9. 
TABELA 9 - Características do processo de desenvolvimento de produtos da Empresa $C$ de acordo com a tipologia proposta por ROZENFELD \& AMARAL (1999)

\begin{tabular}{|c|c|c|c|}
\hline NÍVEL & \multicolumn{2}{|c|}{ FATOR } & TIPO \\
\hline \multirow[t]{4}{*}{ Mercado } & \multicolumn{2}{|l|}{ Setor } & Mecânico \\
\hline & \multicolumn{2}{|l|}{ Concorrência } & Oligopólio competitivo \\
\hline & \multirow[t]{2}{*}{ Alvo } & Geográfico & Mundial \\
\hline & & $\begin{array}{l}\text { Posição na cadeia } \\
\text { de produção }\end{array}$ & Intermediário na cadeia de suprimentos \\
\hline \multirow[t]{3}{*}{ Corporação } & \multicolumn{2}{|l|}{ Inserção } & Matriz \\
\hline & \multirow{2}{*}{$\begin{array}{|ll|}\begin{array}{l}\text { Interação com } \\
\text { unidades }\end{array} \\
\end{array}$} & Responsabilidade & Coordenador de desenvolvimento \\
\hline & & Equipe & Mundial \\
\hline \multirow[t]{8}{*}{ Empresa } & \multicolumn{2}{|c|}{ Responsabilidade técnica } & Centro de adaptação tecnológica \\
\hline & \multirow[t]{2}{*}{ Estratégia } & Competitiva & Misto \\
\hline & & Interprojetos & Novo \\
\hline & \multicolumn{2}{|c|}{ Informações iniciais } & Idéia \\
\hline & \multirow[t]{3}{*}{$\begin{array}{l}\text { Complexidade } \\
\text { do produto }\end{array}$} & $\begin{array}{l}\text { Tecnologia } \\
\text { principal }\end{array}$ & Mecânica / Elétrica \\
\hline & & Interna & Aplicação \\
\hline & & $\begin{array}{llll}\text { Interface } & \text { com } & \text { o } \\
\text { usuário } & & \\
\end{array}$ & Alta complexidade \\
\hline & \multicolumn{2}{|l|}{ Grau de inovação } & Pesquisa e desenvolvimento avançados \\
\hline
\end{tabular}

O processo de desenvolvimento de produtos da Empresa $C$ é apoiado pelo sistema ERP (SAP R/3 3.0F) e por vários sistemas complementares, destacando-se: um sistema gerenciador de projetos; um sistema de trabalho em grupo com funcionalidades de automação de fluxos de trabalho; uma base de dados técnicos de materiais; sistemas CAD bidimensionais e tridimensionais; um sistema CAPP; um sistema proprietário de controle de qualidade; aplicativos de escritório.

Após a escolha das empresas consideradas nos estudos de caso, definiu-se que a coleta dos dados, nesta fase da pesquisa, seria efetuada por meio de entrevistas focalizadas realizadas com membros das empresas analisadas.

A preparação para a realização das entrevistas compreendeu a elaboração prévia de um roteiro, a especificação de critérios para a escolha dos membros das empresas a serem entrevistados e a definição dos entrevistados.

O roteiro de entrevistas foi elaborado a partir dos grupos de funcionalidades de

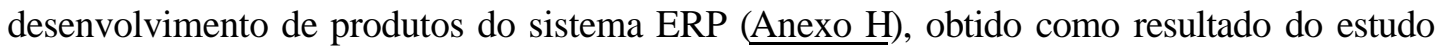
exploratório inicial, com base no modelo de referência do processo de desenvolvimento de produtos considerando a aplicação do sistema ERP (Anexo F). Dos 21 grupos de funcionalidades, 14 foram selecionados, devido à sua maior importância para o processo de desenvolvimento de produtos, para serem verificados nas empresas estudadas. 
Considerando-se os fundamentos metodológicos sobre a preparação de roteiros de entrevistas, discutidos no item 1.4.2 Escolha do Método de Pesquisa e das Técnicas de Coleta de Dados, foram definidas quatro perguntas que são formuladas repetidamente para cada um dos 14 grupos de funcionalidades selecionados anteriormente. A primeira pergunta verifica se a funcionalidade é empregada no desenvolvimento de produtos da empresa, independentemente do sistema utilizado (ERP ou sistema complementar). A segunda pergunta identifica o sistema utilizado para aquela funcionalidade específica (ERP ou sistema complementar). A terceira pergunta questiona os motivos que levaram à escolha por um ou outro sistema na empresa. A quarta pergunta, aplicada somente no caso de o sistema utilizado não ser o ERP, verifica a forma utilizada para integrar o sistema complementar ao ERP. Esse roteiro de entrevistas é apresentado no Anexo E deste texto.

Paralelamente à elaboração do roteiro de entrevistas, foram estabelecidos os critérios para a seleção dos membros das empresas a serem entrevistados. Definiu-se que essas pessoas deveriam possuir bons conhecimentos da aplicação do sistema ERP no desenvolvimento de produtos das empresas nas quais atuam.

A partir desse critério, foram definidas as pessoas entrevistadas. Na Empresa A, foi entrevistado um dos responsáveis pela área de tecnologia da informação da empresa que participou do projeto de implantação do sistema ERP. Na Empresa $B$, foram entrevistadas duas pessoas que atuam no processo de desenvolvimento de produtos utilizando o sistema ERP e sistemas complementares. Uma delas trabalha na área de projeto do produto e a outra trabalha na área de planejamento do processo de fabricação. Na Empresa $C$, foram entrevistadas três pessoas que atuam no desenvolvimento de produtos e que participaram da implantação do sistema ERP e da avaliação de sistemas complementares.

Todas as entrevistas foram realizadas nas próprias empresas analisadas. Isso permitiu que, durante as entrevistas, fossem observados alguns exemplos da utilização do sistema ERP no desenvolvimento de produtos das empresas, possibilitando um contato estreito do pesquisador com a realidade estudada.

\subsection{Análise da Aplicação do Sistema ERP no Processo de Desenvolvimento de Produtos das Empresas Estudadas}

Os dados obtidos nas entrevistas dos estudos de caso, que caracterizam a aplicação do sistema ERP no processo de desenvolvimento de produtos das empresas estudadas, são analisados neste item.

A apresentação e a discussão dos resultados obtidos é organizada em seções que correspondem aos grupos de funcionalidades de desenvolvimento de produtos do sistema 
ERP verificados nos estudos de caso. Para cada grupo de funcionalidades, são comparadas as soluções adotadas em cada uma das empresas.

\section{Gerenciamento de Projetos}

Para apoiar as atividades de planejamento e de controle dos projetos de desenvolvimento de produtos, uma das empresas estudadas (Empresa C) utiliza o sistema ERP em conjunto com um sistema complementar de gerenciamento de projetos. As outras duas empresas analisadas (Empresa A e Empresa B), por sua vez, utilizam apenas um sistema complementar.

Na Empresa A, a decisão de não utilizar o sistema ERP foi tomada após a constatação de que os potenciais benefícios não justificariam o investimento que seria necessário para implantar o módulo de gestão de projetos desse sistema.

A opção da Empresa B de não utilizar o sistema ERP foi decidida observando-se que o sistema complementar é suficiente para atender aos seus requisitos de gerenciamento dos projetos de desenvolvimento de produtos.

Na solução de gerenciamento de projetos adotada pela Empresa $C$, o sistema ERP é responsável pelo gerenciamento dos custos e dos investimentos e por parte da gestão dos recursos dos projetos, enquanto que o sistema complementar é responsável pela programação das atividades de desenvolvimento. Nesse caso, a opção de não gerenciar as datas das atividades utilizando-se o sistema ERP, foi atribuída à alta complexidade e à baixa flexibilidade desse sistema que dificultam a realização de alterações de planejamento durante a execução dos projetos.

Nos estudos de caso verificou-se também que em nenhuma das empresas analisadas o sistema complementar de gerenciamento de projetos está integrado com o sistema ERP.

\section{Cadastro de Materiais}

Em duas das empresas estudadas (Empresa Be Empresa C), o cadastramento de novos materiais durante o desenvolvimento de produtos é realizado diretamente no sistema ERP. Na outra empresa analisada (Empresa A) um material nem sempre é inicialmente cadastrado no ERP.

No desenvolvimento de produtos da Empresa $A$, os materiais podem ser primeiramente especificados no sistema $\mathrm{CAD}$, e posteriormente cadastrados no sistema ERP. Essa opção é decorrente do tipo de produto que demanda a utilização de sistemas CAD específicos e de bibliotecas de materiais padronizados. 
Nas Empresas $B$ e $C$, a determinação de cadastrar os novos materiais no sistema ERP é atribuída à decisão corporativa de se utilizar tal sistema como a "espinha dorsal" de seus sistemas de informação.

Observou-se, na Empresa $C$, que o cadastro de materiais do sistema ERP é complementado por uma base de dados de parâmetros técnicos de materiais. Ou seja, na solução adotada pela Empresa $C$, os dados "administrativos" dos materiais são cadastrados no ERP e os dados técnicos são armazenados na base de dados complementar. Nesse caso, a opção realizada também é justificada pelo tipo de produto, que requer o armazenamento de uma grande quantidade de atributos técnicos muito específicos.

Verificou-se também que apenas uma das empresas estudadas (Empresa C), integra um sistema complementar ao cadastro de materiais do sistema ERP. Nessa empresa, os materiais do ERP são exportados para um sistema CAPP por meio de um kit de integração desenvolvido pelo fornecedor do sistema CAPP e homologado pelo fornecedor do ERP.

\section{Estruturas de Produto}

Em todas as empresas estudadas, o gerenciamento das estruturas de produto durante o processo de desenvolvimento é realizado pelo sistema ERP.

Na Empresa A, no entanto, observou-se que nem todos os materiais são definidos por meio de estruturas de produto.

Nas Empresas $B$ e $C$, a opção de utilizar o sistema ERP para gerenciar as estruturas de produtos, assim como o cadastro de materiais, é decorrente de decisões estratégicas corporativas. Observou-se que o sistema ERP é claramente definido como a "espinha dorsal" dos sistemas de informação dessas empresas.

\section{Configuração Variante de Estruturas de Produto}

Das três empresas estudadas, somente uma (Empresa $C$ ) utiliza estruturas de produto variantes. Na Empresa $C$, as estruturas variantes também são gerenciadas pelo sistema ERP, assim como as estruturas de produto convencionais.

\section{Classificação}

Para apoiar a classificação de materiais, uma das empresas estudadas (Empresa C) utiliza o sistema ERP em conjunto com um sistema CAPP complementar. As outras duas empresas não utilizam o sistema ERP.

$\mathrm{Na}$ Empresa $C$, a classificação de materiais fabricados é realizada no sistema CAPP complementar e a classificação de materiais auxiliares é realizada no sistema ERP. A opção pela classificação de materiais fabricados no CAPP é decorrente da necessidade de dados 
básicos para a determinação automática de planos de processo para famílias de peças. Por sua vez, os materiais auxiliares que não são fabricados são classificados no sistema ERP.

\section{Gerenciamento de Documentos}

Para gerenciar os documentos de desenvolvimento de produtos, duas das empresas estudadas (Empresa Be Empresa C) utilizam o sistema ERP complementado por outras soluções. A outra empresa analisada (Empresa A) não utiliza o ERP.

Na Empresa A, o gerenciamento dos documentos é realizado por meio de um sistema proprietário. Tal sistema, que já era utilizado pela Empresa $A$ antes da implantação do sistema ERP, é suficiente para atender aos seus requisitos de gerenciamento de documentos no processo de desenvolvimento de produtos. Assim, optou-se por não se utilizar as funcionalidades de gerenciamento de documentos do sistema ERP.

$\mathrm{Na}$ Empresa B, os documentos da área de projeto do produto são gerenciados pelo sistema ERP e pelo sistema CAD. Na solução adotada, o sistema ERP armazena os dados "administrativos" dos documentos (identificação, data de validade, lista de distribuição, entre outros) que são cadastrados em uma "ficha". No entanto, as "fichas" do sistema ERP não são relacionadas com os arquivos físicos que definem os documentos e, portanto, não é possível acessar os documentos a partir do sistema ERP. O acesso aos documentos é realizado por meio do sistema CAD que gerencia todos os arquivos de documentos.

$\mathrm{Na}$ mesma empresa, os documentos da área de planejamento do processo de fabricação são totalmente gerenciados pelo sistema ERP. Além de armazenar os dados "administrativos" do documentos, o ERP gerencia o acesso aos arquivos físicos que definem os documentos. Tais arquivos são armazenados em um "cofre de dados" (vault) controlado pelo ERP.

Por fim, a Empresa $C$ utiliza quatro soluções para gerenciar documentos, dependendo do tipo de documento considerado. Os documentos de produtos, com exceção dos desenhos em CAD, são completamente gerenciados pelo ERP. O ERP armazena os dados "administrativos" de tais documentos e controla o acesso aos arquivos físicos que são armazenados em um vault. Os desenhos em CAD, por sua vz, são transformados para em um formato de visualização $(p d f)$ que também é completamente gerenciado pelo ERP. Entretanto, o controle e o acesso aos arquivos físicos originais dos desenhos só podem ser feitos por meio do sistema CAD. Já os documentos de processo de fabricação (detalhamentos do plano de processo) são gerenciados por um sistema CAPP. Finalmente, os documentos do processo de desenvolvimento de produtos são gerenciados por um sistema de trabalho em grupo. 


\section{Dados Técnicos de Recursos}

Duas das empresas analisadas utilizam o sistema ERP para armazenar dados técnicos de recursos (Empresa B e Empresa C). A outra empresa estudada (Empresa A) não utiliza o ERP com essa finalidade.

Na Empresa $A$ os dados técnicos de recursos são armazenados em um sistema CAPP complementar para serem utilizados nas atividades de definição dos planos de processo macro.

$\mathrm{Na}$ Empresa $B$, todos os dados técnicos de equipamentos são armazenados diretamente no sistema ERP.

A Empresa $C$ adota uma solução apoiada em dois sistemas. Os dados técnicos de recursos relacionados com a geração de planos de processo são armazenados em um sistema CAPP enquanto que os dados técnicos necessários para a manutenção dos recursos são armazenados no sistema ERP.

\section{Plano de Processo Macro}

Para apoiar as atividades de geração de planos de processo macro, uma das empresas estudadas (Empresa B) utiliza o sistema ERP. As outras duas empresas analisadas (Empresa $A$ e Empresa $C$ ) utilizam um sistema CAPP complementar.

Na Empresa A, o sistema CAPP complementar já era utilizado antes da implantação do sistema ERP. Como o CAPP atende aos requisitos de geração de planos de processo da empresa, optou-se por continuar utilizando tal sistema.

Na Empresa B, a opção pelo sistema ERP foi feita considerando-se que tal sistema é a "espinha dorsal" dos sistemas de informação da empresa e que o sistema ERP atende aos seus requisitos de planejamento de processo macro.

A Empresa $C$ possui requisitos específicos de planejamento de processo que não são completamente atendidos pelo sistema ERP, como, por exemplo, a geração automática de planos de processo para todos os materiais de uma mesma família a partir de um plano de processo básico e de um conjunto de características dos materiais da família. Devido a sua melhor adequação aos requisitos de geração de planos de processo da Empresa $C$, o sistema CAPP foi definido como o sistema responsável pelo planejamento de processo.

Em uma das empresas que utiliza o sistema CAPP para gerar planos de processo (Empresa C), os planos de processo são exportados do sistema CAPP para o sistema ERP por meio de um kit de integração. 


\section{Detalhamentos dos Planos de Processo}

Em uma das empresas estudadas (Empresa B), a geração dos detalhamentos dos planos de processo é apoiada pelo sistema ERP complementado por aplicativos de escritório. Nas outras duas empresas analisadas (Empresa A e Empresa $C$ ), as atividades de geração dos detalhamentos de planos de processo são apoiadas por um sistema CAPP complementar.

A justificativa para a utilização do CAPP no detalhamento dos planos de processo da Empresa A é a mesma apresentada anteriormente para a geração dos planos de processo macro. Optou-se por continuar utilizando o sistema CAPP que já era utilizado na empresa antes da implantação do sistema ERP.

Na Empresa $B$, alguns detalhamentos do plano de processo são definidos como documentos elaborados com o auxílio de aplicativos de escritório. Tais documentos são então relacionados com as operações do plano de processo macro no sistema ERP. Além disso, alguns detalhamentos, como o ferramental de fabricação, são especificados diretamente no ERP. A adoção do sistema ERP para apoiar tais atividades também é decorrente da definição anterior de se utilizar tal sistema na geração dos planos de processo macro.

Na Empresa $C$, todos os detalhamentos dos planos de processo são gerados com o apoio do sistema CAPP. Essa opção é resultante da decisão corporativa anterior que definiu que o sistema CAPP é responsável pelas atividades de planejamento de processo.

\section{Planos de Controle}

Para apoiar a elaboração de planos de controle, duas das empresas estudadas (Empresa B e Empresa $C$ ) utilizam o sistema ERP complementado como outros aplicativos. A Empresa A utiliza um sistema de controle de qualidade proprietário.

Tanto na Empresa B quanto na Empresa $C$, o sistema ERP é utilizado para gerar os planos de qualidade de recebimento, ou seja, para criar os planos de controle de materiais comprados. Os planos de controle de materiais fabricados, por sua vez, são gerados na Empresa $B$ com o auxílio de aplicativos de escritório, e na Empresa $C$ com o apoio de um sistema proprietário. Essa opção é justificada, em ambas as empresas, pela estratégia de implantação do módulo de qualidade do sistema ERP que priorizou as atividades de controle de materiais comprados. 


\section{Estimativa do Custo de Produtos}

Para estimar custos de produtos, duas das empresas estudadas (Empresa $B$ e Empresa C) utilizam o sistema ERP complementado por uma planilha eletrônica. A outra empresa analisada (Empresa A) utiliza somente uma planilha eletrônica.

Na Empresa A, a determinação preliminar de custos de produtos para a elaboração de orçamentos é dificultada pelo tipo de produto, projetado sob encomenda. Nesse caso, existem poucas informações estruturadas no início do processo de desenvolvimento e há grande variabilidade de produtos. Isso requer a utilização de uma ferramenta de cálculo com grande flexibilidade para a realização de simulações. Dessa forma, optou-se pelo emprego de uma planilha eletrônica.

Nas Empresa Be Empresa $C$, a estimativa de custo de produtos é determinada inicialmente no sistema ERP com base em informações de produtos semelhantes. Para isso são considerados os padrões de cálculo corporativos definidos no ERP. Os dados de custo obtidos no ERP são então analisados em simulações de custo realizadas com o auxílio de uma planilha eletrônica.

\section{Análise de Capacidades}

Apenas uma das empresas estudadas (Empresa C) utiliza o sistema ERP para analisar a capacidade de produção durante o processo de desenvolvimento de produtos. Das outras duas empresas analisadas, uma (Empresa B) utiliza um sistema proprietário, e a outra não realiza esse tipo de analise.

\section{Controle de Modificações de Engenharia}

Todas as empresas estudadas utilizam o sistema ERP para controlar modificações de engenharia durante o desenvolvimento de produtos. Essa opção foi realizada nas empresas considerando-se que o sistema ERP atende aos requisitos do controle de modificações de engenharia e é o sistema responsável pela administração da maioria dos dados corporativos dessas empresas.

\section{Fluxo de Trabalho}

Das três empresas consideradas nos estudos de caso, somente uma (Empresa C) utiliza as funcionalidades de fluxo de trabalho do sistema ERP, complementado pelo sistema de trabalho em grupo. As outras duas empresas não utilizam sistemas computacionais para apoiar o fluxo de trabalho.

Na Empresa $C$ definiu-se que o fluxo de trabalho envolvendo documentação técnica e modificações de engenharia seria controlado no sistema ERP. Essa opção é decorrente da 
opção anterior de se controlar as modificações de engenharia no sistema ERP. Porém, devido principalmente à limitação dos recursos de automação de fluxos de trabalho do sistema ERP e à dificuldade de programação de fluxos de trabalho nesse sistema, definiu-se que outros tipos de fluxo de trabalho seriam controlados pelo sistema complementar de trabalho em grupo. 


\section{CONCLUSÕES E CONSIDERAÇÕES FINAIS}

Neste trabalho analisou-se a aplicabilidade de um sistema ERP no processo de desenvolvimento de produtos. Essa análise, realizada com base em uma abordagem de pesquisa descritiva, foi subdividida em três fases: estudo exploratório, estudo descritivo e estudos de caso.

O estudo exploratório compreendeu a verificação da aplicabilidade do sistema ERP a um processo específico de desenvolvimento de produtos representado por um modelo de referência. Como resultado do estudo exploratório obteve-se uma nova representação desse modelo de referência, considerando a aplicação do sistema ERP (Anexo F).

Tal modelo demonstra que o sistema ERP pode ser utilizado para apoiar 56\% das atividades do processo de desenvolvimento de produtos selecionado para ser avaliado no estudo exploratório.

Por meio do modelo de referência pode-se observar que as principais funcionalidades de desenvolvimento de produtos do sistema ERP são relacionadas com a geração de dados básicos (Cadastro de Materiais, Estruturas de Produto, Planos de Processo Macro), com a gestão do processo de desenvolvimento (Gerenciamento de Projetos, Fluxo de Trabalho, Gerenciamento de Documentos, Controle de Modificações de Engenharia) e com a obtenção de informações que apóiam a tomada de decisões corporativas (Análise de Investimentos, Estimativa do Custo de Produtos, Análise de Capacidades, Sistema de Informações Gerenciais).

Com base no modelo de referência pode-se ainda verificar que o sistema ERP não possui grande parte das funcionalidades necessárias para apoiar as atividades da fase Desenvolver Plano Estratégico e Portfolio de Produtos, do processo de desenvolvimento de produtos analisado.

Outras lacunas do ERP observadas no modelo de referência referem-se principalmente ao apoio à aplicação de determinados métodos e técnicas de desenvolvimento de produtos, tais como FMEA, DFMA e QFD.

O modelo de referência também especifica as sobreposições de funcionalidades do sistema ERP com os sistemas complementares de desenvolvimento de produtos considerados no estudo exploratório. Destacam-se as sobreposições do sistema ERP com o sistema 
gerenciador de projetos (Gerenciamento de Projetos), com o sistema PDM (Cadastro de Materiais, Estruturas de Produto, Configuração Variante de Estruturas de Produtos, Classificação, Gerenciamento de Documentos, Fluxo de Trabalho, Controle de Modificações de Engenharia) e com o sistema CAPP (Cadastro de Materiais, Estruturas de Produto, Classificação, Gerenciamento de Documentos, Dados Técnicos de Recursos, Planos de Processo Macro, Detalhamentos dos Planos de Processo, Planos de Controle, Análise de Capacidades, Estimativa do Custo de Produtos).

Apesar de o sistema ERP e os sistemas complementares possuírem várias funcionalidades comuns, os especialistas entrevistados durante o estudo exploratório ressaltaram que algumas características (interface e recursos) dos sistemas complementares são geralmente mais apropriadas para atender às necessidades do processo de desenvolvimento de produtos.

Além de definir as atividades do processo de desenvolvimento de produtos que podem ser apoiadas pelo sistema ERP e de determinar as sobreposições de funcionalidades entre o ERP e os sistemas complementares, o modelo de referência também especifica os principais pontos de integração entre esses sistemas.

A especificação dos pontos de integração é uma das informações necessárias para a integração entre o sistema ERP e os sistemas complementares. A partir dos pontos de integração pode-se definir o sentido do fluxo de informações de integração (sistema de origem e sistema de destino) e, então, programar as conexões entre os sistemas. Deve-se observar, entretanto, que essas atividades não foram realizadas no estudo exploratório inicial, pois elas dependem de definições adicionais relacionadas com cada caso específico de aplicação do sistema ERP, como, por exemplo, a definição do sistema que é o "dono" de cada uma das informações do processo e a especificação dos sistemas que são utilizados para atualizar essas informações.

Após o estudo exploratório, realizou-se o estudo descritivo de uma aplicação piloto do sistema ERP em um ambiente de desenvolvimento de produtos, denominado Cenário de Desenvolvimento de Produtos Utilizando o Sistema ERP.

Tal Cenário, implantado com base em uma instância do modelo de referência obtido como resultado do estudo exploratório inicial, foi analisado por meio de testes e simulações. Nessa análise, foram observadas as principais soluções e limitações da aplicação prática do ERP no processo de desenvolvimento de produtos.

No Cenário pôde-se verificar, por exemplo, que o sistema ERP possui os recursos necessários para controlar os documentos de desenvolvimento de produtos que são definidos por arquivos físicos, mas o sistema não tem as funcionalidades que permitem o 
gerenciamento de documentos que são definidos como "visões" de bases de dados de sistemas complementares.

No Cenário também foram observadas as limitações do emprego das atuais soluções de integração do sistema ERP com o sistema de gestão de projetos e com o sistema CAPP.

Tais soluções, disponíveis comercialmente, são essencialmente baseadas na troca de arquivos e no envio de informações de um sistema para outro, de forma que os sistemas não manipulam objetos comuns. Nesses casos, verificou-se que a garantia da integridade dos dados de desenvolvimento de produtos que são manipulados pelo sistema ERP e por sistemas complementares depende da especificação de procedimentos rígidos de cadastro e de alteração de informações.

Por fim, realizaram-se os estudos de caso da utilização do sistema ERP no processo de desenvolvimento de produtos de três empresas.

Nos estudos de caso observou-se que o sistema ERP é claramente definido como a "espinha dorsal" dos sistemas de informação de duas das três empresas estudadas. No entanto, apenas uma das empresas pesquisadas utiliza grande parte do potencial do sistema ERP para processo de desenvolvimento de produtos. Além disso, observou-se que em nenhuma das empresas avaliadas existe grande integração do sistema ERP com os sistemas complementares de desenvolvimento de produtos.

Com relação ao método de pesquisa, considera-se que o emprego de três formas de pesquisa descritiva (estudo exploratório, estudo descritivo e estudos de caso) foi fundamental para a obtenção de uma visão sobre o tema do trabalho que fosse, ao mesmo tempo, ampla e pormenorizada. O estudo exploratório inicial é bastante aprofundado, porém restrito a um processo específico de desenvolvimento de produtos e limitado pelo enfoque conceitual da análise baseada no modelo de referência. O estudo descritivo e os estudos de caso, por sua vez, complementam o estudo exploratório com um enfoque mais prático e aplicado.

Durante o estudo exploratório verificou-se que a comparação de modelos de referência foi um método bastante eficiente para a localização das funcionalidades de desenvolvimento de produtos do sistema ERP, resultando na identificação de três quartos dessas funcionalidades. Isso sugere que a comparação de modelos pode ser um meio eficaz de as empresas identificarem as atividades de desenvolvimento de produtos que são atendidas pelo sistema ERP.

Apesar do bom resultado obtido na comparação de modelos, observou-se que o emprego de outras técnicas de coleta de dados complementares (observação direta e entrevista focalizada) foi essencial para a identificação de funcionalidades de desenvolvimento de produtos que não haviam sido localizadas na comparação de modelos, e 
para a realização de correções e ajustes sobre a melhor forma de utilização dessas funcionalidades.

Além disso, durante o estudo exploratório verificou-se também que o estabelecimento de requisitos bem detalhados do processo de desenvolvimento de produtos é essencial para a definição de lacunas muito específicas do sistema ERP. Isso indica uma limitação do emprego de modelos de referência pouco detalhados na especificação de lacunas do sistema ERP para o desenvolvimento de produtos.

De uma maneira geral, os resultados obtidos neste trabalho demonstram que o sistema ERP pode ser aplicado para apoiar grande parte das atividades de desenvolvimento de produtos e que ainda existem limitações e barreiras à essa aplicação. A partir desse resultado, considera-se que é pertinente realizar novos trabalhos nesta área de pesquisa.

Inicialmente, imagina-se que este trabalho possa ser complementado com análises semelhantes sobre os novos componentes, módulos e funcionalidades dos sistemas ERP, entre os quais o PLM (Product Lifecycle Management), o CRM (Customer Relationship Management), as aplicações analíticas baseadas em soluções de data warehousing e os serviços on-line oferecidos pela Internet, tais como os marketplaces.

Além disso, considera-se que as limitações relacionadas com a utilização das atuais soluções de integração do sistema ERP, observadas no Cenário, e a baixa integração do sistema ERP com os sistemas complementares, verificada nas empresas analisadas nos estudos de caso, indicam que deva-se buscar novos meios para melhorar a integração entre esses sistemas no desenvolvimento de produtos.

Finalmente, considera-se também que os resultados parciais das fases desta pesquisa podem originar novos trabalhos, como a criação de uma metodologia para a avaliação da aderência de sistemas ERP ao processo de desenvolvimento de produtos de empresas, adaptada das etapas realizadas no estudo exploratório; o aprimoramento do Cenário e a sua aplicação para apoiar a realização de cursos; a realização de estudos de caso mais detalhados sobre a aplicação de funcionalidades específicas do sistema ERP (Gerenciamento de Projetos, Controle de Modificações de Engenharia, entre outras). 


\section{ANEXOS}

Anexo A - Roteiro de Entrevista - Funcionalidades de DP do Sistema ERP

Duração prevista: 3 horas

Data:

Local:

Horário início:

Horário término:

\section{Introdução}

Duração prevista: 10 minutos

Apresentar resumidamente as justificativas, o objetivo, o método e as etapas gerais do trabalho. Localizar a entrevista nas etapas do trabalho.

\section{Dados do Entrevistado}

Duração prevista: 5 minutos

Empresa:

Nome:

Cargo:

Resumo da experiência na área:

3. Identificação e Validação das Funcionalidades do ERP que Apóiam o Processo de Desenvolvimento de Produtos

Duração prevista: 2 horas e 45 minutos

Para cada subatividade do modelo de referência do processo de desenvolvimento de produtos, responder as questões abaixo:

1. A especificação das funcionalidades do sistema ERP para a subatividade é adequada?

2. Existe mais alguma funcionalidade do sistema ERP que pode ser utilizada para apoiar a subatividade? 


\section{Anexo B - Roteiro de Entrevista - Sobreposição ERP / PDM}

Duração prevista: 2 horas e 30 minutos

Data:

Local:

Horário início:

Horário término:

\section{Introdução}

Duração prevista: 10 minutos

Apresentar resumidamente as justificativas, o objetivo, o método e as etapas gerais do trabalho. Localizar a entrevista nas etapas do trabalho.

\section{Dados do Entrevistado}

Duração prevista: 5 minutos

Empresa:

Nome:

Cargo:

Resumo da experiência na área:

\section{Validação das Sobreposições de Funcionalidades entre o Sistema ERP e o Sistema PDM}

Duração prevista: 2 horas e 15 minutos

As funcionalidades listadas abaixo estão disponíveis tanto no sistema ERP quanto no sistema PDM analisados neste trabalho. Para cada uma dessas sobreposições de funcionalidades, responder a seguinte questão:

1. A definição da sobreposição de funcionalidades é adequada? Em caso afirmativo, comente as principais semelhanças/diferenças existentes entre as funcionalidades disponíveis em ambos os sistemas.

๑ Cadastro de materiais.

- Estruturas de produto.

a Configuração variante de estruturas de produto.

- Gerenciamento de documentos. 
- Fluxo de Trabalho.

口 Classificação.

a Controle de modificações de engenharia.

2. Além das sobreposições de funcionalidades citadas anteriormente, existe mais alguma sobreposição de função entre o ERP e o sistema PDM?

3. Quais são as funcionalidades e características exclusivas do sistema PDM? 


\section{Anexo C - Roteiro de Entrevista - Sobreposição ERP / CAPP}

Duração prevista: 2 horas e 30 minutos

Data:

Local:

Horário início:

Horário término:

\section{Introdução}

Duração prevista: 10 minutos

Apresentar resumidamente as justificativas, o objetivo, o método e as etapas gerais do trabalho. Localizar a entrevista nas etapas do trabalho.

\section{Dados do Entrevistado}

Duração prevista: 5 minutos

Empresa:

Nome:

Cargo:

Resumo da experiência na área:

\section{Validação das Sobreposições de Funcionalidades entre o Sistema ERP e o Sistema CAPP}

Duração prevista: 2 horas e 15 minutos

As funcionalidades listadas abaixo estão disponíveis tanto no sistema ERP quanto no sistema CAPP analisados neste trabalho. Para cada uma dessas sobreposições de funcionalidades, responder a seguinte questão:

1. A definição da sobreposição de funcionalidades é adequada? Em caso afirmativo, comente as principais semelhanças/diferenças existentes entre as funcionalidades disponíveis em ambos os sistemas.

a Cadastro de materiais.

Estruturas de produto.

๑ Classificação.

․ Dados técnicos de equipamentos. 
- Planos de processo macro.

- Detalhamentos do plano de processo.

๑ Planos de controle.

- Estimativa do custo de produtos.

- Análise de capacidades.

2. Além das sobreposições de funcionalidades citadas anteriormente, existe mais alguma sobreposição de função entre o ERP e o sistema CAPP?

3. Quais são as funcionalidades e características exclusivas do sistema CAPP? 
Anexo D - Roteiro de Entrevista - Integração

Duração prevista: 2 horas e 30 minutos

Data:

Local:

Horário início:

Horário término:

\section{Introdução}

Duração prevista: 10 minutos

Apresentar resumidamente as justificativas, o objetivo, o método e as etapas gerais do trabalho. Localizar a entrevista nas etapas do trabalho.

\section{Dados do Entrevistado}

Duração prevista: 5 minutos

Empresa:

Nome:

Cargo:

Resumo da experiência na área:

\section{Determinação Conceitual das Formas de Integração}

Duração prevista: 1 horas e 45 minutos

A partir das sobreposições de funcionalidades entre o sistema ERP e os sistemas complementares e das lacunas do ERP, discutir a questão abaixo:

1. Quais são os principais pontos de integração entre o ERP e os sistemas complementares de desenvolvimento de produtos? 


\section{Anexo E - Roteiro de Entrevista - Estudos de Caso}

Duração prevista: 2 horas

Data:

Horário início:
Local:

Horário término:

1. Introdução

Duração prevista: 10 minutos

Apresentar resumidamente as justificativas, o objetivo, o método e as etapas gerais do trabalho.

Localizar a entrevista nas etapas do trabalho.

\section{Dados do Entrevistado}

Duração prevista: 5 minutos

Empresa:

Nome:

Cargo:

Resumo da experiência na área: 


\section{Caracterização do Desenvolvimento de Produto da Empresa}

\section{Duração prevista: 5 minutos}

1. Caracterizar o desenvolvimento de produtos da empresa de acordo com a tipologia proposta por ROZENFELD \& AMARAL (1999).

TABELA 10 - Tipologia de processos de desenvolvimento de produtos (ROZENFELD \& AMARAL, 1999)

\begin{tabular}{|c|c|c|c|}
\hline NÍVEL & \multicolumn{2}{|c|}{ FATOR } & TIPOS \\
\hline \multirow[t]{4}{*}{ Mercado } & \multicolumn{2}{|l|}{ Setor } & $\begin{array}{l}\text { Automobilístico, aeronáutico, petroquímico, } \\
\text { máquinas-ferramenta, eletrodomésticos, linha } \\
\text { branca, indústria de base }\end{array}$ \\
\hline & \multicolumn{2}{|l|}{ Concorrência } & $\begin{array}{l}\text { Monopólio, oligopólio competitivo, oligopólio } \\
\text { diferenciado, concorrência perfeita }\end{array}$ \\
\hline & \multirow[t]{2}{*}{ Alvo } & Geográfico & Local, regional, mundial \\
\hline & & $\begin{array}{l}\text { Posição na cadeia } \\
\text { de produção }\end{array}$ & $\begin{array}{l}\text { Contato com cliente final, intermediário na } \\
\text { cadeia de suprimentos }\end{array}$ \\
\hline \multirow[t]{3}{*}{ Corporação } & \multicolumn{2}{|l|}{ Inserção } & Unidade independente, matriz, filial \\
\hline & \multirow[t]{2}{*}{$\begin{array}{l}\text { Interação com } \\
\text { unidades }\end{array}$} & Responsabilidade & $\begin{array}{l}\text { Coordenador de desenvolvimento, participante } \\
\text { de co-desenvolvimento }\end{array}$ \\
\hline & & Equipe & Local, regional, mundial \\
\hline \multirow[t]{8}{*}{ Empresa } & \multicolumn{2}{|c|}{ Responsabilidade técnica } & $\begin{array}{l}\text { Centro de adaptação tecnológico, aquisição e } \\
\text { adaptação de tecnologia, centro de } \\
\text { desenvolvimento de produto, centro de } \\
\text { desenvolvimento tecnológico de manufatura, } \\
\text { centro de manufatura }\end{array}$ \\
\hline & \multirow[t]{2}{*}{ Estratégia } & Competitiva & Custo, qualidade, tempo, misto \\
\hline & & Interprojetos & Novo, simultâneo, seqüencial, posterior \\
\hline & \multicolumn{2}{|c|}{ Informações iniciais } & $\begin{array}{l}\text { Idéia, requisitos de desempenho, parte do } \\
\text { projeto do produto, parte do projeto do produto } \\
\text { e protótipos, produto em produção }\end{array}$ \\
\hline & \multirow[t]{3}{*}{$\begin{array}{l}\text { Complexidade } \\
\text { do produto }\end{array}$} & $\begin{array}{l}\text { Tecnologia } \\
\text { principal }\end{array}$ & $\begin{array}{l}\text { Mecânica, elétrica, eletrônica, mecatrônica, } \\
\text { opto-eletrônica, química }\end{array}$ \\
\hline & & Interna & $\begin{array}{l}\text { Número de componentes, números de linhas de } \\
\text { softwares, número de insumos e etapas }\end{array}$ \\
\hline & & $\begin{array}{l}\text { Interface com o } \\
\text { usuário }\end{array}$ & Alta complexidade, baixa complexidade \\
\hline & \multicolumn{2}{|l|}{ Grau de inovação } & $\begin{array}{l}\text { Pesquisa e desenvolvimento avançados, } \\
\text { breakthrough ou radical, plataformas ou nova } \\
\text { geração e derivados }\end{array}$ \\
\hline
\end{tabular}




\section{Caracterização dos Sistemas de Informação da Empresa}

Duração prevista: 10 minutos

1. Quais são os sistemas de informação empregados no processo de desenvolvimento de produtos da empresa (especificar versão)?

\section{Análise da Aplicação e Integração do Sistema ERP no Processo de Desenvolvimento de Produtos}

Duração prevista: 120 minutos

Para cada uma dos grupos de funcionalidades listados abaixo, responder o seguinte conjunto de questões:

1. A empresa utiliza a funcionalidade em seu processo de desenvolvimento de produtos?

2. Qual sistema foi escolhido para realizar a função na empresa?

3. Quais os motivos que levaram a essa escolha? Avaliar atendimento dos requisitos do processo, flexibilidade e facilidade de utilização.

No caso de o sistema utilizado não ser o ERP:

4. Como o sistema utilizado foi integrado ao ERP? Detalhar as informações que são transferidas entre os sistemas, o sentido de transferência das informações e a forma de integração adotada.

- Gerenciamento de projetos.

a Cadastro de materiais.

a Estruturas de produto.

- Configuração variante de estruturas de produto.

- Classificação.

a Gerenciamento de documentos. 
口 Dados técnicos de recursos.

a Planos de processo macro.

- Detalhamentos dos planos de processo.

a Planos de controle.

- Estimativa do custo de produtos.

\ Análise de capacidades.

- Fluxo de trabalho.

a Controle de modificações de engenharia. 
Anexo F - Modelo de Referência do Processo de Desenvolvimento de Produtos Considerando a Utilização de um Sistema ERP 


\begin{tabular}{|c|c|c|c|c|c|c|c|c|c|}
\hline \multirow[t]{2}{*}{ N. } & \multirow[t]{2}{*}{ Ação } & \multirow[t]{2}{*}{$\begin{array}{ll}T \\
\end{array}$} & \multirow[t]{2}{*}{ Recurso } & \multicolumn{3}{|c|}{ Transação } & \multirow[t]{2}{*}{ Informação de Entrada } & \multirow[t]{2}{*}{ Informação de Saída } & \multirow[t]{2}{*}{ Organização } \\
\hline & & & & Nome & Cod. & Caminho & & & \\
\hline 1 & $\begin{array}{l}\text { Preparar Estruturas para o } \\
\text { Desenvolvimento de Produtos }\end{array}$ & & & & & & & & \\
\hline \multirow[t]{2}{*}{3} & \multirow[t]{2}{*}{ Criar WBS padronizadas } & \multirow[t]{2}{*}{$\mathrm{C}$} & ERP & \begin{tabular}{|c|} 
Create \\
Standard \\
WBS
\end{tabular} & CJ91 & & & & \\
\hline & & & Ger. Projetos & & & & & & \\
\hline \multirow[t]{2}{*}{$\overline{3}$} & \multirow[t]{2}{*}{$\begin{array}{r}\text { Criar redes de atividades } \\
\text { padronizadas }\end{array}$} & \multirow[t]{2}{*}{$C$} & ERP & $\begin{array}{l}\text { Create } \\
\text { Standard } \\
\text { Network }\end{array}$ & CN01 & & & & \\
\hline & & & Ger. Projetos & & & & & & \\
\hline \multirow[t]{2}{*}{3} & \multirow[t]{2}{*}{ Criar milestones padronizados } & \multirow[t]{2}{*}{$\mathrm{C}$} & ERP & \begin{tabular}{|c|} 
Create \\
Standard \\
Milestone
\end{tabular} & CN11 & & & & \\
\hline & & & Ger. Projetos & & & & & & \\
\hline \multirow[t]{2}{*}{3} & \multirow[t]{2}{*}{$\begin{array}{r}\text { Definir procedimentos de controle de } \\
\text { modificações de engenharia }\end{array}$} & \multirow[t]{2}{*}{$C$} & ERP & $\begin{array}{l}\text { Create } \\
\text { hange } \\
\text { Master }\end{array}$ & $\mathrm{CC} 01$ & & & & \\
\hline & & & PDM & & & & & & \\
\hline & \begin{tabular}{|l|} 
Criar características, classes e \\
hierarquia de classes para \\
classificação (componentes, \\
documentos, máquinas, ferramentas, \\
operações)
\end{tabular} & $\mathrm{C}$ & ERP & $\begin{array}{c}\text { Create } \\
\text { Characteris } \\
\text { tic }\end{array}$ & CT01 & & & & \\
\hline
\end{tabular}




\begin{tabular}{|c|c|c|c|c|c|c|c|c|c|}
\hline \multirow[t]{2}{*}{ N. } & \multirow[t]{2}{*}{ Ação } & \multirow[t]{2}{*}{$\bar{T}$} & \multirow[t]{2}{*}{ Recurso } & \multicolumn{3}{|c|}{ Transação } & \multirow[t]{2}{*}{ Informação de Entrada } & \multirow[t]{2}{*}{ Informação de Saída } & \multirow[t]{2}{*}{ Organização } \\
\hline & & & & Nome & Cod. & Caminho & & & \\
\hline & & & ERP & $\begin{array}{l}\text { Create } \\
\text { Class }\end{array}$ & CL01 & & & & \\
\hline & & & ERP & \multicolumn{2}{|c|}{$\begin{array}{c}\text { Allocate Characteristics to } \\
\text { Class }\end{array}$} & [Characteristics & & & \\
\hline & & & ERP & $\begin{array}{c}\text { Allocate } \\
\text { Classes to } \\
\text { Class }\end{array}$ & CL22 & & & & \\
\hline & & & PDM & & & & & & \\
\hline & & & CAPP & & & & & & \\
\hline 3 & $\begin{array}{r}\text { Definir características de } \\
\text { inspeção padronizadas }\end{array}$ & $\mathrm{C}$ & ERP & \begin{tabular}{|c|} 
Create \\
Master \\
Inspection \\
Characteris \\
tics
\end{tabular} & QQS21 & & & & \\
\hline 3 & $\begin{array}{r}\text { Criar métodos de inspeção } \\
\text { padronizados }\end{array}$ & $\mathrm{C}$ & ERP & $\begin{array}{c}\text { Create } \\
\text { Inspection } \\
\text { Method }\end{array}$ & QQS31 & & & & \\
\hline & & & CAPP & & & & & & \\
\hline 3 & $\begin{array}{r}\text { Criar conjuntos de operações de } \\
\text { fabricação padronizadas }\end{array}$ & $\mathrm{C}$ & ERP & \begin{tabular}{|c|} 
Create \\
Reference \\
Operation \\
Set
\end{tabular} & CCA11 & & & & \\
\hline
\end{tabular}




\begin{tabular}{|c|c|c|c|c|c|c|c|c|c|}
\hline \multirow[t]{2}{*}{ N. } & \multirow[t]{2}{*}{ Ação } & \multirow[t]{2}{*}{$T$} & \multirow[t]{2}{*}{ Recurso } & \multicolumn{3}{|c|}{ Transação } & \multirow[t]{2}{*}{ | Informação de Entrada } & \multirow[t]{2}{*}{ |Informação de Saída | } & \multirow[t]{2}{*}{ Organização } \\
\hline & & & & Nome & Cod. & Caminho & & & \\
\hline & & & ERP & $\begin{array}{c}\text { Create } \\
\text { Reference } \\
\text { Rate } \\
\text { Routing }\end{array}$ & $1^{\text {CCA3 }}$ & & & & \\
\hline & & & CAPP & & & & & & \\
\hline 3 & $\begin{array}{r}\text { Criar fórmula / métodos / processos } \\
\text { de cálculo para CAPP }\end{array}$ & $\mathrm{C}$ & ERP & $\begin{array}{c}\text { Create } \\
\text { CAPP } \\
\text { Formula }\end{array}$ & CE11 & & & & \\
\hline & & & ERP & $\begin{array}{l}\text { Create } \\
\text { CAPP } \\
\text { Method }\end{array}$ & CE21 & & & & \\
\hline & & & $\begin{array}{l}\text { ERP } \\
\text { CAPP }\end{array}$ & $\begin{array}{l}\text { Create } \\
\text { CAPP } \\
\text { Process } \\
\end{array}$ & CCE31 & & & & \\
\hline 1 & $\begin{array}{l}\text { Desenvolver Plano } \\
\text { Estratégico e Portfólio de } \\
\text { Projetos }\end{array}$ & & & & & & & & \\
\hline 2 & Atualizar / Desenvolver Missão & $M / R$ & & & & & $\begin{array}{l}\text { Indices de Desempenho } \\
\text { Plano Estratégico e } \\
\text { Missão }\end{array}$ & Missão & Diretoria \\
\hline 3 & Atualizar / desenvolver missão & $\mathrm{M} / \mathrm{R}$ & & & & & & & \\
\hline 2 & Avaliar Posicionamento Estratégico & & & & & & $\begin{array}{l}\text { Missão } \\
\text { Fatores Estratégicos }\end{array}$ & Fatores Estratégicos & Diretoria \\
\hline
\end{tabular}




\begin{tabular}{|c|c|c|c|c|c|c|c|c|c|}
\hline \multirow[t]{2}{*}{ N. } & \multirow[t]{2}{*}{ Ação } & \multirow[t]{2}{*}{$T$} & \multirow[t]{2}{*}{ Recurso } & \multicolumn{3}{|c|}{ Transação } & \multirow{2}{*}{$\begin{array}{l}\text { Informação de } \\
\text { Entrada }\end{array}$} & \multirow[t]{2}{*}{ Informação de Saída } & \multirow[t]{2}{*}{ Organização } \\
\hline & & & & Nome & Cod. & Caminho & & & \\
\hline 3 & $\begin{array}{r}\text { Avaliar necessidades dos } \\
\text { consumidores / tendências de } \\
\text { mercado }\end{array}$ & M/R & & & & & & & \\
\hline 3 & Avaliar tendências tecnológicas & $\mathrm{M} / \mathrm{R}$ & & & & & & & \\
\hline 3 & $\begin{array}{r}\text { Avaliar capacidade dos canais de } \\
\text { venda }\end{array}$ & $\mathrm{M} / \mathrm{R} / \mathrm{C}$ & ERP & \begin{tabular}{|c|} 
Sales \\
Information \\
System
\end{tabular} & MCTO & & & & \\
\hline 3 & Avaliar capacidade da cadeia de valor & $\mathrm{M} / \mathrm{R} / \mathrm{C}$ & ERP & \begin{tabular}{|c|} 
Logistics \\
Information \\
System
\end{tabular} & MC00 & & & & \\
\hline 3 & Levantar metas financeiras & $\mathrm{M} / \mathrm{R} / \mathrm{C}$ & ERP & \begin{tabular}{|c|} 
Executive \\
Information \\
System
\end{tabular} & KCMN & & & & \\
\hline 3 & Avaliar posição competitiva & $\mathrm{M} / \mathrm{R} / \mathrm{C}$ & ERP & \begin{tabular}{|c|} 
Logistics \\
Information \\
System
\end{tabular} & $\mathrm{MCO0}$ & & & & \\
\hline 2 & Atualizar / Desenvolver Estratégia & & & & & & \begin{tabular}{|l} 
Missão \\
Fatores Estratégicos
\end{tabular} & \begin{tabular}{|l|} 
Mercado Alvo \\
Estratégia Competitiva \\
Capacitação e \\
Recursos \\
Necessários
\end{tabular} & Diretoria \\
\hline 3 & Definir oportunidades estratégicas & $\mathrm{M} / \mathrm{R}$ & & & & & & & \\
\hline
\end{tabular}




\begin{tabular}{|c|c|c|c|c|c|c|c|c|c|}
\hline \multirow[t]{2}{*}{$\mathbf{N}$. } & \multirow[t]{2}{*}{ Ação } & \multirow[t]{2}{*}{$\bar{T}$} & \multirow[t]{2}{*}{ Recurso } & \multicolumn{3}{|c|}{ Transação } & \multirow[t]{2}{*}{ Informação de Entrada } & \multirow[t]{2}{*}{ Informação de Saída } & \multirow[t]{2}{*}{ Organização } \\
\hline & & & & Nome & Cod. & Caminho & & & \\
\hline 3 & $\begin{array}{r}\text { Desenvolver cenários (uso da value } \\
\text { chain, tecnologia, crescimento, } \\
\text { competição, eventos futuros, etc.) }\end{array}$ & $\bar{C}$ & $\begin{array}{l}\text { Planilha } \\
\text { Eletrônica }\end{array}$ & & & & & & \\
\hline 3 & $\begin{array}{r}\text { Determinar estratégias para ser bem } \\
\text { sucedido no maior número de } \\
\text { cenários }\end{array}$ & $\mathrm{M} / \mathrm{R}$ & & & & & & & \\
\hline 3 & Avaliar Riscos & $\bar{M} / \mathrm{R}$ & & & & & & & \\
\hline 2 & $\begin{array}{c}\text { Atualizar / Desenvolver Portfólio de } \\
\text { Projetos }\end{array}$ & & & & & & Plano Estratégico & \begin{tabular}{|l|} 
Pefinição das \\
Plataformas e Oferta \\
de Produtos
\end{tabular} & Diretoria \\
\hline & $\begin{array}{r}\text { Atualizar / desenvolver plataformas de } \\
\text { produtos }\end{array}$ & $\mathrm{M} / \mathrm{R} / \mathrm{C}$ & $\begin{array}{l}\text { Planilha } \\
\text { Eletrônica }\end{array}$ & & & & & & \\
\hline 3 & $\begin{array}{r}\text { Programar plataformas e } \\
\text { oferta de produtos }\end{array}$ & $\mathrm{M} / \mathrm{R} / \mathrm{C}$ & $\begin{array}{l}\text { Planilha } \\
\text { Eletrônica }\end{array}$ & & & & & & \\
\hline & & & Ger. Projetos & & & & & & \\
\hline 2 & Aprovar Plano Estratégico & & & & & & Plano Estratégico & Plano Estratégico & Diretoria \\
\hline 3 & $\begin{array}{r}\text { Preparar documento do plano } \\
\text { estratégico }\end{array}$ & $\bar{C}$ & $\begin{array}{c}\text { Editor de } \\
\text { Textos } \\
\text { Planilha } \\
\text { Eletrônica }\end{array}$ & & & & & & \\
\hline 3 & Aprovar documento & $\mathrm{R}$ & & & & & & & \\
\hline 3 & Divulgar plano estratégico & $\bar{R}$ & $\begin{array}{l}\text { Sistema de } \\
\text { Apresentaçã }\end{array}$ & & & & & & \\
\hline
\end{tabular}




\begin{tabular}{|c|c|c|c|c|c|c|c|c|c|}
\hline \multirow[t]{2}{*}{$\mathbf{N}$. } & \multirow[t]{2}{*}{ Ação } & \multirow[t]{2}{*}{$\mathbf{T}$} & \multirow[t]{2}{*}{ Recurso } & \multicolumn{3}{|c|}{ Transação } & \multirow[t]{2}{*}{ Informação de Entrada } & \multirow[t]{2}{*}{ Informação de Saída } & \multirow[t]{2}{*}{ Organização } \\
\hline & & & & Nome & Cod. & Caminho & & & \\
\hline 2 & Propor Estudo de Produto & & & & & & Plano Estratégico & Diretrizes & $\begin{array}{c}\text { Diretoria } \\
\text { Coordenador de } \\
\text { Produto }\end{array}$ \\
\hline 3 & Escolher Time de Concepção & $\mathrm{R} / \mathrm{C}$ & ERP & $\begin{array}{c}\text { Find for } \\
\text { Qualifications }\end{array}$ & PPCP & \multicolumn{2}{|c|}{ Reporting -» Find -» For Qualifications } & & \\
\hline 3 & $\begin{array}{r}\text { Propor Coordenador de } \\
\text { Produto }\end{array}$ & $\mathrm{R} / \mathrm{C}$ & ERP & $\begin{array}{c}\text { Find for } \\
\text { Qualifications } \\
\end{array}$ & PCP & \multicolumn{2}{|c|}{ Reporting -» Find -» For Qualifications } & & \\
\hline 3 & $\begin{array}{r}\text { Iniciar a definição de } \\
\text { diretrizes preliminares }\end{array}$ & $\mathrm{R}$ & & & & & & & \\
\hline 3 & \multirow[t]{4}{*}{$\begin{array}{r}\text { Distribuir diretrizes para } \\
\text { análise individual }\end{array}$} & \multirow[t]{4}{*}{$C$} & ERP & Inbox & SO01 & $\begin{array}{c}\text { Entry } \gg \text { Create } \\
-\gg \text { New }\end{array}$ & & & \\
\hline & & & ERP & Start Task & SWUS & & & & \\
\hline & & & $\begin{array}{c}\text { Correio } \\
\text { Eletrônico }\end{array}$ & & & & & & \\
\hline & & & PDM & & & & & & \\
\hline 1 & Conceber Produto & & & & & & & & \\
\hline 2 & Planejar Concepção & & & & & & $\begin{array}{c}\text { Plano Estratégico } \\
\text { Diretrizes }\end{array}$ & $\begin{array}{c}\text { Cronograma de } \\
\text { Concepção }\end{array}$ & $\begin{array}{c}\text { Coordenador de } \\
\text { Produto }\end{array}$ \\
\hline 3 & Criar/ estruturar projeto & C & ERP & $\begin{array}{l}\text { Create Project } \\
\text { Definition }\end{array}$ & CJ06 & & & & \\
\hline
\end{tabular}




\begin{tabular}{|c|c|c|c|c|c|c|c|c|c|}
\hline \multirow[t]{2}{*}{ N. } & \multirow[t]{2}{*}{ Ação } & \multirow[t]{2}{*}{$\mathbf{T}$} & \multirow[t]{2}{*}{ Recurso } & \multicolumn{3}{|c|}{ Transação } & \multirow[t]{2}{*}{ Informação de Entrada } & \multirow[t]{2}{*}{ Informação de Saída } & \multirow[t]{2}{*}{ Organização } \\
\hline & & & & Nome & Cod. & Caminho & & & \\
\hline & & & ERP & $\begin{array}{l}\text { Change } \\
\text { Project - } \\
\text { Project } \\
\text { Release }\end{array}$ & CJ02 & $\begin{array}{c}\text { Edit -» Status -» } \\
\text { Release }\end{array}$ & & & \\
\hline & & & Ger. Projetos & & & & & & \\
\hline \multirow[t]{7}{*}{3} & \multirow[t]{7}{*}{$\begin{array}{r}\text { Elaborar cronograma macro das } \\
\text { atividades de Concepção }\end{array}$} & \multirow[t]{7}{*}{$\mathrm{C}$} & ERP & $\begin{array}{r}\text { Change WBS } \\
\text { Element }\end{array}$ & $\begin{array}{l}\text { CJ12 } \\
\end{array}$ & & & & \\
\hline & & & ERP & $\begin{array}{l}\text { Create } \\
\text { Network }\end{array}$ & CN21 & & & & \\
\hline & & & ERP & $\begin{array}{l}\text { Change } \\
\text { Structure } \\
\text { Planning - } \\
\text { Activities }\end{array}$ & CJ20 & [Activity data] & & & \\
\hline & & & ERP & \begin{tabular}{|c|} 
Change Time \\
Scheduling
\end{tabular} & CJ21 & Edit „» Schedule & & & \\
\hline & & & ERP & \begin{tabular}{|c|} 
Display Project \\
Planning \\
Board
\end{tabular} & CJ2C & & & & \\
\hline & & & ERP & $\begin{array}{l}\text { Change } \\
\text { Network - } \\
\text { Network } \\
\text { Release }\end{array}$ & CN22 & \begin{tabular}{|c|} 
Edit $-\gg$ Status -» \\
Release
\end{tabular} & & & \\
\hline & & & Ger. Projetos & & & & & & \\
\hline
\end{tabular}




\begin{tabular}{|c|c|c|c|c|c|c|c|c|c|}
\hline \multirow[t]{2}{*}{ N. } & \multirow[t]{2}{*}{ Ação } & \multirow[t]{2}{*}{$\mathbf{T}$} & \multirow[t]{2}{*}{ Recurso } & \multicolumn{3}{|c|}{ Transação } & \multirow[t]{2}{*}{ Informação de Entrada } & \multirow[t]{2}{*}{ Informação de Saída } & \multirow[t]{2}{*}{ Organização } \\
\hline & & & & Nome & Cod. & Caminho & & & \\
\hline \multirow[t]{2}{*}{3} & \multirow{2}{*}{$\begin{array}{r}\text { Integrar cronograma macro das } \\
\text { atividades de Concepação }\end{array}$} & \multirow[t]{2}{*}{1} & & & & & & & \\
\hline & & & Ger. Projetos & & & & & & \\
\hline 2 & Gerenciar Concepção & & & & & & $\begin{array}{c}\text { Cronograma de } \\
\text { Concepcão }\end{array}$ & $\begin{array}{l}\text { Cronograma de } \\
\text { Concepcão }\end{array}$ & $\begin{array}{l}\text { Coordenador de } \\
\text { Produto }\end{array}$ \\
\hline \multirow[t]{2}{*}{3} & \multirow[t]{2}{*}{ Verificar planejamento da Concepção } & \multirow[t]{2}{*}{ C } & ERP & \begin{tabular}{|l|} 
Display Project \\
Planning \\
Board
\end{tabular} & CJ2C & & & & \\
\hline & & & Ger. Projetos & & & & & & \\
\hline \multirow[t]{3}{*}{$\overline{3}$} & \multirow{3}{*}{$\begin{array}{r}\text { Confirmar o término das atividades de } \\
\text { Concepção }\end{array}$} & \multirow[t]{3}{*}{$C$} & \multirow[t]{2}{*}{ ERP } & Confirm & \multirow[t]{2}{*}{ CN25 } & & & & \\
\hline & & & & $\begin{array}{l}\text { Completions in } \\
\text { Network }\end{array}$ & & & & & \\
\hline & & & Ger. Projetos & & & & & & \\
\hline \multirow[t]{3}{*}{3} & \multirow{3}{*}{$\begin{array}{r}\text { Integrar informações de } \\
\text { acompanhamento das atividades de } \\
\text { Concepção }\end{array}$} & $\mathrm{T}$ & ERP & & & & & & \\
\hline & & & & & & & & & \\
\hline & & & Ger. Projetos & & & & & & \\
\hline 2 & Identificar e Completar Diretrizes & & & & & & $\begin{array}{c}\text { Cronograma de } \\
\text { Concepção } \\
\text { Diretrizes }\end{array}$ & Diretrizes & Time de Concepção \\
\hline 3 & Analisar diretrizes preliminares & $\mathrm{M}$ & & & & & & & \\
\hline & & & & & & & & & \\
\hline
\end{tabular}




\begin{tabular}{|c|c|c|c|c|c|c|c|c|c|}
\hline \multirow[t]{2}{*}{ N. } & \multirow[t]{2}{*}{ Ação } & \multirow[t]{2}{*}{$\mathbf{T}$} & \multirow[t]{2}{*}{ Recurso } & \multicolumn{3}{|c|}{ Transação } & \multirow[t]{2}{*}{ Informação de Entrada } & \multirow[t]{2}{*}{ Informação de Saída } & \multirow[t]{2}{*}{ Organização } \\
\hline & & & & Nome & Cod. & Caminho & & & \\
\hline 3 & $\begin{array}{r}\text { Identificar e propor definições e } \\
\text { conceitos como diretrizes a serem } \\
\text { seguidas pelo produto }\end{array}$ & $\bar{M}$ & & & & & & & \\
\hline 3 & $\begin{array}{l}\text { Completar as diretrizes (tecnologia, } \\
\text { mercado, investimentos necessários, } \\
\text { custo alvo, data de lançamento, etc...) }\end{array}$ & $\mathrm{C}$ & $\begin{array}{c}\text { Editor de } \\
\text { Textos }\end{array}$ & & & & & & \\
\hline 3 & $\begin{array}{r}\text { Identificar pessoas qualificadas para } \\
\text { participar do Time de } \\
\text { Desenvolvimento de Produto (PDT) }\end{array}$ & $\mathrm{C}$ & ERP & $\begin{array}{c}\text { Find for } \\
\text { Qualifications }\end{array}$ & PPCP & \multicolumn{2}{|c|}{ Reporting -» Find -» For Qualifications } & & \\
\hline 2 & Compilar Propostas de Diretrizes & & & & & & Diretrizes & Diretrizes & $\begin{array}{l}\text { Coordenador de } \\
\text { Produto }\end{array}$ \\
\hline 3 & Compilar material para reunião & $\mathrm{C}$ & $\begin{array}{c}\text { Editor de } \\
\text { Textos }\end{array}$ & & & & & & \\
\hline$\overline{3}$ & Distribuir material para reunião & $\mathrm{C}$ & ERP & Inbox & $\mathrm{SO} 01$ & $\begin{array}{c}\text { Entry } \gg \text { Create } \\
\quad \gg \text { New }\end{array}$ & & & \\
\hline & & & ERP & Start Task & SWUS & & & & \\
\hline & & & $\begin{array}{c}\text { Correio } \\
\text { Eletrônico }\end{array}$ & & & & & & \\
\hline & & & PDM & & & & & & \\
\hline 3 & $\begin{array}{l}\text { Marcar reunião do Time de } \\
\text { Concepção }\end{array}$ & $\mathrm{C}$ & ERP & $\begin{array}{c}\text { Maintain } \\
\text { Appointments } \\
\text { Diary }\end{array}$ & SSC1 & & & & \\
\hline
\end{tabular}




\begin{tabular}{|c|c|c|c|c|c|c|c|c|c|}
\hline \multirow[t]{2}{*}{ N. } & \multirow[t]{2}{*}{ Ação } & \multirow[t]{2}{*}{$\mathbf{T}$} & \multirow[t]{2}{*}{ Recurso } & \multicolumn{3}{|c|}{ Transação } & \multirow[t]{2}{*}{ Informação de Entrada } & \multirow[t]{2}{*}{ Informação de Saída } & \multirow[t]{2}{*}{ Organização } \\
\hline & & & & Nome & Cod. & Caminho & & & \\
\hline & & & $\begin{array}{c}\text { Agenda } \\
\text { Eletrônica }\end{array}$ & & & & & & \\
\hline 2 & Discutir e Definir Diretrizes & & & & & & Diretrizes & $\begin{array}{l}\text { Diretrizes } \\
\text { PDT }\end{array}$ & $\begin{array}{l}\text { Time de Concepção } \\
\text { Coordenador de } \\
\text { Produto }\end{array}$ \\
\hline 3 & $\begin{array}{c}\text { Discutir diretrizes do produto } \\
\text { (tecnologia, mercado, investimentos } \\
\text { necessários, custo alvo, data de } \\
\text { lançamento, etc...) }\end{array}$ & $\mathrm{R}$ & & & & & & & \\
\hline 3 & $\begin{array}{r}\text { Discutir cronograma macro de } \\
\text { desenvolvimento de produto }\end{array}$ & $\mathrm{R}$ & & & & & & & \\
\hline & $\begin{array}{c}\text { Formar Time de Desenvolvimento de } \\
\text { Produtos (PDT) com especialistas } \\
\text { das áreas afins e parceiros }\end{array}$ & $\mathrm{R}$ & & & & & & & \\
\hline 2 & Completar e Consolidar Diretrizes & & & & & & Diretrizes & $\begin{array}{l}\text { Diretrizes } \\
\text { Relatório } \\
\text { deConcepção }\end{array}$ & $\begin{array}{l}\text { Coordenador de } \\
\text { Produto }\end{array}$ \\
\hline 3 & Revisar diretrizes e consolidá-las & $\mathrm{C}$ & $\begin{array}{l}\text { Editor de } \\
\text { Textos }\end{array}$ & & & & & & \\
\hline 3 & Gerenciar documento diretrizes & $\mathrm{C}$ & ERP & \begin{tabular}{|c|} 
Create \\
Document Info \\
Record
\end{tabular} & CV01 & & & & \\
\hline & & & PDM & & & & & & \\
\hline
\end{tabular}




\begin{tabular}{|c|c|c|c|c|c|c|c|c|c|}
\hline \multirow[t]{2}{*}{ N. } & \multirow[t]{2}{*}{ Ação } & \multirow[t]{2}{*}{$\mathbf{T}$} & \multirow[t]{2}{*}{ Recurso } & \multicolumn{3}{|c|}{ Transação } & \multirow[t]{2}{*}{ Informação de Entrada } & \multirow[t]{2}{*}{ |Informação de Saída | } & \multirow[t]{2}{*}{ Organização } \\
\hline & & & & Nome & Cod. & Caminho & & & \\
\hline 3 & Gerar relatório de Concepção & $\mathrm{C}$ & $\begin{array}{l}\text { Editor de } \\
\text { Textos }\end{array}$ & & & & & & \\
\hline & Gerenciar relatório final de Concepção & $\mathrm{C}$ & PDM & \begin{tabular}{|c|} 
Create \\
Document Info \\
Record
\end{tabular} & CV01 & & & & \\
\hline 2 & Planejar Desenvolvimento & & & & & & \begin{tabular}{|l} 
Diretrizes \\
Relatório de Concepção
\end{tabular} & $\begin{array}{l}\text { Cronograma Macro } \\
\text { de Desenvolvimento }\end{array}$ & $\begin{array}{l}\text { Coordenador de } \\
\text { Produto }\end{array}$ \\
\hline 3 & $\begin{array}{r}\text { Elaborar cronograma macro de } \\
\text { desenvolvimento (WBS) }\end{array}$ & $\mathrm{C}$ & ERP & Change Project & CJ02 & & & & \\
\hline 3 & $\begin{array}{r}\text { Marcar reunião com o Time de } \\
\text { Desenvolvimento de Produto (PDT) }\end{array}$ & $C$ & $\begin{array}{c}\text { Agenda } \\
\text { Eletrônica }\end{array}$ & \begin{tabular}{|c|} 
Maintain \\
Appointments \\
Diary
\end{tabular} & SSC1 & & & & \\
\hline 2 & Phase Gate Conceber & & & & & & Relatório de Concepção & $\begin{array}{c}\text { Relatório Gate } \\
\text { onceber }\end{array}$ & Diretoria \\
\hline 3 & Análise financeira & $\mathrm{C}$ & $\begin{array}{l}\text { ERP } \\
\text { ERP }\end{array}$ & \begin{tabular}{|l|}
\multicolumn{1}{|c|}{$\frac{\text { Create }}{\text { Appropriation }}$} \\
Request
\end{tabular} & IMA1 & & & & \\
\hline
\end{tabular}




\begin{tabular}{|c|c|c|c|c|c|c|c|c|c|}
\hline \multirow[t]{2}{*}{$\mathbf{N .}$} & \multirow[t]{2}{*}{ Ação } & \multirow[t]{2}{*}{$\mathbf{T}$} & \multirow[t]{2}{*}{ Recurso } & \multicolumn{3}{|c|}{ Transação } & \multirow[t]{2}{*}{ Informação de Entrada } & \multirow[t]{2}{*}{ Informação de Saída } & \multirow[t]{2}{*}{ Organização } \\
\hline & & & & Nome & Cod. & Caminho & & & \\
\hline & & & ERP & $\begin{array}{l}\frac{\text { Appropriation }}{\text { Request }} \\
\underline{\text { Planning- }} \\
\text { Revenues } \\
\end{array}$ & IMAV & & & & \\
\hline & & & ERP & $\begin{array}{c}\begin{array}{c}\text { Change } \\
\text { Appropriation }\end{array} \\
\underline{\text { Request }}\end{array}$ & IMA2 & $\begin{array}{l}\text { [Variant } \\
\text { Overview] }\end{array}$ & & & \\
\hline & & & $\begin{array}{l}\text { Planilha } \\
\text { Eletrônica }\end{array}$ & & & & & & \\
\hline 3 & Análise dos critérios do phase gate & $\mathrm{R}$ & & & & & & & \\
\hline 3 & Registro das best / bad practices & C & & & & & & & \\
\hline 1 & Conceituar Produto & & & & & & & & \\
\hline 2 & Planejar Conceituação & & & & & & $\begin{array}{l}\text { Cronograma de } \\
\text { Desenvolvimento }\end{array}$ & $\begin{array}{l}\text { Cronograma de } \\
\text { Conceituação }\end{array}$ & $\begin{array}{l}\text { Coordenador de } \\
\text { Produto PDT }\end{array}$ \\
\hline 3 & $\begin{array}{r}\text { Detalhar planejamento da } \\
\text { Conceituação }\end{array}$ & $\mathrm{C}$ & ERP & $\begin{array}{l}\text { Transfer } \\
\text { Project for } \\
\text { Simulation }\end{array}$ & CJV4 & & & & \\
\hline & & & ERP & $\begin{array}{l}\text { Change } \\
\text { Simulation }\end{array}$ & CJV2 & & & & \\
\hline & & & ERP & $\begin{array}{c}\text { Change WBS } \\
\text { Element }\end{array}$ & CJ12 & & & & \\
\hline & & & ERP & $\begin{array}{c}\text { Create } \\
\text { Network }\end{array}$ & CN21 & & & & \\
\hline
\end{tabular}




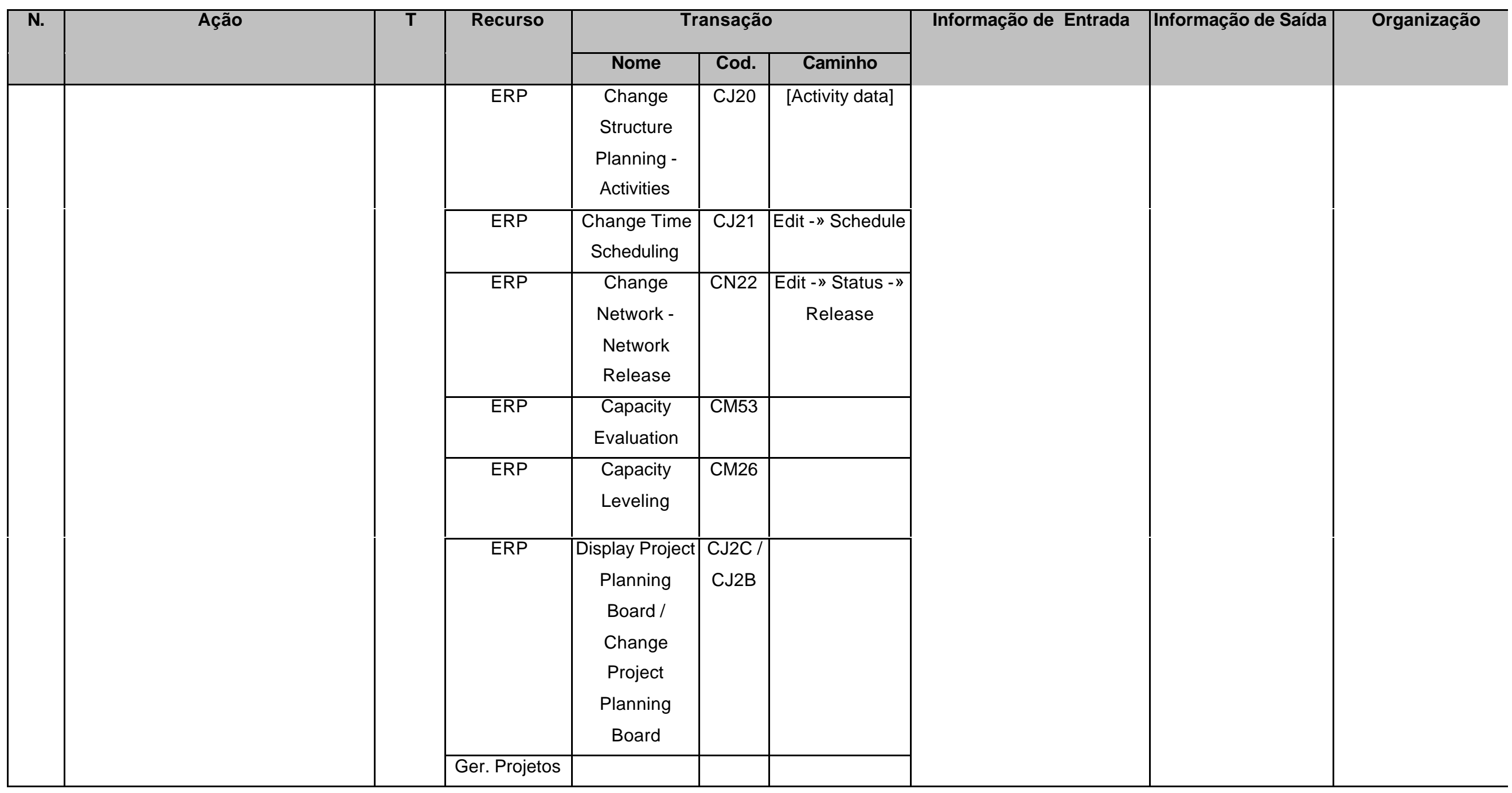




\begin{tabular}{|c|c|c|c|c|c|c|c|c|c|}
\hline \multirow[t]{2}{*}{ N. } & \multirow[t]{2}{*}{ Ação } & \multirow[t]{2}{*}{$\mathbf{T}$} & \multirow[t]{2}{*}{ Recurso } & \multicolumn{3}{|c|}{ Transação } & \multirow[t]{2}{*}{ Informação de Entrada } & \multirow[t]{2}{*}{ Informação de Saída } & \multirow[t]{2}{*}{ Organização } \\
\hline & & & & Nome & Cod. & Caminho & & & \\
\hline \multirow[t]{2}{*}{3} & $\begin{array}{c}\text { Integrar cronograma das atividades } \\
\text { de Conceituação }\end{array}$ & $\mathrm{T}$ & ERP & & & & & & \\
\hline & & & Ger. Projetos & & & & & & \\
\hline 2 & Gerenciar Conceituação & & & & & & $\begin{array}{l}\text { Cronograma de } \\
\text { Conceituação }\end{array}$ & $\begin{array}{l}\text { Cronograma de } \\
\text { Conceituação }\end{array}$ & $\begin{array}{l}\text { Coordenador de } \\
\text { Produto }\end{array}$ \\
\hline \multirow[t]{2}{*}{3} & $\begin{array}{l}\text { Verificar planejamento da } \\
\text { Conceituação }\end{array}$ & C & ERP & \begin{tabular}{|c|} 
Display Project \\
Planning \\
Board
\end{tabular} & CJ2C & & & & \\
\hline & & & Ger. Projetos & & & & & & \\
\hline \multirow[t]{2}{*}{3} & $\begin{array}{c}\text { Gerar relatórios de acompanhamento } \\
\text { das atividades }\end{array}$ & $\mathrm{C}$ & ERP & $\begin{array}{l}\text { Project } \\
\text { Managemet } \\
\text { Report } \\
\text { Selection }\end{array}$ & CJR1 & & & & \\
\hline & & & Ger. Projetos & & & & & & \\
\hline \multirow[t]{2}{*}{3} & $\begin{array}{c}\text { Confirmar o término das atividades de } \\
\text { Conceituação }\end{array}$ & C & ERP & \begin{tabular}{|c|} 
Confirm \\
Completions in \\
Network
\end{tabular} & CN25 & & & & \\
\hline & & & Ger. Projetos & & & & & & \\
\hline \multirow[t]{2}{*}{3} & $\begin{array}{c}\text { Integrar informações de } \\
\text { acompanhamento das atividades de } \\
\text { Conceituação }\end{array}$ & $\mathrm{T}$ & ERP & & & & & & \\
\hline & & & Ger. Projetos & & & & & & \\
\hline
\end{tabular}




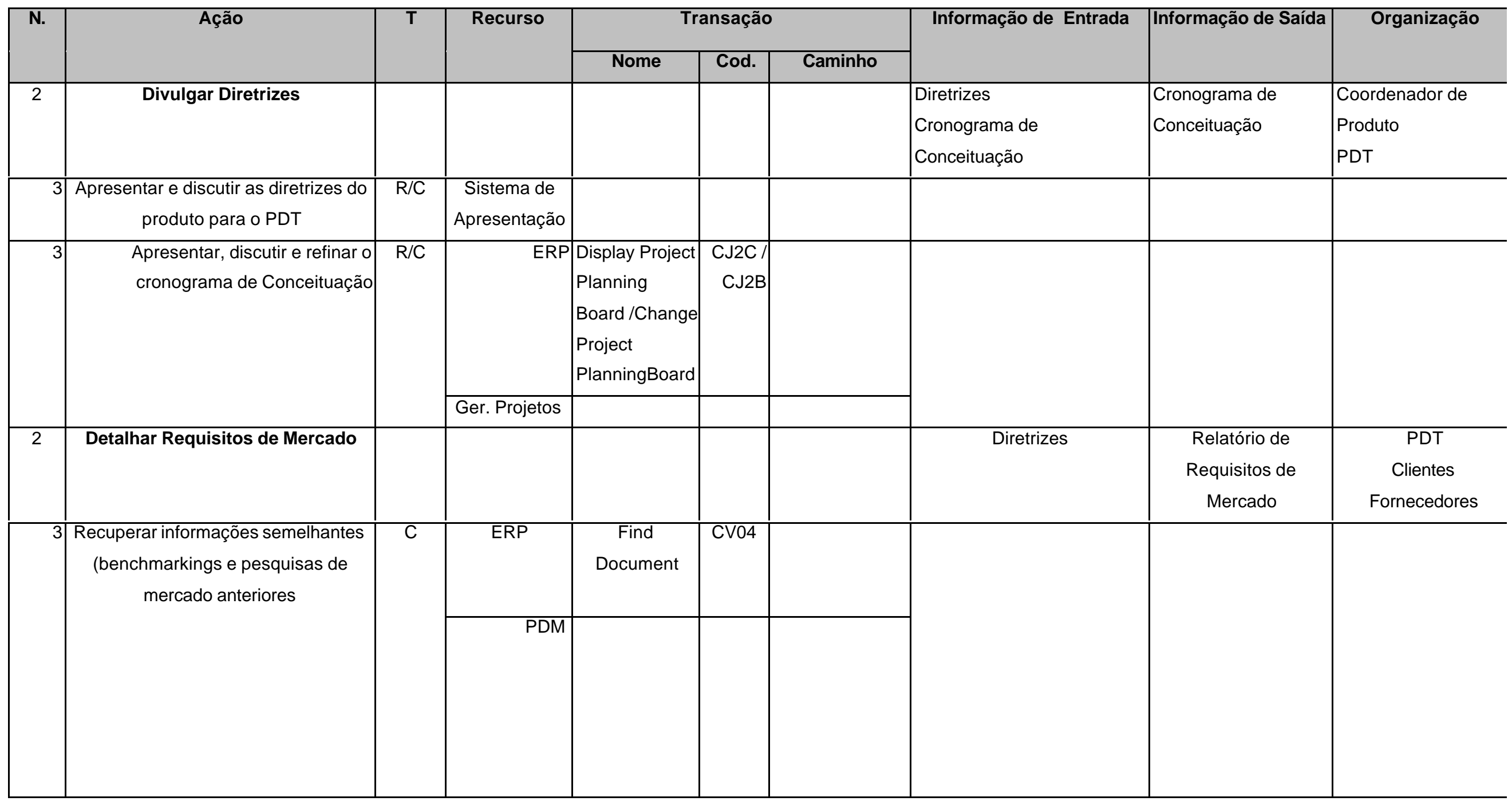




\begin{tabular}{|c|c|c|c|c|c|c|c|c|c|}
\hline \multirow[t]{2}{*}{ N. } & \multirow[t]{2}{*}{ Ação } & \multirow[t]{2}{*}{$\bar{T}$} & \multirow[t]{2}{*}{ Recurso } & \multicolumn{3}{|c|}{ Transação } & \multirow[t]{2}{*}{ Informação de Entrada } & \multirow[t]{2}{*}{ Informação de Saída } & \multirow[t]{2}{*}{ Organização } \\
\hline & & & & Nome & Cod. & Caminho & & & \\
\hline & \begin{tabular}{|r|} 
Recuperar reclamações de clientes e \\
informações sobre defeitos em \\
produtos semelhantes
\end{tabular} & $\bar{C}$ & ERP & \begin{tabular}{|l|} 
Material efects \\
Analysis/Qualit \\
y Notifications \\
Analysis
\end{tabular} & $\begin{array}{l}\mathrm{MCXX} / \\
\mathrm{MCXV}\end{array}$ & & & & \\
\hline 3 & Sistematizar informações & $\mathrm{M} / \mathrm{R} / \mathrm{C}$ & $\begin{array}{c}\text { Editor de } \\
\text { Textos } \\
\text { Planilha } \\
\text { Eletrônica }\end{array}$ & & & & & & \\
\hline 3 & $\begin{array}{r}\text { Realizar pesquisa de mercado e } \\
\text { benchmarking }\end{array}$ & M/R & & & & & & & \\
\hline 3 & $\begin{array}{r}\text { Comparar resultados com as } \\
\text { diretrizes propostas na Concepção }\end{array}$ & M/R & & & & & & & \\
\hline & $\begin{array}{r}\text { Gerar relatório de requisitos de } \\
\text { mercado }\end{array}$ & $C$ & $\begin{array}{c}\text { Editor de } \\
\text { Textos } \\
\text { Planilha } \\
\text { Eletrônica }\end{array}$ & & & & & & \\
\hline & $\begin{array}{r}\text { Gerenciar relatório de requisitos de } \\
\text { mercado }\end{array}$ & $\mathrm{C}$ & PDM & \begin{tabular}{|l|} 
Create \\
Document Info \\
Record
\end{tabular} & CV01 & & & & \\
\hline 2 & Definir Características Técnicas & & & & & & $\begin{array}{l}\text { Diretrizes } \\
\text { Relatório de Requisitos de } \\
\text { Mercado }\end{array}$ & \begin{tabular}{|l|} 
Relatório de \\
Requisitos Técnicos
\end{tabular} & \begin{tabular}{|l|} 
PDT \\
Fornecedores
\end{tabular} \\
\hline
\end{tabular}




\begin{tabular}{|c|c|c|c|c|c|c|c|c|c|}
\hline \multirow[t]{2}{*}{ N. } & \multirow[t]{2}{*}{ Ação } & \multirow[t]{2}{*}{$T$} & \multirow[t]{2}{*}{ Recurso } & \multicolumn{3}{|c|}{ Transação } & \multirow[t]{2}{*}{ Informação de Entrada } & \multirow[t]{2}{*}{ Informação de Saída } & \multirow[t]{2}{*}{ Organização } \\
\hline & & & & Nome & Cod. & Caminho & & & \\
\hline 3 & Aplicar técnica de QFD & $\mathrm{R}$ & & & & & & & \\
\hline 3 & Documentar QFD & C & QFD & & & & & & \\
\hline \multirow[t]{2}{*}{3} & \multirow[t]{2}{*}{ Gerar relatório de requisitos técnicos } & \multirow[t]{2}{*}{$C$} & $\begin{array}{l}\text { Editor de } \\
\text { Textos }\end{array}$ & & & & & & \\
\hline & & & $\begin{array}{c}\text { Planilha } \\
\text { Eletrônica }\end{array}$ & & & & & & \\
\hline \multirow[t]{2}{*}{3} & \multirow[t]{2}{*}{$\begin{array}{l}\text { Gerenciar documento QFD e } \\
\text { relatório de requisitos técnicos }\end{array}$} & \multirow[t]{2}{*}{$\mathrm{C}$} & ERP & \begin{tabular}{|c|} 
Create \\
Document Info \\
Record
\end{tabular} & CV01 & & & & \\
\hline & & & PDM & & & & & & \\
\hline 2 & $\begin{array}{c}\text { Especificar Linha de Produto } \\
\text { Modular }\end{array}$ & & & & & & $\begin{array}{c}\text { Diretrizes } \\
\text { Relatório de Requisitos } \\
\text { Técnicos }\end{array}$ & $\begin{array}{c}\text { Família de Produtos } \\
\text { Croquis }\end{array}$ & PDT \\
\hline \multirow[t]{5}{*}{3} & \multirow[t]{5}{*}{$\begin{array}{c}\text { Especificar número de produtos e } \\
\text { principais características }\end{array}$} & \multirow[t]{5}{*}{$\mathrm{M} / \mathrm{C}$} & ERP & \begin{tabular}{|l|} 
Create \\
Finished \\
Product/Create \\
Configurable \\
Material
\end{tabular} & $\begin{array}{l}\text { MMF1 } \\
\text { MMK1 }\end{array}$ & & & & \\
\hline & & & ERP & \begin{tabular}{|c|} 
Create \\
Characteristic
\end{tabular} & CT01 & & & & \\
\hline & & & ERP & Create Class & $\overline{\mathrm{CL} 01}$ & & & & \\
\hline & & & PDM & & & & & & \\
\hline & & & CAPP & & & & & & \\
\hline
\end{tabular}




\begin{tabular}{|c|c|c|c|c|c|c|c|c|c|}
\hline \multirow[t]{2}{*}{ N. } & \multirow[t]{2}{*}{ Ação } & \multirow[t]{2}{*}{$\mathbf{T}$} & \multirow[t]{2}{*}{ Recurso } & \multicolumn{3}{|c|}{ Transação } & \multirow[t]{2}{*}{ Informação de Entrada } & \multirow[t]{2}{*}{ Informação de Saída } & \multirow[t]{2}{*}{ Organização } \\
\hline & & & & Nome & Cod. & Caminho & & & \\
\hline 3 & Gerar croquis dos produtos & $\mathrm{C}$ & CAD & & & & & & \\
\hline \multirow[t]{3}{*}{3} & \multirow[t]{3}{*}{ Gerenciar croquis dos produtos } & \multirow[t]{3}{*}{ C } & ERP & \begin{tabular}{|c|} 
Create \\
Document Info \\
Record
\end{tabular} & CV01 & & & & \\
\hline & & & PDM & & & & & & \\
\hline & & & CAPP & & & & & & \\
\hline \multirow[t]{3}{*}{3} & \multirow[t]{3}{*}{$\begin{array}{c}\text { Integrar identificação e característica } \\
\text { de produtos }\end{array}$} & \multirow[t]{3}{*}{1} & ERP & & & & & & \\
\hline & & & PDM & & & & & & \\
\hline & & & CAPP & & & & & & \\
\hline 2 & Desenhar e Pré-Estruturar Produto & & & & & & $\begin{array}{l}\text { Diretrizes } \\
\text { Relatório de Requisitos } \\
\text { Técnicos } \\
\text { Família de Produtos } \\
\text { Croquis }\end{array}$ & \begin{tabular}{|l|} 
Desenho de Conjunto \\
Estrutura de Produto \\
Especificação de \\
Componentes
\end{tabular} & PDT \\
\hline \multirow[t]{4}{*}{3} & \multirow[t]{4}{*}{$\begin{array}{l}\text { Recuperar desenhos de produtos } \\
\text { anteriores }\end{array}$} & \multirow[t]{4}{*}{$\mathrm{C}$} & ERP & \begin{tabular}{|c|} 
Object Search \\
in Class
\end{tabular} & CL30 & & & & \\
\hline & & & ERP & $\begin{array}{c}\text { Find } \\
\text { Document }\end{array}$ & CV04 & & & & \\
\hline & & & PDM & & & & & & \\
\hline & & & CAPP & & & & & & \\
\hline 3 & $\begin{array}{c}\text { Visualizar desenhos de produtos } \\
\text { anteriores }\end{array}$ & $\mathrm{C}$ & Visualizador & & & & & & \\
\hline
\end{tabular}




\begin{tabular}{|c|c|c|c|c|c|c|c|c|c|}
\hline \multirow[t]{2}{*}{ N. } & \multirow[t]{2}{*}{ Ação } & \multirow[t]{2}{*}{$\mathrm{T}$} & \multirow[t]{2}{*}{ Recurso } & \multicolumn{3}{|c|}{ Transação } & \multirow[t]{2}{*}{ Informação de Entrada } & \multirow[t]{2}{*}{ Informação de Saída } & \multirow[t]{2}{*}{ Organização } \\
\hline & & & & Nome & Cod. & Caminho & & & \\
\hline \multirow[t]{3}{*}{3} & \multirow[t]{3}{*}{ Acessar croquis dos produtos } & \multirow[t]{3}{*}{$\bar{C}$} & ERP & \begin{tabular}{|c|} 
Change \\
Document Info \\
Record
\end{tabular} & CV02 & & & & \\
\hline & & & PDM & & & & & & \\
\hline & & & CAPP & & & & & & \\
\hline 3 & $\begin{array}{r}\text { Gerar/modificar croquis com } \\
\text { dimensões básicas de cada } \\
\text { componente quando necessário }\end{array}$ & $\mathrm{C}$ & CAD & & & & & & \\
\hline \multirow[t]{3}{*}{3} & \multirow[t]{3}{*}{ Classificar produto } & \multirow[t]{3}{*}{$\mathrm{C}$} & ERP & $\begin{array}{c}\text { Allocate Object } \\
\text { to Classes }\end{array}$ & CL20 & & & & \\
\hline & & & PDM & & & & & & \\
\hline & & & CAPP & & & & & & \\
\hline \multirow[t]{3}{*}{3} & \multirow[t]{3}{*}{ Recuperar componentes semelhantes } & \multirow[t]{3}{*}{$C$} & ERP & $\begin{array}{c}\text { Object Search } \\
\text { in Class }\end{array}$ & CL30 & & & & \\
\hline & & & PDM & & & & & & \\
\hline & & & CAPP & & & & & & \\
\hline$\overline{3}$ & $\begin{array}{r}\text { Visualizar desenhos de componentes } \\
\text { semelhantes }\end{array}$ & $\mathrm{C}$ & Visualizador & & & & & & \\
\hline \multirow[t]{4}{*}{\begin{tabular}{|l|}
3 \\
\end{tabular}} & \multirow[t]{4}{*}{$\begin{array}{r}\text { Identificar novos componentes do } \\
\text { produto }\end{array}$} & \multirow[t]{4}{*}{$\mathrm{C}$} & ERP & $\begin{array}{l}\text { Create } \\
\text { Material }\end{array}$ & MM01 & & & & \\
\hline & & & PDM & & & & & & \\
\hline & & & CAPP & & & & & & \\
\hline & & & CAD & & & & & & \\
\hline
\end{tabular}




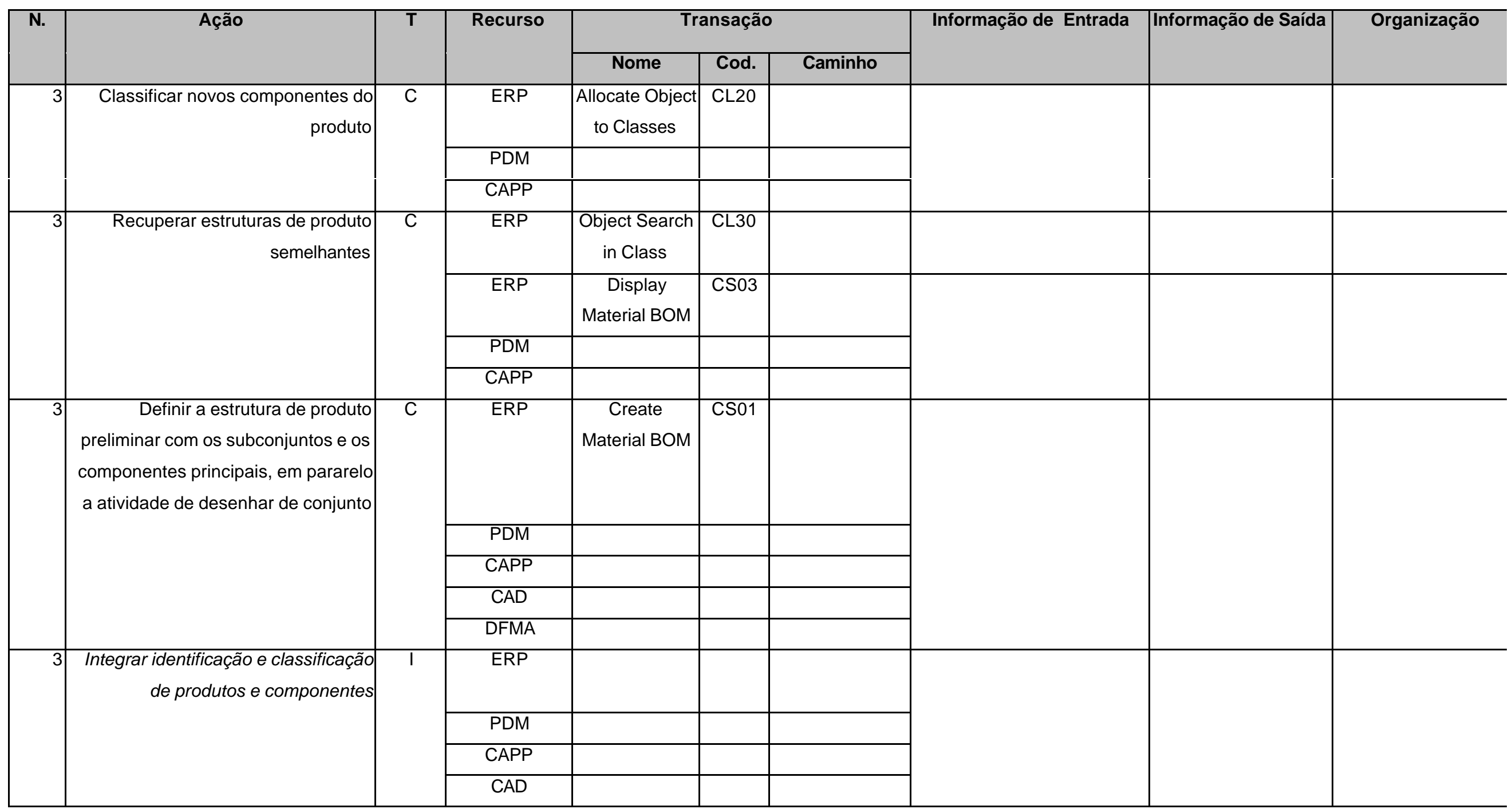




\begin{tabular}{|c|c|c|c|c|c|c|c|c|c|}
\hline \multirow[t]{2}{*}{ N. } & \multirow[t]{2}{*}{ Ação } & \multirow[t]{2}{*}{$\begin{array}{lll}T \\
T\end{array}$} & \multirow[t]{2}{*}{ Recurso } & \multicolumn{3}{|c|}{ Transação } & \multirow[t]{2}{*}{ Informação de Entrada } & \multirow[t]{2}{*}{ |Informação de Saída | } & \multirow[t]{2}{*}{ Organização } \\
\hline & & & & Nome & Cod. & Caminho & & & \\
\hline \multirow[t]{5}{*}{3} & \multirow[t]{5}{*}{ Integrar estruturas de produto } & \multirow[t]{5}{*}{1} & ERP & & & & & & \\
\hline & & & PDM & & & & & & \\
\hline & & & CAPP & & & & & & \\
\hline & & & CAD & & & & & & \\
\hline & & & DFMA & & & & & & \\
\hline 2 & Pré-Estruturar Processo & & & & & & $\begin{array}{l}\text { Diretrizes } \\
\text { Relatório de Requisitos } \\
\text { Técnicos } \\
\text { Desenho de Conjunto } \\
\text { Estrutura de Produto } \\
\text { Especificação de } \\
\text { Componentes }\end{array}$ & $\begin{array}{l}\text { Planos de Processo } \\
\text { Macro }\end{array}$ & PDT \\
\hline \multirow[t]{4}{*}{3} & \multirow[t]{4}{*}{$\begin{array}{r}\text { Recuperar planos de processo de } \\
\text { produtos e componentes anteriores }\end{array}$} & \multirow[t]{4}{*}{ C } & ERP & \begin{tabular}{|l|} 
Object Search \\
in Class
\end{tabular} & CL30 & & & & \\
\hline & & & ERP & Display outing & $\mathrm{CA03}$ & & & & \\
\hline & & & ERP & $\begin{array}{l}\text { Display Rate } \\
\text { Routing }\end{array}$ & CA23 & & & & \\
\hline & & & CAPP & & & & & & \\
\hline & \multirow{4}{*}{$\begin{array}{l}\text { Elaborar planos de processo macro } \\
\text { de fabricação e montagem }\end{array}$} & \multirow[t]{4}{*}{ C } & ERP & Create Routing & CA01 & & & & \\
\hline & & & ERP & Create Rate & & & & & \\
\hline & & & & Routing & A21 & & & & \\
\hline & & & CAPP & & & & & & \\
\hline & \multirow{2}{*}{$\begin{array}{l}\text { Integrar planos de processo macro de } \\
\text { fabricação e montagem }\end{array}$} & \multirow[t]{2}{*}{$\mathrm{I}$} & ERP & & & & & & \\
\hline & & & CAPP & & & & & & \\
\hline
\end{tabular}




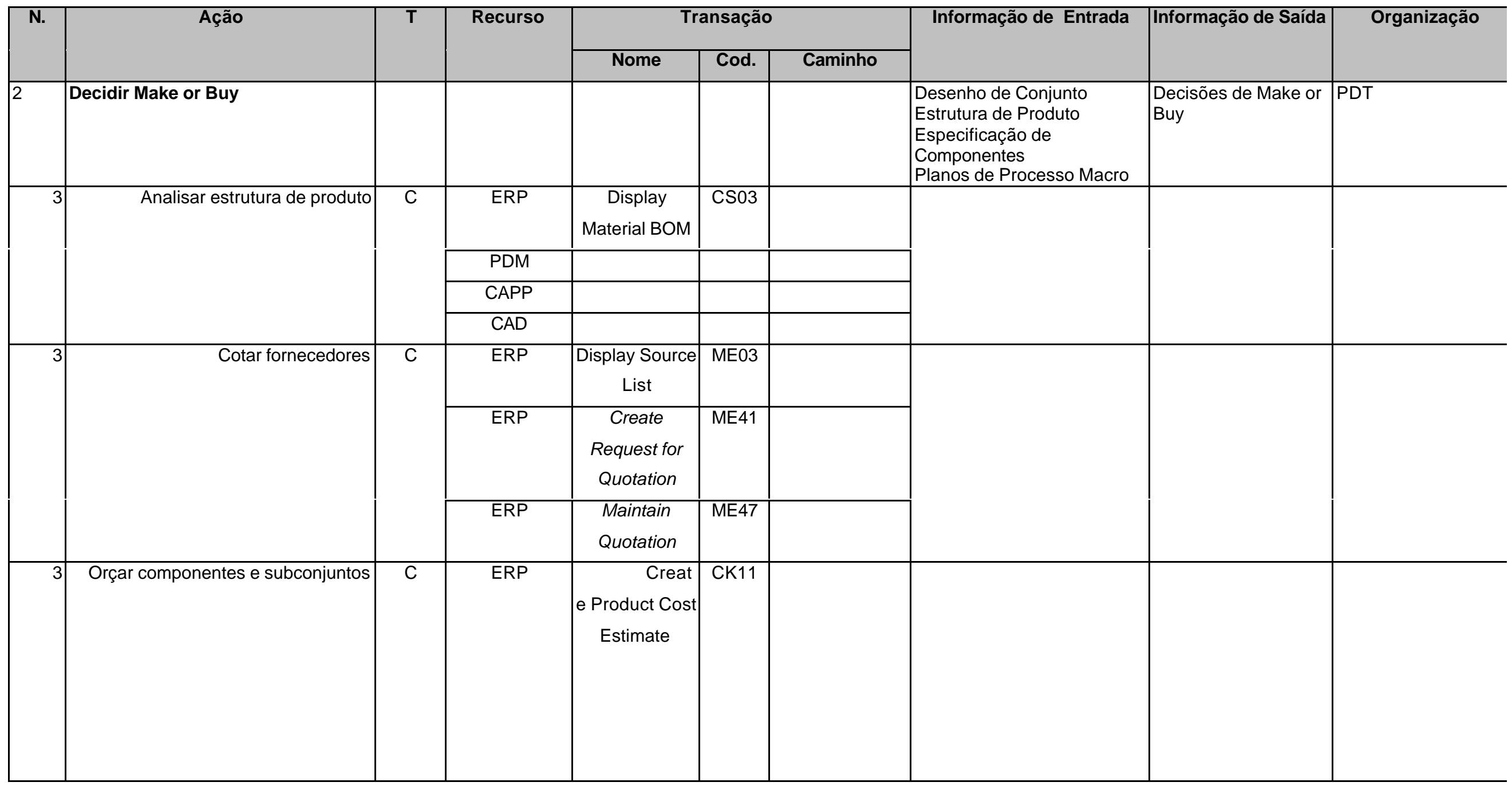




\begin{tabular}{|c|c|c|c|c|c|c|c|c|c|}
\hline \multirow[t]{2}{*}{ N. } & \multirow[t]{2}{*}{ Ação } & \multirow[t]{2}{*}{$\mathbf{T}$} & \multirow[t]{2}{*}{ Recurso } & \multicolumn{3}{|c|}{ Transação } & \multirow[t]{2}{*}{ Informação de Entrada } & \multirow[t]{2}{*}{ Informação de Saída | } & \multirow[t]{2}{*}{ Organização } \\
\hline & & & & Nome & Cod. & Caminho & & & \\
\hline & & & ERP & $\begin{array}{c}\text { Application } \\
\text { Tree Report } \\
\text { Selection } \\
\text { Product Cost } \\
\text { Planning }\end{array}$ & SART & \begin{tabular}{|l|} 
Logistics -» \\
Production -» \\
Product Cost \\
Planning -» \\
Information \\
System -» \\
Report Selection
\end{tabular} & & & \\
\hline & & & $\begin{array}{c}\text { CAPP } \\
\text { Planilha } \\
\text { Eletrônica }\end{array}$ & & & & & & \\
\hline 3 & $\begin{array}{r}\text { Comparar custo calculado com } \\
\text { orçamento/cotação }\end{array}$ & $\mathrm{C}$ & $\begin{array}{c}\text { ERP } \\
\text { Planilha } \\
\text { Eletrônica }\end{array}$ & $\begin{array}{r}\text { Price } \\
\text { comparison }\end{array}$ & ME49 & & & & \\
\hline 3 & Decidir "make or buy" & $\mathrm{R}$ & & & & & & & \\
\hline 3 & $\begin{array}{r}\text { Documentar decisões de } \\
\text { "make or buy" }\end{array}$ & $\mathrm{C}$ & ERP & $\begin{array}{l}\text { Change } \\
\text { Material }\end{array}$ & CM02 & & & & \\
\hline 3 & $\begin{array}{r}\text { Integrar informações de custo de } \\
\text { componentes e subconjuntos e } \\
\text { decisões de "make or buy" }\end{array}$ & $\mathrm{T}$ & $\begin{array}{l} \\
\text { PDM } \\
\text { CAPP }\end{array}$ & & & & & & \\
\hline
\end{tabular}




\begin{tabular}{|c|c|c|c|c|c|c|c|c|c|}
\hline \multirow[t]{2}{*}{ N. } & \multirow[t]{2}{*}{ Ação } & \multirow[t]{2}{*}{$\mathbf{T}$} & \multirow[t]{2}{*}{ Recurso } & \multicolumn{3}{|c|}{ Transação } & \multirow[t]{2}{*}{ Informação de Entrada } & \multirow[t]{2}{*}{ |Informação de Saída | } & \multirow[t]{2}{*}{ Organização } \\
\hline & & & & Nome & Cod. & Caminho & & & \\
\hline & & & $\begin{array}{c}\text { Planilha } \\
\text { Eletrônica }\end{array}$ & & & & & & \\
\hline 2 & $\begin{array}{r}\text { Estudar Viabilidade Econômica e } \\
\text { Avaliar Ciclo de Vida }\end{array}$ & & & & & & \begin{tabular}{|l|} 
Diretrizes \\
Estrutura de Produto \\
Planos de Processo Macro \\
Decisões Make or Buy
\end{tabular} & $\begin{array}{l}\text { Relatório de } \\
\text { Viabilidade } \\
\text { Econômica }\end{array}$ & $\overline{P D T}$ \\
\hline \multirow[t]{4}{*}{3} & \multirow[t]{4}{*}{ Estimar custo do projeto } & \multirow[t]{4}{*}{$\mathrm{C}$} & ERP & $\begin{array}{c}\text { Change } \\
\text { Project Cost } \\
\text { Plan }\end{array}$ & CJ40 & & & & \\
\hline & & & ERP & $\begin{array}{c}\text { Network } \\
\text { Costing } \\
\text { Calculation }\end{array}$ & CJ9K & & & & \\
\hline & & & Ger. Projeto & & & & & & \\
\hline & & & $\begin{array}{c}\text { Planilha } \\
\text { Eletrônica }\end{array}$ & & & & & & \\
\hline \multirow[t]{2}{*}{3} & \multirow[t]{2}{*}{ Montar fluxo de caixa do projeto } & \multirow[t]{2}{*}{$\mathrm{C}$} & ERP & \begin{tabular}{c|}
$\begin{array}{c}\text { Create } \\
\text { Appropriation }\end{array}$ \\
$\underline{\text { Request }}$
\end{tabular} & IMA1 & & & & \\
\hline & & & ERP & $\begin{array}{l}\frac{\text { Appropriation }}{\text { Request }} \\
\frac{\text { Planning- }}{\text { Costs }}\end{array}$ & IMAP & & & & \\
\hline
\end{tabular}




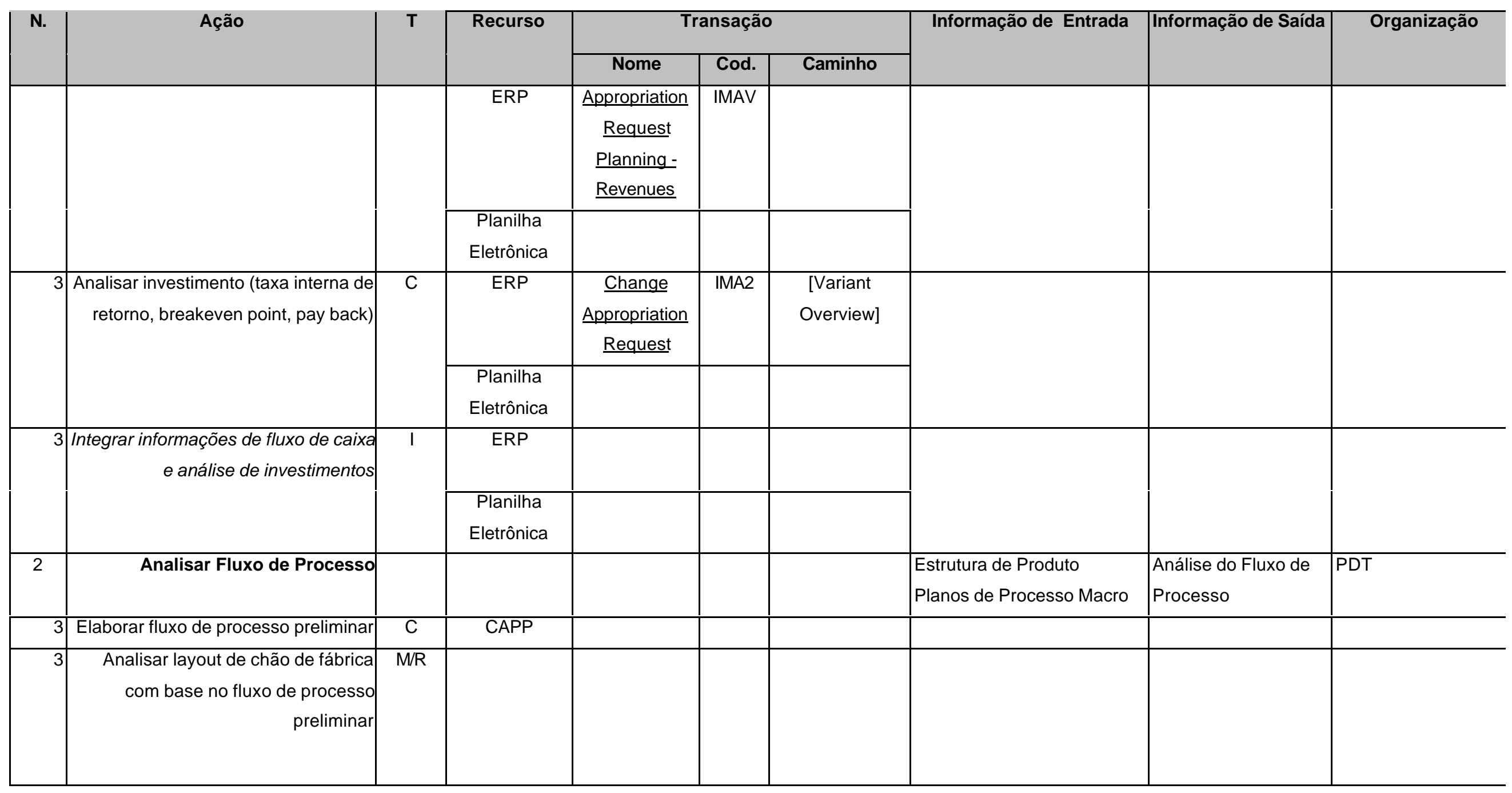




\begin{tabular}{|c|c|c|c|c|c|c|c|c|c|}
\hline \multirow[t]{2}{*}{ N. } & \multirow[t]{2}{*}{ Ação } & \multirow[t]{2}{*}{$\begin{array}{c}T \\
T\end{array}$} & \multirow[t]{2}{*}{ Recurso } & \multicolumn{3}{|c|}{ Transação } & \multirow[t]{2}{*}{ Informação de Entrada } & \multirow[t]{2}{*}{ Informação de Saída } & \multirow[t]{2}{*}{ Organização } \\
\hline & & & & Nome & Cod. & Caminho & & & \\
\hline 2 & Analisar Impacto Interno & & & & & & \begin{tabular}{|l} 
Diretrizes \\
Estruturas de Produto \\
Planos de Processo Macro \\
Decisões Make or Buy
\end{tabular} & $\begin{array}{l}\text { Relatório de Impacto } \\
\text { Interno }\end{array}$ & PDT \\
\hline 3 & Analisar capacidade dos recursos & & ERP & $\begin{array}{c}\text { Capacity } \\
\text { Evaluation }\end{array}$ & CM50 & & & & \\
\hline 2 & Consolidar Conceituação & & & & & & \begin{tabular}{|l} 
Diretrizes \\
Relatório de Mercado \\
Relatório Técnicos \\
Família de Produtos \\
Desenho de Conjunto \\
Estrutura de Produto \\
Especificações de \\
Componentes \\
Planos de Processo \\
macros \\
Decisões de Make or Buy \\
Relatório de Viabilidade \\
Econômica \\
Análise do Fluxo de Proceso \\
Relatório de Impacto Interno
\end{tabular} & $\begin{array}{l}\text { Relatório de } \\
\text { Conceituação }\end{array}$ & $\begin{array}{l}\text { Coordenador de } \\
\text { Produto }\end{array}$ \\
\hline
\end{tabular}




\begin{tabular}{|c|c|c|c|c|c|c|c|c|c|}
\hline \multirow[t]{2}{*}{$\mathbf{N}$. } & \multirow[t]{2}{*}{ Ação } & \multirow[t]{2}{*}{$\mathrm{T}$} & \multirow[t]{2}{*}{ Recurso } & \multicolumn{3}{|c|}{ Transação } & \multirow[t]{2}{*}{ Informação de Entrada } & \multirow[t]{2}{*}{ Informação de Saída } & \multirow[t]{2}{*}{ Organização } \\
\hline & & & & Nome & Cod. & Caminho & & & \\
\hline \multirow[t]{3}{*}{3} & \multirow[t]{3}{*}{$\begin{array}{r}\text { Revisar as informações geradas e } \\
\text { consolidá-las }\end{array}$} & & ERP & \begin{tabular}{|c|} 
Display \\
Document Info \\
Record
\end{tabular} & CV03 & & & & \\
\hline & & & ERP & \begin{tabular}{|c|} 
Change \\
Document Info \\
Record
\end{tabular} & CV02 & & & & \\
\hline & & & PDM & & & & & & \\
\hline 3 & Gerar relatório de Conceituação & $\mathrm{C}$ & $\begin{array}{l}\text { Editor de } \\
\text { Textos }\end{array}$ & & & & & & \\
\hline \multirow[t]{2}{*}{3} & \multirow[t]{2}{*}{ Gerenciar relatório de Conceituação } & \multirow[t]{2}{*}{$\mathrm{C}$} & ERP & \begin{tabular}{|c|} 
Create \\
Document Info \\
Record
\end{tabular} & CV01 & & & & \\
\hline & & & PDM & & & & & & \\
\hline \multirow[t]{2}{*}{3} & \multirow[t]{2}{*}{$\begin{array}{r}\text { Marcar reunião com o grupo de } \\
\text { concepção }\end{array}$} & \multirow[t]{2}{*}{$\mathrm{C}$} & ERP & \begin{tabular}{|c|} 
Maintain \\
Appointments \\
Diary
\end{tabular} & SSC1 & & & & \\
\hline & & & $\begin{array}{c}\text { Agenda } \\
\text { Eletrônica }\end{array}$ & & & & & & \\
\hline 2 & Validar Diretrizes & & & & & & $\begin{array}{l}\text { Diretrizes } \\
\text { Relatório de Conceituação }\end{array}$ & Diretrizes & $\begin{array}{l}\text { Grupo Concepção } \\
\text { Coordenador de } \\
\text { Produto } \\
\text { PDT }\end{array}$ \\
\hline
\end{tabular}




\begin{tabular}{|c|c|c|c|c|c|c|c|c|c|}
\hline \multirow[t]{2}{*}{$\mathbf{N}$. } & \multirow[t]{2}{*}{ Ação } & \multirow[t]{2}{*}{$\mathbf{T}$} & \multirow[t]{2}{*}{ Recurso } & \multicolumn{3}{|c|}{ Transação } & \multirow[t]{2}{*}{ Informação de Entrada } & \multirow[t]{2}{*}{ Informação de Saída } & \multirow[t]{2}{*}{ Organização } \\
\hline & & & & Nome & Cod. & Caminho & & & \\
\hline 3 & $\begin{array}{l}\text { Aprovar os conceitos do produto, } \\
\text { levando em conta suas diretrizes }\end{array}$ & $\mathrm{R}$ & & & & & & & \\
\hline 3 & $\begin{array}{r}\text { Identificar pessoas qualificadas para } \\
\text { participar do time expandido de } \\
\text { desenvolvimento de produto }\end{array}$ & $\mathrm{C}$ & ERP & $\begin{array}{c}\text { Find for } \\
\text { Qualifications }\end{array}$ & PPCP & $\begin{array}{l}\text { Reporting -» } \\
\text { Find -» For } \\
\text { Qualifications }\end{array}$ & & & \\
\hline 3 & $\begin{array}{r}\text { Escolher os especialistas a serem } \\
\text { incoporados ao PDT Expandido } \\
\text { (EPDT) }\end{array}$ & $\mathrm{R}$ & & & & & & & \\
\hline 3 & $\begin{array}{r}\text { Marcar reunião para a apresentação } \\
\text { das informações com o EPDT }\end{array}$ & $C$ & $\begin{array}{c}\text { Agenda } \\
\text { Eletrônica }\end{array}$ & $\begin{array}{c}\text { Maintain } \\
\text { Appointments } \\
\text { Diary } \\
\end{array}$ & SSC1 & & & & \\
\hline 2 & Phase Gate Conceituar & & & & & & Relatório de Conceituação & $\begin{array}{l}\text { Relatório Gate } \\
\text { Conceituar }\end{array}$ & Diretoria \\
\hline 3 & Análise financeira & $\mathrm{C}$ & ERP & \begin{tabular}{|c}
$\begin{array}{c}\text { Appropriation } \\
\text { Request } \\
\text { Planning- } \\
\text { Costs }\end{array}$ \\
$\begin{array}{c}\text { Appropriation } \\
\text { Request }\end{array}$ \\
$\underline{\text { Planning - }}$ \\
Revenues \\
\end{tabular} & IMAV & & & & \\
\hline
\end{tabular}




\begin{tabular}{|c|c|c|c|c|c|c|c|c|c|}
\hline \multirow[t]{2}{*}{ N. } & \multirow[t]{2}{*}{ Ação } & \multirow[t]{2}{*}{$\mathbf{T}$} & \multirow[t]{2}{*}{ Recurso } & \multicolumn{3}{|c|}{ Transação } & \multirow[t]{2}{*}{ Informação de Entrada } & \multirow[t]{2}{*}{ Informação de Saída } & \multirow[t]{2}{*}{ Organização } \\
\hline & & & & Nome & Cod. & Caminho & & & \\
\hline & & & ERP & $\begin{array}{c}\text { Change } \\
\text { Appropriation } \\
\text { Request }\end{array}$ & IMA2 & $\begin{array}{c}\text { [Variant } \\
\text { Overview] }\end{array}$ & & & \\
\hline & & & $\begin{array}{l}\text { Planilha } \\
\text { Eletrônica }\end{array}$ & & & & & & \\
\hline & Análise dos critérios do phase gate & & & & & & & & \\
\hline 3 & Registro das best / bad practices & & & & & & & & \\
\hline 1 & Projetar Produto e Processo & & & & & & & & \\
\hline 2 & Planejar Projeto & & & & & & $\begin{array}{l}\text { Cronograma de } \\
\text { Desenvolvimento }\end{array}$ & 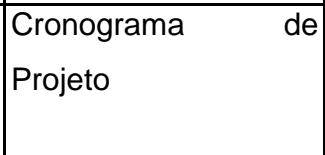 & $\begin{array}{l}\text { Coordenador de } \\
\text { Produto } \\
\text { EPDT }\end{array}$ \\
\hline 3 & Planejar atividades de projeto & & ERP & $\begin{array}{l}\text { Transfer } \\
\text { Project for } \\
\text { Simulation }\end{array}$ & CJV4 & & & & \\
\hline & & & ERP & $\begin{array}{l}\text { Change } \\
\text { Simulation }\end{array}$ & CJV2 & & & & \\
\hline & & & ERP & $\begin{array}{c}\text { Change WBS } \\
\text { Element }\end{array}$ & CJ12 & & & & \\
\hline & & & ERP & $\begin{array}{l}\text { Change } \\
\text { Structure } \\
\text { Planning - } \\
\text { Activities }\end{array}$ & CJ20 & [Activity data] & & & \\
\hline
\end{tabular}




\begin{tabular}{|c|c|c|c|c|c|c|c|c|c|}
\hline \multirow[t]{2}{*}{ N. } & \multirow[t]{2}{*}{ Ação } & \multirow[t]{2}{*}{$\mathbf{T}$} & \multirow[t]{2}{*}{ Recurso } & \multicolumn{3}{|c|}{ Transação } & \multirow[t]{2}{*}{ Informação de Entrada } & \multirow[t]{2}{*}{ Informação de Saída } & \multirow[t]{2}{*}{ Organização } \\
\hline & & & & Nome & Cod. & Caminho & & & \\
\hline & & & ERP & \begin{tabular}{|c} 
Change Time \\
Scheduling
\end{tabular} & CJ21 & Edit -» Schedule & & & \\
\hline & & & ERP & $\begin{array}{c}\text { Change } \\
\text { Network - } \\
\text { Network } \\
\text { Release }\end{array}$ & CN22 & $\begin{array}{l}\text { Edit -» Status -» } \\
\text { Release }\end{array}$ & & & \\
\hline & & & ERP & $\begin{array}{c}\text { Capacity } \\
\text { Evaluation }\end{array}$ & CM53 & & & & \\
\hline & & & ERP & Capacity & $M 26$ & & & & \\
\hline & & & ERP & Display Project & CJ2C / & & & & \\
\hline & & & & Planning & CJ2B & & & & \\
\hline & & & & Board/ & & & & & \\
\hline & & & & Change & & & & & \\
\hline & & & & Project & & & & & \\
\hline & & & & Planning & & & & & \\
\hline & & & & Board & & & & & \\
\hline & & & Ger. Projetos & & & & & & \\
\hline \multirow[t]{2}{*}{3} & Integrar cronograma das atividades & 1 & ERP & & & & & & \\
\hline & & & Ger. Projetos & & & & & & \\
\hline 2 & Gerenciar Projeto & & & & & & Cronograma de Projeto & Cronograma de & Coordenador de \\
\hline & & & & & & & & Projeto & Produto \\
\hline
\end{tabular}




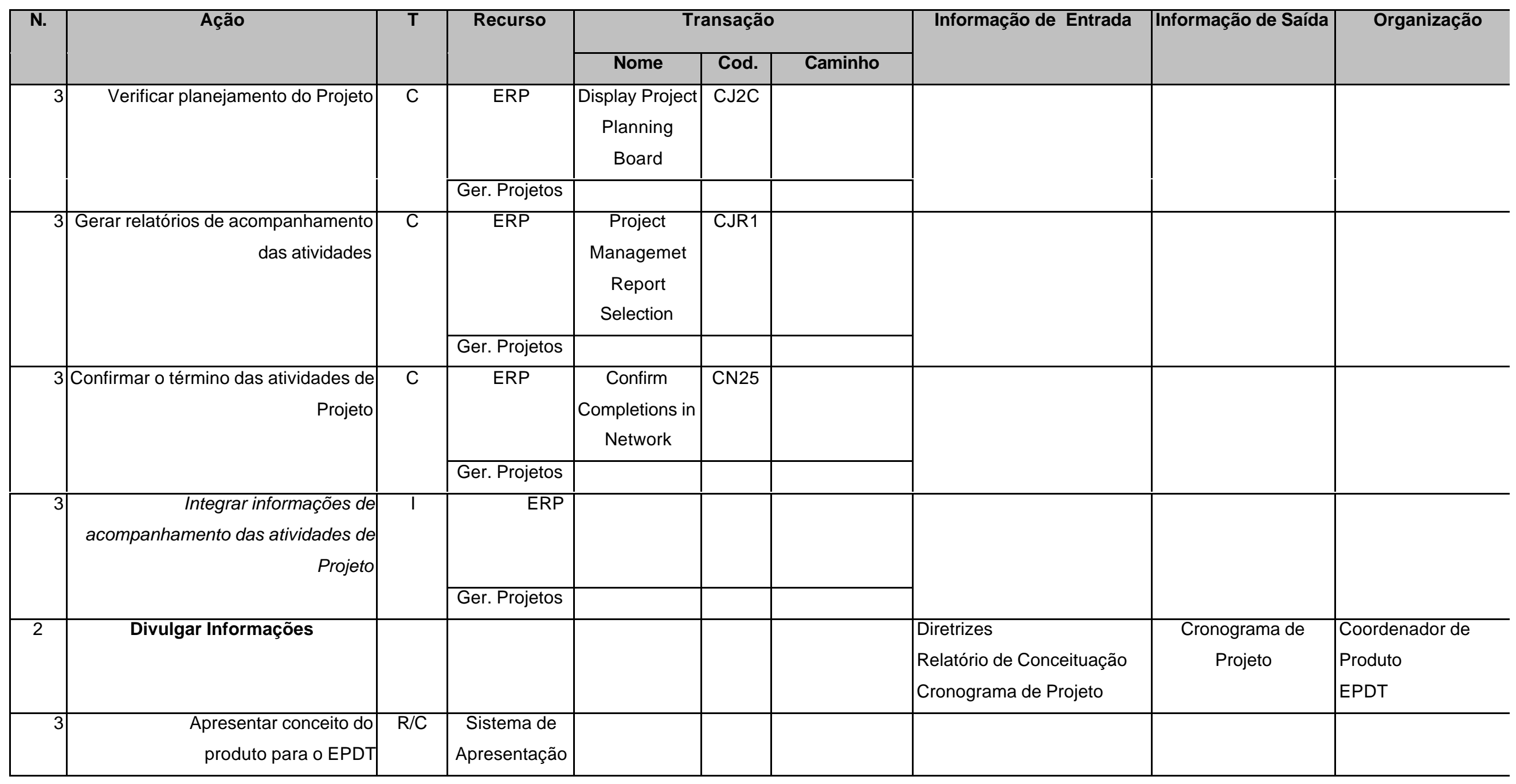




\begin{tabular}{|c|c|c|c|c|c|c|c|c|c|}
\hline \multirow[t]{2}{*}{$\mathbf{N}$. } & \multirow[t]{2}{*}{ Ação } & \multirow[t]{2}{*}{$T$} & \multirow[t]{2}{*}{ Recurso } & \multicolumn{3}{|c|}{ Transação } & \multirow[t]{2}{*}{ Informação de Entrada } & \multirow[t]{2}{*}{ Informação de Saída } & \multirow[t]{2}{*}{ Organização } \\
\hline & & & & Nome & Cod. & Caminho & & & \\
\hline \multirow[t]{2}{*}{3} & \multirow[t]{2}{*}{$\begin{array}{l}\text { Apresentar, discutir e refinar o } \\
\text { cronograma de Projeto }\end{array}$} & \multirow[t]{2}{*}{$\mathrm{R} / \mathrm{C}$} & ERP & $\begin{array}{l}\text { Displa } \\
\text { y Project } \\
\text { Planning } \\
\text { Board / } \\
\text { Change } \\
\text { Project } \\
\text { Planning } \\
\text { Board }\end{array}$ & $\begin{array}{l}\mathrm{CJ} 2 \mathrm{C} / \\
\mathrm{CJ} 2 \mathrm{~B}\end{array}$ & & & & \\
\hline & & & Ger. Projetos & & & & & & \\
\hline 2 & Estruturar Produto & & & & & & Estrutura de Produto & \begin{tabular}{|c} 
Estrutura de Produto \\
Especificação de \\
Componentes
\end{tabular} & EPDT \\
\hline \multirow[t]{3}{*}{3} & \multirow[t]{3}{*}{ Recuperar componentes semelhantes } & \multirow[t]{3}{*}{ C } & ERP & $\begin{array}{l}\text { Object Search } \\
\text { in Class }\end{array}$ & CL30 & & & & \\
\hline & & & PDM & & & & & & \\
\hline & & & CAPP & & & & & & \\
\hline 3 & $\begin{array}{c}\text { Visualizar desenhos de componentes } \\
\text { semelhantes }\end{array}$ & $\mathrm{C}$ & Visualizador & & & & & & \\
\hline \multirow[t]{3}{*}{3} & \multirow[t]{3}{*}{$\begin{array}{l}\text { Identificar novos componentes do } \\
\text { produto }\end{array}$} & \multirow[t]{3}{*}{ C } & ERP & $\begin{array}{l}\text { Create } \\
\text { Material }\end{array}$ & MM01 & & & & \\
\hline & & & PDM & & & & & & \\
\hline & & & CAPP & & & & & & \\
\hline
\end{tabular}




\begin{tabular}{|c|c|c|c|c|c|c|c|c|c|}
\hline \multirow[t]{2}{*}{ N. } & \multirow[t]{2}{*}{ Ação } & \multirow[t]{2}{*}{$\begin{array}{c}\mathrm{T} \\
\mathrm{T}\end{array}$} & \multirow[t]{2}{*}{ Recurso } & \multicolumn{3}{|c|}{ Transação } & \multirow[t]{2}{*}{ Informação de Entrada } & \multirow[t]{2}{*}{ Informação de Saída } & \multirow[t]{2}{*}{ Organização } \\
\hline & & & & Nome & Cod. & Caminho & & & \\
\hline & \multirow[t]{3}{*}{$\begin{array}{r}\text { Classificar novos componentes do } \\
\text { produto }\end{array}$} & \multirow[t]{3}{*}{$\mathrm{C}$} & ERP & $\begin{array}{c}\text { Allocate Object } \\
\text { to Classes }\end{array}$ & CL20 & & & & \\
\hline & & & PDM & & & & & & \\
\hline & & & CAPP & & & & & & \\
\hline \multirow[t]{6}{*}{3} & \multirow{6}{*}{$\begin{array}{r}\text { Completar as estruturas de produtos } \\
\text { preliminares }\end{array}$} & \multirow[t]{6}{*}{ C } & ERP & Change & CS02 & & & & \\
\hline & & & & Material BOM & & & & & \\
\hline & & & PDM & & & & & & \\
\hline & & & CAPP & & & & & & \\
\hline & & & CAD & & & & & & \\
\hline & & & DFMA & & & & & & \\
\hline \multirow[t]{8}{*}{3} & \multirow{8}{*}{$\begin{array}{r}\text { Definir regras para a configuração de } \\
\text { estruturas de produto variantes (rede } \\
\text { de dependência, etc...) }\end{array}$} & \multirow[t]{8}{*}{$\mathrm{C}$} & ERP & Create & CU41 & & & & \\
\hline & & & & Configuration & & & & & \\
\hline & & & & Profile & & & & & \\
\hline & & & ERP & Create & CU21 & & & & \\
\hline & & & & Dependency & & & & & \\
\hline & & & ERP & \begin{tabular}{|l|} 
Configuration \\
\end{tabular} & CU50 & & & & \\
\hline & & & & Simulation & & & & & \\
\hline & & & PDM & & & & & & \\
\hline \multirow[t]{4}{*}{3} & \multirow{4}{*}{$\begin{array}{r}\text { Integrar identificação e classificação } \\
\text { de componentes }\end{array}$} & \multirow[t]{4}{*}{1} & ERP & & & & & & \\
\hline & & & & & & & & & \\
\hline & & & PDM & & & & & & \\
\hline & & & CAPP & & & & & & \\
\hline
\end{tabular}




\begin{tabular}{|c|c|c|c|c|c|c|c|c|c|}
\hline \multirow[t]{2}{*}{ N. } & \multirow[t]{2}{*}{ Ação } & \multirow[t]{2}{*}{$\mathrm{T}$} & \multirow[t]{2}{*}{ Recurso } & \multicolumn{3}{|c|}{ Transação } & \multirow[t]{2}{*}{ Informação de Entrada } & \multirow[t]{2}{*}{ Informação de Saída } & \multirow[t]{2}{*}{ Organização } \\
\hline & & & & Nome & Cod. & Caminho & & & \\
\hline & & & CAD & & & & & & \\
\hline \multirow[t]{5}{*}{3} & \multirow[t]{5}{*}{ Integrar estruturas de produto } & \multirow[t]{5}{*}{$\mathrm{I}$} & ERP & & & & & & \\
\hline & & & PDM & & & & & & \\
\hline & & & CAPP & & & & & & \\
\hline & & & CAD & & & & & & \\
\hline & & & DFMA & & & & & & \\
\hline \multirow[t]{3}{*}{3} & \multirow{3}{*}{$\begin{array}{r}\text { Integrar regras para a configuração } \\
\text { de estruturas de produto variantes }\end{array}$} & \multirow[t]{3}{*}{1} & ERP & & & & & & \\
\hline & & & & & & & & & \\
\hline & & & PDM & & & & & & \\
\hline \multirow[t]{5}{*}{2} & \multirow[t]{5}{*}{ Definir Procedência } & & & & & & \multirow{5}{*}{$\begin{array}{l}\text { Desenho de Conjunto } \\
\text { Estrutura de Produto } \\
\text { Especificação de } \\
\text { Componentes }\end{array}$} & Relatório de & Projetista \\
\hline & & & & & & & & Procedência & Engenheiro de \\
\hline & & & & & & & & & Qualidade \\
\hline & & & & & & & & & Engenheiro de \\
\hline & & & & & & & & & Compras \\
\hline 3 & Analisar a curva $A B C$ & & ERP & ABC Analysis & & & & & \\
\hline \multirow[t]{6}{*}{3} & \multirow{6}{*}{$\begin{array}{r}\text { Cotar os fornecedores dos } \\
\text { componentes } \mathrm{B} \text { e C }\end{array}$} & \multirow[t]{6}{*}{$\mathrm{C}$} & ERP & Display Source & \multirow[t]{2}{*}{ ME03 } & & & & \\
\hline & & & & List & & & & & \\
\hline & & & ERP & Create & ME41 & & & & \\
\hline & & & & $\begin{array}{l}\text { Request for } \\
\text { Quotation }\end{array}$ & & & & & \\
\hline & & & ERP & Maintain & ME47 & & & & \\
\hline & & & & Quotation & & & & & \\
\hline
\end{tabular}




\begin{tabular}{|c|c|c|c|c|c|c|c|c|c|}
\hline \multirow[t]{2}{*}{$\mathbf{N}$. } & \multirow[t]{2}{*}{ Ação } & \multirow[t]{2}{*}{$\mathbf{T}$} & \multirow[t]{2}{*}{ Recurso } & \multicolumn{3}{|c|}{ Transação } & \multirow[t]{2}{*}{ Informação de Entrada } & \multirow[t]{2}{*}{ Informação de Saída } & \multirow[t]{2}{*}{ Organização } \\
\hline & & & & Nome & Cod. & Caminho & & & \\
\hline 3 & $\begin{array}{r}\text { Definir os fornecedores dos } \\
\text { componentes B e C }\end{array}$ & $\mathrm{R}$ & & & & & & & \\
\hline 3 & $\begin{array}{r}\text { Definir planos de inspeção } \\
\text { para componentes comprados }\end{array}$ & $\mathrm{C}$ & ERP & $\begin{array}{c}\text { Create } \\
\text { Inspection } \\
\text { Plan }\end{array}$ & QP01 & & & & \\
\hline & & & CAPP & & & & & & \\
\hline 3 & $\begin{array}{r}\text { Definir métodos amostragem para } \\
\text { componentes comprados }\end{array}$ & $\mathrm{C}$ & ERP & $\begin{array}{l}\text { Create } \\
\text { Sampling } \\
\text { Scheme }\end{array}$ & QDP1 & & & & \\
\hline & & & ERP & $\begin{array}{c}\text { Create } \\
\text { Sampling } \\
\text { Procedure }\end{array}$ & QDV1 & & & & \\
\hline 3 & $\begin{array}{r}\text { Integrar planos de inspeção para } \\
\text { componentes comprados }\end{array}$ & $\mathrm{I}$ & ERP & & & & & & \\
\hline & & & CAPP & & & & & & \\
\hline 2 & Desenvolver/Conferir Conjunto & & & & & & \begin{tabular}{|l} 
Desenho de Conjunto \\
Estrutura de Produto \\
Especificação de \\
Componentes \\
Desenhos de Componentes
\end{tabular} & $\begin{array}{l}\text { Desenhos de } \\
\text { Conjunto }\end{array}$ & $\begin{array}{l}\text { Projetista } \\
\text { EPDT }\end{array}$ \\
\hline 3 & $\begin{array}{r}\text { Acessar desenho de conjunto } \\
\text { preliminiar }\end{array}$ & $C$ & ERP & $\begin{array}{c}\text { Change } \\
\text { Document Info } \\
\text { Record }\end{array}$ & CV02 & & & & \\
\hline
\end{tabular}




\begin{tabular}{|c|c|c|c|c|c|c|c|c|c|}
\hline \multirow[t]{2}{*}{ N. } & \multirow[t]{2}{*}{ Ação } & \multirow[t]{2}{*}{$\mathbf{T}$} & \multirow[t]{2}{*}{ Recurso } & \multicolumn{3}{|c|}{ Transação } & \multirow[t]{2}{*}{ Informação de Entrada } & \multirow[t]{2}{*}{ |Informação de Saída } & \multirow[t]{2}{*}{ Organização } \\
\hline & & & & Nome & Cod. & Caminho & & & \\
\hline & & & PDM & & & & & & \\
\hline & & & CAPP & & & & & & \\
\hline 3 & Detalhar desenho de conjunto & C & CAD & & & & & & \\
\hline 3 & Aplicar a técnica de DFA & $\mathrm{R} / \mathrm{C}$ & DFMA & & & & & & \\
\hline \multirow[t]{3}{*}{3} & \multirow[t]{3}{*}{ Localizar desenhos de componentes } & \multirow[t]{3}{*}{$\mathrm{C}$} & ERP & Find Document & CV04 & & & & \\
\hline & & & PDM & & & & & & \\
\hline & & & CAPP & & & & & & \\
\hline 3 & $\begin{array}{r}\text { Verificar desenho de conjunto a partir } \\
\text { de desenhos dos componentes }\end{array}$ & C & Visualizador & & & & & & \\
\hline \multirow[t]{4}{*}{3} & \multirow[t]{4}{*}{ Distribuir tarefas de projeto } & \multirow[t]{4}{*}{ C } & ERP & $\underline{\text { Inbox }}$ & SO01 & $\begin{array}{l}\text { Entry } \gg \text { Create } \\
\gg \text { New }\end{array}$ & & & \\
\hline & & & ERP & $\begin{array}{l}\text { Start } \\
\text { Task }\end{array}$ & WUS & & & & \\
\hline & & & $\begin{array}{l}\text { Correi } \\
\text { o Eletrônico }\end{array}$ & & & & & & \\
\hline & & & PDM & & & & & & \\
\hline 2 & Simular Produto & & & & & & Desenho de Conjunto & $\begin{array}{l}\text { Relatório } \\
\text { Simulação }\end{array}$ & Projetista \\
\hline 3 & Simular o produto em funcionamento & $\mathrm{C}$ & CAE & & & & & & \\
\hline 2 & Desenhar Componentes & & & & & & \begin{tabular}{|l|} 
Desenho de Conjunto \\
Estrutura de Produto \\
Especificação \\
Componentes \\
\end{tabular} & $\begin{array}{l}\text { Desenhos de } \\
\text { Componentes }\end{array}$ & $\begin{array}{l}\text { Projetista } \\
\text { EPDT }\end{array}$ \\
\hline 3 & Receber aviso de tarefa & C & ERP & Inbox & SO01 & & & & \\
\hline
\end{tabular}




\begin{tabular}{|c|c|c|c|c|c|c|c|c|c|}
\hline \multirow[t]{2}{*}{ N. } & \multirow[t]{2}{*}{ Ação } & \multirow[t]{2}{*}{$\mathbf{T}$} & \multirow[t]{2}{*}{ Recurso } & \multicolumn{3}{|c|}{ Transação } & \multirow[t]{2}{*}{ Informação de Entrada } & \multirow[t]{2}{*}{ Informação de Saída } & \multirow[t]{2}{*}{ Organizaçãc } \\
\hline & & & & Nome & Cod. & Caminho & & & \\
\hline & & & PDM & & & & & & \\
\hline & & & Correio & & & & & & \\
\hline & & & Eletrônico & & & & & & \\
\hline \multirow[t]{4}{*}{3} & \multirow[t]{4}{*}{ Recuperar componentes semelhantes } & \multirow[t]{4}{*}{ C } & ERP & Object Search & CL30 & & & & \\
\hline & & & & in Class & & & & & \\
\hline & & & PDM & & & & & & \\
\hline & & & CAPP & & & & & & \\
\hline \multirow[t]{2}{*}{3} & Visualizar desenhos de componentes & $\mathrm{C}$ & Visualizador & & & & & & \\
\hline & 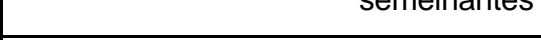 & & & & & & & & \\
\hline \multirow[t]{2}{*}{3} & Localizar componentes padronizados & \multirow[t]{2}{*}{ C } & & & & & & & \\
\hline & em bibliotecas & & & & & & & & \\
\hline 3 & Desenhar componentes & & CAD & & & & & & \\
\hline \multirow[t]{5}{*}{3} & \multirow[t]{5}{*}{ Gerenciar desenhos de componentes } & \multirow[t]{5}{*}{ C } & ERP & Create & CV01 & & & & \\
\hline & & & & Document Info & & & & & \\
\hline & & & & Record & & & & & \\
\hline & & & PDM & & & & & & \\
\hline & & & CAPP & & & & & & \\
\hline 3 & Aplicar técnica DFM & $\mathrm{R} / \mathrm{C}$ & DFMA & & & & & & \\
\hline 2 & Calcular Componente & & & & & & Desenhos de Componentes & Memorial de Cálculo & \\
\hline 3 & Calcular e otimizar componentes & & CAE & & & & & & \\
\hline & segundo os esforços a que são & & & & & & & & \\
\hline & submetidos & & & & & & & & \\
\hline
\end{tabular}




\begin{tabular}{|c|c|c|c|c|c|c|c|c|c|}
\hline \multirow[t]{2}{*}{ N. } & \multirow[t]{2}{*}{ Ação } & \multirow[t]{2}{*}{$T$} & \multirow[t]{2}{*}{ Recurso } & \multicolumn{3}{|c|}{ Transação } & \multirow[t]{2}{*}{ Informação de Entrada } & \multirow[t]{2}{*}{ |nformação de Saída } & \multirow[t]{2}{*}{ Organização } \\
\hline & & & & Nome & Cod. & Caminho & & & \\
\hline 2 & Detalhar Componente & & & & & & Desenhos de Componentes & $\begin{array}{l}\text { Desenhos de } \\
\text { Componentes }\end{array}$ & Projetista \\
\hline 3 & Receber aviso de tarefa & C & ERP & Inbox & SO01 & & & & \\
\hline & & & PDM & & & & & & \\
\hline & & & $\begin{array}{l}\text { Correio } \\
\text { Eletrônico }\end{array}$ & & & & & & \\
\hline 3 & Acessar desenhos de componentes & $\mathrm{C}$ & ERP & $\begin{array}{c}\text { Change } \\
\text { Document Info } \\
\text { Record }\end{array}$ & CV02 & & & & \\
\hline & & & PDM & & & & & & \\
\hline & & & CAPP & & & & & & \\
\hline 3 & $\begin{array}{r}\text { Detalhar componente (hachuras, } \\
\text { cotas, tolerâncias, etc.) }\end{array}$ & C & CAD & & & & & & \\
\hline 2 & Verificar Montagem & & & & & & Desenho de Conjunto & $\begin{array}{l}\text { Relatório de Análise } \\
\text { da Cadeia } \\
\text { Dimensional }\end{array}$ & Processista \\
\hline 3 & $\begin{array}{r}\text { Verificar montagem através da cadeia } \\
\text { dimensional }\end{array}$ & $\mathrm{M} / \mathrm{C}$ & $\begin{array}{l}\text { Planilha } \\
\text { Eletrônica }\end{array}$ & & & & & & \\
\hline 2 & Elaborar FMEA de Produto & & & & & & $\begin{array}{l}\text { Desenho de Conjunto } \\
\text { Estrutura de Produto }\end{array}$ & DFMEA & EPDT \\
\hline 3 & Recuperar DFMEAs anteriores & C & FMEA & & & & & & \\
\hline 3 & $\begin{array}{r}\text { Verificar problemas anteriores em } \\
\text { produtos semelhantes }\end{array}$ & $\mathrm{C}$ & ERP & $\begin{array}{l}\text { Material } \\
\text { Defects } \\
\text { Analysis }\end{array}$ & MCXX & & & & \\
\hline
\end{tabular}




\begin{tabular}{|c|c|c|c|c|c|c|c|c|c|}
\hline \multirow[t]{2}{*}{ N. } & \multirow[t]{2}{*}{ Ação } & \multirow[t]{2}{*}{$\mathbf{T}$} & \multirow[t]{2}{*}{ Recurso } & \multicolumn{3}{|c|}{ Transação } & \multirow[t]{2}{*}{ Informação de Entrada } & \multirow[t]{2}{*}{ Informação de Saída } & \multirow[t]{2}{*}{ Organização } \\
\hline & & & & Nome & Cod. & Caminho & & & \\
\hline & & & ERP & $\begin{array}{c}\text { Quality } \\
\text { Notifications } \\
\text { Analysis }\end{array}$ & $\mathrm{MCXV}$ & & & & \\
\hline 3 & $\begin{array}{r}\text { Elaborar/alterar DFMEA de acordo } \\
\text { com os requisitos da família de } \\
\text { produtos }\end{array}$ & $\mathrm{R}$ & & & & & & & \\
\hline 3 & Documentar DFMEA & & FMEA & & & & & & \\
\hline \multirow[t]{3}{*}{3} & \multirow[t]{3}{*}{ Planejar e gerenciar ações corretivas } & \multirow[t]{3}{*}{$C$} & ERP & $\begin{array}{l}\text { Change } \\
\text { Structure } \\
\text { Planning - } \\
\text { Activities }\end{array}$ & CJ20 & & & & \\
\hline & & & FMEA & & & & & & \\
\hline & & & Ger. Projetos & & & & & & \\
\hline 2 & Ajustar Processo Macro & & & & & & $\begin{array}{l}\text { Planos de Processo Macro } \\
\text { Desenho de Conjunto } \\
\text { Desenhos de Componentes }\end{array}$ & \begin{tabular}{|l|} 
Planos de Processo \\
Macro
\end{tabular} & Processista \\
\hline \multirow[t]{3}{*}{3} & \multirow[t]{3}{*}{$\begin{array}{r}\text { Ajustar processo de fabricação e } \\
\text { montagem macros }\end{array}$} & \multirow[t]{3}{*}{$\mathrm{C}$} & ERP & $\begin{array}{l}\text { Change } \\
\text { Routing }\end{array}$ & CA02 & & & & \\
\hline & & & ERP & $\begin{array}{c}\text { Change Rate } \\
\text { Routing }\end{array}$ & CA22 & & & & \\
\hline & & & CAPP & & & & & & \\
\hline
\end{tabular}




\begin{tabular}{|c|c|c|c|c|c|c|c|c|c|}
\hline \multirow[t]{2}{*}{ N. } & \multirow[t]{2}{*}{ Ação } & \multirow[t]{2}{*}{$T$} & \multirow[t]{2}{*}{ Recurso } & \multicolumn{3}{|c|}{ Transação } & \multirow[t]{2}{*}{ Informação de Entrada } & \multirow[t]{2}{*}{ Informação de Saída } & \multirow[t]{2}{*}{ Organização } \\
\hline & & & & Nome & Cod. & Caminho & & & \\
\hline \multirow[t]{2}{*}{3} & \multirow[t]{2}{*}{$\begin{array}{r}\text { Integrar processo de fabricação e } \\
\text { montagem macro }\end{array}$} & \multirow[t]{2}{*}{$\mathrm{I}$} & ERP & & & & & & \\
\hline & & & CAPP & & & & & & \\
\hline 2 & Aprovar Desenho & & & & & & Desenhos de Componentes & $\begin{array}{l}\text { Desenhos de } \\
\text { Componentes }\end{array}$ & Projetista \\
\hline \multirow[t]{3}{*}{3} & \multirow[t]{3}{*}{ Receber aviso de tarefa } & \multirow[t]{3}{*}{$\mathrm{C}$} & ERP & Inbox & SO01 & & & & \\
\hline & & & PDM & & & & & & \\
\hline & & & $\begin{array}{l}\text { Correi } \\
\text { o Eletrônico }\end{array}$ & & & & & & \\
\hline \multirow[t]{3}{*}{3} & \multirow[t]{3}{*}{ Acessar desenhos de componentes } & \multirow[t]{3}{*}{ C } & ERP & $\begin{array}{c}\text { Find } \\
\text { Document / } \\
\text { Display } \\
\text { Document }\end{array}$ & $\begin{array}{l}\text { CV04/ } \\
\text { CV03 }\end{array}$ & & & & \\
\hline & & & PDM & & & & & & \\
\hline & & & CAPP & & & & & & \\
\hline 3 & Verificar desenhos & $\mathrm{C}$ & Visualizador & & & & & & \\
\hline 3 & Indicar alterações necessárias & $\mathrm{C}$ & Visualizador & & & & & & \\
\hline 3 & Aprovar desenhos & C & ERP & $\begin{array}{c}\text { Change } \\
\text { Document Info } \\
\text { Record }\end{array}$ & CV02 & & & & \\
\hline & & & PDM & & & & & & \\
\hline
\end{tabular}




\begin{tabular}{|c|c|c|c|c|c|c|c|c|c|}
\hline \multirow[t]{2}{*}{ N. } & \multirow[t]{2}{*}{ Ação } & \multirow[t]{2}{*}{$\begin{array}{ll}T \\
\end{array}$} & \multirow[t]{2}{*}{ Recurso } & \multicolumn{3}{|c|}{ Transação } & \multirow[t]{2}{*}{ Informação de Entrada } & \multirow[t]{2}{*}{ Informação de Saída } & \multirow[t]{2}{*}{ Organização } \\
\hline & & & & Nome & Cod. & Caminho & & & \\
\hline 2 & Detalhar Processo & & & & & & $\begin{array}{l}\text { Planos de Processo Macro } \\
\text { Desenho de Conjunto } \\
\text { Desenhos de Componentes }\end{array}$ & \begin{tabular}{|l|} 
Detalhamentos do \\
Plano de Processo \\
Planos de Montagem \\
Planos de Qualidade \\
Programas CN
\end{tabular} & Processista \\
\hline \multirow[t]{2}{*}{3} & \multirow[t]{2}{*}{ Receber aviso de tarefa } & \multirow[t]{2}{*}{$\mathrm{C}$} & ERP & Inbox & SO01 & & & & \\
\hline & & & $\begin{array}{c}\text { PDM } \\
\text { Correio } \\
\text { Eletrônico }\end{array}$ & & & & & & \\
\hline \multirow[t]{2}{*}{3} & \multirow[t]{2}{*}{ Detalhar plano de montagem } & \multirow[t]{2}{*}{$\mathrm{C}$} & ERP & Create Routing & CA01 & & & & \\
\hline & & & CAPP & & & & & & \\
\hline \multirow[t]{2}{*}{3} & \multirow[t]{2}{*}{ Calculo de tempos de montagem } & \multirow[t]{2}{*}{$\mathrm{C}$} & ERP & $\begin{array}{l}\text { Change } \\
\text { Routing }\end{array}$ & CA02 & Extras $-\gg$ CAPP & & & \\
\hline & & & CAPP & & & & & & \\
\hline \multirow[t]{2}{*}{3} & \multirow[t]{2}{*}{$\begin{array}{r}\text { Detalhar plano de fabricação (setup, } \\
\text { folhas de instrução, ...) }\end{array}$} & \multirow[t]{2}{*}{$\mathrm{C}$} & ERP & $\begin{array}{l}\text { Change } \\
\text { Routing }\end{array}$ & CA02 & & & & \\
\hline & & & $\overline{\text { CAPP }}$ & & & & & & \\
\hline 3 & Detalhar plano de fabricação (CNC) & $\mathrm{C}$ & CAM & & & & & & \\
\hline \multirow[t]{2}{*}{3} & \multirow[t]{2}{*}{ Calcular tempos de fabricação } & \multirow[t]{2}{*}{ C } & ERP & $\begin{array}{l}\text { Change } \\
\text { Routing }\end{array}$ & CA02 & Extras -» CAPP & & & \\
\hline & & & CAPP & & & & & & \\
\hline
\end{tabular}




\begin{tabular}{|c|c|c|c|c|c|c|c|c|c|}
\hline \multirow[t]{2}{*}{ N. } & \multirow[t]{2}{*}{ Ação } & \multirow[t]{2}{*}{$\mathbf{T}$} & \multirow[t]{2}{*}{ Recurso } & \multicolumn{3}{|c|}{ Transação } & \multirow[t]{2}{*}{ Informação de Entrada } & \multirow[t]{2}{*}{ Informação de Saída } & \multirow[t]{2}{*}{ Organização } \\
\hline & & & & Nome & Cod. & Caminho & & & \\
\hline \multirow[t]{4}{*}{3} & \multirow[t]{4}{*}{ Definir ferramental de fabricação } & \multirow[t]{4}{*}{$\mathrm{C}$} & ERP & Change & \multirow[t]{3}{*}{$\overline{\mathrm{CA02}}$} & Goto -» & & & \\
\hline & & & & Routing - PRT & & Production & & & \\
\hline & & & & & & Resource Tools & & & \\
\hline & & & CAPP & & & & & & \\
\hline \multirow[t]{4}{*}{3} & \multirow[t]{4}{*}{ Elaborar plano de controle } & \multirow[t]{4}{*}{$C$} & ERP & Create & QP01 & & & & \\
\hline & & & & Inspection & & & & & \\
\hline & & & & Plan & & & & & \\
\hline & & & CAPP & & & & & & \\
\hline \multirow[t]{6}{*}{3} & \multirow[t]{6}{*}{ Definir métodos de amostragem } & \multirow[t]{6}{*}{$\mathrm{C}$} & ERP & Create & QDP1 & & & & \\
\hline & & & & Sampling & & & & & \\
\hline & & & & Scheme & & & & & \\
\hline & & & ERP & Create & QDV1 & & & & \\
\hline & & & & Sampling & & & & & \\
\hline & & & & Procedure & & & & & \\
\hline \multirow[t]{2}{*}{3} & \multirow[t]{2}{*}{ Elaborar matriz de características } & \multirow[t]{2}{*}{ C } & Planilha & & & & & & \\
\hline & & & Eletrônica & & & & & & \\
\hline 3 & Elaborar fluxo de processo definitivo & $\mathrm{C}$ & CAPP & & & & & & \\
\hline \multirow[t]{5}{*}{3} & Analisar layout de chão de fábrica & \multirow[t]{5}{*}{$M$} & & & & & & & \\
\hline & com base no fluxo de processo & & & & & & & & \\
\hline & definitivo & & & & & & & & \\
\hline & & & & & & & & & \\
\hline & & & & & & & & & \\
\hline
\end{tabular}




\begin{tabular}{|c|c|c|c|c|c|c|c|c|c|}
\hline \multirow[t]{2}{*}{ N. } & \multirow[t]{2}{*}{ Ação } & \multirow[t]{2}{*}{$\mathrm{T}$} & \multirow[t]{2}{*}{ Recurso } & \multicolumn{3}{|c|}{ Transação } & \multirow[t]{2}{*}{ Informação de Entrada } & \multirow[t]{2}{*}{ Informação de Saída } & \multirow[t]{2}{*}{ Organização } \\
\hline & & & & Nome & Cod. & Caminho & & & \\
\hline 3 & $\begin{array}{c}\text { Avaliar necessidade de calibração de } \\
\text { meios de medição }\end{array}$ & $\mathrm{C}$ & ERP & \begin{tabular}{|l|} 
Create \\
Calibration \\
Inspection \\
Order
\end{tabular} & IW31 & & & & \\
\hline 3 & Analisar meios de medição & $\mathrm{M}$ & & & & & & & \\
\hline 3 & $\begin{array}{r}\text { Realizar estudo preliminar da } \\
\text { Capabilidade de Processo }\end{array}$ & $\bar{M}$ & & & & & & & \\
\hline 3 & $\begin{array}{r}\text { Integrar detalhamentos dos planos de } \\
\text { processo de fabricação e montagem } \\
\text { (tempos, suboperações, setup, } \\
\text { documentos, ...) }\end{array}$ & 1 & CAPP & & & & & & \\
\hline 3 & Integrar planos de controle & 1 & $\begin{array}{c}\text { ERP } \\
\text { CAPP }\end{array}$ & & & & & & \\
\hline 2 & Projetar Recursos & & & & & & $\begin{array}{l}\text { Detalhamentos do Plano de } \\
\text { Processo }\end{array}$ & Projeto de Recursos & Projetista \\
\hline 3 & $\begin{array}{r}\text { Especificar recursos utilizados na } \\
\text { fabricação }\end{array}$ & $\mathrm{C}$ & ERP & \begin{tabular}{|c|} 
Create \\
Production \\
Resource/Tool \\
\end{tabular} & CF01 & & & & \\
\hline & & & CAPP & & & & & & \\
\hline 3 & $\begin{array}{r}\text { Projetar recursos utilizados na } \\
\text { fabricação }\end{array}$ & $\mathrm{C}$ & CAD & & & & & & \\
\hline
\end{tabular}




\begin{tabular}{|c|c|c|c|c|c|c|c|c|c|}
\hline \multirow[t]{2}{*}{ N. } & \multirow[t]{2}{*}{ Ação } & \multirow[t]{2}{*}{$\mathbf{T}$} & \multirow[t]{2}{*}{ Recurso } & \multicolumn{3}{|c|}{ Transação } & \multirow[t]{2}{*}{ Informação de Entrada } & \multirow[t]{2}{*}{ Informação de Saída } & \multirow[t]{2}{*}{ Organização } \\
\hline & & & & Nome & Cod. & Caminho & & & \\
\hline \multirow[t]{3}{*}{3} & \multirow[t]{3}{*}{ Gerenciar documentos de recursos } & \multirow[t]{3}{*}{$\mathrm{C}$} & ERP & $\begin{array}{c}\text { Create } \\
\text { Document Info } \\
\text { Record }\end{array}$ & CV01 & & & & \\
\hline & & & PDM & & & & & & \\
\hline & & & CAPP & & & & & & \\
\hline \multirow[t]{2}{*}{3} & \multirow[t]{2}{*}{ Integrar especificação de recursos } & \multirow[t]{2}{*}{$T$} & ERP & & & & & & \\
\hline & & & CAPP & & & & & & \\
\hline 2 & Elaborar FMEA de Processo & & & & & & $\begin{array}{l}\text { Planos de Processo Macro } \\
\text { Detalhamentos do Plano de } \\
\text { Processo } \\
\text { Planos de Montagem } \\
\text { Planos de Qualidade }\end{array}$ & PFMEA & EPDT \\
\hline 3 & Recuperar PMEA anteriores & $\mathrm{C}$ & FMEA & & & & & & \\
\hline \multirow[t]{2}{*}{3} & \multirow[t]{2}{*}{$\begin{array}{r}\text { Verificar problemas anteriores em } \\
\text { produtos semelhantes }\end{array}$} & \multirow[t]{2}{*}{$\mathrm{C}$} & ERP & $\begin{array}{l}\text { Material } \\
\text { Defects } \\
\text { Analysis }\end{array}$ & $\overline{M C X X}$ & & & & \\
\hline & & & ERP & $\begin{array}{c}\text { Quality } \\
\text { Notifications } \\
\text { Analysis }\end{array}$ & MCXV & & & & \\
\hline 3 & $\begin{array}{r}\text { Elaborar/alterar PFMEA de acordo } \\
\text { com os requisitos da família de } \\
\text { produtos }\end{array}$ & $\mathrm{R}$ & & & & & & & \\
\hline 3 & Documentar FMEA & $\mathrm{C}$ & FMEA & & & & & & \\
\hline
\end{tabular}




\begin{tabular}{|c|c|c|c|c|c|c|c|c|c|}
\hline \multirow[t]{2}{*}{$\mathbf{N}$. } & \multirow[t]{2}{*}{ Ação } & \multirow[t]{2}{*}{$\mathrm{T}$} & \multirow[t]{2}{*}{ Recurso } & \multicolumn{3}{|c|}{ Transação } & \multirow[t]{2}{*}{ Informação de Entrada } & \multirow[t]{2}{*}{ Informação de Saída } & \multirow[t]{2}{*}{ Organização } \\
\hline & & & & Nome & Cod. & Caminho & & & \\
\hline \multirow[t]{3}{*}{3} & \multirow[t]{3}{*}{ Planejar e gerenciar ações corretivas } & \multirow[t]{3}{*}{$\mathrm{C}$} & ERP & $\begin{array}{l}\text { Change } \\
\text { Structure } \\
\text { Planning - } \\
\text { Activities }\end{array}$ & CJ20 & [Activities] & & & \\
\hline & & & FMEA & & & & & & \\
\hline & & & Ger. Projetos & & & & & & \\
\hline 2 & Aprovar Processo & & & & & & $\begin{array}{l}\text { Planos de Processo Macro } \\
\text { Detalhamentos do Plano de } \\
\text { Processo } \\
\text { Planos de Montagem } \\
\text { Planos de Qualidade }\end{array}$ & $\begin{array}{l}\text { Planos de Processo } \\
\text { Macro } \\
\text { Detalhamentos do } \\
\text { Plano de Processo } \\
\text { Planos de Montagem } \\
\text { Planos de Qualidade }\end{array}$ & Processita \\
\hline \multirow[t]{3}{*}{3} & \multirow[t]{3}{*}{ Receber aviso de tarefa } & \multirow[t]{3}{*}{$C$} & ERP & Inbox & SO01 & & & & \\
\hline & & & PDM & & & & & & \\
\hline & & & $\begin{array}{c}\text { Correio } \\
\text { Eletrônico }\end{array}$ & & & & & & \\
\hline \multirow[t]{3}{*}{3} & \multirow[t]{3}{*}{ Verificar processos } & \multirow[t]{3}{*}{$\mathrm{C}$} & ERP & $\begin{array}{l}\text { Display } \\
\text { Routing }\end{array}$ & CA03 & & & & \\
\hline & & & ERP & $\begin{array}{c}\text { Display Rate } \\
\text { Routing }\end{array}$ & CA23 & & & & \\
\hline & & & CAPP & & & & & & \\
\hline \multirow[t]{2}{*}{3} & \multirow[t]{2}{*}{ Indicar alterações necessárias } & \multirow[t]{2}{*}{ C } & ERP & $\underline{\operatorname{lnbox}}$ & SO01 & & & & \\
\hline & & & ERP & Start Task & SWUS & & & & \\
\hline
\end{tabular}




\begin{tabular}{|c|c|c|c|c|c|c|c|c|c|}
\hline \multirow[t]{2}{*}{ N. } & \multirow[t]{2}{*}{ Ação } & \multirow[t]{2}{*}{$\bar{T}$} & \multirow[t]{2}{*}{ Recurso } & \multicolumn{3}{|c|}{ Transação } & \multirow[t]{2}{*}{ Informação de Entrada } & \multirow[t]{2}{*}{ Informação de Saída } & \multirow[t]{2}{*}{ Organização } \\
\hline & & & & Nome & Cod. & Caminho & & & \\
\hline & & & PDM & & & & & & \\
\hline & & & $\begin{array}{c}\text { Correio } \\
\text { Eletrônico }\end{array}$ & & & & & & \\
\hline \multirow[t]{3}{*}{3} & \multirow[t]{3}{*}{ Aprovar processos } & \multirow[t]{3}{*}{ C } & ERP & $\begin{array}{l}\text { Change } \\
\text { Routing - } \\
\text { Header / } \\
\text { Status }\end{array}$ & CA02 & & & & \\
\hline & & & ERP & $\begin{array}{c}\text { Change Rate } \\
\text { Routing - } \\
\text { Header / } \\
\text { Status } \\
\end{array}$ & CA22 & & & & \\
\hline & & & CAPP & & & & & & \\
\hline \multirow[t]{2}{*}{3} & \multirow[t]{2}{*}{ Integrar status de planos de processo } & \multirow[t]{2}{*}{$\mathrm{I}$} & ERP & & & & & & \\
\hline & & & CAPP & & & & & & \\
\hline 2 & Projetar Embalagem & & & & & & \begin{tabular}{|l|} 
Diretrizes \\
Desenho de Conjunto
\end{tabular} & $\begin{array}{ll}\text { Projeto } & \mathrm{da} \\
\text { Embalagem } & \end{array}$ & Projetista \\
\hline 3 & Consultar padrões de embalagem & $\bar{M}$ & & & & & & & \\
\hline 3 & Especificar embalagem & C & ERP & $\begin{array}{c}\text { Create } \\
\text { Packaging } \\
\text { Material }\end{array}$ & MMV1 & & & & \\
\hline 3 & Projetar embalagem & C & CAD & & & & & & \\
\hline 3 & $\begin{array}{r}\text { Gerenciar documentos da } \\
\text { embalagem }\end{array}$ & C & ERP & $\begin{array}{c}\text { Create } \\
\text { Document Info } \\
\text { Record }\end{array}$ & CV01 & & & & \\
\hline & & & PDM & & & & & & \\
\hline
\end{tabular}




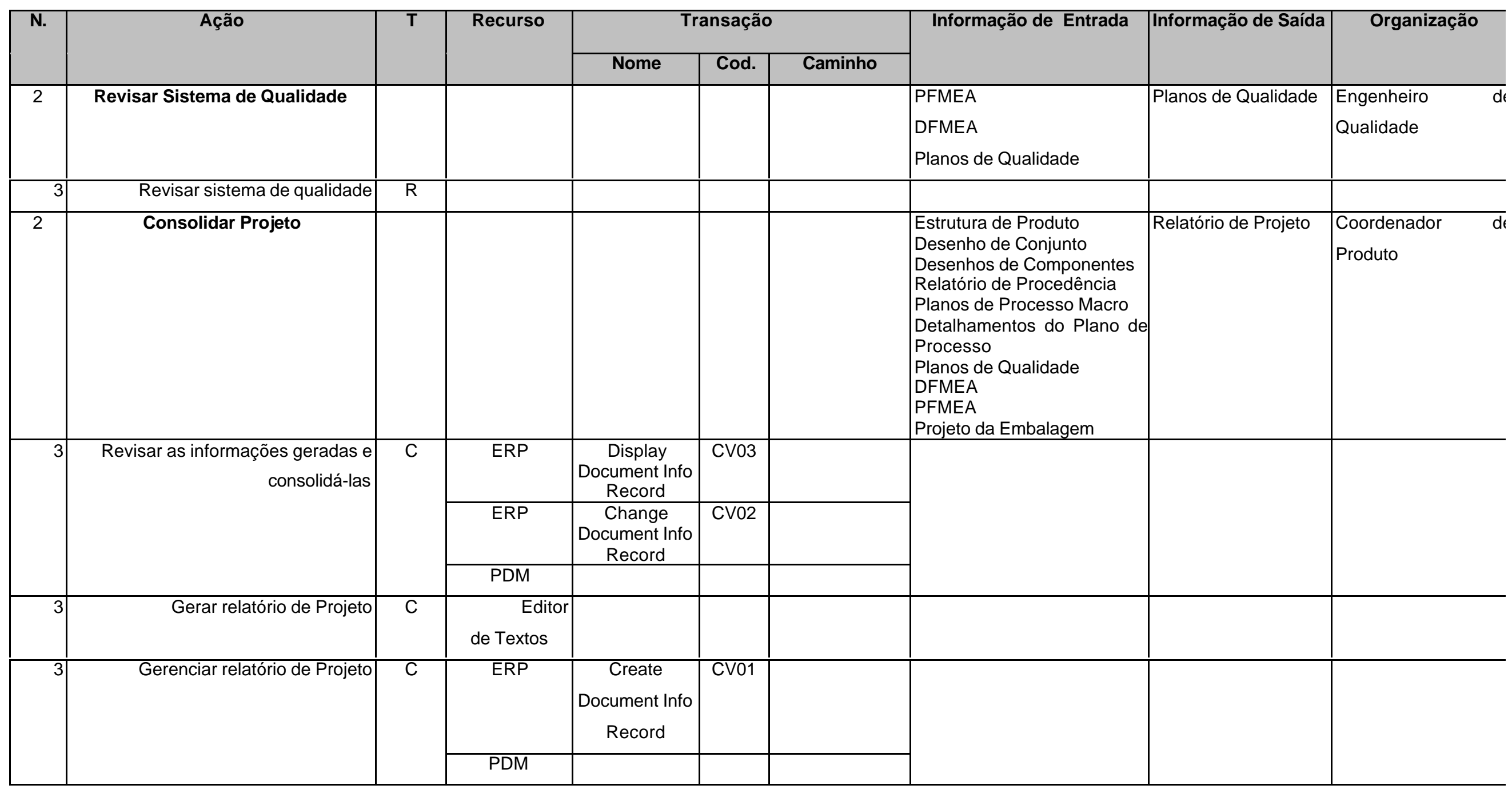




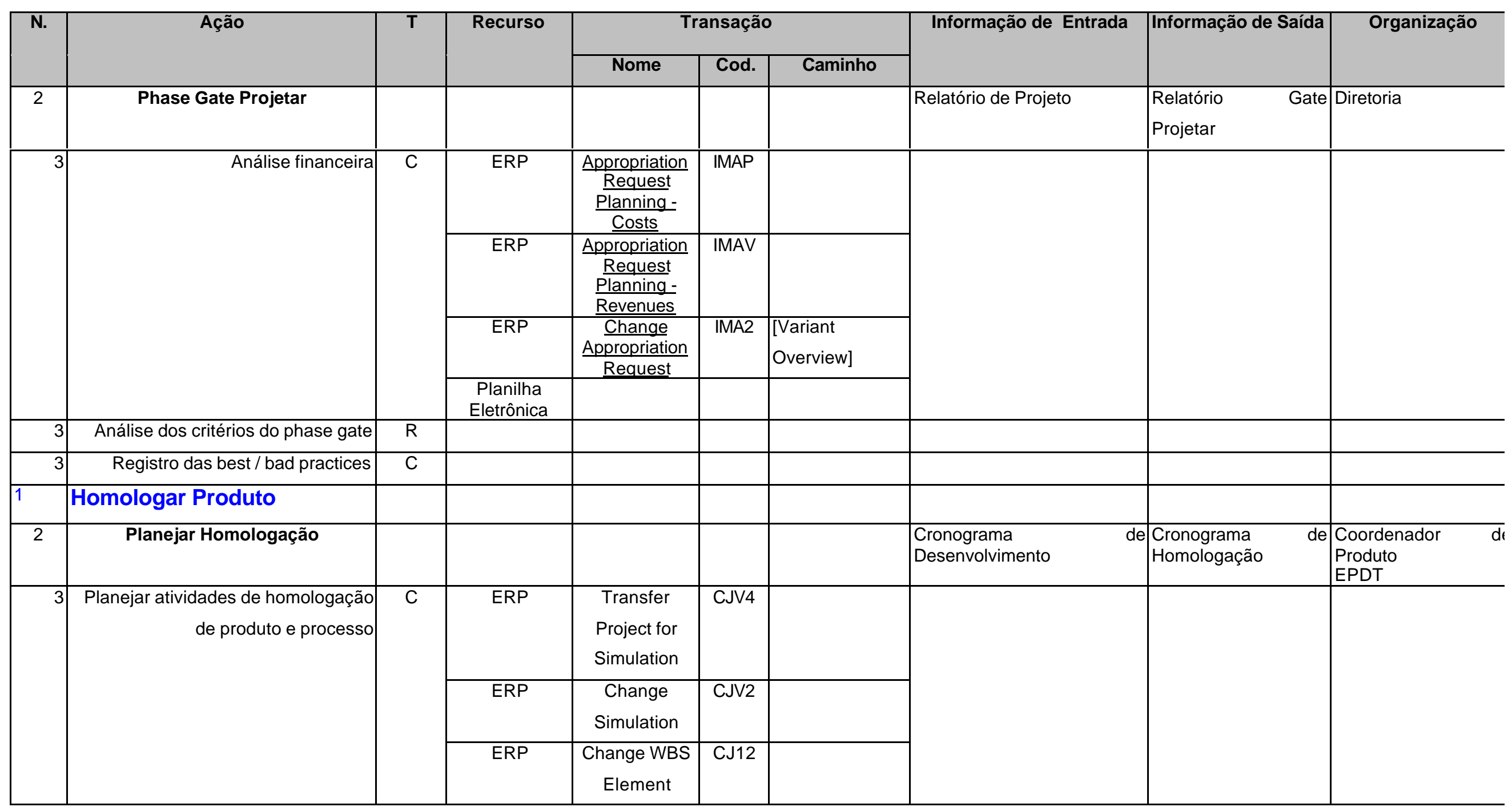




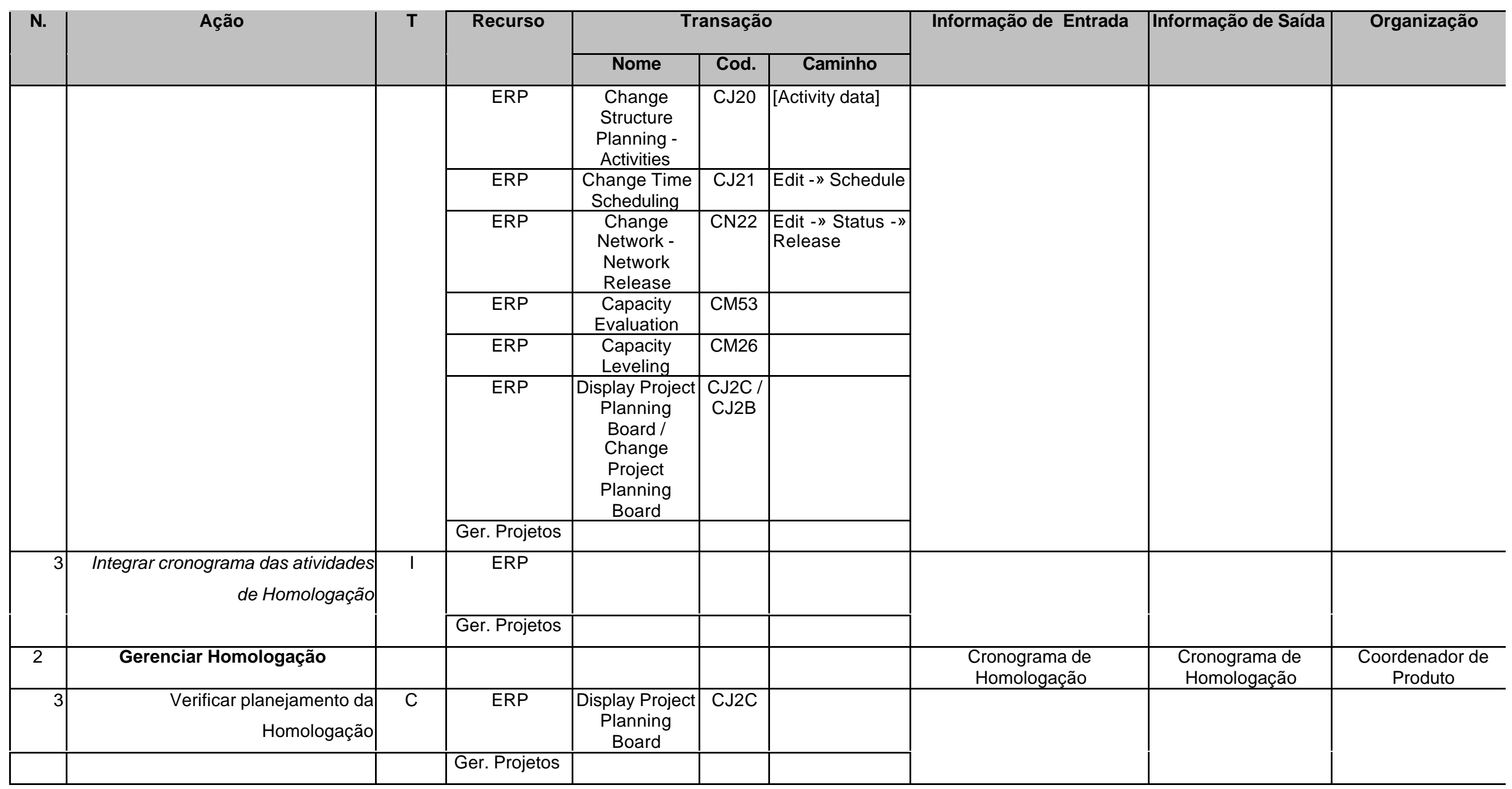




\begin{tabular}{|c|c|c|c|c|c|c|c|c|c|}
\hline \multirow[t]{2}{*}{ N. } & \multirow[t]{2}{*}{ Ação } & \multirow[t]{2}{*}{$\mathbf{T}$} & \multirow[t]{2}{*}{ Recurso } & \multicolumn{3}{|c|}{ Transação } & \multirow[t]{2}{*}{ Informação de Entrada } & \multirow[t]{2}{*}{ Informação de Saída } & \multirow[t]{2}{*}{ Organização } \\
\hline & & & & Nome & Cod. & Caminho & & & \\
\hline \multirow[t]{2}{*}{3} & \multirow[t]{2}{*}{$\begin{array}{r}\text { Gerar relatórios de acompanhamento } \\
\text { das atividades }\end{array}$} & \multirow[t]{2}{*}{$\mathrm{C}$} & ERP & $\begin{array}{l}\text { Project } \\
\text { Managemet } \\
\text { Report } \\
\text { Selection }\end{array}$ & CJR1 & & & & \\
\hline & & & Ger. Projetos & & & & & & \\
\hline \multirow[t]{2}{*}{3} & \multirow[t]{2}{*}{$\begin{array}{r}\text { Confirmar o término das atividades de } \\
\text { Homologação }\end{array}$} & \multirow[t]{2}{*}{$\mathrm{C}$} & ERP & $\begin{array}{c}\text { Confirm } \\
\text { Completions in } \\
\text { Network }\end{array}$ & CN25 & & & & \\
\hline & & & Ger. Projetos & & & & & & \\
\hline \multirow[t]{2}{*}{3} & \multirow[t]{2}{*}{$\begin{array}{r}\text { Integrar informações de } \\
\text { acompanhamento das atividades de } \\
\text { Homologação }\end{array}$} & $\mathrm{I}$ & ERP & & & & & & \\
\hline & & & Ger. Projetos & & & & & & \\
\hline 2 & $\begin{array}{l}\text { Definir quantidade e tipo de } \\
\text { protótipos }\end{array}$ & & & & & & \begin{tabular}{|l} 
Diretrizes \\
Relatório de Projeto
\end{tabular} & $\begin{array}{l}\text { Quantidade e Tipos } \\
\text { de Protótipos }\end{array}$ & PDT \\
\hline 3 & Definir quantidade e tipo de protótipos & $\mathrm{M}$ & & & & & & & \\
\hline 3 & Especificar protótipos & $\mathrm{C}$ & ERP & $\begin{array}{l}\text { Create } \\
\text { Material }\end{array}$ & MM01 & & & & \\
\hline 2 & $\begin{array}{c}\text { Definir e Planejar Programas } \\
\text { deTestes }\end{array}$ & & & & & & $\begin{array}{|llll|}\text { Quantidade } & \text { e } & \text { Tipos } & \text { de } \\
\text { Protótipos } & & & \\
\end{array}$ & Programa de Testes & PDT \\
\hline 3 & Definir programa de testes & $\mathrm{R}$ & & & & & & & \\
\hline 3 & $\begin{array}{r}\text { Planejar testes utilizando a técnica } \\
\mathrm{DOE}\end{array}$ & $\mathrm{M}$ & & & & & & & \\
\hline
\end{tabular}




\begin{tabular}{|c|c|c|c|c|c|c|c|c|c|}
\hline \multirow[t]{2}{*}{ N. } & \multirow[t]{2}{*}{ Ação } & \multirow[t]{2}{*}{$\mathbf{T}$} & \multirow[t]{2}{*}{ Recurso } & \multicolumn{3}{|c|}{ Transação } & \multirow[t]{2}{*}{ Informação de Entrada } & \multirow[t]{2}{*}{ Informação de Saída } & \multirow[t]{2}{*}{ Organização } \\
\hline & & & & Nome & Cod. & Caminho & & & \\
\hline 2 & Produzir Protótipo & & & & & & \begin{tabular}{|l} 
Relatório de Projeto \\
Programa de Testes
\end{tabular} & Protótipos & PDT \\
\hline \multirow[t]{3}{*}{3} & \multirow[t]{3}{*}{$\begin{array}{r}\text { Definir procedência dos componentes } \\
\text { dos protótipos }\end{array}$} & \multirow[t]{3}{*}{$C$} & ERP & $\begin{array}{c}\text { Display Source } \\
\text { List }\end{array}$ & ME03 & & & & \\
\hline & & & ERP & $\begin{array}{c}\text { Create } \\
\text { Request for } \\
\text { Quotation }\end{array}$ & ME41 & & & & \\
\hline & & & ERP & $\begin{array}{l}\text { Maintain } \\
\text { Quotation }\end{array}$ & ME47 & & & & \\
\hline \multirow[t]{2}{*}{3} & \multirow[t]{2}{*}{$\begin{array}{r}\text { Definir processo dos componentes } \\
\text { dos protótipos }\end{array}$} & \multirow[t]{2}{*}{$\mathrm{C}$} & ERP & Create Routing & CA01 & & & & \\
\hline & & & CAPP & & & & & & \\
\hline \multirow[t]{2}{*}{3} & \multirow[t]{2}{*}{$\begin{array}{r}\text { Elaborar plano de controle dos } \\
\text { protótipos }\end{array}$} & \multirow[t]{2}{*}{$\mathrm{C}$} & ERP & $\begin{array}{c}\text { Create } \\
\text { Inspection } \\
\text { Plan }\end{array}$ & QP01 & & & & \\
\hline & & & CAPP & & & & & & \\
\hline \multirow[t]{2}{*}{3} & Definir equipamentos & $\mathrm{C}$ & ERP & $\begin{array}{l}\text { PRT Where- } \\
\text { used Lists }\end{array}$ & CA70 & & & & \\
\hline & & & ERP & \begin{tabular}{|} 
Displa \\
y Production \\
Resources/To \\
ols
\end{tabular} & F03 & & & & \\
\hline 3 & Adaptar equipamentos & $\mathrm{M}$ & & & & & & & \\
\hline
\end{tabular}




\begin{tabular}{|c|c|c|c|c|c|c|c|c|c|}
\hline \multirow[t]{2}{*}{ N. } & \multirow[t]{2}{*}{ Ação } & \multirow[t]{2}{*}{$\mathbf{T}$} & \multirow[t]{2}{*}{ Recurso } & \multicolumn{3}{|c|}{ Transação } & \multirow[t]{2}{*}{ Informação de Entrada } & \multirow[t]{2}{*}{ Informação de Saída } & \multirow[t]{2}{*}{ Organização } \\
\hline & & & & Nome & Cod. & Caminho & & & \\
\hline 3 & Planejar produção dos protótipos & $\mathrm{C}$ & ERP & \begin{tabular}{|c|} 
Material \\
Requirements \\
Planning
\end{tabular} & CMRP & & & & \\
\hline 3 & Fabricar componentes internos & $\mathrm{M}$ & & & & & & & \\
\hline 3 & Comprar material e serviços externos & M & & & & & & & \\
\hline 3 & Montar protótipos & M & & & & & & & \\
\hline 3 & $\begin{array}{r}\text { Integrar plano de processo e plano de } \\
\text { controle dos protótipos }\end{array}$ & $\mathrm{T}$ & ERP & & & & & & \\
\hline 2 & Testar Protótipo & & & & & & Protótipos & $\begin{array}{l}\text { Ensaio e Teste de } \\
\text { Peças }\end{array}$ & PDT \\
\hline 3 & Especificar lotes de inspeção & C & ERP & \begin{tabular}{|c|} 
Create \\
Inspection Lot
\end{tabular} & QA01 & & & & \\
\hline 3 & Ensaiar e testar protótipos & M & & & & & & & \\
\hline 3 & Documentar resultados dos testes & C & ERP & $\begin{array}{l}\text { Record } \\
\text { Sample } \\
\text { Results }\end{array}$ & QE04 & & & & \\
\hline & $\begin{array}{c}\text { Consolidar Homolgação do } \\
\text { Produto }\end{array}$ & & & & & & \begin{tabular}{|l|} 
Programa de Testes \\
Protótipos \\
Ensaio e Teste de Protótipos
\end{tabular} & $\begin{array}{l}\text { Relatório de } \\
\text { Homologação do } \\
\text { Produto }\end{array}$ & $\begin{array}{l}\text { Coordenador de } \\
\text { Produto }\end{array}$ \\
\hline 3 & $\begin{array}{r}\text { Revisar as informações geradas e } \\
\text { consolidá-las }\end{array}$ & C & ERP & \begin{tabular}{|c|} 
Display \\
Document Info \\
Record
\end{tabular} & CV03 & & & & \\
\hline
\end{tabular}




\begin{tabular}{|c|c|c|c|c|c|c|c|c|c|}
\hline \multirow[t]{2}{*}{$\mathbf{N}$. } & \multirow[t]{2}{*}{ Ação } & \multirow[t]{2}{*}{$T$} & \multirow[t]{2}{*}{ Recurso } & \multicolumn{3}{|c|}{ Transação } & \multirow[t]{2}{*}{ Informação de Entrada } & \multirow[t]{2}{*}{ Informação de Saída } & \multirow[t]{2}{*}{ Organização } \\
\hline & & & & Nome & Cod. & Caminho & & & \\
\hline & & & ERP & \begin{tabular}{|c|} 
Change \\
Document Info \\
Record
\end{tabular} & CV02 & & & & \\
\hline & & & PDM & & & & & & \\
\hline 3 & $\begin{array}{r}\text { Gerar relatório de Homologação do } \\
\text { Produto }\end{array}$ & $\mathrm{C}$ & $\begin{array}{l}\text { Editor de } \\
\text { Textos }\end{array}$ & & & & & & \\
\hline \multirow[t]{2}{*}{3} & \multirow[t]{2}{*}{$\begin{array}{r}\text { Gerenciar relatório de Homoogação } \\
\text { do Produto }\end{array}$} & \multirow[t]{2}{*}{$\mathrm{C}$} & ERP & \begin{tabular}{|c|} 
Create \\
Document Info \\
Record
\end{tabular} & CV01 & & \multirow{2}{*}{ 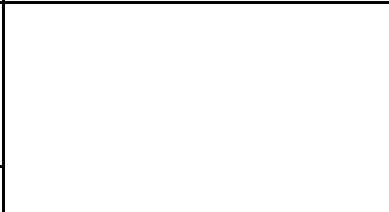 } & & \\
\hline & & & PDM & & & & & & \\
\hline 2 & Phase Gate Homologar Produto & & & & & & Relatório de Projeto & $\begin{array}{l}\text { Relatório Gate } \\
\text { Homologar Produto }\end{array}$ & Diretoria \\
\hline \multirow[t]{3}{*}{3} & \multirow[t]{3}{*}{ Análise financeira } & \multirow[t]{3}{*}{$\mathrm{C}$} & ERP & $\begin{array}{l}\frac{\text { Appropriation }}{\text { Request }} \\
\frac{\text { Planning - }}{\text { Costs }}\end{array}$ & IMAP & & & & \\
\hline & & & ERP & $\begin{array}{l}\text { Appropriation } \\
\underline{\text { Request }} \\
\underline{\text { Planning - }} \\
\text { Revenues }\end{array}$ & IMAV & & & & \\
\hline & & & ERP & $\begin{array}{c}\frac{\text { Change }}{\text { Appropriation }} \\
\underline{\text { Request }}\end{array}$ & IMA2 & $\begin{array}{l}\text { [Variant } \\
\text { Overview] }\end{array}$ & & & \\
\hline
\end{tabular}




\begin{tabular}{|c|c|c|c|c|c|c|c|c|c|}
\hline \multirow[t]{2}{*}{$\mathbf{N}$. } & \multirow[t]{2}{*}{ Ação } & \multirow[t]{2}{*}{$\mathrm{T}$} & \multirow[t]{2}{*}{ Recurso } & \multicolumn{3}{|c|}{ Transação } & \multirow[t]{2}{*}{ Informação de Entrada } & \multirow[t]{2}{*}{ Informação de Saída } & \multirow[t]{2}{*}{ Organização } \\
\hline & & & & Nome & Cod. & Caminho & & & \\
\hline & & & $\begin{array}{c}\text { Planilha } \\
\text { Eletrônica }\end{array}$ & & & & & & \\
\hline 3 & Análise dos critérios do phase gate & $\mathrm{R}$ & & & & & & & \\
\hline 3 & Registro das best / bad practices & $\mathrm{C}$ & & & & & & & \\
\hline 1 & Homologar Processo & & & & & & & & \\
\hline 2 & Avaliar Meios de Medição & & & & & & Planos de Qualidade & $\begin{array}{l}\text { Relatório de Análise } \\
\text { dos Sistemas de } \\
\text { Medição }\end{array}$ & PDT \\
\hline 3 & Avaliar Meios de Medição & $\mathrm{M}$ & & & & & & & \\
\hline 2 & Calcular Capabilidade de Processo & & & & & & Planos de Processo Macro & $\begin{array}{|ll|}\text { Relatório } & \text { de } \\
\text { Capabilidade } & \text { de } \\
\text { Processo } & \end{array}$ & PDT \\
\hline 3 & Calcular capabilidade de processo & $\mathrm{M}$ & & & & & & & \\
\hline 2 & $\begin{array}{c}\text { Calcular Repetibilidade de } \\
\text { Ferramental }\end{array}$ & & & & & & $\begin{array}{l}\text { Detalhamentos do Plano de } \\
\text { Processo }\end{array}$ & \begin{tabular}{|ll} 
Relatório & de \\
Repetibilidade & do \\
Ferramental &
\end{tabular} & PDT \\
\hline 3 & Calcular repetibilidade de ferramental & $\mathrm{M}$ & & & & & & & \\
\hline 2 & Produzir Lote Piloto & & & & & & $\begin{array}{l}\text { Planos de Processo Macro } \\
\text { Detalhamentos dos Planos } \\
\text { de Processo } \\
\text { PFMEA } \\
\text { Planos de Qualidade }\end{array}$ & Lote Piloto & Manufatura \\
\hline
\end{tabular}




\begin{tabular}{|c|c|c|c|c|c|c|c|c|c|}
\hline \multirow[t]{2}{*}{ N. } & \multirow[t]{2}{*}{ Ação } & \multirow[t]{2}{*}{$\mathbf{T}$} & \multirow[t]{2}{*}{ Recurso } & \multicolumn{3}{|c|}{ Transação } & \multirow[t]{2}{*}{ Informação de Entrada } & \multirow[t]{2}{*}{ Informação de Saída } & \multirow[t]{2}{*}{ Organização } \\
\hline & & & & Nome & Cod. & Caminho & & & \\
\hline 3 & Disponibilizar recursos & $\mathrm{M}$ & & & & & & & \\
\hline 3 & $\begin{array}{r}\text { Definir e planejar produção do lote } \\
\text { piloto }\end{array}$ & $\mathrm{C}$ & ERP & \begin{tabular}{|c|} 
Material \\
Requirements \\
Planning
\end{tabular} & CMRP & & & & \\
\hline 3 & Fabricar lote piloto & $\mathrm{M}$ & & & & & & & \\
\hline 2 & Testar Lote Piloto & & & & & & Lote Piloto & Análise do Lote Piloto & PDT \\
\hline 3 & Especificar lotes de inspeção & $\mathrm{C}$ & ERP & \begin{tabular}{|c|} 
Create \\
Inspection Lot
\end{tabular} & QA01 & & & & \\
\hline 3 & Testar produtos & $\mathrm{M}$ & & & & & & & \\
\hline 3 & Documentar resultados dos testes & $\mathrm{C}$ & ERP & $\begin{array}{l}\text { Record } \\
\text { Sample } \\
\text { Results }\end{array}$ & QE04 & & & & \\
\hline 3 & Avaliar embalagem & $M$ & & & & & & & \\
\hline 2 & $\begin{array}{c}\text { Revisar Plano de Controle de } \\
\text { Produção }\end{array}$ & & & & & & Plano de Qualidade & Plano de Qualidade & PDT \\
\hline 3 & $\begin{array}{r}\text { Revisar plano de controle de } \\
\text { produção }\end{array}$ & $\mathrm{C}$ & ERP & $\begin{array}{c}\text { Change } \\
\text { Inspection } \\
\text { Planning }\end{array}$ & QP02 & & & & \\
\hline & & & CAPP & & & & & & \\
\hline 3 & Integrar plano de controle & 1 & ERP & & & & & & \\
\hline & & & CAPP & & & & & & \\
\hline
\end{tabular}




\begin{tabular}{|c|c|c|c|c|c|c|c|c|c|}
\hline \multirow[t]{2}{*}{ N. } & \multirow[t]{2}{*}{ Ação } & \multirow[t]{2}{*}{$T$} & \multirow[t]{2}{*}{ Recurso } & \multicolumn{3}{|c|}{ Transação } & \multirow[t]{2}{*}{ Informação de Entrada } & \multirow[t]{2}{*}{ Informação de Saída } & \multirow[t]{2}{*}{ Organização } \\
\hline & & & & Nome & Cod. & Caminho & & & \\
\hline 2 & $\begin{array}{c}\text { Consolidar Homologação de } \\
\text { Processo }\end{array}$ & & & & & & \begin{tabular}{|l|} 
Planos de Processo Macro \\
Detalhamentos dos Planos \\
de Processo \\
PFMEA \\
Planos de Qualidade \\
Análise do Lote Piloto
\end{tabular} & $\begin{array}{|ll|}\text { Relatório } & \text { de } \\
\text { Homologação } & \text { do } \\
\text { Processo } & \end{array}$ & $\begin{array}{l}\text { Coordenador } \\
\text { Produto }\end{array}$ \\
\hline 3 & $\begin{array}{r}\text { Revisar as informações geradas e } \\
\text { consolidá-las }\end{array}$ & $C$ & ERP & $\begin{array}{c}\text { Display } \\
\text { Document Info } \\
\text { Record }\end{array}$ & CV03 & & & & \\
\hline & & & ERP & $\begin{array}{c}\text { Change } \\
\text { Document Info } \\
\text { Record }\end{array}$ & CV02 & & & & \\
\hline & & & PDM & & & & & & \\
\hline 3 & $\begin{array}{r}\begin{array}{r}\text { Gerar relatório de Homologação do } \\
\text { Processo }\end{array} \\
\end{array}$ & $\mathrm{C}$ & $\begin{array}{l}\text { Editor de } \\
\text { Textos }\end{array}$ & & & & & & \\
\hline 3 & $\begin{array}{r}\text { Gerenciar relatório de Homologação } \\
\text { do Processo }\end{array}$ & $\mathrm{C}$ & ERP & $\begin{array}{c}\text { Create } \\
\text { Document Info } \\
\text { Record }\end{array}$ & CV01 & & & & \\
\hline & & & PDM & & & & & & \\
\hline 2 & Liberar Produção & & & & & & $\begin{array}{|ll|}\text { Relatório de } & \text { Homologação } \\
\text { do Produto } & \\
\text { Relatório de } & \text { Homologação } \\
\text { do Processo } & \end{array}$ & PAPP & PDT \\
\hline
\end{tabular}




\begin{tabular}{|c|c|c|c|c|c|c|c|c|c|}
\hline \multirow[t]{2}{*}{$\mathbf{N}$. } & \multirow[t]{2}{*}{ Ação } & \multirow[t]{2}{*}{$\mathbf{T}$} & \multirow[t]{2}{*}{ Recurso } & \multicolumn{3}{|c|}{ Transação } & \multirow[t]{2}{*}{ Informação de Entrada } & \multirow[t]{2}{*}{ Informação de Saída } & \multirow[t]{2}{*}{ Organização } \\
\hline & & & & Nome & Cod. & Caminho & & & \\
\hline 3 & Preparar PAPP & $\mathrm{R} / \mathrm{C}$ & PAPP & & & & & & \\
\hline \multirow[t]{2}{*}{2} & \multirow[t]{2}{*}{ Phase Gate Homologar Processo } & & & & & & \multirow[t]{2}{*}{ Relatório de Projeto } & Relatório & \multirow[t]{2}{*}{ Diretoria } \\
\hline & & & & & & & & Homologar Processo & \\
\hline 3 & Análise financeira & $\mathrm{C}$ & ERP & $\begin{array}{l}\frac{\text { Appropriation }}{\text { Request }} \\
\frac{\text { Planning - }}{\underline{\text { Costs }}}\end{array}$ & IMAP & & & & \\
\hline & & & ERP & $\frac{\text { Appropriation }}{\frac{\text { Request }}{\text { Planning }}}$ & IMAV & & & & \\
\hline & & & ERP & $\begin{array}{c}\begin{array}{c}\text { Change } \\
\text { Appropriation }\end{array} \\
\text { Request }\end{array}$ & IMA2 & \begin{tabular}{|l} 
[Variant \\
Overview]
\end{tabular} & & & \\
\hline & & & $\begin{array}{c}\text { Planilha } \\
\text { Eletrônica }\end{array}$ & & & & & & \\
\hline 3 & Análise dos critérios do phase gate & $\mathrm{R}$ & & & & & & & \\
\hline 3 & Registro das best / bad practices & C & & & & & & & \\
\hline 1 & Lançar Produto & & & & & & & & \\
\hline 2 & Preparar Documentação Técnica & & & & & & \begin{tabular}{|l|} 
Diretrizes \\
Relatório de Projeto \\
Relatório de Homologação \\
do Produto \\
Relatório de Homologação \\
do Processo
\end{tabular} & Catálogo Técnico & PDT \\
\hline
\end{tabular}




\begin{tabular}{|c|c|c|c|c|c|c|c|c|c|}
\hline \multirow[t]{2}{*}{$\mathbf{N}$. } & \multirow[t]{2}{*}{ Ação } & \multirow[t]{2}{*}{$\mathbf{T}$} & \multirow[t]{2}{*}{ Recurso } & \multicolumn{3}{|c|}{ Transação } & \multirow[t]{2}{*}{ Informação de Entrada } & \multirow[t]{2}{*}{ Informação de Saída } & \multirow[t]{2}{*}{ Organização } \\
\hline & & & & Nome & Cod. & Caminho & & & \\
\hline 3 & Criar catálogo do produto & $\mathrm{C}$ & ERP & $\begin{array}{c}\text { Create Product } \\
\text { Catalog }\end{array}$ & WWM1 & & & & \\
\hline 2 & Preparar Documentação Comercial & & & & & & $\begin{array}{l}\text { Diretrizes } \\
\text { Relatório de Projeto } \\
\text { Relatório de Homologação } \\
\text { do Produto } \\
\text { Relatório de Homologação } \\
\text { do Processo }\end{array}$ & Catálogo Comercial & PDT \\
\hline 3 & Criar catálogo do produto & $\mathrm{C}$ & ERP & $\begin{array}{c}\text { Create Product } \\
\text { Catalog }\end{array}$ & WWM1 & & & & \\
\hline 2 & $\begin{array}{c}\text { Desenvolver Sistema de Apoio a } \\
\text { Vendas }\end{array}$ & & & & & & \begin{tabular}{|l|} 
Diretrizes \\
Relatório de Projeto \\
Relatório de Homologação \\
do Produto \\
Relatório de Homologação \\
do Processo
\end{tabular} & $\begin{array}{l}\text { Sistema de Apoio à } \\
\text { Vendas }\end{array}$ & PDT \\
\hline 3 & $\begin{array}{r}\text { Criar sistema de configuração de } \\
\text { produtos }\end{array}$ & $\mathrm{C}$ & PDM & $\begin{array}{c}\text { Configuration - } \\
\text { Characteristics } \\
\text { Value } \\
\text { Assignment }\end{array}$ & CU50 & $\begin{array}{l}\text { Goto -» Char. } \\
\text { Val. Assigmt. } \\
\text { Values -» } \\
\text { Interface Design } \\
\text {-» Chars group }\end{array}$ & & & \\
\hline 3 & $\begin{array}{r}\text { Integrar regras e padrões de } \\
\text { configuração de produtos }\end{array}$ & $\mathrm{I}$ & ERP & & & & & & \\
\hline
\end{tabular}




\begin{tabular}{|c|c|c|c|c|c|c|c|c|c|}
\hline \multirow[t]{2}{*}{$\mathbf{N}$. } & \multirow[t]{2}{*}{ Ação } & \multirow[t]{2}{*}{$\mathbf{T}$} & \multirow[t]{2}{*}{ Recurso } & \multicolumn{3}{|c|}{ Transação } & \multirow[t]{2}{*}{ Informação de Entrada } & \multirow[t]{2}{*}{ Informação de Saída } & \multirow[t]{2}{*}{ Organização } \\
\hline & & & & Nome & Cod. & Caminho & & & \\
\hline & & & PDM & & & & & & \\
\hline 2 & Ensinar Empresa & & & & & & \begin{tabular}{|l|} 
Diretrizes \\
Relatório de Projeto \\
Relatório de Homologação \\
do Produto \\
Relatório de Homologação \\
do Processo
\end{tabular} & \begin{tabular}{|r} 
Treinamento \\
\\
\end{tabular} & PDT \\
\hline 3 & Treinar vendedores & $\mathrm{R}$ & & & & & & & \\
\hline 3 & Treinar operadores & $\mathrm{R}$ & & & & & & & \\
\hline 3 & Treinar assistência técnica & $\mathrm{R}$ & & & & & & & \\
\hline 2 & Aprovar Lancamento & & & & & & & & PDT \\
\hline 3 & Aprovar Lancamento & $\mathrm{R}$ & & & & & & & \\
\hline 2 & Lançar Produto & & & & & & & & PDT \\
\hline 3 & Lançar Produto & $\mathrm{R}$ & & & & & & & \\
\hline 1 & $\begin{array}{l}\text { Avaliar e Acionar Ações } \\
\text { Corretivas }\end{array}$ & & & & & & & & \\
\hline 2 & $\begin{array}{c}\text { Avaliar Desvios de Diretriz e } \\
\text { Desenvolvimento }\end{array}$ & & & & & & \begin{tabular}{|l} 
Diretrizes \\
Cronograma \\
Desenvolvimento
\end{tabular} & \begin{tabular}{|l|} 
Diretrizes \\
Cronograma \\
Desenvolvimento
\end{tabular} & $\begin{array}{l}\text { Coordenador } \\
\text { Produto } \\
\text { PDT }\end{array}$ \\
\hline 3 & Verificar planejamento do Projeto & $\mathrm{C}$ & ERP & \begin{tabular}{|c|} 
Display Project \\
Planning \\
Board
\end{tabular} & CJ2C & & & & \\
\hline
\end{tabular}




\begin{tabular}{|c|c|c|c|c|c|c|c|c|c|}
\hline \multirow[t]{2}{*}{ N. } & \multirow[t]{2}{*}{ Ação } & \multirow[t]{2}{*}{$\mathbf{T}$} & \multirow[t]{2}{*}{ Recurso } & \multicolumn{3}{|c|}{ Transação } & \multirow[t]{2}{*}{ Informação de Entrada } & \multirow[t]{2}{*}{ Informação de Saída } & \multirow[t]{2}{*}{ Organização } \\
\hline & & & & Nome & Cod. & Caminho & & & \\
\hline & & & Ger. Projetos & & & & & & \\
\hline \multirow[t]{2}{*}{3} & \multirow[t]{2}{*}{$\begin{array}{r}\text { Gerar relatórios de acompanhamento } \\
\text { das atividades }\end{array}$} & \multirow[t]{2}{*}{$\mathrm{C}$} & ERP & $\begin{array}{c}\text { Project } \\
\text { Managemet } \\
\text { Report } \\
\text { Selection }\end{array}$ & CJR1 & & & & \\
\hline & & & Ger. Projetos & & & & & & \\
\hline 3 & Avaliar desvios de desenvolvimento & $\mathrm{R}$ & & & & & & & \\
\hline 3 & Avaliar desvios de diretrizes & $\mathrm{R}$ & & & & & & & \\
\hline 2 & $\begin{array}{r}\text { Atualizar Diretrizes, Estudo de } \\
\text { Viabilidade e de Ciclo de Vida }\end{array}$ & & & & & & \begin{tabular}{|ll} 
DiretrizesRelatório & de \\
Viabilidade Econômica &
\end{tabular} & \begin{tabular}{|l|} 
DiretrizesRelatório de \\
Viabilidade \\
Econômica
\end{tabular} & $\begin{array}{l}\text { Coordenador } \\
\text { Produto } \\
\text { PDT }\end{array}$ \\
\hline 3 & Acessar documento diretrizes & $\mathrm{C}$ & ERP & $\begin{array}{c}\text { Change } \\
\text { Document Info } \\
\text { Record }\end{array}$ & CV01 & & & & \\
\hline & & & PDM & & & & & & \\
\hline 3 & Atualizar diretrizes & $\mathrm{C}$ & $\begin{array}{l}\text { Editor de } \\
\text { Textos }\end{array}$ & & & & & & \\
\hline 3 & $\begin{array}{r}\text { Atualizar estimativa de custo do } \\
\text { projeto }\end{array}$ & $\mathrm{C}$ & ERP & $\begin{array}{c}\text { Change } \\
\text { Project Cost } \\
\text { Plan }\end{array}$ & CJ40 & & & & \\
\hline & & & ERP & $\begin{array}{c}\text { Network } \\
\text { Costing } \\
\text { Calculation }\end{array}$ & CJ9K & & & & \\
\hline
\end{tabular}




\begin{tabular}{|c|c|c|c|c|c|c|c|c|c|}
\hline \multirow[t]{2}{*}{$\mathbf{N}$. } & \multirow[t]{2}{*}{ Ação } & \multirow[t]{2}{*}{$\mathbf{T}$} & \multirow[t]{2}{*}{ Recurso } & \multicolumn{3}{|c|}{ Transação } & \multirow[t]{2}{*}{ Informação de Entrada } & \multirow[t]{2}{*}{ Informação de Saída } & \multirow[t]{2}{*}{ Organização } \\
\hline & & & & Nome & Cod. & Caminho & & & \\
\hline & & & Ger. Projeto & & & & & & \\
\hline & & & $\begin{array}{c}\text { Planilha } \\
\text { Eletrônica }\end{array}$ & & & & & & \\
\hline 3 & Atualizar fluxo de caixa do projeto & & ERP & \begin{tabular}{|c|}
$\frac{\text { Appropriation }}{\text { Request }}$ \\
$\frac{\text { Planning- }}{\underline{\text { Costs }}}$
\end{tabular} & IMAP & & & & \\
\hline & & & ERP & \begin{tabular}{|c|} 
Appropriation \\
$\underline{\text { Request }}$ \\
Planning- \\
Revenues
\end{tabular} & IMAV & & & & \\
\hline & & & $\begin{array}{c}\text { Planilha } \\
\text { Eletrônica }\end{array}$ & & & & & & \\
\hline 3 & $\begin{array}{r}\text { Atualizar análise de investimento } \\
\text { (taxa de retorno, breakeven point, pay } \\
\text { back) }\end{array}$ & C & ERP & \begin{tabular}{|c|}
$\frac{\text { Change }}{\text { Appropriation }}$ \\
$\underline{\text { Request }}$
\end{tabular} & IMA2 & \begin{tabular}{|l} 
[Variant \\
Overview]
\end{tabular} & & & \\
\hline & & & \begin{tabular}{|l|} 
Planilha \\
Eletrônica
\end{tabular} & & & & & & \\
\hline 2 & Acompanhar Ações Corretivas & & & & & & $\begin{array}{l}\text { DFMEA } \\
\text { PFMEA }\end{array}$ & $\begin{array}{l}\text { DFMEA } \\
\text { PFMEA }\end{array}$ & $\begin{array}{l}\text { Coordenador } \\
\text { Produto } \\
\text { PDT }\end{array}$ \\
\hline 3 & Acompanhar ações corretivas & $\mathrm{M} / \mathrm{C}$ & ERP & \begin{tabular}{|c|} 
Display Project \\
Planning \\
Board
\end{tabular} & CJ2C & & & & \\
\hline
\end{tabular}




\begin{tabular}{|c|c|c|c|c|c|c|c|c|c|}
\hline \multirow[t]{2}{*}{$\overline{\mathbf{N}}$. } & \multirow[t]{2}{*}{ Ação } & \multirow[t]{2}{*}{$T$} & \multirow[t]{2}{*}{ Recurso } & \multicolumn{3}{|c|}{ Transação } & \multirow[t]{2}{*}{ Informação de Entrada } & \multirow[t]{2}{*}{ Informação de Saída } & \multirow[t]{2}{*}{ Organização } \\
\hline & & & & Nome & Cod. & Caminho & & & \\
\hline & & & FMEA & & & & & & \\
\hline & & & Ger. Projetos & & & & & & \\
\hline 3 & Revisar FMEA de produto e processo & $\mathrm{R} / \mathrm{C}$ & FMEA & & & & & & \\
\hline \multirow[t]{3}{*}{2} & Monitorar Custo Calculado & & & & & & Decisões de Make or Buy & & Coordenador \\
\hline & & & & & & & Planos de Processo Macro & & Produto \\
\hline & & & & & & & Estrutura de Produto & & PDT \\
\hline \multirow[t]{5}{*}{3} & Orçar produto & $\mathrm{C}$ & ERP & Create Product & CK11 & & & & \\
\hline & & & & Cost Estimate & & & & & \\
\hline & & & CAPP & & & & & & \\
\hline & & & Planilha & & & & & & \\
\hline & & & Eletrônica & & & & & & \\
\hline \multirow[t]{5}{*}{3} & Analisar custo calculado & $\mathrm{C}$ & ERP & Application & SART & Logistics -» & & & \\
\hline & & & & Tree Report & & $\begin{array}{l}\text { Production -» } \\
\text { Product Cost }\end{array}$ & & & \\
\hline & & & & Selection & & Planning -» & & & \\
\hline & & & & Product Cost & & $\begin{array}{l}\text { Information } \\
\text { System -» }\end{array}$ & & & \\
\hline & & & & Planning & & Report Selection & & & \\
\hline 2 & Gerenciar Itens Críticos & & & & & & & & \\
\hline 3 & Identificar itens críticos & $\bar{R}$ & & & & & & & \\
\hline 3 & Apresentar meios para não ocorrer & $\mathrm{R}$ & & & & & & & \\
\hline & atrazos & & & & & & & & \\
\hline
\end{tabular}


Anexo G - Modelo de Referência do Cenário de Desenvolvimento de Produtos 


\begin{tabular}{|c|c|c|c|c|c|c|c|c|c|}
\hline \multirow[t]{2}{*}{$\mathbf{N}$. } & \multirow[t]{2}{*}{ Ação } & \multirow[t]{2}{*}{$\begin{array}{c}\mathrm{T} \\
\end{array}$} & \multirow[t]{2}{*}{ Recurso } & \multicolumn{3}{|l|}{ Transação } & \multirow[t]{2}{*}{ Informação de Entrada } & \multirow[t]{2}{*}{ Informação de Saída } & \multirow[t]{2}{*}{ Organização } \\
\hline & & & & Nome & Cod. & Caminho & & & \\
\hline 1 & Conceituar Produto & & & & & & & & \\
\hline 2 & Planejar Conceituação & & & & & & $\begin{array}{l}\text { Cronograma de } \\
\text { Desenvolvimento }\end{array}$ & $\begin{array}{l}\text { Cronograma de } \\
\text { Conceituação }\end{array}$ & $\begin{array}{l}\text { Coordenador de } \\
\text { Produto } \\
\text { PDT } \\
\end{array}$ \\
\hline \multirow[t]{9}{*}{3} & \multirow[t]{7}{*}{$\begin{array}{r}\text { Detalhar planejamento da } \\
\text { Conceituação }\end{array}$} & \multirow[t]{7}{*}{$\mathrm{C}$} & ERP & $\begin{array}{l}\text { Transfer } \\
\text { Project for } \\
\text { Simulation }\end{array}$ & CJV4 & & & & \\
\hline & & & ERP & $\begin{array}{l}\text { Change } \\
\text { Simulation }\end{array}$ & CJV2 & & & & \\
\hline & & & ERP & $\begin{array}{c}\text { Change WBS } \\
\text { Element }\end{array}$ & CJ12 & & & & \\
\hline & & & ERP & $\begin{array}{l}\text { Create } \\
\text { Network }\end{array}$ & CN21 & & & & \\
\hline & & & ERP & $\begin{array}{l}\text { Change } \\
\text { Structure } \\
\text { Planning - } \\
\text { Activities }\end{array}$ & CJ20 & [Activity data] & & & \\
\hline & & & ERP & $\begin{array}{l}\text { Change Time } \\
\text { Scheduling }\end{array}$ & CJ21 & Edit -» Schedule & & & \\
\hline & & & ERP & $\begin{array}{c}\text { Change } \\
\text { Network - } \\
\text { Network } \\
\text { Release }\end{array}$ & CN22 & $\begin{array}{l}\text { Edit -» Status -» } \\
\text { Release }\end{array}$ & & & \\
\hline & & & ERP & $\begin{array}{l}\text { Capacity } \\
\text { Evaluation }\end{array}$ & CM53 & & & & \\
\hline & & & ERP & $\begin{array}{l}\text { Capacity } \\
\text { Leveling }\end{array}$ & CM26 & & & & \\
\hline
\end{tabular}




\begin{tabular}{|c|c|c|c|c|c|c|c|c|c|}
\hline \multirow[t]{2}{*}{ N. } & \multirow[t]{2}{*}{ Ação } & \multirow[t]{2}{*}{$T$} & \multirow[t]{2}{*}{ Recurso } & \multicolumn{3}{|c|}{ Transação } & \multirow[t]{2}{*}{ Informação de Entrada } & \multirow[t]{2}{*}{ Informação de Saída } & \multirow[t]{2}{*}{ Organização } \\
\hline & & & & Nome & Cod. & Caminho & & & \\
\hline & & & ERP & \begin{tabular}{|c|} 
Display Project \\
Planning \\
Board / \\
Change \\
Project \\
Planning \\
Board
\end{tabular} & \begin{tabular}{|l|}
$\mathrm{CJ} 2 \mathrm{C} /$ \\
$\mathrm{CJ} 2 \mathrm{~B}$
\end{tabular} & & & & \\
\hline \multirow[t]{2}{*}{3} & $\begin{array}{r}\text { Exportar cronograma macro das } \\
\text { atividades de Conceituação do ERP } \\
\text { para o Gerenciador de Projetos }\end{array}$ & $\mathrm{T}$ & ERP & & \begin{tabular}{|l|} 
CN41 \\
\end{tabular} & $\begin{array}{c}\text { Evaluation -» } \\
\text { Export }\end{array}$ & & $\begin{array}{l}\text { Cronograma de } \\
\text { Conceituação }\end{array}$ & \\
\hline & & & Ger. Projetos & & & & \begin{tabular}{|l} 
Cronograma de \\
Conceituação
\end{tabular} & & \\
\hline 3 & $\begin{array}{r}\text { Detalhar planejamento da } \\
\text { Conceituação }\end{array}$ & $\mathrm{C}$ & Ger. Projetos & & & & & & \\
\hline 2 & $\begin{array}{c}\text { Especificar Linha de Produto } \\
\text { Modular }\end{array}$ & & & & & & $\begin{array}{l}\text { Diretrizes } \\
\text { Relatório de Requisitos } \\
\text { Técnicos }\end{array}$ & $\begin{array}{l}\text { Família de Produtos } \\
\text { Croquis }\end{array}$ & PDT \\
\hline 3 & $\begin{array}{r}\text { Especificar número de produtos e } \\
\text { principais características }\end{array}$ & $\mathrm{M} / \mathrm{C}$ & ERP & \begin{tabular}{|c|} 
Create \\
Finished \\
Product / \\
Create \\
Configurable \\
Material
\end{tabular} & $\begin{array}{l}\text { MMF1/ } \\
\text { MMK1 }\end{array}$ & & & & \\
\hline
\end{tabular}




\begin{tabular}{|c|c|c|c|c|c|c|c|c|c|}
\hline \multirow[t]{2}{*}{ N. } & \multirow[t]{2}{*}{ Ação } & \multirow[t]{2}{*}{$\bar{T}$} & \multirow[t]{2}{*}{ Recurso } & \multicolumn{3}{|c|}{ Transação } & \multirow[t]{2}{*}{ Informação de Entrada } & \multirow[t]{2}{*}{ Informação de Saída } & \multirow[t]{2}{*}{ Organização } \\
\hline & & & & Nome & Cod. & Caminho & & & \\
\hline & & & ERP & \begin{tabular}{|c|} 
Create \\
Characteristic
\end{tabular} & CT01 & & & & \\
\hline & & & ERP & Create Class & CL01 & & & & \\
\hline 3 & Gerar croquis dos produtos & C & CAD & & & & & & \\
\hline 3 & Gerenciar croquis dos produtos & C & ERP & \begin{tabular}{|c|} 
Create \\
Document Info \\
Record
\end{tabular} & CV01 & & & & \\
\hline 2 & Desenhar e Pré-Estruturar Produto & & & & & & $\begin{array}{l}\text { Diretrizes } \\
\text { Relatório de Requisitos } \\
\text { Técnicos } \\
\text { Família de Produtos } \\
\text { Croquis }\end{array}$ & \begin{tabular}{|l|} 
Desenho de Conjunto \\
Estrutura de Produto \\
Especificação de \\
Componentes
\end{tabular} & PDT \\
\hline 3 & $\begin{array}{r}\text { Recuperar desenhos de produtos } \\
\text { anteriores }\end{array}$ & $\mathrm{C}$ & ERP & $\begin{array}{c}\text { Object Search } \\
\text { in Class }\end{array}$ & CL30 & & & & \\
\hline & & & ERP & $\begin{array}{c}\text { Find } \\
\text { Document }\end{array}$ & CV04 & & & & \\
\hline 3 & $\begin{array}{r}\text { Visualizar desenhos de produtos } \\
\text { anteriores }\end{array}$ & C & Visualizador & & & & & & \\
\hline 3 & Acessar croquis dos produtos & $\mathrm{C}$ & ERP & \begin{tabular}{|c|} 
Change \\
Document Info \\
Record
\end{tabular} & CV02 & & & & \\
\hline 3 & $\begin{array}{r}\text { Gerar/modificar croquis com } \\
\text { dimensões básicas de cada } \\
\text { componente quando necessário }\end{array}$ & C & CAD & & & & & & \\
\hline
\end{tabular}




\begin{tabular}{|c|c|c|c|c|c|c|c|c|c|}
\hline \multirow[t]{2}{*}{ N. } & \multirow[t]{2}{*}{ Ação } & \multirow[t]{2}{*}{$\mathbf{T}$} & \multirow[t]{2}{*}{ Recurso } & \multicolumn{3}{|c|}{ Transação } & \multirow[t]{2}{*}{ Informação de Entrada } & \multirow[t]{2}{*}{ Informação de Saída } & \multirow[t]{2}{*}{ Organização } \\
\hline & & & & Nome & Cod. & Caminho & & & \\
\hline 3 & Classificar produto & C & ERP & $\begin{array}{c}\text { Allocate Object } \\
\text { to Classes }\end{array}$ & CL20 & & & & \\
\hline 3 & Recuperar componentes semelhantes & $\mathrm{C}$ & ERP & $\begin{array}{c}\text { Object Search } \\
\text { in Class }\end{array}$ & CL30 & & & & \\
\hline 3 & $\begin{array}{r}\text { Visualizar desenhos de componentes } \\
\text { semelhantes }\end{array}$ & $\mathrm{C}$ & Visualizador & & & & & & \\
\hline 3 & $\begin{array}{r}\text { Identificar novos componentes do } \\
\text { produto }\end{array}$ & $\mathrm{C}$ & ERP & $\begin{array}{l}\text { Create } \\
\text { Material }\end{array}$ & MM01 & & & & \\
\hline 3 & $\begin{array}{r}\text { Classificar novos componentes do } \\
\text { produto }\end{array}$ & $\mathrm{C}$ & ERP & $\begin{array}{c}\text { Allocate Object } \\
\text { to Classes }\end{array}$ & CL20 & & & & \\
\hline 3 & $\begin{array}{r}\text { Recuperar estruturas de produto } \\
\text { semelhantes }\end{array}$ & C & ERP & $\begin{array}{c}\text { Object Search } \\
\text { in Class }\end{array}$ & CL30 & & & & \\
\hline & & & ERP & \begin{tabular}{|c|} 
Display \\
Material BOM
\end{tabular} & CS03 & & & & \\
\hline 3 & \begin{tabular}{|r|} 
Definir a estrutura de produto \\
preliminar com os subconjuntos e os \\
componentes principais, em pararelo \\
a atividade de desenhar de conjunto
\end{tabular} & C & ERP & \begin{tabular}{|c|} 
Create \\
Material BOM
\end{tabular} & CS01 & & & & \\
\hline 3 & $\begin{array}{r}\text { Exportar cadastro de produtos e } \\
\text { componentes do ERP para o CAPP }\end{array}$ & $\mathrm{I}$ & ERP & & & & & Cadastro de Materiais & \\
\hline & & & CAPP & & & & Cadastro de Materiais & & \\
\hline
\end{tabular}




\begin{tabular}{|c|c|c|c|c|c|c|c|c|c|}
\hline \multirow[t]{2}{*}{$\mathbf{N}}$. & \multirow[t]{2}{*}{ Ação } & \multirow[t]{2}{*}{$\begin{array}{c}\mathrm{T} \\
\mathrm{T}\end{array}$} & \multirow[t]{2}{*}{ Recurso } & \multicolumn{3}{|c|}{ Transação } & \multirow[t]{2}{*}{ Informação de Entrada } & \multirow[t]{2}{*}{ Informação de Saída } & \multirow[t]{2}{*}{ Organização } \\
\hline & & & & Nome & Cod. & Caminho & & & \\
\hline 2 & Pré-Estruturar Processo & & & & & & \begin{tabular}{|l|} 
Diretrizes \\
Relatório de Requisitos \\
Técnicos \\
Desenho de Conjunto \\
Estrutura de Produto \\
Especificação \\
Componentes
\end{tabular} & $\begin{array}{lll}\text { Planos de } & \text { Processo } \\
\text { Macro } & & \\
\end{array}$ & PDT \\
\hline 3 & $\begin{array}{l}\text { Recuperar planos de processo de } \\
\text { produtos e componentes anteriores }\end{array}$ & $\mathrm{C}$ & CAPP & & & & & & \\
\hline 3 & $\begin{array}{r}\text { Elaborar planos de processo macro } \\
\text { de fabricação e montagem }\end{array}$ & $\mathrm{C}$ & CAPP & & & & & & \\
\hline 3 & $\begin{array}{r}\text { Exportar planos de processo do } \\
\text { CAPP para o ERP }\end{array}$ & $\mathrm{T}$ & CAPP & & & & & $\begin{array}{|lll|}\text { Planos de } & \text { Processo } \\
\text { Macro } & & \end{array}$ & \\
\hline & & & ERP & & & & Planos de Processo Macro & & \\
\hline 1 & Projetar Produto e Processo & & & & & & & & \\
\hline 2 & Planejar Projeto & & & & & & \begin{tabular}{|ll} 
Cronograma & de \\
Desenvolvimento &
\end{tabular} & Cronograma de Projeto & $\begin{array}{l}\text { Coordenador de } \\
\text { Produto } \\
\text { EPDT }\end{array}$ \\
\hline 3 & Planejar atividades de projeto & $\mathrm{C}$ & ERP & $\begin{array}{l}\text { Transfer } \\
\text { Project for } \\
\text { Simulation }\end{array}$ & CJV4 & & & & \\
\hline & & & ERP & $\begin{array}{l}\text { Change } \\
\text { Simulation }\end{array}$ & CJV2 & & & & \\
\hline
\end{tabular}




\begin{tabular}{|c|c|c|c|c|c|c|c|c|c|}
\hline \multirow[t]{2}{*}{$\mathrm{N}}$. & \multirow[t]{2}{*}{ Ação } & \multirow[t]{2}{*}{$\mathrm{T}$} & \multirow[t]{2}{*}{ Recurso } & \multicolumn{3}{|c|}{ Transação } & \multirow[t]{2}{*}{ Informação de Entrada } & \multirow[t]{2}{*}{ Informação de Saída } & \multirow[t]{2}{*}{ Organização } \\
\hline & & & & Nome & Cod. & Caminho & & & \\
\hline & & & ERP & $\begin{array}{c}\text { Change WBS } \\
\text { Element }\end{array}$ & CJ12 & & & & \\
\hline & & & ERP & $\begin{array}{l}\text { Change } \\
\text { Structure } \\
\text { Planning - } \\
\text { Activities }\end{array}$ & CJ20 & [Activity data] & & & \\
\hline & & & ERP & \begin{tabular}{|c|} 
Change Time \\
Scheduling
\end{tabular} & CJ21 & Edit -» Schedule & & & \\
\hline & & & ERP & $\begin{array}{c}\text { Change } \\
\text { Network - } \\
\text { Network } \\
\text { Release }\end{array}$ & CN22 & $\begin{array}{l}\text { Edit -» Status -» } \\
\text { Release }\end{array}$ & & & \\
\hline & & & ERP & $\begin{array}{l}\text { Capacity } \\
\text { Evaluation }\end{array}$ & CM53 & & & & \\
\hline & & & ERP & $\begin{array}{l}\text { Capacity } \\
\text { Leveling }\end{array}$ & CM26 & & & & \\
\hline & & & ERP & \begin{tabular}{|c|} 
Display Project \\
Planning \\
Board / \\
Change \\
Project \\
Planning \\
Board
\end{tabular} & & J2C / CJ2B & & & \\
\hline
\end{tabular}




\begin{tabular}{|c|c|c|c|c|c|c|c|c|c|}
\hline \multirow[t]{2}{*}{$\mathbf{N}$. } & \multirow[t]{2}{*}{ Ação } & \multirow[t]{2}{*}{$T$} & \multirow[t]{2}{*}{ Recurso } & \multicolumn{3}{|c|}{ Transação } & \multirow[t]{2}{*}{ Informação de Entrada } & \multirow[t]{2}{*}{ Informação de Saída } & \multirow[t]{2}{*}{ Organização } \\
\hline & & & & Nome & Cod. & Caminho & & & \\
\hline 3 & \begin{tabular}{|r|} 
Exportar cronograma macro das \\
atividades de Projeto do ERP para o \\
Gerenciador de Projetos
\end{tabular} & $\mathrm{I}$ & ERP & & CN41 & \begin{tabular}{|l|} 
Evaluation $\quad-»$ \\
Export
\end{tabular} & & Cronograma de Projeto & \\
\hline & & & Ger. Projetos & & & & Cronograma de Projeto & & \\
\hline 3 & Detalhar planejamento do Projeto & C & Ger. Projetos & & & & & & \\
\hline 2 & Estruturar Produto & & & & & & Estrutura de Produto & \begin{tabular}{|l|} 
Estrutura de Produto \\
Especificação de \\
Componentes
\end{tabular} & EPDT \\
\hline 3 & Recuperar componentes semelhantes & C & ERP & $\begin{array}{c}\text { Object Search } \\
\text { in Class }\end{array}$ & CL30 & & & & \\
\hline 3 & $\begin{array}{r}\text { Visualizar desenhos de componentes } \\
\text { semelhantes }\end{array}$ & $\mathrm{C}$ & Visualizador & & & & & & \\
\hline 3 & $\begin{array}{r}\text { Identificar novos componentes do } \\
\text { produto }\end{array}$ & $\mathrm{C}$ & ERP & $\begin{array}{l}\text { Create } \\
\text { Material }\end{array}$ & MM01 & & & & \\
\hline & $\begin{array}{r}\text { Classificar novos componentes do } \\
\text { produto }\end{array}$ & $\mathrm{C}$ & ERP & $\begin{array}{c}\text { Allocate Object } \\
\text { to Classes }\end{array}$ & CL20 & & & & \\
\hline 3 & $\begin{array}{r}\text { Completar as estruturas de produtos } \\
\text { preliminares }\end{array}$ & $\mathrm{C}$ & ERP & \begin{tabular}{|c|} 
Change \\
Material BOM
\end{tabular} & CS02 & & & & \\
\hline 3 & $\begin{array}{l}\text { Definir regras para a configuração de } \\
\text { estruturas de produto variantes (rede }\end{array}$ & C & ERP & \begin{tabular}{|c|} 
Create \\
Configuration \\
Profile
\end{tabular} & CU41 & & & & \\
\hline & & & ERP & $\begin{array}{c}\text { Create } \\
\text { Dependency } \\
\text { Net }\end{array}$ & CU21 & & & & \\
\hline
\end{tabular}




\begin{tabular}{|c|c|c|c|c|c|c|c|c|c|}
\hline \multirow[t]{2}{*}{ N. } & \multirow[t]{2}{*}{ Ação } & \multirow[t]{2}{*}{$\mathbf{T}$} & \multirow[t]{2}{*}{ Recurso } & \multicolumn{3}{|c|}{ Transação } & \multirow[t]{2}{*}{ Informação de Entrada } & \multirow[t]{2}{*}{ Informação de Saída } & \multirow[t]{2}{*}{ Organização } \\
\hline & & & & Nome & Cod. & Caminho & & & \\
\hline & & & ERP & \begin{tabular}{|c|} 
Configuration \\
Simulation
\end{tabular} & CU50 & & & & \\
\hline \multirow[t]{3}{*}{3} & Exportar cadastro de componentes do & $T$ & ERP & & & & & Cadastro de Materiais & \\
\hline & & & & & & & & & \\
\hline & & & CAPP & & & & Cadastro de Materiais & & \\
\hline 2 & Desenvolver/Conferir Conjunto & & & & & & $\begin{array}{ll}\text { Desenho de Conjunto } & \\
\text { Estrutura de Produto } & \\
\text { Especificação } & \\
\text { Componentes } & \\
\text { Desenhos } & \text { de } \\
\text { Componentes } & \end{array}$ & Desenhos de Conjunto & $\begin{array}{l}\text { Projetista } \\
\text { EPDT }\end{array}$ \\
\hline 3 & $\begin{array}{r}\text { Acessar desenho de conjunto } \\
\text { preliminiar }\end{array}$ & $\mathrm{C}$ & ERP & \begin{tabular}{|c|} 
Change \\
Document Info \\
Record
\end{tabular} & CV02 & & & & \\
\hline 3 & Detalhar desenho de conjunto & $\mathrm{C}$ & CAD & & & & & & \\
\hline 3 & Aplicar a técnica de DFA & $\mathrm{R} / \mathrm{C}$ & $\overline{D F M A}$ & & & & & & \\
\hline 3 & Localizar desenhos de componentes & $C$ & ERP & $\begin{array}{c}\text { Find } \\
\text { Document }\end{array}$ & CV04 & & & & \\
\hline 3 & $\begin{array}{c}\text { Verificar desenho de conjunto a partir } \\
\text { de desenhos dos componentes }\end{array}$ & $\mathrm{C}$ & Visualizador & & & & & & \\
\hline 3 & Distribuir tarefas de projeto & C & ERP & Start Task & SWUS & & & & \\
\hline
\end{tabular}




\begin{tabular}{|c|c|c|c|c|c|c|c|c|c|}
\hline \multirow[t]{2}{*}{ N. } & \multirow[t]{2}{*}{ Ação } & \multirow[t]{2}{*}{$\mathbf{T}$} & \multirow[t]{2}{*}{ Recurso } & \multicolumn{3}{|c|}{ Transação } & \multirow[t]{2}{*}{ Informação de Entrada } & \multirow[t]{2}{*}{ Informação de Saída } & \multirow[t]{2}{*}{ Organização } \\
\hline & & & & Nome & Cod. & Caminho & & & \\
\hline 2 & Desenhar Componentes & & & & & & \begin{tabular}{|l|} 
Desenho de Conjunto \\
Estrutura de Produto \\
Especificação \\
Componentes
\end{tabular} & $\begin{array}{ll}\text { Desenhos } & \text { de } \\
\text { Componentes } & \end{array}$ & $\begin{array}{l}\text { Projetista } \\
\text { EPDT }\end{array}$ \\
\hline 3 & Receber aviso de tarefa & C & $\begin{array}{c}\text { Correio } \\
\text { Eletrônico }\end{array}$ & & & & & & \\
\hline 3 & Recuperar componentes semelhantes & $\mathrm{C}$ & ERP & $\begin{array}{l}\text { Object Search } \\
\text { in Class }\end{array}$ & CL30 & & & & \\
\hline 3 & $\begin{array}{r}\text { Visualizar desenhos de componentes } \\
\text { semelhantes }\end{array}$ & $\mathrm{C}$ & Visualizador & & & & & & \\
\hline 3 & $\begin{array}{r}\text { Localizar componentes padronizados } \\
\text { em bibliotecas }\end{array}$ & $\mathrm{C}$ & & & & & & & \\
\hline 3 & Desenhar componentes & C & CAD & & & & & & \\
\hline 3 & Gerenciar desenhos de componentes & $\mathrm{C}$ & ERP & \begin{tabular}{|c} 
Create \\
Document Info \\
Record
\end{tabular} & CV01 & & & & \\
\hline 3 & Aplicar técnica DFM & $\mathrm{R} / \mathrm{C}$ & DFMA & & & & & & \\
\hline 2 & Calcular Componente & & & & & & \begin{tabular}{|l|} 
Desenhos \\
Componentes
\end{tabular} & Memorial de Cálculo & \\
\hline 3 & $\begin{array}{r}\text { Calcular e otimizar componentes } \\
\text { segundo os esforços a que são } \\
\text { submetidos }\end{array}$ & C & CAE & & & & & & \\
\hline
\end{tabular}




\begin{tabular}{|c|c|c|c|c|c|c|c|c|c|}
\hline \multirow[t]{2}{*}{$\mathbf{N}$. } & \multirow[t]{2}{*}{ Ação } & \multirow[t]{2}{*}{$\mathbf{T}$} & \multirow[t]{2}{*}{ Recurso } & \multicolumn{3}{|c|}{ Transação } & \multirow[t]{2}{*}{ Informação de Entrada } & \multirow[t]{2}{*}{ Informação de Saída } & \multirow[t]{2}{*}{ Organização } \\
\hline & & & & Nome & Cod. & Caminho & & & \\
\hline 2 & Detalhar Componente & & & & & & $\begin{array}{|ll|}\text { Desenhos } & \mathrm{de} \\
\text { Componentes } & \end{array}$ & $\begin{array}{ll}\text { Desenhos } & \text { de } \\
\text { Componentes } & \end{array}$ & Projetista \\
\hline 3 & Receber aviso de tarefa & $\mathrm{C}$ & $\begin{array}{l}\text { Correio } \\
\text { Eletrônico }\end{array}$ & & & & & & \\
\hline 3 & Acessar desenhos de componentes & $\mathrm{C}$ & ERP & $\begin{array}{c}\text { Change } \\
\text { Document Info } \\
\text { Record }\end{array}$ & CV02 & & & & \\
\hline 3 & $\begin{array}{r}\text { Detalhar componente (hachuras, } \\
\text { cotas, tolerâncias, etc.) }\end{array}$ & $\mathrm{C}$ & CAD & & & & & & \\
\hline 2 & Ajustar Processo Macro & & & & & & \begin{tabular}{|l|} 
Planos de Processo Macro \\
Desenho de Conjunto \\
Desenhos de \\
Componentes
\end{tabular} & $\begin{array}{l}\text { Planos de } \text { Processo } \\
\text { Macro }\end{array}$ & Processista \\
\hline 3 & $\begin{array}{r}\text { Ajustar processo de fabricação e } \\
\text { montagem macros }\end{array}$ & $\mathrm{C}$ & CAPP & & & & & & \\
\hline 2 & Aprovar Desenho & & & & & & \begin{tabular}{|l|} 
Desenhos \\
Componentes
\end{tabular} & \begin{tabular}{|l|} 
Desenhos \\
Componentes
\end{tabular} & Projetista \\
\hline 3 & Receber aviso de tarefa & $\mathrm{C}$ & $\begin{array}{l}\text { Correio } \\
\text { Eletrônico }\end{array}$ & & & & & & \\
\hline 3 & Acessar desenhos de componentes & $\mathrm{C}$ & ERP & $\begin{array}{l}\text { Find } \\
\text { Document / } \\
\text { Display } \\
\text { Document }\end{array}$ & $\begin{array}{l}\text { CV04/ } \\
\text { CV03 }\end{array}$ & & & & \\
\hline
\end{tabular}




\begin{tabular}{|c|c|c|c|c|c|c|c|c|c|}
\hline \multirow[t]{2}{*}{$\mathbf{N}$. } & \multirow[t]{2}{*}{ Ação } & \multirow[t]{2}{*}{$\begin{array}{c}\mathrm{T} \\
\mathrm{T}\end{array}$} & \multirow[t]{2}{*}{ Recurso } & \multicolumn{3}{|c|}{ Transação } & \multirow[t]{2}{*}{ Informação de Entrada } & \multirow[t]{2}{*}{ Informação de Saída } & \multirow[t]{2}{*}{ Organização } \\
\hline & & & & Nome & Cod. & Caminho & & & \\
\hline 3 & Verificar desenhos & C & Visualizador & & & & & & \\
\hline 3 & Indicar alterações necessárias & $\mathrm{C}$ & Visualizador & & & & & & \\
\hline 3 & Aprovar desenhos & C & ERP & $\begin{array}{l}\text { Change } \\
\text { Document Info } \\
\text { Record }\end{array}$ & CV02 & & & & \\
\hline 2 & Detalhar Processo & & & & & & $\begin{array}{l}\text { Planos de Processo Macro } \\
\text { Desenho de Conjunto } \\
\text { Desenhos de } \\
\text { Componentes }\end{array}$ & $\begin{array}{l}\text { Detalhamentos do } \\
\text { Plano de Processo } \\
\text { Planos de Montagem } \\
\text { Planos de Qualidade } \\
\text { Programas CN }\end{array}$ & Processista \\
\hline 3 & Receber aviso de tarefa & $\mathrm{C}$ & $\begin{array}{c}\text { Correio } \\
\text { Eletrônico }\end{array}$ & & & & & & \\
\hline 3 & Detalhar plano de montagem & C & CAPP & & & & & & \\
\hline 3 & Calculo de tempos de montagem & C & CAPP & & & & & & \\
\hline 3 & $\begin{array}{r}\text { Detalhar plano de fabricação (setup, } \\
\text { folhas de instrução, ...) }\end{array}$ & $\mathrm{C}$ & CAPP & & & & & & \\
\hline 3 & Detalhar plano de fabricação (CNC) & $\mathrm{C}$ & CAM & & & & & & \\
\hline 3 & Calcular tempos de fabricação & $\mathrm{C}$ & CAPP & & & & & & \\
\hline 3 & Definir ferramental de fabricação & $\mathrm{C}$ & CAPP & & & & & & \\
\hline 3 & Elaborar plano de controle & C & CAPP & & & & & & \\
\hline 3 & Definir métodos de amostragem & $\mathrm{C}$ & ERP & $\begin{array}{l}\text { Create } \\
\text { Sampling } \\
\text { Scheme }\end{array}$ & QDP1 & & & & \\
\hline
\end{tabular}




\begin{tabular}{|c|c|c|c|c|c|c|c|c|c|}
\hline \multirow[t]{2}{*}{$\mathrm{N}}$. & \multirow[t]{2}{*}{ Ação } & \multirow[t]{2}{*}{$\mathbf{T}$} & \multirow[t]{2}{*}{ Recurso } & \multicolumn{3}{|c|}{ Transação } & \multirow[t]{2}{*}{ Informação de Entrada } & \multirow[t]{2}{*}{ Informação de Saída } & \multirow[t]{2}{*}{ Organização } \\
\hline & & & & Nome & Cod. & Caminho & & & \\
\hline & & & ERP & $\begin{array}{c}\text { Create } \\
\text { Sampling } \\
\text { Procedure }\end{array}$ & QDV1 & & & & \\
\hline 3 & Elaborar matriz de características & $\mathrm{C}$ & $\begin{array}{l}\text { Planilha } \\
\text { Eletrônica }\end{array}$ & & & & & & \\
\hline 3 & Elaborar fluxo de processo definitivo & $\mathrm{C}$ & CAPP & & & & & & \\
\hline 3 & $\begin{array}{r}\text { Analisar layout de chão de fábrica } \\
\text { com base no fluxo de processo } \\
\text { definitivo }\end{array}$ & $\mathrm{M}$ & & & & & & & \\
\hline 3 & $\begin{array}{r}\text { Avaliar necessidade de calibração de } \\
\text { meios de medição }\end{array}$ & $\mathrm{C}$ & ERP & $\begin{array}{c}\text { Create } \\
\text { Calibration } \\
\text { Inspection } \\
\text { Order }\end{array}$ & IW31 & & & & \\
\hline 3 & Analisar meios de medição & $\mathrm{M}$ & & & & & & & \\
\hline 3 & $\begin{array}{r}\text { Realizar estudo preliminar da } \\
\text { Capabilidade de Processo }\end{array}$ & $\bar{M}$ & & & & & & & \\
\hline 2 & Elaborar FMEA de Processo & & & & & & \begin{tabular}{|l|} 
Planos de Processo Macro \\
Detalhamentos do Plano \\
de Processo \\
Planos de Montagem \\
Planos de Qualidade
\end{tabular} & PFMEA & EPDT \\
\hline 3 & Recuperar PMEA anteriores & C & FMEA & & & & & & \\
\hline 3 & $\begin{array}{r}\text { Verificar problemas anteriores em } \\
\text { produtos semelhantes }\end{array}$ & $\mathrm{C}$ & ERP & $\begin{array}{l}\text { Material } \\
\text { Defects } \\
\text { Analysis }\end{array}$ & $\mathrm{MCXX}$ & & & & \\
\hline
\end{tabular}




\begin{tabular}{|c|c|c|c|c|c|c|c|c|c|}
\hline \multirow[t]{2}{*}{ N. } & \multirow[t]{2}{*}{ Ação } & \multirow[t]{2}{*}{$\mathbf{T}$} & \multirow[t]{2}{*}{ Recurso } & \multicolumn{3}{|c|}{ Transação } & \multirow[t]{2}{*}{ Informação de Entrada } & \multirow[t]{2}{*}{ Informação de Saída } & \multirow[t]{2}{*}{ Organização } \\
\hline & & & & Nome & Cod. & Caminho & & & \\
\hline & & & ERP & $\begin{array}{c}\text { Quality } \\
\text { Notifications } \\
\text { Analysis }\end{array}$ & MCXV & & & & \\
\hline 3 & $\begin{array}{r}\text { Elaborar/alterar PFMEA de acordo } \\
\text { com os requisitos da família de } \\
\text { produtos }\end{array}$ & $\mathrm{R}$ & & & & & & & \\
\hline 3 & Documentar FMEA & $\mathrm{C}$ & FMEA & & & & & & \\
\hline 3 & Planejar e gerenciar ações corretivas & C & FMEA & & & & & & \\
\hline 2 & Aprovar Processo & & & & & & $\begin{array}{l}\text { Planos de Processo Macro } \\
\text { Detalhamentos do Plano } \\
\text { de Processo } \\
\text { Planos de Montagem } \\
\text { Planos de Qualidade }\end{array}$ & \begin{tabular}{|l|} 
Planos de Processo \\
Macro \\
Detalhamentos do \\
Plano de Processo \\
Planos de Montagem \\
Planos de Qualidade
\end{tabular} & Processita \\
\hline 3 & Receber aviso de tarefa & $\mathrm{C}$ & $\begin{array}{c}\text { Correio } \\
\text { Eletrônico }\end{array}$ & & & & & & \\
\hline 3 & Verificar processos & $\mathrm{C}$ & CAPP & & & & & & \\
\hline 3 & Indicar alterações necessárias & $\mathrm{C}$ & $\begin{array}{c}\text { Correio } \\
\text { Eletrônico }\end{array}$ & & & & & & \\
\hline 3 & Aprovar processos & $\mathrm{C}$ & CAPP & & & & & & \\
\hline 3 & $\begin{array}{r}\text { Exportar planos de processo macro, } \\
\text { planos de montagem e planos de } \\
\text { inspeção do sistema CAPP para o } \\
\text { sistema ERP }\end{array}$ & $\mathrm{T}$ & CAPP & & & & & \begin{tabular}{|l|} 
Planos de Processo \\
Macro \\
Planos de Montagem \\
Planos de Inspeção \\
\end{tabular} & \\
\hline & & & ERP & & & & \begin{tabular}{|l} 
Planos de Processo Macro \\
Planos de Montagem \\
Planos de Inspeção
\end{tabular} & & \\
\hline
\end{tabular}




\section{Anexo $\mathrm{H}$ - Grupos de Funcionalidades de Desenvolvimento de Produtos do Sistema ERP}

A TABELA 11 apresenta os grupos de funcionalidades de desenvolvimento de produtos do sistema ERP, sistematizados a partir do modelo de referência do processo de desenvolvimento de produtos considerando a aplicação do sistema ERP (스exo F).

TABELA 11 - Grupos de Funcionalidades de Desenvolvimento de Produtos do Sistema ERP

\begin{tabular}{|c|c|}
\hline $\begin{array}{l}\text { GRUPOS DE } \\
\text { FUNCIONALIDADES }\end{array}$ & $\begin{array}{c}\text { FUNCIONALIDADES DE DESENVOLVIMENTO DE } \\
\text { PRODUTOS DO SISTEMA ERP }\end{array}$ \\
\hline $\begin{array}{l}\text { Sistema de Informações } \\
\text { Gerenciais }\end{array}$ & $\begin{array}{l}\text { Sales Information System; Logistics Information System; Executive } \\
\text { Information System. }\end{array}$ \\
\hline Gerenciamento de Projetos & $\begin{array}{l}\text { Create Standard WBS; Create Standard Network; Create Standard } \\
\text { Milestone; Create Project Definition; Change Project; Change WBS } \\
\text { Element; Create Network; Change Structure Planning; Change Time } \\
\text { Scheduling; Display Project Planning Board; Change Project Planning } \\
\text { Board; Change Network; Confirm Completions in Network; Transfer } \\
\text { Project for Simulation; Change Simulation; Capacity Evaluation; } \\
\text { Capacity Leveling; Project Management Report Selection; Change } \\
\text { Project Cost Plan; Network Costing Calculation. }\end{array}$ \\
\hline Cadastro de Materiais & $\begin{array}{l}\text { Create Material; Change Material; Create Finish Product; Create } \\
\text { Configurable Material; Create Packaging Material; Display Source } \\
\text { List; Create Request for Quotation; Maintain Quotation; Price } \\
\text { Comparison; ABC Analysis. }\end{array}$ \\
\hline Estruturas de Produto & Create Material BOM; Change Material BOM; Display Material BOM. \\
\hline $\begin{array}{l}\text { Configuração Variante de } \\
\text { Estruturas de Produto }\end{array}$ & $\begin{array}{l}\text { Create Configurable Material; Create Configuration Profile; Create } \\
\text { Dependency Net; Configuration Simulation; Configuration - } \\
\text { Characteristics Value Assignment. }\end{array}$ \\
\hline Classificação & $\begin{array}{l}\text { Create Characteristic; Create Class; Allocate Characteristics to Class; } \\
\text { Allocate Classes to Class; Allocate Object to Classes; Object Search in } \\
\text { Class. }\end{array}$ \\
\hline $\begin{array}{l}\text { Gerenciamento de } \\
\text { Documentos }\end{array}$ & $\begin{array}{l}\text { Create Document Info Record; Change Document Info Record; } \\
\text { Display Document Info Record; Find Document. }\end{array}$ \\
\hline $\begin{array}{l}\text { Dados Técnicos de } \\
\text { Recursos }\end{array}$ & $\begin{array}{l}\text { Create Production Resource Tool; PRT Where-used Lists; Display } \\
\text { Production Resource Tool. }\end{array}$ \\
\hline Planos de Processo Macro & $\begin{array}{l}\text { Create Reference Operation Set; Create Reference Rate Routing; } \\
\text { Create Routing; Create Rate Routing; Display Routing; Display Rate } \\
\text { Routing; Change Routing; Change Rate Routing. }\end{array}$ \\
\hline $\begin{array}{l}\text { Detalhamentos dos Planos } \\
\text { de Processo }\end{array}$ & $\begin{array}{l}\text { Create CAPP Formula; Create CAPP Method; Create CAPP Process; } \\
\text { Change Routing - PRT. }\end{array}$ \\
\hline Análise de Capacidades & Capacity Evaluation. \\
\hline $\begin{array}{l}\text { Estimativa do Custo de } \\
\text { Produtos }\end{array}$ & $\begin{array}{l}\text { Create Product Cost Estimate; Application Tree Report Selection - } \\
\text { Product Cost Planning. }\end{array}$ \\
\hline Análise de Investimentos & $\begin{array}{l}\text { Create Appropriation Request; Appropriation Request Planning - } \\
\text { Costs; Appropriation Request Planning - Revenues; Change } \\
\text { Appropriation Request. }\end{array}$ \\
\hline Planos de Controle & $\begin{array}{l}\text { Create Master Inspection Characteristics; Create Inspection Method; } \\
\text { Create Inspection Plan; Create Sampling Scheme; Create Sampling }\end{array}$ \\
\hline
\end{tabular}




\begin{tabular}{l|l}
\hline & Procedure; Change Inspection Planning. \\
\hline Qualidade & $\begin{array}{l}\text { Material Defect Analysis; Quality Notification Analysis; Create } \\
\text { Calibration Inspection Order; Create Inspection Lot; Record Sampling } \\
\text { Results. }\end{array}$ \\
\hline $\begin{array}{l}\text { Base de Dados de } \\
\text { Qualificações }\end{array}$ & Find for Qualifications. \\
\hline $\begin{array}{l}\text { Elaboração de } \\
\text { Documentação Técnica }\end{array}$ & Create Product Catalog. \\
\hline Correio Eletrônico & Inbox. \\
\hline Agenda Eletrônica & Maintain Appointments Diary. \\
\hline Fluxo de Trabalho & Start Task; Inbox. \\
\hline $\begin{array}{l}\text { Controle de Modificações } \\
\text { de Engenharia }\end{array}$ & Create Change Master. \\
\hline
\end{tabular}




\section{REFERÊNCIAS BIBLIOGRÁFICAS}

AGUIAR, A.F.S; ROZENFELD,H. \& ZANCUL, E.S. (1997). Capacitação de Pessoal para o Processo de Desenvolvimento de Produtos. In: CONGRESSO BRASILEIRO DE ENGENHARIA MECÂNICA, 14., Bauru, 1997. Anais.

ALLIPRANDINI, D.H. (1996). Metodologia para a Intervenção na Manufatura com Orientação nos Processos e Baseada nas Abordagens CIM e da Qualidade. São Carlos, 165p. Tese (Doutorado) - Escola de Engenharia de São Carlos, Universidade de São Paulo.

AMARAL, D.C. (1997). Modelo de Referência para o Processo de Desenvolvimento de Produtos Considerando a Integração Cliente-Fornecedor. /projeto de pesquisa/.

AMARAL D.C.; ZANCUL, E.S; ROZENFELD, H. (1999). Cenário de Engenharia Integrada: Ampliando e Avaliando uma Aplicação em Educação. In: ENCONTRO NACIONAL DE ENGENHARIA DE PRODUÇÃO, 19., Rio de Janeiro, 1999. Anais.

AMR (2000). SAP Gets a Life - Product Lifecycle That is - With a New MySAP.com Wrapper. http://www.amrresearch.com/preview/000224sapstory1.asp (18 abr.).

AUTOMOTIVE INDUSTRY ACTION GROUP (1994). APQP - Advanced Product Quality Planning \& Control Plan.

BIELAWSKI, L. \& BOYLE, J. (1997). Electronic Document Management Systems. Upper Saddle River, Prentice Hall.

BOOTHROYD DEWHURST (1996). Design for Manufacturing and Assembly - User Guide.

BOURKE, R. W. (1996). Product Data Management and Enterprise Resource Planning: Conference Reports. http://www.pdmic.com (19 Ago.).

BOURKE, R. W. (1997). PDM and ERP Continue to Converge. APICS the Performance Advantage. v.7, n.8, Aug. 
BOURKE, R. W. (1998). New Directions in the Aerospace and Defense Industry: the integration of product data management and enterprise resource planning systems. http://www.pdmic.com/articles/misscrit.html (10 Set.).

BOURKE, R. W. (1999). Product Data Management: more than just an ERP module. http://www.pdmic.com/articles/artmor.html (09 Mar.).

BRADHAM, J.H. (1998). STEP-Driven Manufacturing. Computer and Automated Systems Association/Society of Manufacturing Engineers (CASA/SME).

BREMER, C.F. (1995). Proposta de uma Metodologia Para o Planejamento e Implantação da Manufatura Integrada por Computador. São Carlos, 214p. Tese (Doutorado) Escola de Engenharia de São Carlos, Universidade de São Paulo.

BROWN S.L. \& EISENHARDT, K.M. (1995). Product Development: Past Research, Present Findings, and Future Directions. Academy of Management Review, v.20, n.2, p.343-378.

CARTER D.E.; BAKER, B.S. (1992). Concurrent Engineering: the product development environment for the 1990s. Reading, Addison-Wesley.

CARUSO, D. (1998). Get a Backbone. Intelligent Enterprise, p.18-20, Dec.

CARUSO, D. (1999a). Implementing ERP. Intelligent Enterprise, p.24-26, Apr.

CARUSO, D. (1999b) Life After Live. Intelligent Enterprise, p.18,61, June.

CARUSO, D.; JOHNSON, R. (1999). The Vision Thing. Intelligent Enterprise, p.16-18, Jan.

CERVO, A.L.; BERVIAN, P.A. (1983). Metodologia Científica. São Paulo, Makron.

CHAUDHRY, O. (1998). Enterprise Supply Chain Management: An Expanding Software Horizon. APICS the Performance Advantage. v.8, n.9, Sept.

CIMDATA (1996). Product Data Management: the definition. CIMData.

CIMDATA (2000). News Release - CIMData Reports PDM Market Grows 27\% to Reach \$1.4 Billion in 1998. http://www.cimdata.com/index.htm. (28. Abr.).

ClARCK K.B.; FUJIMOTO, T. (1991). Product Development Performance: strategy, organization and management in the world auto industry. Boston, Harvard Business School Press. 
CLAUSING, D. (1994). Total Quality Development: A Step-by-Step Guide to World-Class Concurrent Engineering. 2. ed. New York, ASME Press.

COOPER, R.G. (1994). Third-Generation New Product Process. Journal of Product Innovation Management, v.11, p.3-14.

COOPER R.G. \& KLEINSCHMIDT, E.J. (1995). Benchmarking the Firm's Critical Success Factors in New Product Development. Journal of Product Innovation Management, v.12, p.374-391.

CORRÊA, H.L.; GIANESI, I.G.N.; CAON, M. (1997). Planejamento, Programação e Controle da Produção: MRP II/ERP - Conceitos, Uso e Implantação. São Paulo, Atlas.

CURRAN, T. \& KELLER, G. (1998). SAP R/3 Business Blueprint. Prentice Hall, Upper Saddle River, New Jersey.

DANE, F.C. (1990). Research Methods. Belmont, California, Brooks/Cole.

DATASUL (1999). Arquitetura de Gestão Competitiva. São Paulo. Ifolder/

DATE, (1986). Introdução a Sistemas de Base de Dados. Rio de Janeiro. Campus.

DAVENPORT, T.H. (1994). Reengenharia de Processos. Rio de Janeiro, Campus.

DAVENPORT, T.H. (1998). Putting the Enterprise into the Enterprise System. Harvard Business Review, p. 121-131, July/Aug.

DOLESCHEL, S. (1999). Integrated Distributed PDM. (transparência). 40 transparências color.

DICKERSON, C. (1996). Product Data Management: an overview. Computer and Automated Systems Association/Society of Manufacturing Engineers (CASA/SME).

DIRKS, C.; KELLER, G.; SCHÖDER, G. (1997). Development of Integrated Enterprise Models. In: INTERNATIONAL CONFERENCE ON ENTERPRISE INTEGRATION AND MODELING TECHNOLOGY, Torino, 1997. Anais.

DRÄGER, E. (1998). Projektmanagement mit SAP R/3 . Bonn, Addison-Wesley-Longman.

EAI (2000). VisView Enterprise-wide Product Data Visualization. http://eai.com/ products/visview (3 abr.).

ECONOMIST (1999). ERP RIP. The Economist. 26.Jun. 
EISENHARDT, K.M \& BROWN S.L. (1998). Time Pacing: Competing in Markets that won't Stand Still. Harvard Business Review, p. 59-69, Mar./Apr.

EVERSHEIM, W.; KLOCKE, F.; PFEIFER, T.; WECK, M. (1997). Manufacturing Excellence in Global Markets. London, Champman \& Hall.

FERMAN, J.H. (1998). ERP to PDM Integration. http://www.pdmic.com/IPDMUG/ wp_erp_pdm.html (17 Jun.).

FÜRSTENAU, E. (1978). Dicionário de Termos Técnicos Inglês - Português. Volume I e II. 10.ed. Porto Alegre, Editora Globo.

GARTNER GROUP (1998). $3^{\circ}$ Conferência Anual sobre o Futuro da Tecnologia da Informação. São Paulo.

GARVIN, D.A. (1995). Leveraging Processes for Strategic Advantage. Harvard Business Review, p. 77-90, Sept./Oct.

GARVIN, D.A. (1998). The Processes of Organization and Management. Sloan Management Review. p.33-50.

GASCOIGNE, B. (1995). PDM: The Essential Technology for Concurrent Engineering. World Class Design for Manufacturing, v. 2, n. 1, p. 38-42.

GEIGER, E.A. (1999). ERP and Data Warehousing Meet. DB2 Magazine. p.16-23, Summer.

GIURLIANI, S. (2000). A Segunda Onda do ERP. http://www.uol.com.br/idg/ gestaoempresarial/solucoes/crm/000314crm.htm (17 abr.).

GONÇALVES, J.E.L. (1994). Reengenharia: um Guia de Referência para o Executivo. Revista de Administração de Empresas. v.34, n.4, p.23-30, Jul./Ago.

GREENBAUM, J. (1999). ERP Portals: Too Little, Too Early. Intelligent Enterprise. p.1415 , Sept.

GRIFFIN, A. (1997). PDMA Research on New Product Development Practices: Updating Trends and Benchmarking Best Practices. Journal of Product Innovation Management, v.14, p.429-458.

GRIMES, S. (1998). Object/Relational. DBMS, p.51-55, Apr.

HAMMER, M. (1990). Reengineering Work: Don’t Automate, Obliterate. Harvard Business Review, p.104-112, July/Aug. 
HAMMER, M.\& CHAMPY, J. (1994). Reengenharia: Revolucionando a Empresa em Função dos Clientes, da Concorrência e das Grandes Mudanças na Gerência. Rio de Janeiro, Campus.

HAMMER, M. \& STANTON, S. (1999). How Process Enterprises Really Work. Harvard Business Review, p.108-118, Nov./Dec.

HAMERI, A. \& NIHTILÄ, J. (1998). Product Data Management - Exploratory Study on the State-of-the-Art in One-of-a-Kind Industry, Computers in Industry, v.35, p.195-206.

HARRINGTON, H.J. (1991). Business Process Improvement. McGrawHill.

HOUGH, D.A. (1998). Bridging the Functionality Gap: Configurable Interoperability for Agile ERP Execution. Integrated Design \&Manufacturing, p.28-32,June.

HOYLE; D. (1997). QS-9000 Quality Systems Handbook. Warrendale, Society of Automotive Engineers.

IQS (2000). IQS PPAP Manager. http://www.iqs.com/ppap.html (4 mar.).

JARDIM-GONÇALVES, R.; SILVA, H.; VITAL, M.; SOUSA, P.; SEIGER-GARÇÃO, A.; PAMIÈS-TEIXEIRA, J. (1997). Implementation of Computer Integrated Manufacturing Systems Using SIP: CIM Case Studies Using a STEP Approach. International Journal of Computer Integrated Manufacturing, v. 10, n.1-4, p.172-180.

JETLY, N. (1999). ERP's Last Mile. Intelligent Enterprise, p.39-45, Dec.

KELlER, G. \& TEUFEL, T. (1998). SAP R/3 Process Oriented Implementation. Harlow, Addison-Wesley.

KEMPFER, L. (1998). Linking PDM to ERP. http://www.caenet.com (23 out.).

KIRCHMER, M. (1998). Business Process Oriented Implementation of Standard Software. Heidelberg, Springer-Verlag.

KSR (1998a). Sistema CAPPE - Manual do Usuário - Módulo Básico.

KSR (1998b). Sistema CAPPE - Manual do Usuário - Módulo Avançado.

KSR (1999). K-FMEA - Failure Mode and Effect Analysis. Ifolderl

KSR (2000). KSR-APQP - Advanced Product and Quality Planning. Ifolder/ 
LAUDON, K.C.; LAUDON, J.P. (1998). Management Information Systems: new approaches to organization \& technology. Upper Saddle River, Prentice Hall.

LÜDKE, M.; ANDRÉ, M.E.D.A (1986); Pesquisa em Educação: abordagens qualitativas. São Paulo, Pedagógica e Universitária.

MARCONI, M.A.; LAKATOS, E.M. (1990). Técnicas de Pesquisa. São Paulo, Atlas.

MARTIN, R. (1998). Can IT Improve Knowledge Transfer Between R\&D and Manufacturing?. The Report on Manufacturing. AMR, Aug.

MAYER, R.C. (1998). Quem usa os Softwares de Gestão Empresarial. Developers Magazine. p.32-33, abr.

MICROSOFT (1997). User's Guide for Microsoft Project 98: Complete Project Comunication and Control.

MILLER, E.; MENDEL, A. (1997). Executive Overview of SAP's R/3 PDM Program. Ann Arbor, CIMdata.

MILLER, E. (1999). PDM/ERP Report: Integrating PDM and ERP. http://www.penton.com /cae/res/archives/9903pdmerp.html (11 Mar.).

MOREIRA, D.A. (1994). Reengenharia: Dinâmica para a Mudança. São Paulo, Pioneira.

NOLEN, J. (1989). Computer Automated Process Planning for the World-class Manufacturing. Marcel Dekker.

OLIVEIRA, C.B.M. (1999) Estruturação, Identificação e Classificação de Produtos em Ambientes Integrados de Manufatura. São Carlos, Dissertação (Mestrado) Departamento de Engenharia Mecânica, Escola de Engenharia de São Carlos, Universidade de São Paulo.

OMOKAWA, R. (1999). Utilização de Sistemas PDM em Ambientes de Engenharia Simultânea: O Caso de uma Implantação em uma Montadora de Veículos Pesados. São Carlos, Dissertação (Mestrado) - Departamento de Engenharia Mecânica, Escola de Engenharia de São Carlos, Universidade de São Paulo.

ORACLE (1999). Oracle Supply Chain Applications. São Paulo. /folder/

PÁDUA, E.M.M. (1997). Metodologia de pesquisa: abordagem teórico-prática. Campinas, Papirus. (Coleção Magistério: Formação e Trabalho Pedagógico) 
PIRES, A. (1997). CORBA: Uma Padrão para Objetos Distribuídos. Developers Magazine. p.36-39, ago.

PTC (2000). Application Programming Toolkit. http://www.ptc.com/products/proe/ app_toolkit.htm $(12$ mar.)

QUALISOFT (1991). Manual do Software QFD Designer.

PRASAD, B. (1996). Concurrent Engineering Fundamentals: integrated product and process organization. Upper Saddle River, Prentice Hall.

PRIMAVERA (2000). Products \& Solutions. http://primavera.com/products/concentric0. $\underline{\mathrm{html}}(29 \mathrm{abr}$.$) .$

REIMANN, N. \& RADEMEIER, E. (1999). Enterprise PDM Meets PPS. Industrielle Informations-tecknik. n.4, p.20-23,Juni.

ROZENFELD, H. (1992). Implantação Distribuida do Planejamento de Processo Assistido por Computador na Manufatura Integrada. São Carlos. Tese (Livre Docência) - Escola de Engenharia de São Carlos, Universidade de São Paulo.

ROZENFELD, H. (1996). Reflexões sobre a Manufatura Integrada por Computador. Manufatura de Classe Mundial: mitos \& realidade, São Paulo.

ROZENFELD, H. (1997). Modelo de Referência para o Desenvolvimento Integrado de Produtos. In: ENCONTRO NACIONAL DE ENGENHARIA DE PRODUÇÃO, 17., Gramado, RS, 1997. Anais. Porto Alegre, UFRGS, CD-ROM.

ROZENFELD, H., AGUIAR, A.S., OLIVEIRA, C.B.M., OMOKAWA, R. (1998). Development of a Concurrent Engineering Scenario for Educational Purposes. In: SOCIETY OF MANUFACTURING ENGINEERS: Manufacturing Education for the $21^{\text {st }}$ Century. Dearborn, 1998. V. 5, p. 145-150. Proceedings of the $2^{\text {d }}$ International Conference on Education and Manufacturing.

ROZENFELD, H.; AMARAL, D.C. (1999). Proposta de uma Tipologia de Processos de Desenvolvimento de Produto Visando a Construção de Modelos de Referência. In: CONGRESSO BRASILEIRO DE GESTÃO DO DESENVOLVIMENTO DE PRODUTOS, 1., Belo Horizonte, 1999. Anais. 
ROZENFELD, H.; RIBEIRO, C.E.S.; KERRY, H.T.Jr.; ALMEIDA, A.S.L. (1999). Otimizar a Obtenção da Documentação para a QS-9000 Através da Integração. In: CONGRESSO INTERNACIONAL DE TECNOLOGIA DA MOBILIDADE, 6., São Paulo, 1999. SAE Technical Paper Series.

ROZENFELD, H. \& ZANCUL, E.S. (2000). Identificação das Funcionalidades de Desenvolvimento de Produtos de um Sistema ERP. In: CONGRESSO NACIONAL DE ENGENHARIA MECÂNICA, 1., Natal, 2000. /no prelo/

SAP (1996). R/3 System Integrated Manufacturing - Functions in Detail PP. Wayne. SAP.

SAP (1997). The SAP PDM Strategy. Wayne, SAP.

SAP (1998a). R/3 System Release 4.0B Online Documentation. (CD ROM).

SAP (1998b). Sintese de Administração de Projetos. /material de curso/.

SAP (1998c) SAP PP Partner Academy. /material de curso/

SAP (1998d) Classificação. /material de curso/

SAP (2000a) Líder Mundial em Soluções de Negócios. Ifolderl

SAP (2000b). Product Lifecycle Management with mySAP.com. http://www.sap.com/ solutions/plm/plm_over.htm $(29$ mar.).

SAP (2000c). Document Management System with SAP's R/3 System. Ifolder/

SCHEER, A.W. (1992). Architektur Integrierter Informations-Systeme. Berlin, SpringerVerlag.

SCHEER, A.W. (1998). Business Process Engineering: reference models for industrial enterprises, Heidelberg, Springer-Verlag.

SCHMIDT, U. (1999). SAP als PDM-Lösungsanbieter. (transparência). 28 transparências color.

SCHUH, G.; ZIMMERMANN, H.H.; GÖRANSSON, A.; WILLI, U. (1997). Enterprise Engineering and Integration - Future Chalanges. In: INTERNATIONAL CONFERENCE ON ENTERPRISE INTEGRATION AND MODELING TECHNOLOGY, Torino, 1997. Anais. 
SCHÜTZER, K.; SOUZA, N.L. (1998). A Utilização de Sistemas CAD/CAM pelos Fornecedores do Setor Automotivo. In: SEMINÁRIO INTERNACIONAL DE TECNOLOGIA - DESENVOLVIMENTO DISTRIBUÍDO DE PRODUTOS, 3., Piracicaba, 1998. Anais. Piracicaba, UNIMEP.

SCHÜTZER, K.; SOUZA, N.L. (1999). O Desafio de Integrar as Linguagens CAD/CAM no setor automotivo. Máquinas e Metais. p.74-83, set.

SELL, L.L.(1953). English-Portuguese Comprehensive Technical Dictionary. São Paulo, McGraw-Hill.

SLACK, N.; CHAMBERS, S.; HARLAND, C.; HARRISON, A.; JOHNSTON R. (1998). Operations Management. Londres, Pitman.

STOODER, D.(1999a). Reengineering SAP. Intelligent Enterprise, p.46-49, Dec.

STOODER, D. (1999b). CRM: aka, the Intelligent Enterprise. Intelligent Enterprise, p.4-5, Nov.

SWANTON, B. (1997). Are PDM/EDM Systems Really Controlling Product Data? The Report on Manufcturing, AMR, May, p.3-17.

SYAN, C.S. (1994). Introduction to Concurrent Engineering. In: SYAN C.S.; MENON, U. Concurrent Engineering: concepts, implementation and practice. London, Chapman \& Hall. p.3-24

TAPSCOTT, D.; CASTON, A. (1995). Mudança de Paradigma. São Paulo, Makron.

TIBERTI, A. J. (1996). Desenvolvimento de um Sistema Gerenciador de Fluxo de Trabalho para um Ambiente de Suporte a Atividades de Engenharia. São Carlos. Dissertação (Mestrado) - Escola de Engenharia de São Carlos, Universidade de São Paulo.

ULLMAN, D.G. (1992). The Mechanical Design Process. Hightstown. McGraw-Hill.

VENKATRAMAN, N.; HENDERSON, J.C. (1998). Real Strategies for Virtual Organizing. Sloan Management Review. p.33-48.

VERNADAT, F.B. (1996). Enterprise Modeling and Integration: principles and applications. London, Chapman \& Hall.

VOLLMANN, T.E.; BERRY, W.L.; WHYBARK,D.C. (1993). Integrated Production and Inventory Management: Revitalizing the Manufacturing Enterprise. Homewood, Business One Irwin. 
WESSNER, M. (1999). PDM mit R/3. Industrielle Informations-tecknik. n.4, p.20-23,Juni.

WHEELWRIGHT, S.C.; CLARCK, K.B. (1992). Revolutionizing Product Development: quantum leaps in speed, efficiency, and quality. New York, The Free Press.

ZANCUL, E.S.; AMARAL, D.; AGUIAR, A.F.S. \& ROZENFELD, H. (1998). Aplicações de uma Nova Abordagem de Ensino do Processo de Desenvolvimento de Produtos. In: CONGRESSO BRASILEIRO DE ENSINO DE ENGENHARIA, XXVI., Osasco, 1998. Anais. (CD-ROM).

ZANCUL, E.S.; GUERRERO, V.; ROZENFELD, H.; OLIVEIRA, C.B.M. (1999). Análise das Abordagens de Integração entre Sistemas PDM e ERP. In: CONGRESSO INTERNACIONAL DE TECNOLOGIA DA MOBILIDADE, 6., São Paulo, 1999. SAE Technical Paper Series. 